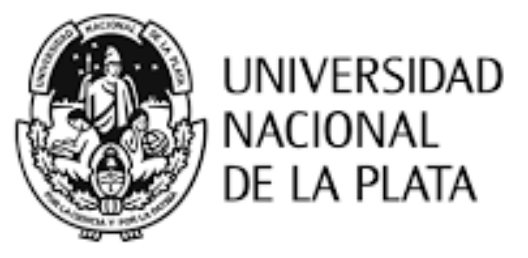

Facultad de Ciencias Jurídicas y Sociales

Instituto de Relaciones Internacionales

\title{
Régimen internacional educativo del Mercosur
}

\section{Los problemas de inserción de los migrantes intrabloque en el nivel de la educación básica. Un enfoque desde Argentina}

Tesis para optar al grado académico de Magister en Relaciones Internacionales

\author{
Candidata: Esp. Julia Espósito \\ Director: Dr. Norberto E. Consani \\ Co-directora: Dra. Laura Lucía Bogado Bordazar
}

La Plata, diciembre de 2020 


\section{Índice general}

Índice general

Siglas y acrónimos

Error! Bookmark not defined.

$\begin{array}{lr}\text { Agradecimientos } & 8\end{array}$

$\begin{array}{lr}\text { Índice de tablas, mapas y esquemas } & 9\end{array}$

$\begin{array}{ll}\text { Capítulo I } & 11\end{array}$

$\begin{array}{ll}\text { Introducción } & 11\end{array}$

1. Planteo: los niños, niñas y adolescentes migrantes y el acceso a la educación en el Mercosur 11

I. Hipótesis planteada 13

$\begin{array}{ll}\text { II. Algunas aclaraciones terminológicas } & 15\end{array}$

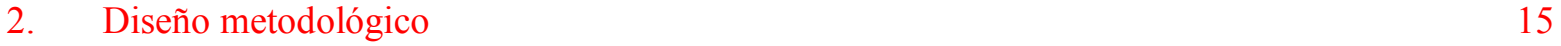

3. Marco teórico: conceptos necesarios para el análisis 20

$\begin{array}{ll}\text { Capítulo II } & 28\end{array}$

$\begin{array}{lr}\text { Migrar, un derecho humano } & 28\end{array}$

$\begin{array}{lr}\text { 1. Flujo migratorio internacional } & 29\end{array}$

I. Normativa internacional 30

1. Convención internacional sobre la protección de los derechos de todos los trabajadores migratorios y de sus familiares 31

2. Convención sobre los derechos del niño 34

3. Otros 39

i. Conferencia internacional sobre la Población y el Desarrollo 39

ii. Foro mundial sobre Migración y Desarrollo 41 
iii. El Pacto Mundial sobre Migración y la meta 10.7 de la Agenda 2030 para el Desarrollo Sostenible

2. Flujo migratorio en América Latina y el Caribe

I. Normativa iberoamericana, latinoamericana, sudamericana...

1. Convenio multilateral iberoamericano de seguridad social para trabajadores migrantes

i. Conferencia suramericana sobre migraciones

ii. Opiniones consultivas de la Corte Interamericana de Derechos Humanos

iii. El derecho a la información sobre la asistencia consular en el marco de las garantías del debido proceso legal. Opinión consultiva OC-16/99 de 1 de octubre de 1999

iv. Condición jurídica y derechos de los migrantes indocumentados. Opinión consultiva OC-18/03 de 17 de septiembre de 2003

v. Derechos y garantías de niñas y niños en el contexto de la migración y/o en necesidad de protección internacional. Opinión consultiva OC-21/14 de 19 de agosto de 2014

3. Flujo migratorio en el Mercosur

I. Normativa migratoria en el Mercosur

1. De Asunción a los Acuerdos de residencia

2. Acuerdos sobre residencia para nacionales de los Estados Partes del Mercosur y Estados Asociados

3. Otros

i. Foro especializado migratorio del Mercosur (FEM) 68

ii. Declaraciones y comunicados

iii. Instituto de Políticas Públicas en Derechos Humanos del Mercosur (IPPDH) 73

4. $\quad$ El caso de Argentina $\quad 75$

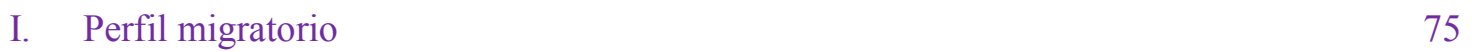

$\begin{array}{lll}\text { II. } & \text { La Ley de Migraciones n }{ }^{\circ} 25.871 & 77\end{array}$

$\begin{array}{ll}\text { III. Regularización de la situación migratoria } & 81\end{array}$ 
1. El derecho a la educación en el orden internacional 86

I. Normativa internacional 86

1. Declaración Universal de los Derechos Humanos 86

2. Convención relativa a la lucha contra las discriminaciones en la esfera de la $\begin{array}{ll}\text { enseñanza } & 87\end{array}$

3. Pacto Internacional de Derechos Económicos, Sociales y Culturales 88

i. Observaciones Generales n ${ }^{\circ} 11$ y n 13 del Comité de Derecho Económicos, $\begin{array}{ll}\text { Sociales y Culturales } & 89\end{array}$

4. Convención sobre los Derechos del Niño 90

5. Convenio ${ }^{\circ} 169$ de la Organización Internacional del Trabajo (OIT) sobre los Pueblos Indígenas y Tribales en Países Independientes 91

6. Otros 92

i. Conferencia Mundial sobre la Educación para Todos y su Marco de acción 92

ii. Foro Mundial sobre la Educación en 2000 y 2015

iii. El Objetivo de Desarrollo Sostenible (ODS) $4 \quad 94$

2. El derecho a la educación en América Latina y el Caribe 96

$\begin{array}{ll}\text { I. Normativa regional } & 97\end{array}$

1. Declaración Americana de los Derechos y Deberes del Hombre 97

2. Convención Americana sobre Derechos Humanos 98

3. Otros 99

i. Compromiso de las Américas 99

$\begin{array}{ll}\text { ii. Metas Educativas } 2021 \text { de la OEI } & 101\end{array}$

iii. Reunión Regional de Ministros y Ministras de Educación de América Latina y el Caribe | Declaración de Lima de 2014 y de Buenos Aires de $2017 \quad 102$ 
iv. Opinión Consultiva OC-17/02 de la Corte Interamericana de Derechos Humanos

3. El derecho a la educación en el ámbito del Mercosur

I. El Sector Educativo del Mercosur

II. Estructura del SEM

III. Planes de acción del SEM

4. El derecho a la educación en Argentina

5. Recapitulación

\section{Capítulo IV}

El Programa de Escuelas Interculturales Bilingües de Frontera

1. En búsqueda de programas/políticas educativas y migratorias destinadas a la niñez y juventud migrante en el nivel de la enseñanza primaria

I. Revisión de los conceptos de frontera y de interculturalidad

2. Las Escuelas Interculturales Bilingües de Frontera (EIBF)

I. Un poco de historia sobre las EIB

II. El PEBF: de la propuesta a su implementación

III. Las EIB del lado argentino

1. El PEBF en la Provincia de Misiones

2. E1 PEBF en la Provincia de Corrientes

3. El caso de la Provincia de Formosa

\section{Capítulo V}

Conclusiones 


\section{Siglas y acrónimos}

CELADE Centro Latinoamericano y Caribeño de Demografía (División de Población de la CEPAL)

CEPAL Comisión Económica Para América Latina y el Caribe de Naciones Unidas

CIDH Corte Interamericana de Derechos Humanos

CMC Consejo Mercado Común del Mercosur

CSM Conferencia Sudamericana de Migraciones

EIB Escuelas Interculturales Bilingües

FEM Foro Especializado Migratorio

GTEIF Grupo de Trabajo Escuelas Interculturales de Frontera

IPPDH Instituto de Políticas Públicas en Derechos Humanos del Mercosur

Mercosur Mercado Común del Sur

NN/NNA Niños y niñas / Niños, niñas y adolescentes

OC Opinión Consultiva

ODS Objetivos de Desarrollo Sostenible

OEA Organización de Estados Americanos 
OEI Organización de Estados Iberoamericanos para la Educación, la Ciencia y la Cultura

OIM Organización Internacional para las Migraciones

OIT Organización Internacional del Trabajo

ONU Organización de las Naciones Unidas

PEIBF Programa de Escuelas Interculturales Bilingües de Frontera

PNUD Programa de las Naciones Unidas para el Desarrollo

RME Reunión de Ministros de Educación

SICREMI Sistema Continuo de Reportes sobre Migración Internacional en las Américas

UNESCO Organización de las Naciones Unidas para la Educación, la Ciencia y la Cultura

UNICEF Fondo de las Naciones Unidas para la Infancia 


\section{Agradecimientos}

Quisiera ofrecer mi agradecimiento a quienes, de diferentes maneras, hicieron posible esta tesis. En primer lugar, agradezco a mi director, Dr. Norberto Consani por depositar su confianza siempre en mí y en todos mi emprendimientos académicos. A mí codirectora, Dra. Laura Lucía Bogado Bordazar, por aconsejarme, guiarme y acompañarme en todas las instancias de esta investigación y por haber confiado en mí.

En este espacio quisiera agradecer a todas las personas que me concedieron entrevistas por diferentes medios y me ayudaron en la recolección del material bibliográfico. Agradezco a los siguientes investigadores por su generosidad, por su pronta respuesta ante mis solicitudes y por guiarme en este recorrido: María Laura Díez, Menara Guizardi, Alejandro Grimson, Marcia Regina Pereira Sagaz, Claudia Brovetto, María Elena Martínez y Mónica Escobar. Mi especial gratitud para Vivian Eich del Instituto de Políticas Lingüísticas del Ministerio de Cultura Ciencia, Educación y Tecnología de la Provincia de Misiones, a Valeria Solís de la Dirección de Educación Intercultural Bilingüe del Ministerio de Educación de la Provincia de Corrientes, a Adrián Aranda, Coordinador de la Modalidad de Educación Intercultural Bilingüe del Ministerio de Cultura y Educación de la Provincia de Formosa, a Lauren Dimperio, Coordinadora del Departamento de Segundas Lenguas y Lenguas Extranjeras del Consejo de Educación Inicial y Primaria, a Aldo García de la Dirección de Políticas Lingüísticas, ambos pertenecientes a la Administración Nacional de Educación Pública de la República Oriental del Uruguay. A Claudia Elizabeth Aun y a María Rosa Carbonara por compartir conmigo sus experiencias. A los funcionarios del Ministerio de Educación de la Nación Argentina y a la Secretaría del Mercosur.

A mi compañera y amiga, Juana Álvarez Eiras por aportar su visión estética a este trabajo. A mis compañeros y amigos por apoyarme y comprender que el tiempo que perdimos de charlas y encuentros estuvo dedicado a este trabajo.

Finalmente, agradezco muy especialmente a Nacho, mi compañero, por acompañarme desde el inicio, por su asistencia técnica y por su apoyo incondicional, siempre. 


\section{Índice de tablas, mapas y esquemas}

Tabla n. ${ }^{\circ}$ 1. Metas de los ODS vinculados a la migración

Mapa \#1. Convenio multilateral iberoamericano de seguridad social para trabajadores migrantes

Tabla n. ${ }^{\circ}$ 2. Decisiones adoptadas por el Consejo del Mercado Común del Mercosur

Tabla n. ${ }^{\circ}$ 3. Residencias totales otorgadas en el marco del Acuerdo de Residencia

Tabla n. ${ }^{\circ}$ 4. Declaraciones de los Estados Partes del Mercosur y Asociados vinculadas a la temática migratoria

Tabla n..$^{\circ}$ 5. Porcentaje de población migrante por provincia

Tabla n. ${ }^{\circ}$ 6. Tasa de aprobación, reprobación y abandono en el nivel primario

Esquema n. ${ }^{\circ}$ 1. Organización de los niveles educativos del SEM

Esquema n. ${ }^{\circ}$ 2. Organigrama del SEM

Esquema n. ${ }^{\circ}$ 3. Línea del tiempo que da cuenta del surgimiento del PEIBF

Mapa \#2. Ubicación de las ciudades espejo involucradas en el PEBF

Tabla n. ${ }^{\circ}$ 7. Normas internacionales ratificadas por los Estados Partes del Mercosur 
Mercosur

1001 primaria Merus niñez migrante

régimen internacional Educativo, pol mante

Mercosur Educativo

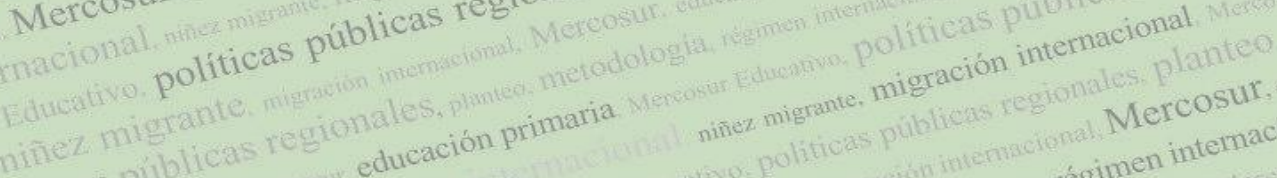

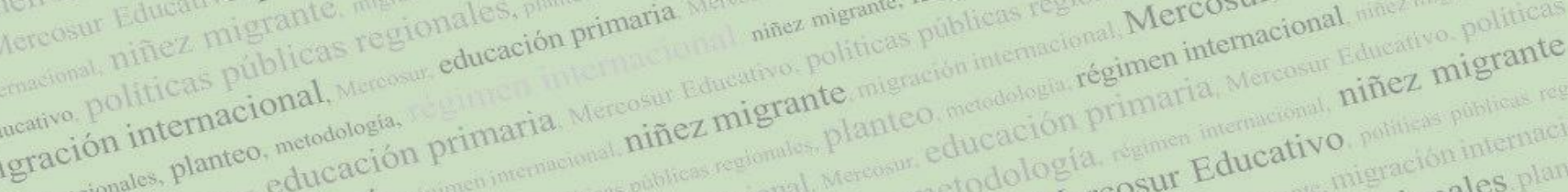

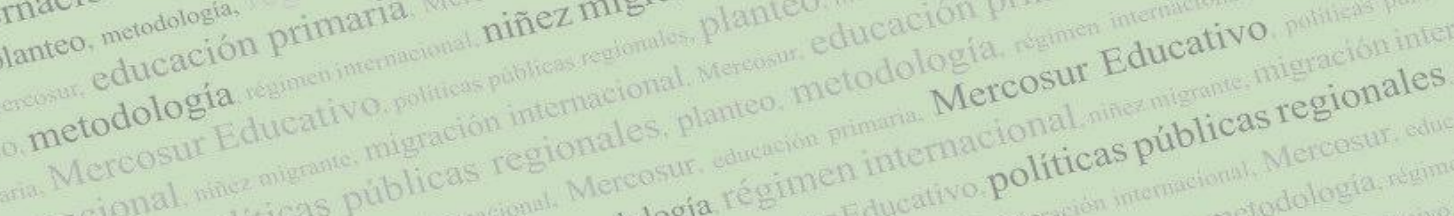

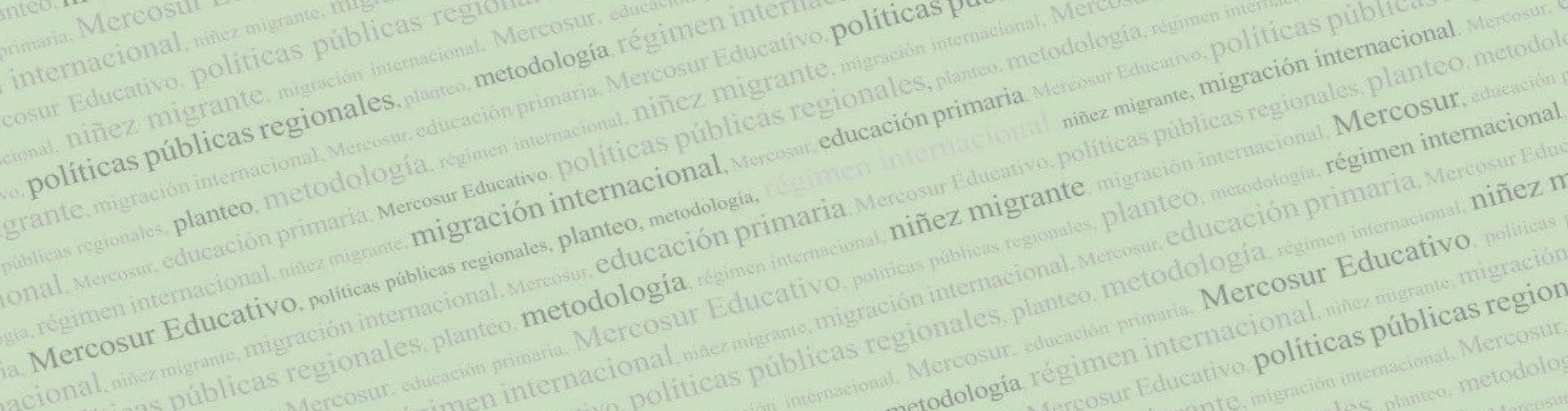$$
\text { metodología }
$$

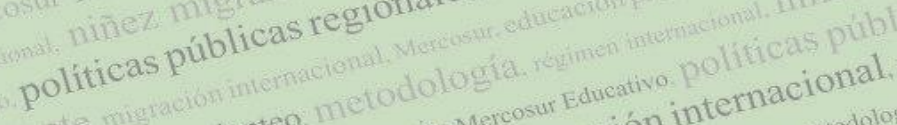

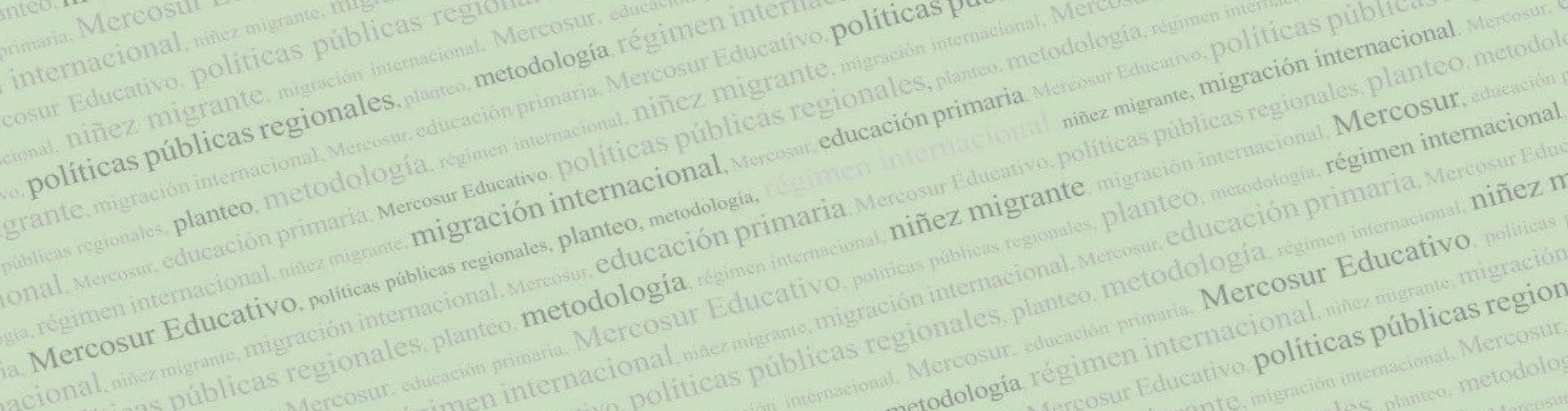
cas públicas regionales.

cosur.

planteo.

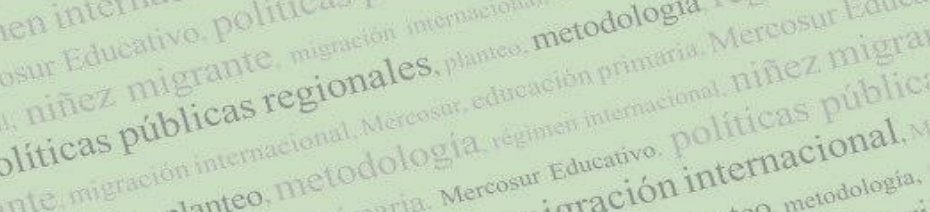
migración internaciona metodola Mercosur Educativo politicas publicas regionales, planter educación p

$$
\text { and }
$$

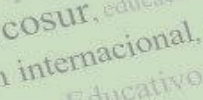

planteo metodologia politicas públicas regionales.

ional

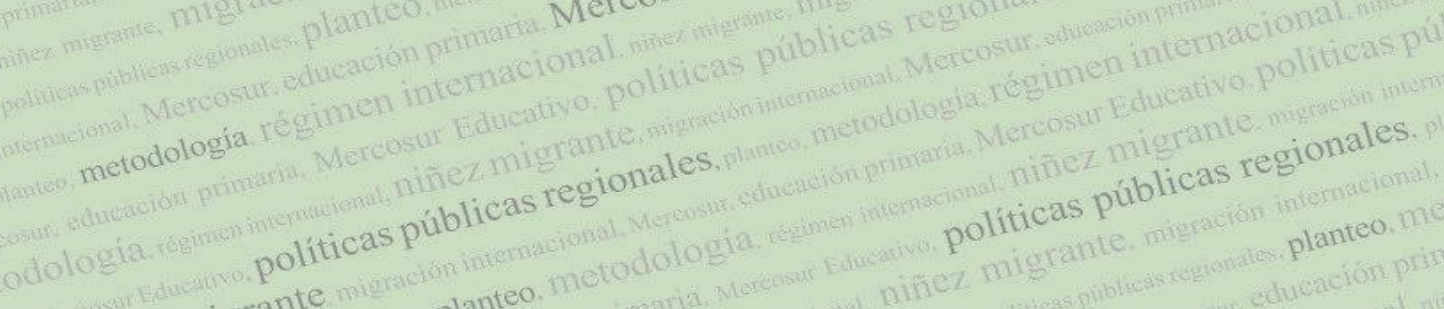

ducativo migrante

\section{Mercosur,}

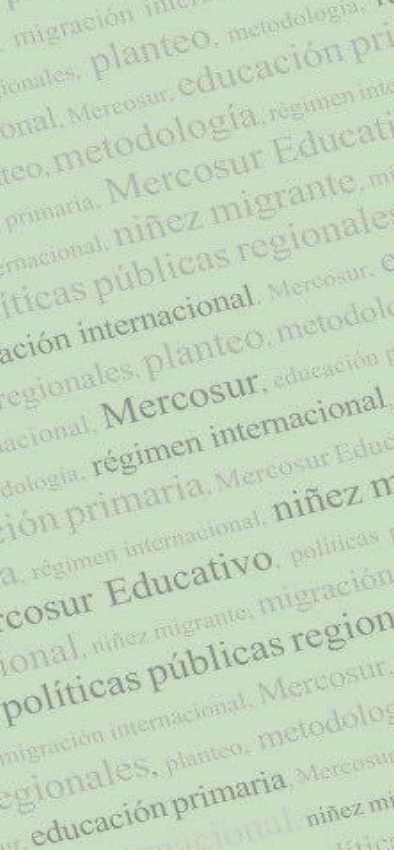




\section{Capítulo I}

\section{Introducción}

1. Planteo: LOS NiÑOS, NiÑAS Y ADOLESCENTES MigRANTES Y EL ACCESO A LA EDUCACIÓN EN EL MERCOSUR

Los procesos de integración regionales implican la coordinación de políticas económicas y comerciales pero también traen aparejadas la coordinación de cuestiones políticas, sociales, educativas y culturales que, en un momento determinado, se convierten (o deberían convertirse) también en políticas regionales. La cuestión cultural y educativa es un tema relegado y, en algunos casos, ubicado en un segundo plano por los bloques de integración. En este sentido, Nora Pérez Vichich ha sostenido que "casi todos los intentos de integración regional apuntaron en primer término, y como condición sine qua non para la estructuración de un mercado común, a limar las diferencias en el nivel económico-comercial existentes entre sus miembros, sin advertir los costos sociales que trae aparejado (...)” (Pérez Vichich 1993 en Sassone, 2004).

La integración debe involucrar a la totalidad de la población de la región de que se trate y, para ello, debe contemplar todas las dimensiones que constituyen la vida social. La educación desempeña un papel fundamental en la conformación de la identidad nacional y regional y en la formación de los pueblos. Al referirnos a la totalidad de la población incluimos, por supuesto, a quienes deciden migrar de un país a otro y permanecer en él de manera transitoria o permanente. Es más, nuestro objeto de estudio son los niños y niñas migrantes que se desplazan entre los distintos países que conforman el Mercosur junto (o no necesariamente) a su grupo familiar y bus- 
can insertarse en el sistema educativo del país de recepción. Concebir a los migrantes como poblaciones transitorias distintas de los nativos obstaculiza su progreso académico, su socialización e impide construir sociedades donde exista diversidad y cohesión (UNESCO, 2018).

En este sentido, compartimos la afirmación sostenida por Roberto Miranda (1999) quien sostiene que la educación es una variable integradora que puede reducir una tensión cultural entre las sociedades civiles y, de esta manera, evitar que esa tensión se convierta en un conflicto político. Sin embargo, buscaremos determinar que luego de 30 años, el Mercosur, que cuenta con una estructura institucional y burocrática y con normativa en materia educativa, no ha logrado de manera acabada ser una variable integradora, al menos en el nivel de la educación primaria.

En América Latina la mayor parte de las legislaciones promueven un sistema educativo que parta del reconocimiento de que se inserta en sociedades multiculturales o pluriculturales y se pone el foco "en la plena vigencia del principio de no discriminación el respeto de las individualidades y la diversidad" y resta "como desafío avanzar hacia una propuesta educativa que parta del reconocimiento de esa diversidad y de la construcción de un vínculo de reconocimiento de cada uno, a partir de su propia identidad" (IIPE UNESCO, 2015, pp. 44-45).

Resulta oportuno reafirmar aquí junto a Flavia Terigi que:

la escolarización afecta de maneras sustantivas la experiencia de sí que tienen los niños, niñas y adolescentes, porque produce en la historia individual un cierto puente con sectores seleccionados de la cultura, porque sus sanciones de éxito y fracaso inciden en la trayectoria subjetiva, y porque formatea o encauza de manera particular el desarrollo de los niños, niñas y adolescentes (Terigi, 2009, p. 4).

La escuela, como espacio social, recepta a la población migrante que se verá influenciada por ella y, a su vez, producirá cambios en ella. En las escuelas tienen lugar encuentros que se ven atravesados por condicionantes y experiencias que exceden los límites de la propia institución (Diez, 2013). Es así que la escolarización se produce en condiciones de interculturalidad. A la escolarización de niños y niñas migrantes, sumamos que el evento de migración como acto psíquico, suele ser traumático. Marie Rose Moro ${ }^{1}$ sostiene que "el traumatismo de la migración no

\footnotetext{
${ }^{1}$ Marie Rose Moro es médica psiquiatra. Psicoanalista y profesora de psiquiatrías de bebés, niños y adolescentes y catedrática de la Universidad de París. Si bien el libro que hemos tomado de esta especialista está dedicado a la primera infancia (niños y niñas
} 
es constante e inevitable, sin embargo puede ocurrir independientemente de la personalidad previa del migrante" (2019, p. 21). Los factores sociales adversos son agravantes como podrían ser las condiciones en el país de recepción vinculadas a la escolarización. Según Moro (2019), el trauma generado por la migración no siempre implica efectos patógenos sino que a veces es fuente de creatividad porque representa para el individuo una metamorfosis.

\section{Hipótesis planteada}

Las aún débiles instituciones burocráticas del Mercosur y el insuficiente desarrollo de políticas públicas nacionales y de alcance regional referidas a las migraciones y a la educación han sido obstáculos para la consolidación del régimen internacional educativo del bloque para dar respuestas a los problemas de inserción de la niñez migrante en el nivel de la educación primaria en el país de recepción.

La presente investigación pretende poner en relación dos supuestos fundamentales en el proceso de integración regional del Mercosur: por una parte, el flujo migratorio al interior del bloque y, por la otra, la inserción de los niños y niñas migrantes en el nivel de la enseñanza primaria en el país de recepción. Partimos de un tercer supuesto que presupone la existencia de un régimen internacional educativo mercosureño que busca sustraer el área de la educación primaria del ámbito de las prácticas unilaterales de los Estados Partes. Analizaremos si existe y, de ser el caso, cuál es su estado de desarrollo, una política pública regional que ponga en relación ambos supuestos en el marco del Mercosur y nos enfocaremos en la perspectiva que Argentina ha adoptado en la materia. Como sugiere Perrota (2013), debemos tomar en cuenta las asimetrías entre los Estados que forman parte del bloque mercosureño y la tensión entre proyectos políticos divergentes y la que se refleja, entre otros, en el diseño institucional que traza el proceso de integración.

Los objetivos específicos que perseguiremos en esta investigación son:

hasta 5 años de edad), consideramos que nos permite advertir con claridad el carácter multidimensional de las migraciones, sobre todo cuando se trata de niñez migrante. 
a) Reconocer y estudiar la regulación del derecho a migrar y el derecho a la educación en el plano internacional, latinoamericano, mercosureño y argentino.

b) Identificar y analizar la relación entre el desplazamiento de los niños y niñas intrabloque y el acceso a la educación primaria en el Mercosur y en Argentina.

c) Discernir si la estructura institucional mercosureña puede dar respuesta a las necesidades de la niñez migrante en materia de educación primaria y cómo ha sido la práctica hasta ahora.

El periodo de estudio se extenderá desde la firma del Tratado de Asunción (1991) hasta diciembre de 2019. El corte temporal se corresponde con el fin del período presidencial de Mauricio Macri, eso trae aparejado el cambio de conducción del Ministerio de Educación y, por consiguiente, el acceso a la información y el planteo de reforma del Programa de Escuelas Interculturales Bilingües de Frontera durante ese año.

En el presente capítulo describiremos el diseño metodológico propuesto y desarrollaremos el marco teórico indispensable para el análisis. A lo largo del segundo capítulo, haremos una revisión de los flujos migratorios internacionales, en América Latina y el Caribe, en el Mercosur y, finalmente, en Argentina. Esta revisión estará acompañada del análisis de la normativa respectiva más importante en la materia y, que consideramos fundamental recuperar para nuestro análisis. El tercer capítulo está dedicado al estudio del derecho a la educación, su regulación en el ámbito internacional, latinoamericano, mercosureño y, más específicamente, su recepción en la legislación argentina. Estos dos últimos capítulos pretenden construir el andamiaje normativo e institucional sobre el que debería tener base el régimen internacional educativo mercosureño y así comprender y estudiar su existencia, solidez (o la falta de la misma) y funcionamiento. Se podrá advertir que no es posible abordar la temática migratoria y educativa como temas estancos sino que, por el contrario, veremos que la normativa migratoria regula el acceso a la educación de la niñez migrante así como la normativa educativa contempla la complejidad intercultural que generan las comunidades de migrantes.

El cuarto capítulo analizará en conjunto la política educativa y migratoria en el Mercosur y en Argentina. Ello nos llevará a abordar el programa de Escuelas Interculturales Bilingües de Frontera en las provincias argentinas de Misiones y Corrientes. Y, por último, en el capítulo 
quinto esbozaremos las conclusiones a las que hemos arribado luego del análisis efectuado en nuestro trabajo de investigación.

\section{Algunas aclaraciones terminológicas}

Consideramos oportuno efectuar aquí precisiones sobre algunos de los términos claves necesarios para el desarrollo del presente trabajo de investigación. Utilizaremos indistintamente los términos "niños, niñas y adolescentes migrantes", "niños y niñas migrantes", "niñez migrante”, “niños y niñas en contexto de migración” y “niñez en contexto de migración”, sin adscribir con ello a ningún posicionamiento teórico ni ideológico.

Si bien en el título de la tesis incluimos en término "educación básica" que comprende los niveles de enseñanza primaria y el primer ciclo de la educación secundaria ${ }^{2}$, nos enfocaremos únicamente en el nivel de la educación primaria por considerarlo como el tramo formativo esencial de las personas que determina sus trayectorias escolares.

\section{DiSEÑO METODOLÓGICO}

El objeto de nuestra investigación es el estudio de las políticas migratorias y educativas del Mercosur destinadas a la inserción de los niños migrantes intrabloque en los niveles de la educación primaria en los países receptores. Consideramos que requiere de una indispensable mirada interdisciplinaria por la complejidad de los supuestos que comprende: "la migración, de hecho, es ante todo un evento sociológico participante de un contexto histórico y político" (Moro, 2019, p. 20). Es por ello que recurriremos con frecuencia a trabajos elaborados desde una perspectiva etnográfica y de la antropología social y de la pedagogía.

La tarea de investigación se desarrolló en dos momentos: un primer análisis documental y, una segunda etapa, derivada de la primera, de estudio del único programa educativo en el nivel de enseñanza primaria que se implementó hasta el momento en el Mercosur.

\footnotetext{
${ }^{2}$ Un nivel de enseñanza uniforme para los cinco países del Mercosur denominado Enseñanza Básica que incluye los niveles Primario y Primer Ciclo de Educación Secundaria (CINE 1 y CINE2), como CINE12. La Clasificación Internacional Normalizada de la Educación (CINE) es el marco de referencia estándar utilizado para categorizar y reportar estadísticas educativas internacionalmente comparables elaborado por la UNESCO.
} 
Para el análisis documental tuvimos en cuenta dos dimensiones que nos permitieron organizar la búsqueda y seleccionar los documentos. Una dimensión temática que se ve reflejada en los capítulos II y III: la política migratoria y la política educativa. Y una dimensión geográfica que nos permitió ubicar en un primer momento las cuestiones bajo estudio en el plano internacional, para luego avanzar hacia el abordaje de las mismas en el plano latinoamericano y, finalmente, arribar al plano regional (mercosureño) y local (argentino). Aquí optamos por una perspectiva multiescalar como proponen Domenech y Pereira (2017) que pretende mostrar "las articulaciones entre lo local, lo nacional, lo regional y lo global".

El corpus documental está integrado por normas internacionales emanadas, en su gran mayoría, de organismos internacionales como las Naciones Unidas. Se trata entonces, según la clasificación de MacDonald y Tipton (en Valles, 1999, p. 121), de documentos escritos y oficiales (tratados internacionales). Aquí no se plantean los problemas que Valles (1999) presenta para este tipo de técnica cualitativa: en cuanto a la autenticidad, disponibilidad y credibilidad del documento por cuanto se trata de documentos que se encuentran disponibles en español en el repositorio que lleva la Oficina de Asuntos Jurídicos - Sección tratados de la Secretaría General de Naciones Unidas disponibles en la página web oficial del organismo. Es tarea de la Secretaría analizar, inscribir, archivar y registrar y publicar tratados y acuerdos internacionales conforme.

La elección documental tiene como fundamento en primer lugar, el carácter vinculante que poseen los tratados para los Estados y para las organizaciones internacionales que los firman y ratifican. El propósito del análisis de los documentos internacionales es contextualizar las políticas migratorias y educativas mercosureñas a partir de las obligaciones y compromisos asumidos por los Estados parte del bloque en el plano internacional y latinoamericano. Y en segundo lugar, como afirma Susana Novick (2005, p. 7), la norma resume y transparenta, esto es, hace más visibles, los factores ideológicos, de manera que nos permite aprehender la riqueza y sustancia de la dimensión jurídica de lo social. Creemos que la interpretación de los documentos nos permitirá conocer y reflexionar si el conjunto de estas políticas están efectivamente dirigidas a consolidar y profundizar la integración regional. Y, sobre todo, si logran configurarse como un régimen internacional regional educativo.

En el proceso de recolección pudimos identificar instrumentos internacionales específicos de las materias que nos interesan como es el caso de la Convención internacional sobre la protec- 
ción de los derechos de todos los trabajadores migratorios y de sus familiares (1990) o la Convención relativa a la lucha contra las discriminaciones en la esfera de la enseñanza (1960). Sin embargo, hay otros instrumentos que también se refieren a los derechos de los migrantes, a la educación como derecho humano o que tratan de cuestiones de especial importancia sobre estos temas pero que serían imposibles abordar por cuestión de extensión de este trabajo de manera exhaustiva.

Ellos son: la Declaración Universal de los Derechos Humanos, el Pacto Internacional de Derechos Económicos, Sociales y Culturales, la Convención contra la Tortura y Otros Tratos o Penas Crueles, Inhumanos o Degradantes, la Convención sobre los derechos del niño y el Convenio $\mathrm{n}^{\circ} 169$ de la Organización Internacional del Trabajo (OIT) sobre los Pueblos Indígenas y Tribales en Países Independientes.

En el plano latinoamericano nos encontramos con el Convenio multilateral iberoamericano de seguridad social para trabajadores migrantes, la Declaración Americana de los Derechos y Deberes del Hombre y la Convención Americana sobre Derechos Humanos. En el ámbito mercosureño haremos un recorrido desde el Tratado de Asunción (1991) a los Acuerdos de Residencia.

En el mismo sentido pero ya en el ámbito local, haremos un recorrido por las principales normas jurídicas que regulan la migración y la educación en nuestro país para comprender la dimensión de estas políticas en Argentina y su correlación con las internacionales y latinoamericanas. Recordamos la advertencia de Novick (2014) en cuanto a que la norma jurídica nos ofrece una realidad instantánea, estática y detenida en un momento en el tiempo y para que se convierta en una herramienta útil para explicar los conflictos sociales es necesario articularla con el contexto económico, político, institucional y demográfico en que tiene lugar. Creemos que tomando en cuenta esta advertencia podremos identificar si la "dimensión jurídica de lo social" (Novick, 2014, p. 65) logra dar respuestas efectivas a las problemáticas que plantea la migración intrabloque mercosureña de niñas, niños y adolescentes.

Sin embargo, y atendiendo al carácter flexible de nuestra investigación (Marradi et al., 2012, p. 56), advertimos en el transcurso de nuestro estudio que además de las normas internacionales, existen otros tipos de documentos escritos que sin ser vinculantes para los Estados, tienen gran influencia en la adopción de políticas migratorias y educativas. Es por ello que inclui- 
mos declaraciones y planes de acción emanados de conferencias internacionales, observaciones de órganos convencionales (Comités) y opiniones consultivas de la Corte Interamericana de Derechos Humanos. Del mismo modo, consideramos oportuno incluir los distintos espacios de discusión internacional existentes, como son los Foros y Conferencias, a fin de determinar si han logrado convertirse o no en verdaderos ámbitos de toma de posiciones.

Asimismo hemos incorporado a nuestro análisis documentos numéricos (Valles, 1999, p. 122) emanados de la Organización Internacional para las Migraciones (OIM), de la División Población del Departamento de Asuntos Económicos y Sociales de las Naciones Unidas (ONU), de la Organización de Estados Americanos (OEA) y datos estadísticos tomados de los últimos censos poblacionales con la finalidad de ilustrar en cifras el fenómeno migratorio en el mundo, en América Latina, en el Cono Sur y en el Mercosur. Incluso agregamos documentos científicos emanados de instituciones especializadas como la UNESCO o la Organización Iberoamericana de Seguridad Social. Por otra parte, hemos tenido la oportunidad de contactar de manera personal a distintos especialistas (sociólogos, antropólogos sociales, etnógrafos, licenciados en ciencias de la educación) que nos ofrecieron en breves entrevistas sus puntos de vista y nos permitieron tener un enfoque multidisciplinar sobre la temática bajo estudio y complementar el estudio estadístico y normativo, brindándonos un pantallazo de la aplicación o ejecución de la política regional en la práctica.

Finalizada la etapa de análisis documental, logramos delinear el panorama normativo internacional y regional que regula la situación de los niños migrantes y sus derechos de acceso a la educación primaria, gratuita y obligatoria. Al adentramos en la segunda instancia de nuestro trabajo, que se desarrolla en su integridad en el ámbito mercosureño, pudimos identificar una situación particular: el Sector Educativo del Mercosur sólo cuenta con un programa en el nivel de la enseñanza primaria mientras que cuenta con varios para el nivel de la educación superior, como es el caso de las iniciativas de acreditación de carreras de grado y posgrado $\mathrm{MEXA}^{3}$ (primera experiencia piloto 2002-2008), ARCU-SUR (a partir de 2009), programas de movilidad académica como ESCALA (2002), JIMA (2004), entre otros. Se trata del Programa de Escuelas

\footnotetext{
${ }^{3}$ MEXA para las carreras de Medicina, Ingeniería y Agronomía. ARCU-SUR incorpora las carreras de Arquitectura, Veterinaria, Odontología y Economía.
} 
bilingües de frontera que se viene implementando desde hace quince años en las provincias argentinas de Corrientes y Misiones con sus vecinos estados brasileños.

Ya en esta instancia, nos interesa comprender el motivo que impulsó al Mercosur a poner en marcha este programa y si el mismo se configura como un aporte a la inserción de los niños migrantes intrabloque en las instituciones educativas de los países receptores. Para ello partimos del estudio de los documentos que le dieron nacimiento (documentos emanados de las Reuniones de Ministros de Educación) y de los informes periódicos que cada provincia debe presentar sobre los avances del programa que forman parte de la política exterior en materia educativa y migratoria de Argentina. Advertimos, asimismo, la importancia de los informes elaborados por otros órganos de la estructura institucional mercosureña como ser los Grupos Técnicos y los Subgrupos de Trabajo. En esta etapa debemos hacer un recorte geográfico: sólo nos ocuparemos de la implementación de este programa en la frontera argentina dada la dificultad de acceder a los informes de las escuelas brasileñas que participan en el programa ${ }^{4}$.

Consideramos un aporte fundamental a nuestra investigación el contraste de la información recabada con las valoraciones de los principales actores o destinatarios del programa educativo bajo estudio. Es así que nos propusimos llevar a cabo entrevistas personales con los administradores de la educación nacional involucrados en la gestión del programa en la Dirección Nacional de Gestión Educativa del Ministerio de Educación de la Nación y, que a su vez, participan del Grupo de Trabajo de Escuelas Interculturales de Fronteras en el ámbito del Mercosur.

Por cuestiones de tiempo y presupuestarias que ya mencionáramos, no pudimos desplazarnos a Misiones y Corrientes para realizar entrevistas semiestructuradas cara a cara con los administradores de la educación regional por lo que implementamos entrevistas virtuales a través de correo electrónico, videoconferencia y/o telefónicas (Marradi et al., 2012, p. 193). Estas entrevistas en profundidad estuvieron dirigidas por una parte, a los encargados y asesores pedagógicos del programa en el Instituto de Políticas Lingüísticas del Ministerio de Cultura, Educación, Ciencia y Tecnología de la Provincia de Misiones y encargados de la Dirección Intercultural Bi-

\footnotetext{
${ }^{4}$ Quisiéramos dejar constancia que esta investigación se realiza sin beca de estudio por lo que no contamos con presupuesto alguno para financiar viajes que nos permitan conocer desde el campo el funcionamiento de las escuelas a ambos lados de la frontera. No nos cabe duda que ningún análisis documental ni entrevista en profundidad se compara con "vivenciar" la frontera argentino-brasilera. A ello sumamos la restricción de circulación debido a la pandemia del COVID-19 durante el año 2020.
} 
lingüe del Ministerio de Educación de la Provincia de Corrientes y al Coordinador de la Modalidad de Educación Intercultural Bilingüe del Ministerio de Cultura y Educación de la Provincia de Formosa ${ }^{5}$. Y, por otra parte, con el propósito de acceder a los actores más directos que contribuyen con el programa y "para conocer cómo ellos interpretan sus experiencias en sus propios términos" (Marradi et al., 2018), las entrevistas autoadministradas estuvieron dirigidas a los directores y maestras de algunas de las escuelas participantes del programa. No hemos obviado a los destinatarios del programa: los estudiantes pero, en el mejor de los casos como sucede con la implementación del programa en Misiones como ya veremos, no pudimos acceder a ellos ante la imposibilidad de desplazamiento al territorio y la suspensión del mismo durante el año 2020 por la pandemia de la COVID-19 (adelantamos aquí las dificultades en contactarnos con autoridades de esta provincia durante la investigación y que recién fue posible en el transcurso del año 2020). A ello sumamos el largo período de tiempo en el que ha estado en marcha el programa y el número elevado de estudiantes que ha involucrado.

La guía para las entrevistas versó sobre cuatro puntos neurálgicos: 1) determinación del rol y la antigüedad del entrevistado en la implementación del programa, lo que nos permitirá obtener su trayectoria histórica; 2) la percepción del entrevistado sobre la finalidad del programa y su evolución; 3) las dificultades experimentadas en el desarrollo del mismo; 4) las relaciones entre las escuelas, los ministerios provinciales, el ministerio nacional y el órgano del SEM; 5) y cuáles serían las herramientas necesarias para ampliar el programa a todas las provincias y si lo visualizan como factible y necesario.

\section{MARCO TEÓRICO: CONCEPTOS NECESARIOS PARA EL ANÁLISIS}

Como sostiene Miranda (2003), las relaciones transnacionales son un fenómeno contemporáneo que se caracteriza por ser multidimensional. Una de esas dimensiones que nos interesa abordar es la educación. Este autor sostiene que la cuestión cultural es la dimensión que mejor da cuenta de la profundidad de la esfera transnacional y dadas las diferencias culturales y las reivindicacio-

\footnotetext{
${ }^{5}$ En el capítulo IV referiremos por qué incorporamos esta provincia en nuestra investigación.
} 
nes identitarias roza el límite con la lógica de las relaciones interestatales. La cooperación interestatal es una respuesta que propende a la armonía intersocietal y los regímenes internacionales son uno de los mayores soportes con los que cuenta (Miranda, 2003).

Hasenclever, Mayer y Rittberger (1999) definen a un régimen internacional "como el conjunto de principios, reglas y procedimientos para la toma de decisiones que rige el comportamiento de los Estados en un área de la política internacional” (p. 499). La definición propuesta por Keohane y Nye (1988) contiene un elemento más puesto que los regímenes son redes de principios, normas, reglas y procedimientos que no solo rigen sino que configuran "el comportamiento y controlan sus efectos en un campo de actividad”. Más allá de estas definiciones que tomaremos como referencia, recordamos con Barbé (1989) que el régimen internacional es una construcción teórica que busca explicar situaciones de orden que existen en un campo de actividad.

Como sostienen Hasenclever, Mayer y Rittberger (1999), estos regímenes son órdenes parciales, creados deliberadamente y de alcance regional o mundial. En nuestra investigación abordamos el estudio de un régimen internacional regional en materia educativa: el Sector Educativo del Mercosur (SEM) o Mercosur Educativo. Los regímenes internacionales tienen por objetivo sustraer ciertas áreas de la política internacional del ámbito de las prácticas unilaterales de los Estados (Hasenclever et al., 1999).

Ya en el año 2003, Roberto Miranda advertía los obstáculos para el desarrollo del régimen internacional educativo mercosureño: la efectividad de las reglas y normas acordadas, la flexibilidad de cada país a cumplir con esas regulaciones según sus intereses o conveniencias y la imprevisibilidad de los actores no estatales en los distintos escenarios de transnacionalización (Miranda, 2003). Sin embargo, en el nivel de la enseñanza superior podemos advertir que en los últimos 17 años sí ha existido un desarrollo y un avance hacia la consolidación del régimen internacional educativo (Perrotta, 2013; Botto, 2016; Espósito, 2014; Nicoletti et al., 2018; Solanas, 2012). No así en lo concerniente a los niveles de la educación primaria y secundaria como veremos en los capítulos subsiguientes, los cuales aún se encuentran “en construcción”. 
Este régimen internacional educativo debemos estudiarlo en el marco del proceso de integración del Mercosur que puede ser caracterizado como bien explica Bogado Bordazar (2020, p. 87):

(1) En primer lugar, en base al concepto de regionalismo que implica la reunión de un limitado número de Estados vinculados geográficamente. Al momento del surgimiento del bloque no existía un alto grado de interdependencia entre los Estados, por el contrario, fue a través del proceso de integración que comenzó a profundizarse la interdependencia: en primer lugar, económica y política y luego social.

(2) En cuanto a la homogeneidad, podríamos encontrar dos niveles: Argentina, Uruguay y Paraguay como Estados que comparten una historia común, lengua y costumbres similares (aunque con matices en las diferentes regiones). Existiendo algunas diferencias entre estos tres países con Brasil, fundamentalmente en el idioma y la historia de la independencia (segundo nivel). Y si tomamos a Venezuela, quinto miembro pleno (actualmente suspendido), se generaría un tercer nivel de heterogeneidad; dado por la diferencia en el proceso político reciente de este país; por su cercanía geográfica a la región del Caribe y por su relación histórica con los Estados Unidos.

Como sostiene Laura Bogado Bordazar (2020),

El sistema institucional elegido por el Mercosur fue el intergubernamental y la cooperación entre los Estados estuvo presente en todos los aspectos de la relación. Estamos entonces ante un proceso de regionalismo entre países que comparten una misma área geográfica, con un grado medio de interdependencia (económica, política y social) entre sus miembros y con distintos niveles de heterogeneidad entre los mismos, siendo la relación de los cuatro miembros originarios con Venezuela la que presenta la mayor disparidad (2020, p. 88).

Resulta imprescindible tener presente la noción de política pública regional. Para ello, tomaremos el modelo de Luján (2012) de las redes nacionales articuladas como modelo posible de institucionalización del Mercosur. La formación de la agenda estará en manos de actores sociales, económicos y políticos y, una vez definida, deben considerar cinco elementos clave: 1) la capacidad de ejecución multinacional de la política pública, 2) la estabilidad de la misma a lo 
largo del tiempo sin importar los cambios de gobiernos en los países del bloque, 3) la adaptabilidad al contexto donde se lleva a cabo, 4) la coherencia interna y externa de la política y 5) la capacidad de articulación con otras políticas que se desarrollan en el mismo momento (Luján, 2012).

Luján afirma que "las políticas públicas regionales deben ser monitoreadas y evaluadas en sus múltiples niveles de desarrollo: el nivel regional, el nacional y el local" (2012, p. 69). Según este autor, el modelo institucional de redes es favorable a la participación de las organizaciones no gubernamentales.

Por otro lado, uno de los fenómenos que planteamos en este trabajo es el de las migraciones internacionales. El "Glosario sobre la migración de la OIM" (2019), define a la migración internacional como el "movimiento de personas fuera de su lugar de residencia habitual y a través de una frontera internacional hacia un país del que no son nacionales" y al migrante internacional como "toda persona que cambia de país de residencia habitual" (p. 127). Recuperamos aquí la propuesta de definición de migración intramercosur elaborada por Bogado Bordazar (2020) que consiste en:

(...) la libre circulación de nacionales de cualquier país del Mercosur con ánimo de residir en otro Estado parte, en el cual tendrán derecho a entrar, salir, circular y permanecer libremente y gozarán de todos los derechos consagrados según los estándares internacionales de protección en un plano de igualdad con el resto de los nacionales (Bogado Bordazar, 2020, p. 40).

A partir de la definición precedente y a los efectos de este trabajo de investigación, proponemos la noción de niñez migrante intramercosur:

Comprende a los niños, niñas y adolescentes menores de 18 años $^{6}$, acompañados o no, nacionales de cualquier país del Mercosur que tienen ánimo de residir en otro Estado parte, en el cual tendrán derecho a entrar, salir, circular y permanecer libremente y gozarán de todos los derechos consagrados según los estándares internacionales de protección en

\footnotetext{
${ }^{6}$ El artículo 1 de la Convención sobre los derechos del niño define 'niño' como "todo ser humano menor de dieciocho años de edad, salvo que, en virtud de la ley que le sea aplicable, haya alcanzado antes la mayoría de edad.”
} 
un plano de igualdad con el resto de los nacionales y cuentan con la documentación requerida o están en situación irregular.

En términos generales, todo proceso de integración tiene efectos sobre la migración internacional y regional (Bogado Bordazar, 2012). A su vez, la migración influye en la educación y se ve influida por ella. Cuando las personas migran tienen que adaptarse a nuevos sistemas, incluido el educativo, enfrentar dificultades legales y administrativas, superar barreras lingüísticas y enfrentar una discriminación potencial, mientras que para los países receptores estas migraciones importan costos de ajuste en los sistemas de enseñanza (UNESCO, 2018). Como sostiene Grimson (2019, p. 180), "la historia de las migraciones implica que la heterogeneidad y la interculturalidad son constitutivas de las sociedades". El concepto de interculturalidad lo desarrollaremos en profundidad en los capítulos subsiguientes cuando surja en las disposiciones de la legislación argentina en materia de educación y en el marco del Programa de Escuelas Interculturales Bilingües de Frontera.

Terigi (2009) afirma que las trayectorias escolares reales de los sujetos permiten reconocer itinerarios frecuentes o más probables que coinciden o están próximos a las trayectorias escolares teóricas que expresan recorridos de los sujetos en el sistema que siguen la progresión lineal prevista en un período de tiempo estándar. Como sostiene la autora, gran parte de los niños, niñas y jóvenes transitan su "escolarización de modo heterogéneos, variables y contingentes" (Terigi, 2009, p. 12). Y ello se debe a un conjunto complejo de factores, entre ellos los procesos migratorios que involucran a los niños, niñas y adolescentes de múltiples maneras, dependiendo de si acompañan a sus padres, emigran solos o permanecen en el país de origen mientras uno o ambos de sus padres emigran (Velázquez, 2014). Los desplazamientos de las personas interrumpen las trayectorias escolares de la niñez migrante. Allí entran en juego las respuestas que puede dar un proceso de integración como el Mercosur para subsanar dicha interrupción.

En los países de la región mercosureña no existe una herramienta estadística educativa consolidada que permita realizar el seguimiento de las trayectorias escolares pero muestran fenómenos que permiten, como sostiene Terigi (2009), formular hipótesis sobre las trayectorias individuales de los niños y niñas. 
Para comprender la política migratoria y su evolución, seguiremos la propuesta de Menara Guizardi (2017) que presenta cinco momentos o ciclos para estudiar el abordaje político sobre las migraciones y que nos permitirá situar las políticas de integración ${ }^{7}$ de la niñez migrante en los sistemas educativos: (1) El primer momento tiene lugar entre los siglos XIX y XX cuando Europa se constituyó en el principal continente emisor de migrantes internacionales, siendo los principales receptores Estados Unidos, Argentina y Brasil que incentivaban la migración con una base ideológica racista/eugenésica de blanqueamiento de la población. (2) El segundo ciclo lo ubica en la primera mitad del siglo XX cuando la migración continuaba siendo en su mayor parte europea producto de las dos grandes guerras y se apoya en la idea positiva de una migración mestiza y proveniente de diferentes pueblos. (3) El tercer momento comienza en la segunda mitad del siglo XX, una vez finalizada la Segunda Guerra Mundial, donde se desarrollan dos modelos aplicados principalmente en Francia y en Alemania, respectivamente. El modelo asimilacionista según el cual la pertenencia y los derechos de los migrantes en el país de recepción estaban condicionados a la asimilación de la cultura nacional y que implicaba la renuncia del migrante, en el espacio público, de sus prácticas religiosas, culturales, sociales y políticas. Y el modelo utilitarista, donde el migrante era aceptado por el Estado si su presencia respondía a una necesidad del país receptor lo que implicaba que debía irse cuando dejara de satisfacer esta utilidad. (4) En el cuarto momento, se desarrollan dos paradigmas: en primer lugar, nos encontramos con el modelo multiculturalista a inicios de la década de 1980 que "limita el reconocimiento de la diversidad al derecho de existencia de 'los diversos"” (Guizardi, 2017, p. 195). Y en segundo lugar, encontramos el paradigma intercultural que se desarrolló vinculado sobre todo a la educación y se fue ampliando propugnando la comprensión de las relaciones entre sujetos y grupos diversos. (5) El último momento, nos dice la autora, es el que vivimos en la actualidad y que algunos denominan “posglobalización”. Este ciclo se caracteriza por la radicalización y la naturalización de la violencia política estatal en contra de la población migrante, refugiada y desplazada, por el incremento de la muerte de migrantes intentando cruzar las fronteras, por la naturalización de

\footnotetext{
${ }^{7}$ Joaquín Arango (2005, p. 17) afirma que "las políticas de inmigración comprenden: a) las normas y prácticas que tienen por objeto la regulación y el control de los flujos migratorios, y especialmente la entrada y permanencia de inmigrantes; b) las regulaciones y prácticas relativas a la demanda de asilo; c) las medidas dirigidas a la integración de los inmigrantes y las minorías étnicas, incluyendo la definición de la ciudadanía y el acceso a la misma; y d) las políticas para combatir el racismo y la discriminación. En realidad, estas cuatro rúbricas pueden reducirse a dos, subsumiendo las dos primeras en la vertiente 'políticas de control' y las dos últimas en las 'políticas de integración"”.
} 
esta violencia por parte de la población en general y por la "deconstrucción" progresiva de los derechos concedidos a las poblaciones migrantes.

En el mismo sentido, Grimson (2019, p. 176) afirma que la geopolítica del norte global vira "hacia una lógica de control militarizado que criminaliza las migraciones sur-norte y a los sujetos que las protagonizan”, convirtiendo así a los migrantes en lo que el autor llama como "invasores indeseados".

Ahora bien, con la ayuda de Novaro, Díez y Martínez (2017) buscaremos relacionar los ciclos o momentos de construcción de las políticas migratorias con las acciones vinculadas a la educación de la población migrante en Argentina. A partir de 1910 (tercer ciclo o momento), se evidencian los proyectos de asimilación donde se produce una nacionalización de la enseñanza, siendo tarea de la escuela borrar las marcas de origen de la población ya sea migrante, indígena o rural. En la última dictadura cívico-militar y en la década de los noventa, la política de asimilación y los sentidos de uniformización van a predominar. A partir de la década de 1980, el respeto a la diversidad y la no discriminación comienzan a estar presentes. "Desde esta perspectiva democratizadora se advierten las profundas raíces conservadoras de los mandatos nacionalistas en educación" (Novaro et al, 2017, p. 9), dando cuenta de una gran tensión política (seguridad y soberanía nacional) y jurídica (perspectiva de los derechos humanos). La sanción de la Ley de Migraciones en 2003 es un punto de inflexión (cuarto momento o ciclo) por su perspectiva de derechos humanos y por el enfoque regional que promueve. En la actualidad (cuarto ciclo o momento), "coexisten las nociones de integración e inclusión para aludir al modo con que se proyecta la presencia de niños y jóvenes migrantes en las escuelas" (Novaro et al, 2017, p. 10): la integración para referirse a categorías como acceso a la ciudadanía y a la movilidad económica y la inclusión como una forma superadora de la asimilación y de la integración que se vincula con el concepto de inserción pensada "como estar en la escuela" y que las autoras citadas consideran que "resulta proclive a la descontextualización de los sujetos y la pérdida de sus referencias colectivas" (2017, p. 11). Describen la presencia de migrantes latinoamericanos y sus descendientes como una forma de inclusión subordinada porque a pesar de la mayor igualdad lograda en el plano legal y la asistencia masiva en el nivel primario que se constata, persisten muchas situaciones de desigualdad. 


$$
\text { Trato }
$$

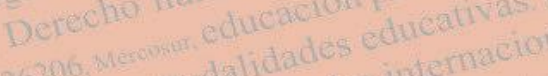

ión in

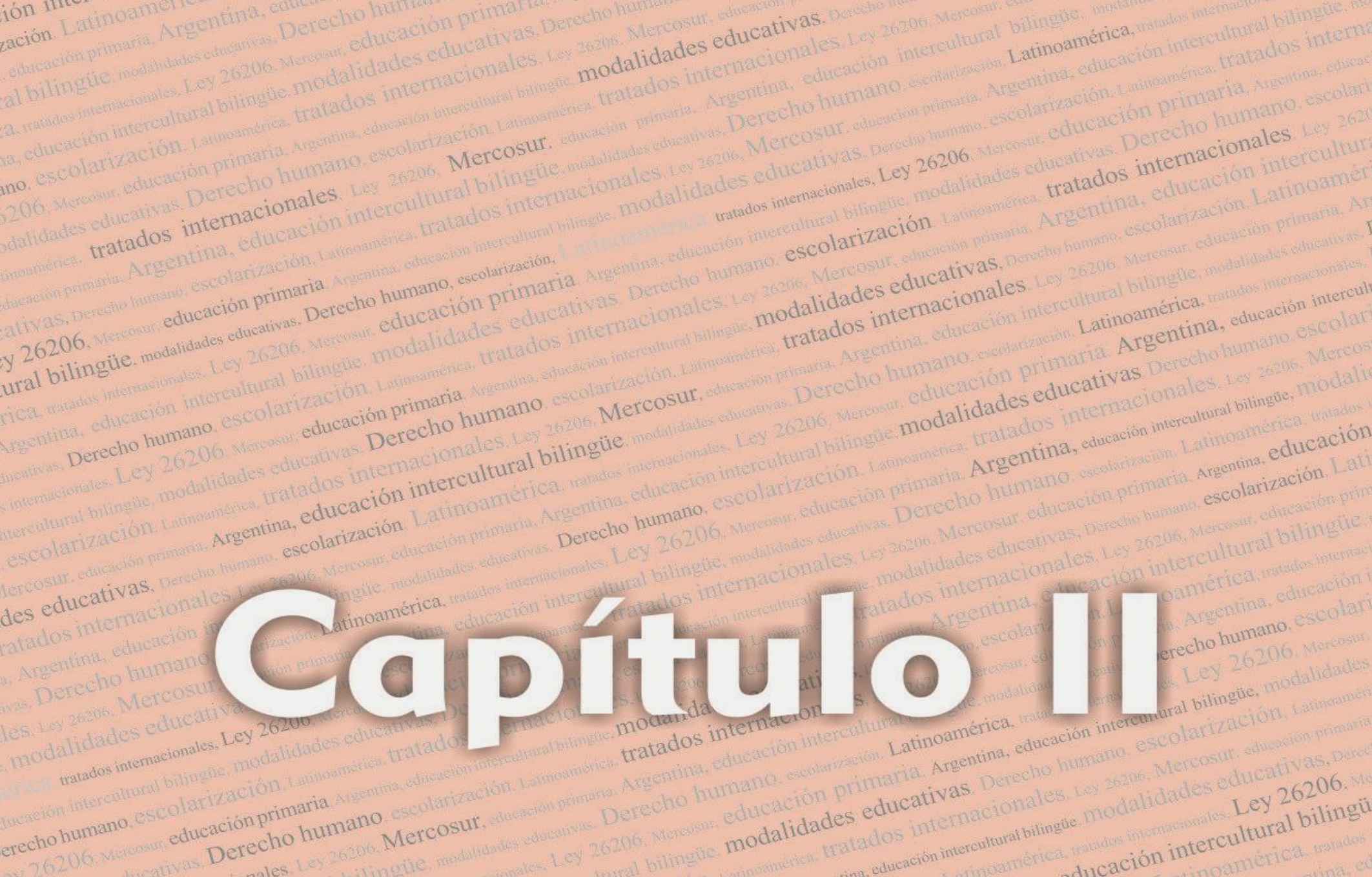
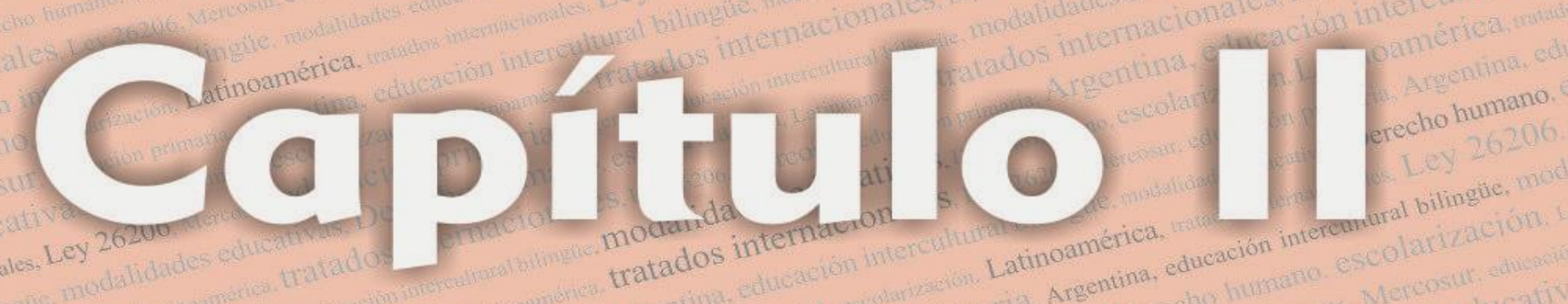

Derecho humano

atural bilingue,$$
\begin{aligned}
& \text { Ley } 26206 \text { educación primaria humano, escolarizaction } \\
& \text { i bilingie, modalidades educativas. Detecho educación pr }
\end{aligned}
$$

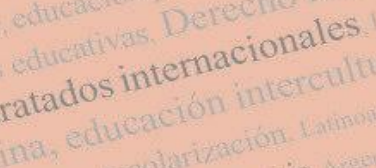

Nercosur.

Latinoamérica watados inter

des educativas. 


\section{Capítulo II}

\section{Migrar, un derecho humano}

Toda persona tiene derecho a salir de cualquier país, incluso del propio, y a regresar a su país. Declaración Universal de los Derechos Humanos (art. 13.2)

El fenómeno migratorio no es un fenómeno nuevo, las migraciones estuvieron presentes en toda la historia de la humanidad. Según Grimson (2011), no tendría sentido intentar delimitar una “época de migraciones”, porque impediría una compresión histórica del fenómeno.

Es por ello que en el presente capítulo buscaremos dar cuenta, de manera general, de los flujos migratorios internacionales, en América Latina y el Caribe, en el Mercosur y, finalmente, en Argentina, en los últimos años. Este panorama se complementará con el análisis de la normativa que regula las migraciones en los diferentes ámbitos. Añadimos algunos aportes que surgen de conferencias y declaraciones y de espacios de discusión sobre el tema tanto intergubernamentales como de la sociedad civil.

Sabemos de antemano que las migraciones continúan siendo una excepción en el comportamiento de la población puesto que la regla es la permanencia en los países de origen. A pesar de que actualmente hay más migrantes que nunca, su cantidad es ínfima en comparación con la población mundial (Weis et al., 2020). Se trata de un fenómeno con gran incidencia en el bienes- 
tar de las personas que participan en él y en las políticas de los Estados tanto de partida como de acogida.

\section{FLUJO MIGRATORIO INTERNACIONAL}

El objetivo de este primer apartado es ponernos en situación sobre la tendencia de los desplazamientos migratorios a nivel internacional en la actualidad como una mirada previa y necesaria para comprender lo que sucede en nuestra región. Los datos estadísticos serán tomados de los distintos informes de organizaciones internacionales abocadas a recabar datos de ésta índole. Es por ello que la migración irregular no podrá ser tenida en cuenta.

Partimos de una cifra que nos proporciona la Migration Wall Chart 2019 elaborada por la División Población de las Naciones Unidas: sólo el 3,4 \% de la población se desplaza de un lugar a otro. Los migrantes internacionales representan 271,642.1 millones de personas (UN, 2019) por sobre un total de 7.715 millones de habitantes del planeta (UNFPA, 2019), es decir, sólo una pequeña porción de la población mundial.

La proporción de migrantes sobre el total de la población varía considerablemente según la región. Oceanía (21.2\%), América del Norte (16\%), Europa (11\%) y África del Norte y el Sudeste Asiático (9.4\%) registran las mayores proporciones de migrantes en su población total. En cambio, los migrantes representan el 2,2\% de la población total en África Subsahariana, el $1,8 \%$ América Latina y el Caribe, el $1 \%$ en el Centro y Sur de Asia y $0.8 \%$ en Asia Oriental y Meridional.

En cuanto al rango etario, el promedio de edad de los migrantes es de 39 años. En algunas regiones del mundo la población migrantes se está volviendo más joven. Los migrantes que viven en África Subsahariana son los más jóvenes (30.9 de edad promedio), seguido por América Latina y el Caribe (33.8 de edad promedio), África del Norte (34 años promedio) y el Sudeste Asiático (40,8 años de edad promedio). En cambio, en Asia Oriental y Asia Meridional, Europa, Oceanía y América del Norte la población migrantes presenta mayor promedio de edad. El 13.9 $\%$ del total de los migrantes estaban por debajo de los 20 años. En África Subsahariana encontramos la población migrante más joven del mundo (27.3\%), seguida por América Latina y el Caribe y Asia (21.6\% cada una). 
Según el Informe del Fondo de Población de las Naciones Unidas (UNFPA, 2019), el $26 \%$ de la población mundial se compone de personas de entre 0 y 14 años de edad. La proporción estimada de niños entre los migrantes internacionales es de 13,9\% (alrededor de los $31 \mathrm{mi}-$ llones). Hay cerca de 13 millones de menores refugiados, 936.000 menores solicitantes de asilo y 17 millones de niños que han tenido que desplazarse dentro de sus países (OIM, 2019).

En 2019, dos tercios de los migrantes internacionales vivían en solo 20 países. El mayor número de migrantes reside en Estados Unidos (51 millones). En Alemania, Arabia Saudita y la Federación Rusa residen 13 millones de migrantes (cada uno), seguidos por Reino Unido de Gran Bretaña e Irlanda del Norte (10 millones), y los Emiratos Árabes Unidos (9 millones).

Cabe aclarar aquí que, tanto para la descripción del flujo migratorio internacional como regional, no serán tenidos en cuenta los refugiados dentro de la categoría de migrante. Los refugiados son personas que huyen de conflictos armados o persecución. Con frecuencia, su situación es tan peligrosa e intolerable que deben cruzar fronteras internacionales para buscar seguridad en los países cercanos y, entonces, convertirse en 'refugiados' reconocidos internacionalmente, con acceso a la asistencia de los Estados, el ACNUR y otras organizaciones. Son reconocidos como tal, precisamente porque es muy peligroso para ellos volver su país y necesitan asilo en algún otro lugar.

Los migrantes deciden trasladarse no a causa de una amenaza directa de persecución o muerte, sino principalmente para mejorar sus vidas al encontrar trabajo o educación, por reunificación familiar, o por otras razones. A diferencia de los refugiados, quienes no pueden volver a su país, los migrantes continúan recibiendo la protección de su gobierno. Los flujos migratorios cambian de manera constante, si bien no nos detendremos a analizar las causas, coincidimos con diferentes autores que el trabajo, la independencia y la seguridad son algunos de los propulsores de las migraciones (Christoph, 2020).

\section{Normativa internacional}

Aquí recuperamos la normativa internacional más importante que regula el desplazamiento migratorio en el plano internacional y en la materia que particularmente nos interesa: los trabajadores y sus familias y, los derechos de la niñez en el contexto migratorio. Es por ello que analiza- 
remos la Convención internacional sobre la protección de los derechos de todos los trabajadores migratorios y de sus familiares y la Convención sobre los derechos del niño.

Consideramos pertinente incorporar en este apartado los avances del Programa de Acción de la V Conferencia internacional sobre la Población y el Desarrollo llevada a cabo entre el 5 y el 13 de septiembre de 1994 en El Cairo (Egipto). Esta Conferencia convocó a 179 delegaciones de los Estados partes de Naciones Unidas, las que elaboraron y aprobaron el Programa de Acción sobre Población y Desarrollo (PA-CIPD) para los próximos veinte años. Si bien no genera obligación para los Estados firmantes, se convirtió en una inspiración que marca pautas a seguir.

\section{Convención internacional sobre la protección de los derechos de todos los traba- jadores migratorios y de sus familiares ${ }^{8}$}

La Convención internacional sobre la protección de los derechos de todos los trabajadores migratorios y de sus familiares fue aprobada el 18 de diciembre de 1990 por la Asamblea General por Resolución $n^{\circ} 45 / 158$ sin votación y quedó abierta a la firma de todos los Estados miembros de las Naciones Unidas. Su aprobación fue el resultado de largos debates, informes y recomendaciones sobre la cuestión de los derechos de los migrantes. Nos podemos remontar a 1972, cuando el Consejo Económico y Social manifestó su preocupación por el transporte ilegal de mano de obra a algunos Estados europeos y por la explotación de los trabajadores de algunos Estados africanos (Resolución $\left.n^{\circ} 1706\right)$.

Luego de un largo camino recorrido, la Convención logró entrar en vigencia el $1^{\circ}$ de julio de 2003, luego de haber sido ratificada por un mínimo de veinte Estados en marzo de ese año. Este tratado internacional pone de relieve la relación entre la migración y los derechos humanos.

\footnotetext{
${ }^{8}$ Como surge del Folleto Informativo $\mathrm{N}^{\circ} 24 \mathrm{de}$ la Oficina del Alto Comisionado de las Naciones Unidas para los Derechos Humanos, la presente Convención es el tratado internacional más completo sobre los derechos de los trabajadores migrantes, sin embargo hay otros instrumentos internacionales que también se refieren a los derechos de los trabajadores migratorios o que tratan de cuestiones de especial importancia para éstos. Ellos son el Pacto Internacional de Derechos Civiles y Políticos, el Pacto Internacional de Derechos Económicos, Sociales y Culturales, la Convención Internacional sobre la Eliminación de todas las Formas de Discriminación Racial, la Convención contra la Tortura y Otros Tratos o Penas Crueles, Inhumanos o Degradantes y la Convención sobre la eliminación de todas las formas de discriminación contra la mujer. Asimismo debemos agregar dos convenios de la Organización Internacional del Trabajo: el Convenio sobre los trabajadores migrantes 1949 ( $N^{\circ}$ 97), que se basa en el principio de igualdad de trato de los nacionales y los trabajadores migratorios regulares en las esferas relacionadas con el trabajo; y el Convenio sobre los trabajadores migrantes (Disposiciones complementarias), 1975 ( $\left.\mathrm{N}^{\circ} 143\right)$, que tiene como fin eliminar la migración ilegal y el empleo ilegal.
} 
La convención proporciona las definiciones del trabajador migratorio y sus familiares. El artículo 2.1 en su parte pertinente dice:

...Se entenderá por «trabajador migratorio» toda persona que vaya a realizar, realice o haya realizado una actividad remunerada en un Estado del que no sea nacional...

...el término «familiares» se refiere a las personas casadas con trabajadores migratorios o que mantengan con ellos una relación que, de conformidad con el derecho aplicable, produzca efectos equivalentes al matrimonio, así como a los hijos a su cargo y a otras personas a su cargo reconocidas como familiares por la legislación aplicable o por acuerdos bilaterales o multilaterales aplicables entre los Estados de que se trate. (Artículo 4)

Es importante destacar que la Convención otorga protección al trabajador migratorio y sus familiares no sólo cuando estén trabajando efectivamente sino

(...) durante todo el proceso de migración de los trabajadores migratorios y sus familiares, que comprende la preparación para la migración, la partida, el tránsito y todo el período de estancia y de ejercicio de una actividad remunerada en el Estado de empleo, así como el regreso al Estado de origen o al Estado de residencia habitual (Artículo 1.2).

En los artículos 8 a 35 se otorga una amplia serie de derechos a todos los trabajadores migratorios y sus familiares, independientemente de cuál sea su condición en tanto que trabajadores migratorios. Entre ellos destacamos para este trabajo lo dispuesto en el artículo 30:

Todos los hijos de los trabajadores migratorios gozarán del derecho fundamental de acceso a la educación en condiciones de igualdad de trato con los nacionales del Estado de que se trate. El acceso de los hijos de trabajadores migratorios a las instituciones de enseñanza preescolar o las escuelas públicas no podrá denegarse ni limitarse a causa de la situación irregular en lo que respecta a la permanencia o al empleo de cualquiera de los padres, ni del carácter irregular de la permanencia del hijo en el Estado de empleo.

El artículo 72 de la Convención prevé la creación de un Comité de protección de los derechos de todos los trabajadores migratorios y de sus familiares. Se trata de un cuerpo de catorce expertos independientes que monitorea la implementación de la Convención por sus Estados parte. Inició sus funciones en el mes de marzo de 2004 y se reúne en Ginebra dos veces por año. 
Los Estados parte deben presentar al Comité un informe sobre cómo implementan los derechos previstos en la Convención. Este informe se presenta al año de haber ratificado la Convención y, luego cada cinco años. El Comité examina los informes y emite una observación con sus preocupaciones y recomendaciones al Estado parte correspondiente.

Bajo determinadas circunstancias, el Comité puede recibir comunicaciones individuales de particulares cuyos derechos protegidos por la Convención hayan sido violados. Este mecanismo no está actualmente en funcionamiento puesto que es necesario que diez Estados parte hayan efectuado la declaración que prevé el artículo 77 de la Convención que habilitaría al Comité a considerar estas comunicaciones sobre violaciones de derechos individuales. Al día de la fecha sólo cinco Estados han formulado la declaración por la cual acuerdan esta competencia al Comité 9 . Resulta lamentable que dicho mecanismo no esté aún en marcha dado que la posibilidad de reclamar en el orden internacional por la violación de los derechos humanos, en nuestro caso, los derechos humanos de los trabajadores migrantes y sus familias, le da sentido al conjunto de derechos contenidos en la Convención ${ }^{10}$.

El Comité también puede realizar reuniones para discutir y establecer posición con respecto a temas vinculados a su trabajo y sobre la interpretación de los contenidos de la Convención. En 2011 y 2013, el Comité emitió observaciones generales (OG) sobre los trabajadores domésticos migratorios y sobre los trabajadores migratorios en situación irregular y de sus familiares.

Cabe destacar las medidas especiales recomendadas para la protección de los niños: los Estados deben velar por que los niños migrantes no realicen ningún tipo de trabajo doméstico que pueda ser peligroso o nocivo para su salud o su desarrollo físico, mental, espiritual, moral o social. Asimismo se abstendrán de adoptar políticas destinadas a contratar a niños migrantes para

\footnotetext{
${ }^{9}$ El Salvador, Guatemala, México, Turquía y Uruguay han formulado la declaración por la cual aceptan que el Comité reciba comunicaciones individuales. Consultado en línea el 12 de enero de 2016 en: https://treaties.un.org/Pages/ViewDetails.aspx?src=TREATY\&mtdsg_no=IV-13\&chapter=4\&lang=en

${ }^{10}$ Cabe destacar que el Comité de protección de los derechos de todos los trabajadores migratorios y de sus familiares, es el único cuerpo de los previstos por los nueve tratados sobre derechos humanos que no puede aún expedirse sobre la violación de los derechos contenidos en la Convención. Los ocho comité que pueden recibir denuncias individuales conforme a los tratados que los establecieron son: el Comité de Derechos Humanos, el Comité para la eliminación de la discriminación contra la mujer, el Comité contra la tortura, el Comité para la eliminación de la discriminación racial, el Comité para los derechos de las personas con discapacidades, el Comité contra la desapariciones forzadas y el Comité para los derechos económicos, sociales y culturales.
} 
que trabajen en el servicio doméstico (párrafo $56 \mathrm{OG} \mathrm{n}^{\circ} 1$ ). Los Estados deben velar porque el trabajo doméstico que realicen los niños no dificulte su educación primaria y secundaria.

La Observación general $\mathrm{n}^{\circ} 2$ parte de la estimación que entre el $10 \%$ y el $15 \%$ de los migrantes internacionales se encuentra en situación de irregularidad. El Comité propone descartar el término "trabajador ilegal" para referirse a los trabajadores migratorios irregulares o no documentados, como los denomina la Convención, puesto que es inadecuado y tiende a vincularlos con la delincuencia.

Quisiéramos destacar la observación que hace el Comité de la Parte III de la Convención destinada la protección de los derechos económicos, sociales y culturales de los trabajadores migratorios. En el párrafo 61 sobre protección contra la explotación laboral, se recuerda que la Convención prevé que las leyes y reglamentaciones sobre la edad mínima de empleo se apliquen igualmente a los niños migrantes. La edad mínima nunca será inferior a 15 años conforme lo establece el artículo 2 del Convenio No 138 (1973) de la OIT sobre la edad mínima de admisión al empleo. Los Estados partes tienen la obligación de velar por que los niños que son trabajadores migrantes estén protegidos de toda forma de esclavitud, prostitución u ocupaciones que puedan poner en peligro su educación, su seguridad, su desarrollo moral y su salud, como aquellas con horarios prolongados. Pesa sobre los Estados parte la obligación de garantizar a los niños trabajadores migratorios sus derechos en materia de educación, salud laboral y esparcimiento.

Por último, en el párrafo 76 el Comité observa que:

... los niños migrantes pueden sufrir múltiples formas de discriminación por motivos de raza, etnia, género y discapacidad, entre otros. El principio de igualdad de trato exige a los Estados partes eliminar toda discriminación contra los niños migrantes en sus sistemas educativos. Por lo tanto, los Estados partes deben evitar la segregación escolar y la aplicación de normas de trato distintas a los hijos de los trabajadores migratorios, y eliminar todas las formas de discriminación contra los hijos de los trabajadores migratorios en las aulas.

\section{Convención sobre los derechos del niño}


La Convención sobre los derechos del niño fue adoptada por la Asamblea General de las Naciones Unidas el 20 de noviembre de 1989. Esta Convención constituye el marco legal internacional desde el cual avanzar en el desarrollo de políticas e instrumentos jurídicos que favorezcan la protección efectiva de los derechos de las niñas/os, superando toda forma de discriminación basada en la nacionalidad, origen étnico o condición social que comúnmente afectan a las niñas, niños y adolescentes que se ven forzados a abandonar su país de origen.

En ese sentido, la Corte Interamericana de Derechos Humanos (CIDH) ha subrayado que la Convención es el tratado internacional que posee mayor vocación de universalidad, lo cual pone de manifiesto un amplio consenso internacional favorable a los principios e instituciones acogidos por dicho instrumento que refleja el desarrollo actual de esta materia ${ }^{11}$.

La Convención contempla cuatro principios rectores: la no discriminación; la adhesión al interés superior del niño; el derecho a la vida, la supervivencia y desarrollo; y el derecho a la libertad de expresión y a ser escuchado. Estos principios constituyen derechos en sí mismos, y a la vez se instauran como guía para la interpretación y respeto de todos los demás derechos presentes en la Convención (SITEAL, 2015). El artículo 2.1 de la Convención exige que los Estados respeten y garanticen los derechos de cada niño sujeto a su jurisdicción

sin distinción alguna, independientemente de la raza, el color, el sexo, el idioma, la religión, la opinión política o de otra índole, el origen nacional, étnico o social, la posición económica, los impedimentos físicos, el nacimiento o cualquier otra condición del niño, de sus padres o de sus representantes legales.

El derecho a la vida, la supervivencia y el desarrollo, descripto en el artículo 6 establece que todo niño tiene el derecho intrínseco a la vida y que los Estados deben garantizar su supervivencia y su desarrollo. La Convención va más allá del derecho a la vida, tal como lo expresan otros tratados de derechos humanos, para adoptar una visión a largo plazo que contemple el desarrollo de los niños en su sentido más amplio.

\footnotetext{
${ }^{11}$ Condición jurídica y Derechos Humanos del niño. Opinión Consultiva OC-17/02 de 28 de agosto de 2002. Serie A No. 17, párrafo 29.
} 
El artículo 12 de la Convención regula el derecho de los niños a la libertad de expresión y a ser escuchados en asuntos públicos y privados que los conciernan siempre teniendo en cuenta su edad y madurez. El artículo 3.1 de la Convención establece que los Estados deberán tener una consideración primordial en todas las medidas concernientes a los niños que será su "interés superior". Como señala Cillero Bruñol (1999), se trata de un principio jurídico garantista porque además de configurarse como una principio rector es una garantía en el sentido de medio idóneo para asegurar el ejercicio de los derechos subjetivos.

El texto de la Convención reúne una serie de derechos que ya estaban contemplados en documentos internacionales previos, algunos de los cuales sólo tenían efectos declarativos o eran de alcances muy generales. A los efectos de este trabajo rescataremos aquellos artículos que consideramos pueden ser de ayuda a los fines de describir el plexo normativo internacional que protege a los niños migrantes. Es por ello, que además de identificar los artículos vinculados a la cuestión migratoria, incluiremos aquellos atinentes a la educación a pesar de que nos ocuparemos en detalle de esta temática en el capítulo siguiente.

El artículo 8 de la Convención reconoce los derechos de los niños a la identidad, a la nacionalidad, al nombre y a las relaciones familiares. Los artículos 9 y 10 contemplan las obligaciones de los Estados parte de asegurar la unidad y la reunificación familiar. El interés superior del niño debe primar siempre en la decisión de separarlo de uno o ambos padres y para que mantenga contacto personal con ellos de manera regular. En cuanto a los pedidos de reunificación familiar ya sea de parte de los niños o de sus padres, los Estados deben responder "de manera positiva, humanitaria y expeditiva" (artículo 10.1), y deben garantizar que estos pedidos no acarrearán consecuencias desfavorables a los solicitantes. En estos casos también se debe asegurar que los niños mantengan relaciones personales con sus padres permitiéndoles la entrada y salida del país que sólo se podrá ver restringida por cuestiones de seguridad nacional o de orden público.

Al igual que la Convención sobre los trabajadores migratorios y sus familiares, la Convención sobre los Derechos del niño crea un cuerpo de 18 expertos independientes denominado Comité de los Derechos del niño cuya función es recibir los informes elaborados por los Estados sobre la situación de los derechos de la infancia en su país en el plazo de dos años a partir de la fecha de ratificación, y luego cada cinco años. Al analizar los informes, el Comité examina la forma en que los gobiernos establecen y cumplen las normas que velan por la satisfacción y la 
protección de los derechos de la infancia enumerados en la Convención o el Protocolo Facultativo. El Comité no supervisa la conducta personal de los padres y las madres y de otros cuidadores, ni tampoco está habilitado para tramitar las quejas de los ciudadanos. Además de las presentaciones periódicas de informes, el Comité podría solicitar información adicional o informes suplementarios (artículo 44).

Además el Comité está facultado para emitir Observaciones generales que especifican los estándares de los derechos reconocidos en la Convención así como las normas complementarias. Hasta el momento, el Comité emitió diecisiete Observaciones ${ }^{12}$, de entre las cuales destacaremos dos: la $\mathrm{OG} \mathrm{n}{ }^{\circ} 1$ Propósitos de la educación y la $\mathrm{OG} \mathrm{n}^{\circ} 6$ Trato de los menores no acompañados y separados de su familia fuera de su país de origen.

La OG $n^{\circ} 1$ fue dictada en abril de año 2001 con el objeto de destacar la importancia del artículo 29.1 de la Convención. Los objetivos allí plasmados son el desarrollo holístico del niño hasta el máximo de sus posibilidades, lo que incluye inculcarle el respeto de los derechos humanos, potenciar su sensación de identidad y pertenencia y su integración en la sociedad e interacción con otros y con el medio ambiente. El Comité aclara que el derecho del niño a la educación "no sólo se refiere al acceso a ella (art. 28), sino también a su contenido" (OG n 1 párrafo 3). En ese sentido, el objetivo principal de la educación debe ser el desarrollo de la personalidad de cada niño reconociendo el hecho de que cada niño tiene características, intereses y capacidades únicas y también necesidades de aprendizaje propias. Todo ello debe verse reflejado en el programa de estudios que debe guardar una relación directa con el marco social, cultural, ambiental y económico del niño y con sus necesidades presentes y futuras.

\footnotetext{
${ }^{12} \mathrm{OG} \mathrm{n}^{\circ} 2$, El papel de las instituciones nacionales independientes de los derechos humanos en la promoción y protección de los derechos del niño (2002); OG n 3, El VIH/SIDA y los derechos del niño (2003); OG n ${ }^{\circ} 4$, La salud y el desarrollo de los adolescentes en el contexto de la Convención sobre los Derechos del Niño (2003); OG n ${ }^{\circ}$, Medidas generales de aplicación de la Convención sobre los Derechos del Niño (2003); OG $\mathrm{n}^{\circ}$ 7, Realización de los derechos del niño en la primera infancia (2005); OG $\mathrm{n}^{\circ} 8$, El derecho del niño a la protección contra los castigos corporales y otras formas de castigo crueles o degradantes (2006); OG $n^{\circ}$ 9, Los derechos de los niños con discapacidad (2006); OG $n^{\circ} 10$, Los derechos del niño en la justicia de niños, niñas y adolescentes (2007); OG $\mathrm{n}^{\circ} 11$, Los niño indígenas y sus derechos en virtud de la Convención sobre los Derechos del Niño (2009); OG n 12, El derecho del niño a ser escuchado (2009); OG n ${ }^{\circ} 13$, Derecho del niño a no ser objeto de ninguna forma de violencia (2011); OG $\mathrm{n}^{\circ} 14$, Sobre el derecho del niño a que su interés superior sea una consideración primordial (2013); OG n 15, Sobre el derecho del niño al disfrute del más alto nivel posible de salud (2013); OG n 16, sobre las obligaciones del Estado en relación con el impacto del sector empresarial en los derechos del niño (20133); y OG n ${ }^{\circ} 17$, sobre el derecho del niño al descanso, el esparcimiento, el juego, las actividades recreativas, la vida cultural y las artes (2013).
} 
En septiembre de 2005, el Comité emitió la OG n 6 con el propósito de dar cuenta de la situación de vulnerabilidad de los niños, niñas y adolescentes no acompañados y separados de su familia, exponer la multiplicidad de problemas que experimentan los Estados y otros actores para conseguir que estos niños, niñas y adolescentes tengan acceso a sus derechos y puedan disfrutar de los mismos, así como proporcionar orientación sobre la protección, atención y trato adecuado de los referidos niños y niñas a la luz de todo el contexto jurídico que representa la Convención.

Partimos de las definiciones que proporciona el Comité de niños no acompañados que son aquellos "niños, niñas y adolescentes que están separados de ambos padres y otros parientes y no están al cuidado de un adulto al que, por ley o costumbre, incumbe esa responsabilidad", y de niños separados que son "los niños, niñas y adolescentes separados de ambos padres o de sus tutores legales o habituales, pero no necesariamente de otros parientes. Por tanto, puede tratarse de niños o niñas acompañados por otros miembros adultos de la familia” ( $\mathrm{OC} \mathrm{n}^{\circ} 6$ párrafos $\left.7 \mathrm{y} 8\right)$.

El Comité afirma que el disfrute de los derechos regulados en la Convención no está limitado a los niños y niñas que sean nacionales del Estado Parte, de modo que, salvo estipulación expresa en contrario en la Convención, serán también aplicables a todos los niños y niñas -sin excluir a los solicitantes de asilo, los refugiados y los niños migrantes- con independencia de su nacionalidad o apátrida, y situación en términos de inmigración.

En el año 2000, la Asamblea General de las Naciones Unidas aprobó dos Protocolos facultativos de la Convención que refuerzan la protección de la infancia contra su participación en los conflictos armados y la explotación sexual. El 19 de diciembre de 2011, la Asamblea General aprobó el tercer Protocolo facultativo relativo al procedimiento de comunicaciones que permitirá a los niños someter denuncias individuales ante el Comité ante las violaciones de sus derechos protegidos en la Convención y en los dos primeros Protocolos facultativos.

Asimismo el tercer Protocolo prevé la posibilidad de que el Comité reciba y examine comunicaciones en que un Estado parte alegue que otro Estado parte no cumple las obligaciones previstas en la Convención y en los dos primeros Protocolos. Y por último, regula un procedimiento de investigación en caso de violaciones graves o sistemáticas.

Para finalizar este apartado diremos que en América Latina sólo Guatemala le ha otorgado a la Convención rango supraconstitucional en su legislación. Argentina, República Dominica- 
na y Venezuela le han otorgado rango constitucional, mientras que Bolivia, Colombia, Costa Rica, Ecuador, El Salvador, Honduras y Paraguay, posicionan al texto de la Convención como supralegal. Por último se encuentra el grupo de países que le ha dado a la Convención rango jurídico legal, conformado por Chile, Cuba, México, Nicaragua, Panamá, Perú y Uruguay (SITEAL, 2015).

Con el propósito de concluir el apartado de normas internacionales vinculantes nos gustaría mencionar que existen otras tratados, más allá del núcleo fundamental de protección de los derechos humanos como son la Declaración Universal de Derechos Humos (1948) y los Pactos Internacionales de Derechos Civiles y Políticos (1966) y de Derechos Económicos, Sociales y Culturales (1966), más específicas que contemplan los derechos de los migrantes y de la niñez migrante, a saber: el Protocolo para Prevenir, Reprimir y Sancionar la Trata de Personas, Especialmente Mujeres y Niños (2000), que complementa la Convención contra la Tortura y Otros Tratos o Penas Crueles, Inhumanos o Degradantes (1984); el Protocolo contra el Tráfico Ilícito de Migrantes por Tierra, Mar y Aire (2000), que complementa la Convención de las Naciones Unidas contra la Delincuencia Organizada Transnacional, el Convenio de la Organización Internacional del Trabajo (OIT) sobre los Trabajadores Migrantes (Revisado), 1949 (núm. 97) y el Convenio sobre los Trabajadores Migrantes (Disposiciones Complementarias), 1975 (núm. 143), de la OIT, la Convención sobre el Estatuto de los refugiados (1951), la Convención sobre el Estatuto de los Apátridas (1954) y la Convención sobre los Derechos de las Personas con Discapacidad (2007). Todos estos instrumentos prevén amplias protecciones para los migrantes y sus familiares pero dada la extensión del presente trabajo solo hemos abordado las que consideramos más relevante para nuestro estudio.

\section{Otros}

i. Conferencia internacional sobre la Población y el Desarrollo

En el marco de la Conferencia internacional sobre la Población y el Desarrollo (CIPD) que tuvo lugar en El Cairo, Egipto en 1994, se aprobó un Programa de Acción que se estableció en base al reconocimiento de las interrelaciones existentes entre población y crecimiento económico soste- 
nido en un marco de desarrollo sostenible, desde las cuales se han determinado temáticas diferenciadas que plasman estas relaciones y los distintos escenarios de acción, donde se ha de actuar a nivel nacional e internacional (CEPAL, 2012, p. 10).

Las áreas temáticas prioritarias del Programa de Acción son las relaciones entre la población, el crecimiento económico sostenido y el desarrollo sostenible, la igualdad y la equidad entre los sexos y la habilitación de la mujer, la familia, sus funciones, derechos, composición y estructura, el crecimiento y estructura de la población, los derechos reproductivos y la salud reproductiva, la salud, morbilidad y mortalidad, la distribución de la población, urbanización y migración interna, la migración internacional, y por último, población, desarrollo y educación.

En este apartado nos interesa el tópico de la migración internacional. En el marco de esta Conferencia se puso de relieve la importancia del diálogo entre países para que la migración resulte un impacto positivo en el desarrollo, tanto de países expulsores como de acogida. Para ello los países deben hacer frente a las causas básicas de la migración, especialmente aquellas ligadas a la pobreza. En cuanto a los migrantes documentados, se lo debe integrar social y económicamente, promover su bienestar y el de sus familias. Con respecto a los migrantes indocumentados, se debe hacer frente a los motivos que provoca la migración indocumentada para lograr reducir su número y se debe asegurar la protección internacional para prevenir el abuso, explotación y tráfico de estos migrantes, como también protegerlos del racismo, etnocentrismo y xenofobia.

En 2019, la CIPD cumplió 25 años desde su celebración en El Cairo. Los días 12 a 14 de noviembre de 2019, más de 8.000 delegados, en representación de gobiernos, defensores, organizaciones de salud, mujeres y jóvenes activistas y otros, de más de 170 países, se reunieron en Kenia para la Cumbre de Nairobi ${ }^{13}$. En esa ocasión se asumieron unos 1.300 compromisos para promover los objetivos de la CIPD. De la Declaración de Nairobi: "Adelantado la promesa" (2019, p. 4), nos gustaría destacar la siguiente propuesta:

Aprovechar la diversidad demográfica para impulsar el crecimiento económico y lograr el desarrollo sostenible, con las siguientes medidas:

\footnotetext{
13 Información disponible en https://www.unfpa.org/es/conferencia-internacional-sobre-la-poblaci\%C3\%B3n-y-el-desarrollo [Consultado el 26/11/2020]
} 
8. Invertir en la educación, las oportunidades de empleo y la salud, incluidos servicios de planificación familiar y salud sexual y reproductiva, para los adolescentes y los jóvenes, especialmente las niñas, con el fin de aprovechar al máximo el potencial del dividendo demográfico.

9. Crear sociedades pacíficas, justas e inclusivas, donde nadie sea dejado detrás y todas las personas, sin distinción de raza, color, religión, sexo, edad, discapacidad, idioma, origen étnico, orientación sexual e identidad o expresión de género, se sientan valoradas y capaces de moldear su propio destino y contribuir a la prosperidad de sus sociedades.

10. Proporcionar datos desagregados de calidad y oportunos que garanticen la privacidad de los ciudadanos y también incluyan a los adolescentes más jóvenes, invirtiendo en innovaciones en salud digital, incluidos sistemas de inteligencia de datos, y mejorando los sistemas de datos para informar políticas dirigidas a lograr un desarrollo sostenible.

11. Comprometernos con el concepto de que no puede discutirse ni decidirse nada sobre la salud y el bienestar de las personas jóvenes sin su significativa participación e intervención ("nada sobre nosotros sin nosotros").

\section{ii. Foro mundial sobre Migración y Desarrollo}

El Foro Mundial sobre Migración y Desarrollo es una iniciativa de los Estados para intercambiar experiencias, fortalecer el diálogo y la cooperación en materia de migración y desarrollo. Asimismo, busca debatir los aspectos multidimensionales, las oportunidades y retos y promover acciones prácticas a nivel nacional, regional y mundial sobre dichos temas. Es un proceso consultivo internacional informal, no vinculante, abierto a los Estados Miembros de la Naciones Unidas.

Su objetivo es la cooperación entre los gobiernos, orientada a promover los beneficios de la migración y minimizar sus efectos negativos. El Foro no busca producir documentos vinculantes o decisiones normativas, sin embargo, se espera que proponga acciones concretas dirigidas a resultados. Desde su primera reunión en Bruselas en el año 2007, este Foro global se ha reunido anualmente y los temas prioritarios han sido identificados por los gobiernos y tratados en mesas redondas. 
Destacaremos IV Foro Mundial realizado entre el 8 y 11 de noviembre de 2010 en Puerto Vallarta, México, cuyo tema principal fue "Alianzas para la Migración y el Desarrollo Humano: Prosperidad compartida, responsabilidad compartida". Conforme el Informe sobre Desarrollo Humano (PNUD, 2009), el desarrollo humano se define como la expansión de la libertad de las personas para vivir como ellas elijan y para buscar la mejor calidad de vida, incluyendo la posibilidad de lograrlo a través de la migración. En el contexto de la migración y el desarrollo, este concepto tiene implicancias políticas en muchas áreas, entre ellas, el acceso a la salud, a la educación y a condiciones de vida y de trabajo decentes.

Una de las mesas redondas se tituló "Migración, familia y género". El documento de referencia elaborado para esta mesa (GFMD, 2010), pone de relieve que tradicionalmente los estudios y las políticas migratorias se han centrado en los individuos: trabajadores, mujeres o niños, y no en la familia como unidad de análisis. Ello no quiere decir que se deba dejar de lado el enfoque de los migrantes como individuos sino que es necesario incorporar una perspectiva de análisis basada en la familia.

Las "familias transnacionales", esto es, las familias cuyos integrantes viven en diferentes países, son una consecuencia muy común de la evolución del mercado laboral mundial. Es por ello que en el Foro se destacó la centralidad de adoptar nuevas políticas para preservar el principio de la unidad familiar. Los resultados sólo pueden ser positivos: un mejor ambiente familiar redunda en un mayor potencial de productividad de los trabajadores migrantes.

En el debate multilateral del foro se sostuvo que "en los casos en que los niños se veían privados de sus padres y/o de su familia durante la migración, sufrían invariablemente una falta de atención y de acceso a la educación y a la protección social" (GFMD, 2010). La recomendación formulada por el Foro consistió en aconsejar a los hacedores de políticas públicas para que tengan en cuenta a la familia en todas las etapas de las políticas migratorias públicas. Sobre todo, deberían contemplar la creación de fórmulas de regularización para los migrantes irregulares con hijos que por nacimiento sean ciudadanos del país de destino.

iii. El Pacto Mundial sobre Migración y la meta 10.7 de la Agenda 2030 para el Desarrollo Sostenible 
El Pacto Mundial para una migración segura, ordenada y regular o Pacto Mundial sobre Migración fue adoptado en diciembre de 2018 en el marco una reunión intergubernamental organizada por Naciones Unidas y no es vinculante jurídicamente. El Pacto comprende 23 objetivos $^{14}$ para gestionar mejor la migración a nivel local, nacional, regional y mundial. Cada objetivo incluye un compromiso específico y una serie de acciones mediante las cuales lograr estos compromisos.

En las declaraciones emitidas en el marco de las Cumbres de presidentes del Mercosur, éstos se han hecho eco de la participación en este foro.

El Pacto Mundial se vincula con la Agenda $2030{ }^{15}$ para el Desarrollo Sostenible donde se reconoció por primera vez la contribución de la migración al desarrollo sostenible. La migración es un fenómeno transversal que se relaciona con todos los Objetivos de Desarrollo Sostenible (ODS). Pero la mención central a la migración en los ODS aparece en la meta 10.7: "Facilitar la migración y la movilidad ordenadas, seguras, regulares y responsables de las personas, incluso mediante la aplicación de políticas migratorias planificadas y bien gestionadas", que forma parte del Objetivo 10: "Reducir la desigualdad en los países y entre ellos".

Las políticas migratorias bien gestionadas incluyen, entre otras, las siguientes acciones: la integración y capacitación de la migración; la protección de los derechos de los migrantes y la promoción del bienestar de los mismos; la mejora de la integración de los migrantes en las comunidades de acogida; la promoción de la movilidad laboral regular; la mejora de la salud de los migrantes; mitigar y abordar las vulnerabilidades de los migrantes y refugiados y desplazados internos, facilitando la reunificación familiar, abordando la migración irregular y proporcionando caminos a la regularidad; atender a las necesidades de las comunidades de acogida; combatir el tráfico y la trata de migrantes (OIM, 2018).

A continuación podemos observar otras metas que aluden directamente a las migraciones:

\footnotetext{
${ }^{14}$ Recomendamos visitar el Portal de datos mundiales sobre las migraciones que presenta indicadores de datos sobre la migración, páginas temáticas sobre temas de la migración, así como blogs y videos de expertos en datos sobre la migración para cada uno de los 23 objetivos. Consultar en: https://migrationdataportal.org/es/global-compact-for-migration

${ }^{15}$ La Asamblea General de las Naciones Unidas aprobó la Agenda 2030 para el Desarrollo Sostenible (Agenda 2030) en septiembre de 2015. La Agenda consiste en un conjunto de 17 Objetivos de Desarrollo Sostenible (ODS) y 169 Metas complementarias. Los 17 Objetivos abarcan una variedad de cuestiones relativas al desarrollo sostenible, entre las cuales figuran la pobreza y el hambre, la salud, la educación, la igualdad de género, el cambio climático y otros (OIM, 2018b).
} 


\begin{tabular}{|c|c|c|}
\hline Objetivo & Meta & Tema \\
\hline $\begin{array}{l}4 \text { Educación } \\
\text { de calidad }\end{array}$ & 4.B. & $\begin{array}{l}\text { Aumentar la movilidad estudiantil internacional } \\
(+ \text { migrantes educacionales })\end{array}$ \\
\hline $\begin{array}{l}5 \text { Igualdad de } \\
\text { género }\end{array}$ & 5.2. & $\begin{array}{l}\text { Eliminar formas de violencia contra todas las } \\
\text { mujeres y niñas, incluidas la trata y la explota- } \\
\text { ción sexual. }\end{array}$ \\
\hline \multirow[t]{3}{*}{$\begin{array}{l}8 \text { Trabajo } \\
\text { decente y } \\
\text { crecimiento } \\
\text { económico }\end{array}$} & 8.7. & $\begin{array}{l}\text { Adoptar medidas inmediatas y eficaces para } \\
\text { erradicar el trabajo forzoso, formas contempo- } \\
\text { ráneas de esclavitud y trata de personas. Elimi- } \\
\text { nación trabajo infantil en todas sus formas y el } \\
\text { reclutamiento de niños soldados }\end{array}$ \\
\hline & 8.5 & $\begin{array}{l}\text { Lograr el empleo pleno y productivo para to- } \\
\text { dos. Igualdad de remuneración por trabajo de } \\
\text { igual valor. }\end{array}$ \\
\hline & 8.8 & $\begin{array}{l}\text { Proteger los derechos laborales y promover un } \\
\text { entorno de trabajo seguro y sin riesgos para } \\
\text { todos los trabajadores, incluidos los trabajado- } \\
\text { res migrantes. }\end{array}$ \\
\hline \multirow[t]{2}{*}{$\begin{array}{l}10 \text { Reducción } \\
\text { de las de- } \\
\text { sigualdades }\end{array}$} & 10.7 & $\begin{array}{l}\text { Facilitar la migración y la movilidad ordenadas, } \\
\text { seguras, regulares y responsables de las perso- } \\
\text { nas (mediante la aplicación de políticas migra- } \\
\text { torias planificadas y bien gestionadas). }\end{array}$ \\
\hline & 10.C. & $\begin{array}{l}\text { Reducir a menos del 3\% los costos de transac- } \\
\text { ción (comisiones) de las remesas de los emi- } \\
\text { grantes y eliminar los canales de envío de re- } \\
\text { mesas con un costo superior al 5\%. }\end{array}$ \\
\hline $\begin{array}{c}16 \text { Paz, } \\
\text { justicia e } \\
\text { Instituciones } \\
\text { sólidas }\end{array}$ & 16.2 . & $\begin{array}{l}\text { Poner fin al maltrato, la explotación, la trata y } \\
\text { todas las formas de violencia y tortura contra } \\
\text { los niños. }\end{array}$ \\
\hline $\begin{array}{l}17 \text { Alianza } \\
\text { para lograr } \\
\text { los objetivos }\end{array}$ & 17.18 & $\begin{array}{l}\text { Mejorar los datos en todos los temas migrato- } \\
\text { rios. Aumentar el desglose de los datos sobre } \\
\text { migración por estatus migratorio y otras varia- } \\
\text { bles. }\end{array}$ \\
\hline
\end{tabular}

Tabla n. ${ }^{\circ}$ 1. Metas de los ODS vinculados a la migración

Fuente: Las migraciones en los Objetivos y las Metas de la Agenda 2030. Bogado Bordazar (2020) 
Como sostiene la OIM (2018b), la inclusión de la migración en la Agenda 2030 ofrece una pluralidad de oportunidades:

1) $\mathrm{Al}$ afectar a una variedad de temas migratorios, los ODS muestran la naturaleza multidimensional de la migración y permiten el progreso en diferentes ámbitos. 2) Los objetivos migratorios de los ODS son universales y relevantes para los países con todo tipo de contextos migratorios, incluidos los países desarrollados y los países en desarrollo. 3) Los ODS tienen el potencial de crear una mayor conciencia en relación con diferentes temas migratorios y los vínculos que tienen con el desarrollo. 4) Los procesos de seguimiento, revisión y presentación de informes de los ODS ayudarán a identificar las lecciones aprendidas y las mejores prácticas relacionadas con todos los aspectos de la migración, así como a mejorar los datos sobre migración, fortaleciendo la evidencia sobre los vínculos entre la migración y el desarrollo (OIM, 2018b, p. 20).

El Pacto Mundial, así como los ODS, no son jurídicamente vinculantes, "de manera tal que será difícil que exista un cumplimiento homogéneo de sus postulados" (Bogado Bordazar, 2020, p. 128). Como sostiene la autora, no se descarta que los Estados se obliguen a su observancia a través de los ODS, dada la incorporación del tema migratorio la Agenda 2030.

\section{FLUJO Migratorio EN AMÉRICA LATINA Y EL CARIBE}

Partimos de la idea de que América Latina y el Caribe (ALC) se caracterizan por sus cuatro condiciones de espacio de tránsito, origen, destino y retorno de migrantes. De acuerdo al último informe del Sistema Continuo de Reportes sobre Migración Internacional en las AméricasSICREMI ${ }^{16}$ (OEA, 2017), la migración internacional en las Américas creció un 5\% por año entre 2010 y 2015. Sin embargo, esta cifra excedió el 11\% para la región de América Latina y el Caribe. A pesar del aumento en la inmigración observado en muchos países de la región latinoamericana y caribeña en años recientes, éstos siguen siendo principalmente países de emigración.

\footnotetext{
${ }^{16}$ El SICREMI es un emprendimiento conjunto de la Organización de Estados Americanos (OEA) y de la Organización para la Cooperación y el Desarrollo Económico (OCDE), con la finalidad de contribuir a los debates de políticas en cuestiones de migración internacional. El objetivo es elaborar estadísticas anuales y análisis de las tendencias de la migración internacional al interior, desde y hacia el continente americano.
} 
La migración hacia países de las Américas sigue siendo para la mayoría de los países de la región, un fenómeno intrarregional, con una predominancia de migrantes de otros países del hemisferio. Existen algunas excepciones como Canadá y Estados Unidos, países tradicionalmente de inmigración, donde hubo relativamente más migrantes provenientes de Asia tanto en 2015 como en los años anteriores. En cambio, en Brasil, Colombia y México, entre el 15 y el 20\% de los migrantes provienen de Asia. En Jamaica más del 40\% de los migrantes son asiáticos, la mayoría de ellos con permisos de trabajo y principalmente provenientes de China e India. La migración entre los países signatarios de acuerdos regionales como Mercosur, Nafta, Caricom y Sica, representa la mayor parte de la inmigración total desde las Américas para los países signatarios en conjunto.

Como bien destaca el Centro Latinoamericano y Caribeño de Demografía (CELADE)División de Población (CEPAL, 2019):

El patrón de migración intrarregional es uno de los rasgos dominantes, vigentes y de importante cuantía que se mantienen desde la segunda mitad del siglo XX, junto con la emigración extrarregional, la inmigración histórica de ultramar y los procesos de retorno a la región. En el patrón intrarregional es de relevancia el componente transfronterizo, enraizado en una historia de intercambios entre los países. (CEPAL, 2019, p. 10)

En 2015, 880.000 personas provenientes de todo el mundo emigraron hacia países de América Latina y el Caribe representando el 20\% del total de emigración. Barbados, Chile, Ecuador y Panamá se han establecido como los nuevos países emergentes de inmigración en las Américas (OEA, 2017).

En cuanto a las edades de los migrantes, los migrantes transfronterizos de toda la vida presentan una estructura etaria altamente concentrada en las edades laborales, es decir de 15 a 64 años. Incluso se observa la tendencia a que este porcentaje de grupo etario es más elevado cuando se trata de migración reciente (CEPAL, 2019).

Como sostiene Selee (2020), en los últimos años las crisis políticas, la violencia y el estancamiento o colapso económico que han tenido algunos países latinoamericanos, han impulsado a millones de sus nacionales a emigrar a países vecinos de la región. Tal es el caso de los venezolanos que comenzaron a emigrar en 2015 a gran escala. A mediados de 2019, alrededor de 4 
millones de venezolanos habían abandonado el país (OIM, 2019). Los principales países receptores son Colombia y Perú, le siguen Ecuador, Chile, Brasil y Argentina. En Guyana y Trinidad y Tobago, la proporción de venezolanos con respecto a la población total es particularmente alta. Desde 2018, entre 80 y 100 mil nicaragüenses huyeron a Costa Rica y pudieron regularizar su situación migratoria temporariamente al solicitar asilo al gobierno costarriqueño. En 2014, 2016 y 2019 migrantes guatemaltecos, hondureños y salvadoreños se dirigieron hacia Estados Unidos. Frente a las dificultades para cruzar la frontera o solicitar asilo en este país, algunos centroamericanos optan por quedarse en México de manera temporal o permanente. Después del terremoto de 2010, se observa la llegada de haitianos a América del Sur, sobre todo a Brasil donde representan el 64\% del total de la emigración permanente en 2015 (OEA, 2017).

\section{Normativa iberoamericana, latinoamericana, sudamericana...}

Al momento de encarar este apartado nos encontramos con un inconveniente: no encontramos un tratado, acuerdo o convenio que abarque la región en su integridad. La realidad de los migrantes en Latinoamérica es compleja, sin embargo, como sostiene Ceriani Cernadas (2011, p. 72), se han ido diseñando marcos normativos y políticas que buscan modificar este panorama. Sin embargo, las políticas migratorias de la mayor parte de los países de la región siguen lo que Javier de Lucas (2004, citado en Ceriani Cernadas 2011, p. 72) llama visión instrumental. Esto quiere decir que la política define la inmigración deseada de acuerdo con intereses y necesidades del país de destino, diseñada de manera unilateral y desde una lógica nacional lo que resulta ineficaz, en virtud de su negación de la complejidad del fenómeno migratorio. Hoy en día no contamos con una política migratoria para la región latinoamericana en su conjunto puesto que la política migratoria se caracteriza por ser coyuntural y no programática.

Es por ello que hemos optado por analizar el único instrumento que regula la situación laboral de los migrantes en Iberoamérica. A ello sumamos un espacio que refleja posicionamientos y compromisos asumidos por los países sudamericanos como son las Cumbres sudamericanas sobre migraciones. Y, por último, consideramos de fundamental importancia las opiniones consultivas emanadas de la Corte Interamericana de Derechos Humanos en materia migratoria. 
No quisiéramos dar inicio a este apartado sin mencionar que en el continente americano existe un mecanismo multilateral de discusión denominado Conferencia Regional sobre Migración (CRM) o Proceso Puebla que inició en 1996 y cuenta con once miembros: Belice, Canadá, Costa Rica, El Salvador, Estados Unidos, Guatemala, Honduras, México, Nicaragua, Panamá y República Dominicana. No vamos a profundizar en él porque la participación de Estados Unidos y Canadá lo pone fuera del alcance geográfico que nos proponemos investigar ya que nos centraremos en el bloque mercosureño con énfasis en el caso de Argentina.

\section{Convenio multilateral iberoamericano de seguridad social para trabajadores migrantes}

El $1^{\circ}$ de mayo de 2011 entró en vigencia este Convenio que fuera adoptado en 2007 en el marco de la Cumbre Iberoamericana de Jefes de Estado y de Gobierno celebrada en Santiago de Chile. El mismo representa un avance importante para fomentar el retorno de los trabajadores migrantes al país de origen en la vejez, otorgando estabilidad económica.

El Convenio es aplicable a las personas que estén o hayan estado sujetas a la legislación de seguridad social de uno o de varios Estados Parte, así como a sus familiares beneficiarios y derechohabientes. Abarca las prestaciones económicas de invalidez, vejez, supervivencia y, accidentes de trabajo y de enfermedad profesional.

El principio rector del Convenio es la igualdad de trato regulado en su artículo 4, el cual establece:

Las personas a las que, conforme a lo establecido en el artículo 2, sea de aplicación el presente Convenio, tendrán derecho a los beneficios y estarán sujetas a las obligaciones establecidas en la legislación del Estado Parte en que desarrollen su actividad, en las mismas condiciones que los nacionales de dicho Estado, salvo disposición en contrario del presente Convenio.

Entre los beneficios que prevé el Convenio podemos resaltar: la totalización de los periodos de cotización acreditados en los distintos Estados Parte, garantizándose la conservación de los derechos en curso de adquisición; se garantiza la conservación de los derechos adquiridos, no 
perdiéndose las prestaciones por trasladarse a otro país; se determina la legislación aplicable a la que estará sujeto el trabajador, que será la del país donde realiza la actividad, con determinadas excepciones; se aplican las disposiciones más favorables al trabajador en el caso de que existan otros Convenios bilaterales ${ }^{17}$.

El artículo 26 del Convenio prevé un Acuerdo de aplicación que establecerá las pautas necesarias para la puesta en marcha del mismo. Este Acuerdo de aplicación se encuentra actualmente abierto a la firma de los Estados parte que hayan ratificado el Convenio. El Acuerdo entrará en vigor en la fecha de la firma respecto de los Estados que hayan ratificado o adherido al Convenio. De los quince Estados iberoamericanos que firmaron el Convenio, sólo doce suscribieron el Acuerdo de Aplicación, es decir, que han implementado el Convenio ${ }^{18}$ : Argentina, Brasil, Bolivia, Chile, Ecuador, El Salvador, España, Paraguay, Perú, Portugal, República Dominicana y Uruguay.

La Organización Iberoamericana de Seguridad Social (OISS), organismo internacional de carácter técnico y especializado, actúa como órgano de contacto entre las instituciones de enlace de los Estados iberoamericanos parte del Convenio y la Secretaría General Iberoamericana.

\footnotetext{
${ }^{17}$ La República Argentina suscribió convenios con Brasil, Chile, Uruguay, Colombia, España, Italia, Portugal, Grecia y Mercosur. El Acuerdo Multilateral del Mercosur se encuentra en vigencia desde el día 1 de junio de 2005. Se aplica a los trabajadores con aportes posteriores a la entrada en vigencia del mismo y reemplaza a los acuerdos bilaterales con la República Federativa del Brasil y República Oriental del Uruguay.

${ }^{18}$ En Colombia, Costa Rica y Venezuela está pendiente por la suscripción del Acuerdo de Aplicación. [Información a agosto de 2020] Disponible en: https://oiss.org/republica-dominicana-el-decimosegundo-pais-en-adherirse-al-convenio-multilateraliberoamericano-de-seguridad-social/
} 


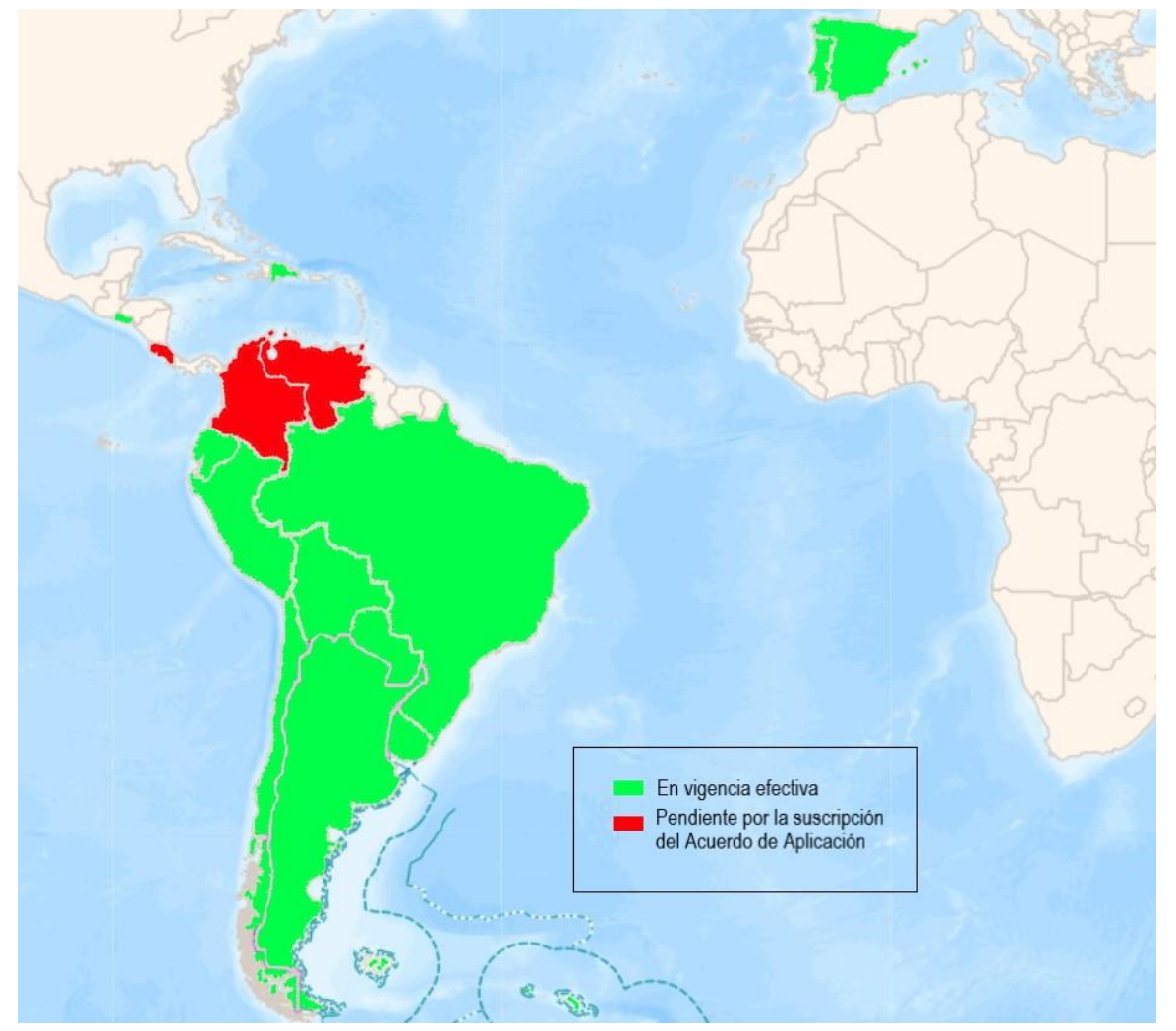

Mapa \#1. Convenio multilateral iberoamericano de seguridad social para trabajadores migrantes

Fuente: elaboración propia a partir de información disponible en la página oficial de la OISS y en base al mapa disponible en el Instituto Geográfico Nacional ${ }^{19}$

\section{i. $\quad$ Conferencia suramericana sobre migraciones}

La Conferencia suramericana sobre migraciones (CSM) es un proceso consultivo y de dialogo intergubernamental no vinculante que surgió de la voluntad de los gobiernos suramericanos con la cooperación técnica de la Organización Internacional para las Migraciones en Lima en el año de 1999 a partir del "Encuentro Sudamericano sobre Migraciones, Integración y Desarrollo".

Dicha reunión inicialmente contó con la participación de Argentina, Bolivia, Brasil, Chile, Colombia, Ecuador, Paraguay, Perú, Uruguay y Venezuela, realizándose en el año 2000, la I Conferencia Sudamericana sobre Migraciones en la ciudad de Buenos Aires, en la cual se deci-

19 El Instituto Geográfico Nacional depende del Ministerio de Defensa de la Nación. Mapa disponible en: https://ide.ign.gob.ar/portal/apps/webappviewer/index.html?id=96debf32a6cd4c27b4e445681f535ec0 
dió invitar a participar de este proceso a Guyana y Surinam ${ }^{20}$. Desde el año 2001 hasta el 2014 se han llevado a cabo las subsiguientes ediciones, a saber: II CSM en Santiago de Chile (2001); III CSM en Quito, Ecuador (2002); IV CSM en Montevideo, Uruguay (2003), V CSM en La Paz, Bolivia (2004); VI CSM en Asunción, Paraguay (2006), VII CSM en Caracas, Venezuela (2007); VIII CSM en Montevideo, Uruguay (2008); IX CSM en Quito, Ecuador (2009); X CSM en Cochabamba, Bolivia (2010); XI CSM en Brasilia, Brasil (2011); XII CSM en Santiago de Chile, Chile (2012); la XIII CSM en Cartagena de Indias, Colombia (2013); la XIV CSM en Lima, Perú (2014); la XV en Santiago, Chile (2015); la XVI CSM en Asunción, Paraguay (2016); la XVII CSM en Montevideo, Uruguay (2017) y, la última en Sucre, Bolivia (2018).

Los tres principios básicos que constituyen los ejes centrales de la CSM son: 1) las migraciones como parte del proceso de integración regional y subregional, 2) la indudable vinculación entre el desarrollo económico y social de los países de origen y las migraciones, y 3) la defensa de los derechos humanos de los migrantes (OIM, 2012, p. 105).

A partir de un proceso iniciado en la X CSM se pone en marcha el Plan Sudamericano de Desarrollo Humano de las Migraciones, que contempla acciones en las áreas de promoción de los derechos de los migrantes, relacionamiento con los organismos de integración, impulso a la participación de la sociedad civil, mejoramiento de la información migratoria y fortalecimiento de la gestión migratoria, incluyendo la gestión fronteriza (Alfonso, 2012, p. 35).

Entre los documentos emanados por la CSM a lo largo de sus veinte años de reuniones podemos destacar la Declaración de principios migratorios y lineamientos generales (Cochabamba, 2010). De la misma surge la necesidad de otorgar un tratamiento multidisciplinario y multilateral a la realidad migratoria, de reconocer a las personas el derecho a migrar y retornar en forma libre, sin posibilidades de considerar como ilegal a una persona por el hecho de estar incurso en una situación migratoria irregular. Asimismo se promueve la participación político-electoral de los migrantes en la sociedad de origen y de destino, de acuerdo a la legislación nacional de cada país y en igualdad de condiciones con los nacionales. Por último, se resalta la importancia que tiene para los procesos de integración económica, cultural y social entre los países la movilidad

\footnotetext{
${ }^{20}$ La participación de los estados ha ido variando en las ediciones de la Conferencia. Guyana sólo estuvo presentes en tres de ellas y Surinam participó en seis. Cabe destacar que México asistió a la X CSM.
} 
con derechos de todas las personas migrantes, para lo cual resulta indispensable la materialización de acuerdos multilaterales regionales en torno a su respeto y promoción.

Asimismo nos encontramos con la Declaración de Buenos Aires de 2013 que presenta el posicionamiento de la CSM ante el II Diálogo de Alto nivel sobre migración internacional y desarrollo de las Naciones Unidas. En este documento se reafirma "el aporte positivo de la persona migrante y su familia al desarrollo en su dimensión social, económica, intercultural, educativa y científica, así como a los procesos de integración y cooperación entre los países” y se manifiesta el descontento de la CSM sobre el tratamiento de las migraciones internacionales en la comunidad internacionales y la exhorta a reformular el espacio de diálogo multilateral considerando que las Naciones Unidas es el foro natural y el ámbito adecuado para la participación de los Estados en pie de igualdad. La CSM sostiene que es "imperativo que los Estados promuevan, respeten y garanticen los derechos humanos de las personas migrantes y sus familias, independientemente de su condición migratoria, en la discusión del nexo entre migración y desarrollo así como en el diseño e implementación de las políticas migratorias nacionales e internacionales”.

Gurrieri (2005) sostiene que la CSM representa la toma de conciencia sobre el valor del diálogo interestatal que ayuda a comprender temas y a armonizar posiciones. Entre los puntos a fortalecer, este autor señala que la Conferencia es un proceso y no una organización por lo que sería conveniente contar con una instancia política superior, o con cierto poder de decisión, dado que hasta el momento el proceso ha tenido un carácter más bien técnico. Por su parte, Nora Pérez Vichich (CSM, 2020) señala que la CSM contribuyó a generar un pensamiento regional autónomo y a transformar el paradigma vigente y considera que a 20 años de su creación continúa siendo una herramienta y una esperanza.

\section{ii. Opiniones consultivas de la Corte Interamericana de Derechos Humanos}

La Corte Interamericana de Derechos Humanos (CIDH) ha logrado asumir a lo largo de su profusa trayectoria, el desafío de convertirse en fiel guardiana del sistema interamericano de protección de los derechos humanos (Trucco, 2011, p. 488). Más allá de su competencia contenciosa, la Corte cuenta con otra importante función orientada a interpretar la Convención Americana de 
Derechos Humanos y otros tratados concernientes a la protección de los derechos humanos de los Estados americanos.

La propia Corte manifiesta que el amplio alcance de su competencia consultiva constituye un servicio que está en capacidad de prestar a todos los integrantes del sistema interamericano, con el propósito de coadyuvar al cumplimiento de sus compromisos internacionales referentes a derechos humanos y de ayudar a los Estados y órganos a cumplir y a aplicar tratados en materia de derechos humanos, sin someterlos al formalismo y al sistema de sanciones que caracteriza al proceso contencioso $^{21}$.

Si bien las opiniones que brinda la Corte no tienen la misma fuerza vinculante que sus sentencias, representan una interpretación auténtica del derecho internacional que como fuente auxiliar del mismo debe ser tenida como norma por los Estados americanos para el cumplimiento de sus obligaciones internacionales (Nikken, 2003, p. 176).

Es por ello que hemos decidido analizar dos opiniones consultivas de la CIDH relativas a la condición jurídica de los migrantes indocumentados y a los derechos y garantías de los niños en el contexto migratorio, dado que representan aportes fundamentales al desarrollo de la protección de los migrantes en el continente americano.

iii. El derecho a la información sobre la asistencia consular en el marco de las garantías del debido proceso legal. Opinión consultiva OC-16/99 de 1 de octubre de 1999

El 9 de diciembre de 1997 México sometió a la CIDH una solicitud de opinión consultiva sobre “diversos tratados concernientes a la protección de los derechos humanos en los Estados americanos". La consulta se relaciona con las garantías judiciales mínimas y el debido proceso en el marco de la pena de muerte, impuesta judicialmente a extranjeros a quienes el Estado receptor no ha informado de su derecho a comunicarse y a solicitar la asistencia de las autoridades consulares del Estado de su nacionalidad. México añadió que la consulta tiene como antecedente las

${ }^{21}$ Condición jurídica y derechos de los migrantes indocumentados. Opinión consultiva OC-18/03 de 17 de septiembre de 2003 , párrafo 64. 
gestiones bilaterales que ha realizado en favor de algunos de sus nacionales, quienes no habrían sido informados oportunamente por el Estado receptor de su derecho a comunicarse con las autoridades consulares mexicanas, y habrían sido sentenciados a muerte en diez entidades federativas de los Estados Unidos de América ${ }^{22}$.

Esta OC trata dos asuntos relevantes de la Convención de Viena sobre Relaciones Consulares: (1) si ella regula derechos individuales de personas extranjeras y (2) de ser así, si esos derechos quedan integrados en el catálogo de garantías necesarias para un debido proceso para la persona que detenida o arrestada en un Estado distinto del que es nacional (Cárdenas Aravena, 2011).

La Corte sostuvo que el artículo 36 de la Convención de Viena sobre Relaciones Consulares reconoce al detenido extranjero derechos individuales, entre ellos el derecho a la información sobre la asistencia consular, a los cuales corresponden deberes correlativos a cargo del Estado receptor y que el mismo concierne a la protección de los derechos del nacional del Estado que envía y está integrada a la normativa internacional de los derechos humanos (párrafos 1 y 2 de la decisión).

Asimismo afirmó que las disposiciones internacionales que conciernen a la protección de los derechos humanos en los Estados americanos, inclusive la consagrada en el artículo 36.1.b) de la Convención de Viena sobre Relaciones Consulares, deben ser respetadas por los Estados americanos Partes en las respectivas convenciones, independientemente de su estructura federal o unitaria (párrafo 8 de la decisión).

Por unanimidad la Corte consideró que el derecho individual a la información establecido en el artículo 36.1.b) de la Convención de Viena sobre Relaciones Consulares permite que adquiera eficacia, en los 76 casos concretos, el derecho al debido proceso legal consagrado en el artículo 14 del Pacto Internacional de Derechos Civiles y Políticos; y que este precepto establece garantías mínimas susceptibles de expansión a la luz de otros instrumentos internacionales como

\footnotetext{
${ }^{22}$ Tanto el Estado que envía como el Estado receptor son Partes en la Convención de Viena sobre Relaciones Consulares; ambos son Miembros de la Organización de los Estados Americanos (en adelante "la OEA") y suscribieron la Declaración Americana de Derechos y Deberes del Hombre (en adelante "la Declaración Americana") y aunque el Estado receptor no ha ratificado la Convención Americana, sí ha ratificado el Pacto Internacional de Derechos Civiles y Políticos de la Organización de las Naciones Unidas (Párrafo 3 de la OC 16/99).
} 
la Convención de Viena sobre Relaciones Consulares, que amplían el horizonte de la protección de los justiciables (párrafo 6 de la decisión).

La relevancia de esta OC radica en haber plasmado una interpretación de la Convención de Viena sobre Relaciones Consulares que luego fuera conformado por la Corte Internacional de Justicia en el caso Alemania vs Estados Unidos de 27 de junio de 2001 (Cárdenas Aravena, 2011).

\section{iv. Condición jurídica y derechos de los migrantes indocumentados. Opinión consul- tiva OC-18/03 de 17 de septiembre de 2003}

El 10 de mayo de 2002 México sometió a la Corte una solicitud de opinión consultiva sobre "la privación del goce y ejercicio de ciertos derechos laborales [a los trabajadores migrantes, y su compatibilidad con la obligación de los Estados americanos de garantizar los principios de igualdad jurídica, no discriminación y protección igualitaria y efectiva de la ley consagrados en instrumentos internacionales de protección a los derechos humanos; así como con la subordinación o condicionamiento de la observancia de las obligaciones impuestas por el derecho internacional de los derechos humanos, incluidas aquellas oponibles erga omnes, frente a la consecución de ciertos objetivos de política interna de un Estado americano" (párrafo 1).

Destacamos de la opinión consultiva el carácter de norma ius cogens reconocido al principio de igualdad ante la ley, igual protección ante la ley y no discriminación dado que sobre él reposa toda la estructura jurídica del orden público nacional e internacional y es un principio presente en el ordenamiento jurídico en su integridad. En base a ello, los Estados no pueden discriminar o tolerar situaciones discriminatorias en perjuicio de los migrantes. Lo que sí pueden hacer es otorgar un trato distinto a los migrantes documentados con respecto de los migrantes indocumentados, o entre migrantes y nacionales, siempre y cuando este trato diferencial sea razonable, objetivo, proporcional y no lesione los derechos humanos (párrafos 101 y 119). Asimismo la Corte considera que el derecho al debido proceso legal debe ser reconocido en el marco de las garantías mínimas que se debe otorgar a todo migrante, independientemente de su estatus migratorio. 
La Corte considera que los trabajadores migrantes indocumentados, que se encuentran en una situación de vulnerabilidad y discriminación con respecto a los trabajadores nacionales, poseen los mismos derechos laborales que corresponden a los demás trabajadores del Estado de empleo y este último debe tomar todas las medidas necesarias para que así se reconozca y se cumpla en la práctica (párrafo 160).

La Corte define la política migratoria de un Estado como aquella que está constituida por todo acto, medida u omisión institucional que versa sobre la entrada, salida o permanencia de población extranjera dentro de su territorio. Debemos recodar aquí que los Estados deben adecuar su derecho interno al momento de ratificar o adherir a un tratado internacional. El artículo 2 de la Convención Americana de Derechos Humanos prevé la obligación para los Estados de suprimir las normas y prácticas que impliquen una violación a las garantías previstas en la Convención. En consecuencia, los objetivos que se planten las políticas migratorias deben respetar los derechos humanos y las mismas deben ejecutarse con el respeto y la garantía de los derechos humanos (párrafos 163, 166, 167 y 168).

En su interpretación la Corte sostiene que los Estados no pueden subordinar o condicionar la observancia del principio de la igualdad ante la ley y la no discriminación a la consecución de los objetivos de sus políticas públicas, cualesquiera que sean éstas, incluidas las de carácter migratorio.

v. Derechos y garantías de niñas y niños en el contexto de la migración y/o en necesidad de protección internacional. Opinión consultiva OC-21/14 de 19 de agosto de 2014

El 7 de julio de 2011 fue presentada una solicitud de opinión consultiva a la Corte por parte de Argentina, Brasil, Uruguay y Paraguay ${ }^{23}$ a fin de que el Tribunal determine con precisión cuáles son las obligaciones de los Estados con relación a las medidas pasibles de ser adoptadas respecto de niñas y niños, asociada a su condición migratoria o a la de sus padres. No sólo se solicita la interpretación a la luz de la Convención Americana sobre Derechos Humanos, sino también de la

\footnotetext{
${ }^{23}$ El Instituto de Políticas Públicas en Derechos Humanos del Mercosur asistió técnicamente en la redacción de esta solicitud de opinión consultiva.
} 
Declaración Americana de Derechos y Deberes del Hombre y la Convención Interamericana para prevenir y sancionar la tortura.

Es importante destacar que los Estados solicitantes reconocieron la existencia de un déficit de la legislación y de las políticas públicas en diferentes temas sometidos a la opinión de la Corte como la falta de articulación de las leyes y políticas migratorias con el sistema de protección de derechos de la niñez. Lo anterior comporta la necesidad de adoptar un enfoque de derechos humanos con relación a las políticas migratorias y respecto a las necesidades de protección internacional, asumiendo la interrelación y convergencia entre estas diferentes ramas del derecho internacional. Pero por tratarse de niños debe prevaler un enfoque encaminado a la protección y garantía de sus derechos en forma integral (párrafo 41).

La Corte afirma que las niñas y niños son titulares de los derechos humanos que corresponden a todos los seres humanos y gozan, además, de derechos especiales derivados de su condición, a lo que corresponde deberes específicos de la familia, la sociedad y el Estado. Por ello, los Estados al diseñar, adoptar e implementar sus políticas migratorias deben priorizar el enfoque de los derechos humanos desde una perspectiva que tenga en cuenta en forma transversal los derechos de niñas y niños y, en particular, su protección y desarrollo integral, los cuales deben primar por sobre cualquier consideración de la nacionalidad o el estatus migratorio, a fin de asegurar la plena vigencia de sus derechos (párrafo 68).

Por otro lado, la Corte opina que cualquier órgano administrativo o judicial que deba decidir acerca de la separación familiar por expulsión motivada por la condición migratoria de uno o ambos progenitores debe contemplar las situaciones particulares del caso concreto y garantizar una decisión individual, evaluando el interés superior del niño. En el mismo sentido, cualquier decisión sobre la devolución de un niño o niña al país de origen o a un tercer país seguro sólo podrá basarse en los requerimientos de su interés superior.

\section{Flujo Migratorio en el Mercosur}

En el Cono Sur podemos distinguir por un lado, aquellos países que en gran medida son receptores de migración como es el caso de Argentina, Brasil y Chile, y por otro, aquellos países que 
son expulsores como Bolivia, Paraguay y Uruguay. Sin embargo, los retos y las problemáticas de la migración son diferentes para cada país (Mondon López, 2010, p. 18).

En este apartado haremos un repaso de los flujos migratorios en cada uno de los Estados parte del bloque en base a la información proporcionada por los perfiles migratorios por país elaborados por la $\mathrm{OIM}^{24}$ y los datos estadísticos de los últimos censos nacionales de población.

Argentina es un país vinculado históricamente a las migraciones internacionales. País receptor de migración de ultramar, en las últimas décadas también recibe flujos continentales y extracontinentales. Combina esta posición con la de expulsor de nativos hacia destinos regionales y extrarregionales. Según el último censo poblacional (2010), la población extranjera en territorio argentino llega a 1.805.957 personas, lo que representa el 4,5\% del total de la población. En cuanto al origen de la migración, el $81,2 \%$ previene de países americanos, el 16,5\% de países europeos, el 1,7\% de países asiáticos, el 0,2\% de países africanos y el 0,1\% del continente oceánico.

Brasil también comparte con Argentina una larga historia ligada a las migraciones internacionales. A fines de 1930, había en Brasil aproximadamente 4,4 millones de inmigrantes provenientes principalmente de Portugal, Italia, Japón y Alemania. Sin embargo, el flujo se alteró en los últimos años y a partir de la década de 1980, se observa un nuevo fenómeno en la dinámica de esta sociedad: la emigración de ciudadanos brasileños para el exterior. Los principales destinos de los brasileños son Estados Unidos, Japón, Portugal, España y China y se estima que en el año 2013 el stock de emigración sumaba 1.769 .639 personas.

De conformidad con el censo poblacional del año 2010, la población extranjera asciende a 599.678 personas, lo que representa el 0,3\% del total de la población brasilera. Esta última cifra nos demuestra que Brasil tiene una población de inmigrantes muy pequeña en relación a la población total del país.

\footnotetext{
${ }^{24}$ Los perfiles migratorios elaborados por la OIM tienen por objeto generar una herramienta que contribuya a promover la gestión eficaz de la migración internacional en América Latina y a mejorar la base de conocimientos de los procesos migratorios que se desarrollan en la región. Cabe aclarar que fueron preparados y publicados en distintos años: Argentina en 2012, Brasil en 2009, Paraguay y Uruguay en 2011. Venezuela no cuenta todavía con un perfil migratorio, sólo con información reducida en la página oficial de esta organización internacional. En alguno caso completamos la información con datos del SICREMI (2015).
} 
Uruguay fue, hasta mediados del siglo XX, un país con saldos migratorios positivos puesto que recibió corrientes de inmigración europea que aportaron un impacto significativo desde el punto de vista demográfico, social y cultural. El saldo migratorio se vuelve negativo en la segunda mitad del siglo XX, provocado por la profunda crisis económica, social y política que desembocó en el golpe de Estado de 1973. Durante este periodo se intensifica la salida de población hacia los países de la región y hacia Norteamérica y Europa. Otras oleadas emigratorias importantes se vivieron con las crisis de 1982 y 2002. En 2012, más de diez mil uruguayos dejaron el país, de los cuales el $41 \%$ se desplazó hacia Argentina.

Conforme el informe del SICREMI (2015), Uruguay experimentó una reducción en el stock de inmigrantes en el período 2010-2013: pasó de tener ochenta mil extranjeros en a contar con setenta y cuatro mil inmigrantes en su territorio. Los inmigrantes representan el 2,2 \% de la población total uruguaya. Los principales países de origen de estos migrantes son Argentina (30,5 \%), España (19,7 \%), Brasil (14,4 \%), Italia (14,2 \%) y Estados Unidos (3,5 \%).

La relación histórica de Paraguay con la migración internacional ha sido constante: se trata de un país expulsor. Las corrientes de emigración que se inician desde la finalización de la guerra de la Triple Alianza en 1870 y se intensifican a lo largo del siglo XX, dado que se han mantenido las condiciones estructurales de expulsión de la población y las políticas públicas en general, y las migratorias en particular, no han tenido modificaciones significativas en ese extenso período.

El último censo se realizó en el año 2012 pero los resultados no han sido publicados aún por lo cual tomaremos los datos del censo poblacional del año 2002. En dicho año los extranjeros censados en territorio paraguayo llegaban a 173.176 personas, lo que representa el 3,4\% de la población total. Los tres primeros países de procedencia de la inmigración a Paraguay son: Brasil (47,7\%), Argentina (36,5\%) y Uruguay (1,9\%).

Venezuela por su parte, se caracteriza por ser un país receptor de migrantes. Según el SICREMI (2015), en el año 2013 se estimaba que el stock de inmigrantes en este país era de 1.171.331 personas, lo que representa el 3,9\% de la población total. Los cinco principales países de origen de la inmigración son Colombia (69\%), España $(5,2 \%)$, Portugal $(3,8 \%)$ y Perú $(3,3 \%)$. 
Como mencionáramos en el último párrafo del Apartado 2 de este capítulo, a partir de 2015 se produjo en Venezuela una emigración a gran escala cambiando, de esta forma, el carácter de país de destino que tradicionalmente tenía este país (migrantes provenientes de Europa y de América del Sur). A mediados de 2019, cerca de 4 millones de venezolanos habían abandonado el país. La gran mayoría se encontraban en países vecinos como Colombia, Perú, Ecuador, Argentina, Chile y Brasil, aunque un número creciente se estaba trasladando también a países de Centroamérica y el Caribe. Colombia y el Perú tenían las mayores poblaciones de migrantes venezolanos al final de 2018, más de 1 millón y 500.000, respectivamente (ACNUR, 2019). La República Bolivariana de Venezuela fue el principal país de origen de solicitantes de asilo del mundo en 2018 - más de 340.000 solicitudes presentados al final de ese año. A modo de ejemplo, a fines de junio de 2018, los venezolanos que llegaban a Estados Unidos presentaron casi 28 mil solicitudes de asilo (OIM, 2019).

Según el informe del SICREMI (OEA, 2017), el Mercosur muestra la concentración más alta de movimientos intrarregionales, con alrededor de tres cuartos de la inmigración intrahemisférica originaria de otro país miembro del bloque mercosureño.

\section{Normativa migratoria en el Mercosur}

\section{De Asunción a los Acuerdos de residencia}

Como bien señala Bogado Bordazar (2012, p. 165), el Tratado de Asunción no previó expresamente la libre circulación de personas entre los países miembros del bloque de integración. Se puede inferir de su artículo $1^{\circ}$ párrafo segundo que la libre circulación de factores productivos incluye la libre circulación de personas al considerar al trabajo como un factor de producción.

Para estructurar este apartado nos pareció interesante tomar un concepto que Susana Novick rescata de trabajos de investigación de Lelio Mármora y Nora Pérez Vichich (1997 en Novick, 2005) que nos permitirá comprender los cambios en las políticas que el Mercosur ha ido tomando en materia migratoria desde su creación hasta el hito fundamental que constituyen los Acuerdos de residencia adoptados en el año 2002. Nos referimos a la distinción entre libre circulación en el plano de la integración y migración tradicional. La migración tradicional significa 
cambiar la condición de ciudadano en extranjero, por el sólo hecho de atravesar una frontera mientras que la libre circulación privilegia la ciudadanía comunitaria por sobre cualquier otra circunstancia. Mármora y Pérez Vichich afirman "que la libre circulación es el concepto que transforma a la variable migratoria en un elemento clave de los procesos de integración económica" (en Novick, 2005, p. 38).

A continuación presentamos un cuadro que da cuenta cronológicamente de las decisiones adoptadas por el Consejo del Mercado Común del Mercosur sobre la circulación de personas, residencia y control integrado de fronteras.

$\underline{\text { Referencias: }}$ ** Pendiente *En vigencia +Derogada

\begin{tabular}{|c|c|c|c|}
\hline Año & Normativa & $\begin{array}{l}\text { Tema } \\
\text { Principal }\end{array}$ & Objetivo General \\
\hline $\begin{array}{l}1993 \\
+\end{array}$ & $\begin{array}{l}\text { Protocolo adicional } \\
\text { reglamentario del } \\
\text { acuerdo de Recife } \\
\text { sobre procedimien- } \\
\text { tos operativo } \\
\text { Decisión } 12 / 93\end{array}$ & $\begin{array}{l}\begin{array}{l}\text { Áreas de } \\
\text { control }\end{array} \\
\text { integrado }\end{array}$ & $\begin{array}{l}\text { Los controles aduaneros a realizar por los funcionarios en el área de con- } \\
\text { trol integrado se refieren a: a) los diversos regímenes aduaneros de los } \\
\text { Estados Partes que regulan la salida y entrada de mercaderías; b) los des- } \\
\text { pachos de exportación e importación de mercaderías por el régimen espe- } \\
\text { cial de comercio o tráfico fronterizo; c) el egreso e ingreso de vehículos } \\
\text { particulares o privados y de transporte de pasajeros y de mercaderías, } \\
\text { incluido el tránsito vecinal; d) el equipaje acompañado de viajeros. }\end{array}$ \\
\hline 1999 & $\begin{array}{l}\text { Tránsito vecinal } \\
\text { fronterizo entre los } \\
\text { Estados Partes del } \\
\text { Mercosur, Bolivia y } \\
\text { Chile } \\
\text { Decisiones } 18 / 99 \text { y } \\
19 / 99\end{array}$ & $\begin{array}{l}\text { Circulación } \\
\text { de personas }\end{array}$ & $\begin{array}{l}\text { Los ciudadanos nacionales o naturalizados de un Estado Parte o sus resi- } \\
\text { dentes legales, nacionales o naturalizados de otro país del Mercosur, que } \\
\text { se domicilien en localidades contiguas de dos o más Estados Parte, podrán } \\
\text { obtener la credencial de Tránsito Vecinal Fronterizo (TVF). La calidad de } \\
\text { residente legal, a los efectos de este convenio, se determinará en base a la } \\
\text { legislación de cada Estado Parte. }\end{array}$ \\
\hline 2000 & $\begin{array}{l}\text { Modificación al } \\
\text { texto del Acuerdo } \\
\text { de Recife } \\
\text { Decisión } 4 / 00\end{array}$ & $\begin{array}{l}\text { Control } \\
\text { integrado } \\
\text { de frontera }\end{array}$ & $\begin{array}{l}\text { Acuerdo para la facilitación de comercio con la finalidad de establecer las } \\
\text { medidas técnicas y operativas que regularán los controles integrados en } \\
\text { frontera entre sus signatarios. Los organismos nacionales competentes } \\
\text { concertarán acuerdos operativos y adoptarán sistemas que complementen } \\
\text { y faciliten el funcionamiento de los controles aduaneros, migratorios, } \\
\text { sanitarios y de transporte, editando para ello, los actos pertinentes, para su } \\
\text { aplicación. }\end{array}$ \\
\hline $\begin{array}{l}2000 \\
*\end{array}$ & $\begin{array}{l}\text { Primer Protocolo } \\
\text { adicional al Acuer- } \\
\text { do de Recife } \\
\text { Decisión } 5 / 00\end{array}$ & $\begin{array}{l}\text { Control } \\
\text { integrado } \\
\text { de frontera }\end{array}$ & $\begin{array}{l}\text { Los controles de salida y entrada de personas en el territorio de un Estado } \\
\text { Parte estarán sujetos a la verificación por parte de los funcionarios compe- } \\
\text { tentes de ambos países situados en el Área de Control Integrado. }\end{array}$ \\
\hline
\end{tabular}




\begin{tabular}{|c|c|c|c|}
\hline 2000 & $\begin{array}{l}\text { Acuerdos reglamen- } \\
\text { tarios Tránsito } \\
\text { Vecinal Fronterizo } \\
\text { Decisiones } 14 / 00 \text { y } \\
15 / 00\end{array}$ & $\begin{array}{l}\text { Circulación } \\
\text { de personas }\end{array}$ & $\begin{array}{l}\text { Las localidades fronterizas comprendidas en el régimen, así como el radio } \\
\text { de circulación a que habilitará el mismo, se fijarán mediante acuerdos } \\
\text { bilaterales o trilaterales, según corresponda, entre los Estados Partes, que } \\
\text { posean fronteras comunes. La "Tarjeta Tránsito Vecinal Fronterizo" per- } \\
\text { mitirá a su beneficiario cruzar la frontera y permanecer en el territorio del } \\
\text { país vecino por un plazo máximo de setenta y dos horas ( } 72 \mathrm{Hs)} \mathrm{a} \mathrm{contar} \\
\text { desde el último ingreso, salvo acuerdo bilateral o trilateral entre los Esta- } \\
\text { dos Partes que establezcan un plazo mayor. }\end{array}$ \\
\hline 2000 & $\begin{array}{l}\text { Acuerdo exención } \\
\text { de traducción de } \\
\text { documentos admi- } \\
\text { nistrativos } \\
\text { Decisión } 44 / 00\end{array}$ & $\begin{array}{l}\text { Circulación } \\
\text { de personas }\end{array}$ & $\begin{array}{l}\text { La exención de traducción se aplicará a los documentos presentados a } \\
\text { efectos de trámites migratorios referentes a solicitud de visa, renovación } \\
\text { de plazo de estadía y concesión de permanencia. }\end{array}$ \\
\hline $\begin{array}{l}2002 \\
*\end{array}$ & $\begin{array}{l}\text { Instalación de cana- } \\
\text { les privilegiados de } \\
\text { entrada en aero- } \\
\text { puertos para ciuda- } \\
\text { danos del Mercosur, } \\
\text { Bolivia y Chile } \\
\text { Decisiones } 46 / 00 \text { y } \\
47 / 00\end{array}$ & $\begin{array}{l}\text { Circulación } \\
\text { de personas }\end{array}$ & $\begin{array}{l}\text { Cada Estado Parte del MERCOSUR instalará, en sus aeropuertos interna- } \\
\text { cionales, canales privilegiados para la entrada de los nacionales de los } \\
\text { demás Estados Partes. La cantidad de canales privilegiados de entrada } \\
\text { deberá ser compatible con el flujo de pasajeros. }\end{array}$ \\
\hline $\begin{array}{l}2002 \\
* *\end{array}$ & $\begin{array}{l}\text { Acuerdos sobre } \\
\text { regularización mi- } \\
\text { gratoria interna de } \\
\text { ciudadanos del } \\
\text { Mercosur, Bolivia y } \\
\text { Chile } \\
\text { Decisión 28/02 }\end{array}$ & $\begin{array}{l}\text { Regulari- } \\
\text { zación } \\
\text { migratoria }\end{array}$ & $\begin{array}{l}\text { Los nacionales de un Estado parte que se encuentren se encuentren en el } \\
\text { territorio de otro Estado Parte podrán efectuar la tramitación migratoria de } \\
\text { su residencia en este sin necesidad de egresar del mismo. }\end{array}$ \\
\hline $\begin{array}{l}2002 \\
*\end{array}$ & $\begin{array}{l}\begin{array}{l}\text { Acuerdos sobre } \\
\text { residencia }\end{array} \\
\text { nacionales de los } \\
\text { Estados Partes del } \\
\text { Mercosur, Bolivia y } \\
\text { Chile } \\
\text { Colombia, Perú y } \\
\text { Ecuador } \\
\text { Decisión 28/02 }\end{array}$ & Residencia & $\begin{array}{l}\text { Los nacionales de un Estado Parte que deseen residir en el territorio de } \\
\text { otro Estado Parte podrán obtener una residencia legal en este último, de } \\
\text { conformidad con los términos de este Acuerdo, mediante la acreditación } \\
\text { de su nacionalidad y presentación de los requisitos previstos. }\end{array}$ \\
\hline \multirow[t]{2}{*}{$\begin{array}{l}2003 \\
* *\end{array}$} & $\begin{array}{l}\text { Acuerdo para la } \\
\text { creación de la visa } \\
\text { Mercosur } \\
\text { Decisión16/03 }\end{array}$ & Circulación & $\begin{array}{l}\text { De aplicación para gerentes y directores ejecutivos, administradores, cien- } \\
\text { tíficos, profesores, artistas, deportistas, periodistas, técnicos a quienes se } \\
\text { les exigirá la "VISA MERCOSUR" que soliciten ingresa para prestar } \\
\text { temporalmente servicios en el territorio de uno de los Estados Parte. }\end{array}$ \\
\hline & $\begin{array}{l}\text { Acuerdo contra el } \\
\text { tráfico ilícito de }\end{array}$ & Tráfico & Prevenir y combatir el tráfico ilícito de migrantes, promover la coopera- \\
\hline
\end{tabular}




\begin{tabular}{|c|c|c|c|}
\hline $\begin{array}{l}2004 \\
* *\end{array}$ & $\begin{array}{l}\text { Migrantes entre los } \\
\text { Estados Partes del } \\
\text { Mercosur, Bolivia y } \\
\text { Chile } \\
\text { Decisión 37/4 }\end{array}$ & ilícito & ción y el intercambio de información entre los Estados partes con ese fin. \\
\hline $\begin{array}{l}2006 \\
* *\end{array}$ & $\begin{array}{l}\text { Acuerdo para la } \\
\text { concesión de un } \\
\text { plazo de } 90 \text { días a } \\
\text { los turistas naciona- } \\
\text { les de los Estados } \\
\text { partes del Mercosur } \\
\text { y Estados asociados } \\
\text { Decisión 10/06 }\end{array}$ & $\begin{array}{l}\text { Circulación } \\
\text { Turismo }\end{array}$ & $\begin{array}{l}\text { A los nacionales de los Estados partes que sean admitidos para ingresar al } \\
\text { territorio de uno de ellos en calidad de turistas, se les otorgará un plazo de } \\
\text { permanencia de } 90 \text { días. }\end{array}$ \\
\hline $\begin{array}{l}2008 \\
*\end{array}$ & $\begin{array}{l}\text { Acuerdos sobre } \\
\text { documentos de } \\
\text { viaje de los Estados } \\
\text { parte del Mercosur } \\
\text { y Estados asociados } \\
\text { Decisión 18/08 }\end{array}$ & $\begin{array}{l}\text { Circulación } \\
\text { Turismo }\end{array}$ & $\begin{array}{l}\text { Reconocer la validez de los documentos de identificación personal de cada } \\
\text { Estado Parte y Asociado establecidos en el Anexo del presente como do- } \\
\text { cumentos de viaje hábiles para el tránsito de nacionales y/o residentes } \\
\text { regulares de los Estados Partes y Asociados del Mercosur por el territorio } \\
\text { de los mismos. }\end{array}$ \\
\hline $\begin{array}{l}2008 \\
* *\end{array}$ & $\begin{array}{l}\text { Acuerdo para la } \\
\text { implementación de } \\
\text { bases de datos } \\
\text { compartidas de } \\
\text { niñas, niños y ado- } \\
\text { lescentes en situa- } \\
\text { ción de vulnerabili- } \\
\text { dad } \\
\text { Decisión 26/08 }\end{array}$ & $\begin{array}{l}\text { Protección } \\
\text { de niños, } \\
\text { niñas y } \\
\text { adolescen- } \\
\text { tes }\end{array}$ & $\begin{array}{l}\text { Las Partes intercambiarán la información disponible que registren en sus } \\
\text { bases de datos respecto a niños, niñas y adolescentes en situación de vul- } \\
\text { nerabilidad. Las Partes deberán intercambiar la información que registren } \\
\text { en sus bases de datos respecto a solicitudes de paradero y/o búsqueda y las } \\
\text { solicitudes que impliquen restricciones de egreso de menores emanadas de } \\
\text { las autoridades competentes correspondientes }\end{array}$ \\
\hline $\begin{array}{l}2010 \\
* *\end{array}$ & $\begin{array}{l}\text { Estatuto de ciuda- } \\
\text { danía del Mercosur } \\
\text { Decisión 64/10 } \\
\text { (Actualizado por } \\
\text { Dec.7/17) }\end{array}$ & $\begin{array}{l}\text { Circulación } \\
\text { de personas }\end{array}$ & $\begin{array}{l}\text { Objetivos: 1) Implementación de una política de libre circulación de per- } \\
\text { sonas en la región; 2) Igualdad de derechos y libertades civiles, sociales, } \\
\text { culturales y económicas para los nacionales de los Estados Partes del } \\
\text { Mercosur y 3) Igualdad de condiciones de acceso al trabajo, a la salud y a } \\
\text { la educación. }\end{array}$ \\
\hline \multirow[t]{2}{*}{$\begin{array}{l}2011 \\
* *\end{array}$} & $\begin{array}{l}\text { Acuerdo modifica- } \\
\text { torio del anexo del } \\
\text { acuerdo sobre do- } \\
\text { cumentos de viaje } \\
\text { de los Estados par- } \\
\text { tes del Mercosur y } \\
\text { Estados asociados } \\
\text { Decisión } 14 / 11\end{array}$ & $\begin{array}{l}\text { Circulación } \\
\text { de personas }\end{array}$ & Se sustituyen los documentos de viajes válidos emitidos por cada país. \\
\hline & $\begin{array}{l}\text { Adhesión de la } \\
\text { República de Perú } \\
\text { al Acuerdo sobre }\end{array}$ & & Adhesión de la República del Perú al Acuerdo sobre Residencia para Na- \\
\hline
\end{tabular}




\begin{tabular}{|c|c|c|c|}
\hline $\begin{array}{l}2011 \\
*\end{array}$ & $\begin{array}{l}\text { residencia } \\
\text { Decisión 4/11 }\end{array}$ & Residencia & cionales de los Estados Partes del MERCOSUR, Bolivia y Chile. \\
\hline $\begin{array}{l}2011 \\
*\end{array}$ & $\begin{array}{l}\text { Adhesión de la } \\
\text { República de Ecua- } \\
\text { dor al Acuerdo } \\
\text { sobre Residencia } \\
\text { Decisión } 21 / 11\end{array}$ & Residencia & $\begin{array}{l}\text { Adhesión de la República del Ecuador al Acuerdo sobre Residencia para } \\
\text { Nacionales de los Estados Partes del MERCOSUR, Bolivia y Chile. }\end{array}$ \\
\hline $\begin{array}{l}2012 \\
*\end{array}$ & $\begin{array}{l}\text { Acuerdo para la } \\
\text { creación de la red } \\
\text { de especialistas en } \\
\text { seguridad documen- } \\
\text { tal migratoria del } \\
\text { Mercosur y Estados } \\
\text { asociados } \\
\text { Decisión } 8 / 12\end{array}$ & $\begin{array}{l}\text { Seguridad } \\
\text { documental } \\
\text { migratoria }\end{array}$ & $\begin{array}{l}\text { La Red de Especialistas en Seguridad Documental Migratoria del MER- } \\
\text { COSUR y Estados Asociados (RED SEGDOC), estará dedicada al análisis } \\
\text { de documentación y a la cooperación entre los funcionarios que integren } \\
\text { dicha Red, a fin de prevenir y evitar el fraude documental migratorio en la } \\
\text { región }\end{array}$ \\
\hline $\begin{array}{l}2012 \\
* *\end{array}$ & $\begin{array}{l}\text { Complementación } \\
\text { del "Acuerdo de } \\
\text { Recife" en materia } \\
\text { migratoria } \\
\text { Decisión } 7 / 12\end{array}$ & $\begin{array}{l}\text { Movilidad } \\
\text { de personas }\end{array}$ & $\begin{array}{l}\text { Regular el control integrado migratorio, utilizando procedimientos admi- } \\
\text { nistrativos y operativos compatibles y semejantes en forma simultánea por } \\
\text { los funcionarios migratorios de las Partes que actúen en el control adop- } \\
\text { tando modalidades que complementen y faciliten su funcionamiento, a fin } \\
\text { de lograr una circulación expedita de personas en la frontera. }\end{array}$ \\
\hline $\begin{array}{l}2012 \\
*\end{array}$ & $\begin{array}{l}\text { Adhesión de la } \\
\text { República de Co- } \\
\text { lombia al Acuerdo } \\
\text { sobre Residencia } \\
\text { Decisión } 20 / 12\end{array}$ & Residencia & $\begin{array}{l}\text { Adhesión de la República de Colombia al "Acuerdo sobre Residencia para } \\
\text { Nacionales de los Estados Partes del MERCOSUR, Bolivia y Chile". }\end{array}$ \\
\hline $\begin{array}{l}2014 \\
*\end{array}$ & $\begin{array}{l}\text { Adhesión Perú al } \\
\text { Acuerdo sobre } \\
\text { exención de traduc- } \\
\text { ción de documentos } \\
\text { administrativos para } \\
\text { efectos de inmigra- } \\
\text { ción } \\
\text { Decisión 15/2014 }\end{array}$ & $\begin{array}{l}\text { Circulación } \\
\text { de personas }\end{array}$ & $\begin{array}{l}\text { La República del Perú expresa su plena y formal adhesión al "Acuerdo } \\
\text { sobre Exención de Traducción de Documentos Administrativos para efec- } \\
\text { tos de Inmigración entre los Estados Partes del MERCOSUR, la República } \\
\text { de Bolivia y la República de Chile". }\end{array}$ \\
\hline $\begin{array}{l}2015 \\
*\end{array}$ & 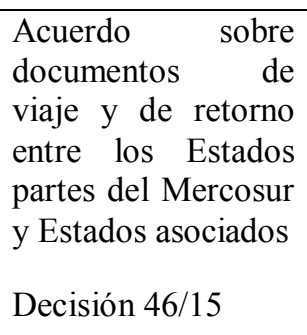 & $\begin{array}{l}\text { Circulación } \\
\text { de personas }\end{array}$ & $\begin{array}{l}\text { Se reconoce la validez de los documentos de identificación personal de } \\
\text { cada Estado Parte y Asociado del Mercosur como documentos de viaje } \\
\text { hábiles para el tránsito de nacionales y/o residentes regulares de aquellos. } \\
\text { Se reconoce la validez de los documentos de retorno emitidos por las } \\
\text { representaciones consulares de los Estados Partes y Asociados a sus na- } \\
\text { cionales por razones de hurto, pérdida y extravío de los documentos de } \\
\text { viaje. }\end{array}$ \\
\hline
\end{tabular}




\begin{tabular}{|c|c|c|c|}
\hline 2015 & $\begin{array}{l}\text { Acuerdo sobre } \\
\text { registración migra- } \\
\text { toria electrónica } \\
\text { Decisión } 53 / 15\end{array}$ & $\begin{array}{l}\text { Circulación } \\
\text { de personas }\end{array}$ & $\begin{array}{l}\text { Se aprueba la modalidad de registración electrónica de los datos de las } \\
\text { personas que se sometan al control migratorio. Será implementado progre- } \\
\text { sivamente en sustitución del formato físico en las fronteras donde existan } \\
\text { puestos de control de tránsito internacional aéreo, fluvial, marítimo y/o } \\
\text { terrestre de los Estados Parte y Asociados del Mercosur. }\end{array}$ \\
\hline 2019 & $\begin{array}{l}\text { Acuerdo operativo } \\
\text { para la implementa- } \\
\text { ción de mecanismos } \\
\text { de intercambio de } \\
\text { información migra- } \\
\text { toria entre los Esta- } \\
\text { dos partes del Mer- } \\
\text { cosur } \\
\text { Decisión } 2 / 19\end{array}$ & $\begin{array}{l}\text { Coopera- } \\
\text { ción para la } \\
\text { movilidad } \\
\text { de personas }\end{array}$ & $\begin{array}{l}\text { Establecer mecanismos coordinados entre las Partes de consulta, verifica- } \\
\text { ción e intercambio de información de personas y otra relacionada, con } \\
\text { fines migratorios tendientes a facilitar la movilidad de las personas entre } \\
\text { sus respectivos territorios y para fortalecer la cooperación para la preven- } \\
\text { ción de delitos del orden transnacional, especialmente aquellos relaciona- } \\
\text { dos con el tráfico ilícito de migrantes y la trata de personas, la falsifica- } \\
\text { ción de documentos de identificación y de viaje e intercambio de todo } \\
\text { antecedente penal, policial y judicial u otra que pueda impactar en la legis- } \\
\text { lación migratoria y en la seguridad ciudadana, de conformidad al ordena- } \\
\text { miento interno de cada Parte. }\end{array}$ \\
\hline 2019 & $\begin{array}{l}\text { Acuerdo sobre } \\
\text { localidades fronte- } \\
\text { rizas vinculadas } \\
\text { Decisión 13/19 }\end{array}$ & $\begin{array}{l}\text { Circulación } \\
\text { de personas }\end{array}$ & $\begin{array}{l}\text { Tiene por objeto facilitar la convivencia de las Localidades Fronterizas } \\
\text { Vinculadas e impulsar su integración a través del otorgamiento de un trato } \\
\text { diferenciado a sus pobladores en materia económica, de tránsito, de régi- } \\
\text { men laboral y de acceso a los servicios públicos de salud, enseñanza y } \\
\text { cultura, entre otros. Los nacionales de los Estados Partes, domiciliados } \\
\text { dentro de los límites previstos en este Acuerdo, podrán solicitar la expedi- } \\
\text { ción del documento para el tránsito vecinal fronterizo, en adelante Docu- } \\
\text { mento de Tránsito Vecinal Fronterizo (DTVF), a las autoridades compe- } \\
\text { tentes del Estado Parte por cuyo territorio de frontera deseen transitar y } \\
\text { desarrollar actividades previstas. }\end{array}$ \\
\hline
\end{tabular}

Tabla n. ${ }^{\circ}$ 2. Decisiones adoptadas por el Consejo del Mercado Común del Mercosur

Fuente: elaboración propia a partir de normas publicadas en la sección Documentos oficiales de la página oficial del

Mercosur: https://documentos.mercosur.int/

Ahora bien, en el apartado siguiente nos enfocaremos en la norma mercosureña más relevantes para nuestro trabajo de investigación, es decir aquella que contempla la situación de la niñez migrante intrabloque y su derecho de acceso a la educación.

\section{Acuerdos sobre residencia para nacionales de los Estados Partes del Mercosur y Estados Asociados}

Considerando que el Acuerdo sobre Residencia para nacionales de los Estados Parte del Merco$\operatorname{sur}^{25}$, Bolivia y Chile, luego extendido por adhesión a Colombia, Ecuador y Perú “constituye una

\footnotetext{
${ }^{25}$ El Acuerdo fue aprobado en 2002 y entró en vigencia en el 28 de julio 2009, un mes después de que Paraguay notificó y depositó su aprobación ante la Secretaría del Mercosur (SAM) en Asunción. Con posterioridad, tres son los países con estatus de Asociados al Mercosur que adhirieron al Acuerdo de Residencia: Perú y Ecuador en junio de 2011 y Colombia en junio del 2012. Los instrumentos de adhesión de Perú y Colombia estipulan su inmediata vigencia, mientras que el de Ecuador establece una ratificación interna, que aconteció en 2014 (OIM, 2018).
} 
piedra fundamental hacia la consecución de la libre circulación de personas en la región" (OIM, 2018, p. 15), un impulso para profundizar el modelo social de integración (Bogado Bordazar, 2012a) y busca ampliar el concepto de derechos humanos (Novick, 2005), hemos decidido desarrollarlo en un apartado.

El Acuerdo establece un criterio migratorio fundado en sola la acreditación de la nacionalidad del solicitante de uno de los Estados Parte del Mercosur y Asociados. Los requisitos básicos para la tramitación de las residencias serían entonces acreditar la nacionalidad, cierta documentación personal y la constancia de ausencia de antecedentes penales. Además se consagran los siguientes derechos: entrar, salir, circular y permanecer libremente en territorio del país de recepción, gozar del derecho a la salud y a la educación, a la reunificación familiar y a transferir libremente las remesas, así como del derecho a ejercer una actividad laboral, entre otros (OIM, 2018).

Nos interesa destacar el artículo 9.6 del Acuerdo que regula el derecho de los hijos de los inmigrantes a gozar en el territorio de los Estado Parte del derecho fundamental a la educación en las mismas condiciones de igualdad que los nacionales del Estado receptor y garantiza que "el acceso a las instituciones de enseñanza preescolar o a las escuelas públicas no podrá denegarse o limitarse a causa de la circunstancial situación irregular de la permanencia de los padres" (art. 9.6 segundo párrafo del Acuerdo).

Según la evaluación de la implementación del Acuerdo realizada por la OIM (2018), Argentina es el principal emisor de residencias, seguido por Chile y Brasil. Entre 2006 y 2016, Argentina había otorgado 2.070 .565 permisos de residencia (entre permanentes y temporarias) (OIM, 2018, p. 58). El principal país de destino para las personas de nacionalidad argentina es Chile (casi un 50\%) seguido de Brasil (33\%). A la inversa, el principal país de nacionalidad de los inmigrantes sudamericanos residentes en Argentina a los que se les concedió en 2016 una residencia por el Acuerdo de Residencia es Paraguay (38\%) seguido por de los migrantes de nacionalidad boliviana con un $25 \%$. 


\begin{tabular}{|c|c|c|c|c|c|c|c|c|c|c|}
\hline \multicolumn{11}{|c|}{ Residencias Totales concedidas en el marco del Acuerdo de Residencia por país según año 2006-2016 } \\
\hline País & $2006 / 2008$ & 2009 & 2010 & 2011 & 2012 & 2013 & 2014 & 2015 & 2016 & Total \\
\hline Argenina & 313.005 & 195.208 & 165.361 & 243.724 & 276.541 & 260.704 & 179.923 & 239.995 & 196.104 & 2.070 .565 \\
\hline Bolivia* & - & - & - & 4.142 & 14.864 & 11.822 & 18.551 & 12.936 & 11.838 & 74.153 \\
\hline Brasil & 5.528 & 5.975 & 6.648 & 21.294 & 31.584 & 37.562 & 32.966 & 25.623 & 23.139 & 190.319 \\
\hline Chile & - & 2.442 & 8.117 & 14.744 & 22.442 & 35.629 & 39.625 & 37.774 & 28.985 & 189.758 \\
\hline Colombia** & - & - & - & - & - & - & 71 & 2.839 & 3.360 & 6.270 \\
\hline Ecuador*** & - & - & - & - & - & - & 14.899 & 16.481 & 15.650 & 47.030 \\
\hline Paraguay & - & 1.125 & 6.521 & 3.396 & 3.574 & 2.429 & 3.683 & 5.780 & 6.230 & 32.738 \\
\hline Perú ${ }^{* * * *}$ & - & - & - & 10 & 763 & 4.028 & 6.160 & 8.767 & 10.090 & 29.818 \\
\hline Uruguay & 4.033 & 2.653 & 1.462 & 772 & 1.236 & 980 & 1.738 & 7.396 & 8.946 & 29.216 \\
\hline Total & 322.566 & 207.403 & 188.109 & 288.082 & 351.004 & 353.154 & 297.616 & 357.591 & 304.342 & 2.669 .867 \\
\hline
\end{tabular}

Tabla n. ${ }^{\circ}$ 3. Residencias totales otorgadas en el marco del Acuerdo de Residencia

Fuente: OIM (2018)

En cuanto a la caracterización demográfica de los migrantes que solicitaron residencia en el marco del Acuerdo, en Argentina y Chile una de cada diez personas que obtuvieron la residencia son menores de 15 años, "lo que sugiere que en estos casos existe una mayor prevalencia de migraciones de núcleos familiares integrados por adultos y sus hijos” (OIM, 2018, p. 80).

Con respecto a la incidencia en el acceso al derecho a la educación previsto en el art. 9.6 del Acuerdo, en Argentina por ser el país que más residencias ha otorgado, también es el que cuenta con mayor número de estudiantes extranjeros. Los desafíos que enfrentan los NNA en los sistemas educativos se vinculan, según el informe de la OIM (2018), en menor medida con los procedimientos burocráticos y complejos para la admisión y revalidación de títulos y, ya sí configurando una limitación en el acceso a la educación, a asignación de cupos en las escuelas públicas. Por último, se señala el tratamiento de la diferencia en las escuelas que provocan dificultades de adaptación. En el caso de Argentina,

los alumnos que no poseen documento nacional de identidad, el cual se obtiene una vez que se tramitó la residencia temporaria o permanente, no pueden acceder a programas sociales escolares (ej. obtención de netbooks a través de los planes Conectar Igualdad o Sarmiento). (...) algunos estudios muestran una elevada proporción de inmigrantes provenientes de Bolivia, Paraguay y del Perú que se sienten discriminados en la escuela, mayormente por sus pares. Esta situación provoca sentimientos de insatisfacción y deteriora la autoestima de los adolescentes. Si bien docentes y directivos no son incriminados por 
un tratamiento discriminatorio por parte de la mayoría de los estudiantes extranjeros, lo cierto es que el bullying ocurre dentro de los ámbitos escolares, lo cual denota una inhabilidad de las instituciones para lidiar con estos comportamientos discriminatorios (OMI, 2018, pp. 111-112).

\section{Otros}

i. $\quad$ Foro especializado migratorio del Mercosur (FEM)

El Foro especializado migratorio del Mercosur y Estados asociados nace en Montevideo el 21 de diciembre de 2003 en el marco de la XIV Reunión de Ministros del Interior (RMI) y tuvo su primera reunión en el mes de abril de 2004 en la ciudad de Buenos Aires bajo la coordinación de dicha RMI. Se trata de un espacio que tiene entre sus funciones el estudio del impacto de las migraciones en la región y fuera de ella, el análisis y desarrollo de proyectos de normas y/o acuerdos en materia migratoria que regirán para los países del bloque.

Una de las primeras tareas que llevó a cabo el FEM fue redactar un proyecto de Declaración de Principios sobre la política migratoria en el Mercosur y Estados asociados, que fue suscripta en la Reunión extraordinaria de Ministro del Interior en Chile el 17 de mayo de 2014. Se trata de una Declaración política conjunta que fija una posición común sobre las migraciones que pretende dar una fuerte señal de integración, de respeto a los derechos humanos de los migrantes y del reconocimiento positivo de su contribución pasada y actual al desarrollo económico, social y cultural de los países.

En la reunión del FEM del mes de octubre de 2005, la delegación argentina presentó un proyecto de declaración sobre trata de personas que fue discutida y aprobada en el seno del Foro. La RMI aprobó en su reunión de noviembre de ese mismo año la Declaración de Montevideo contra la Trata de Personas en el Mercosur y Estados asociados, comprometiéndose a obrar los mecanismos necesarios para evitar la explotación. Al finalizar el primer semestre de 2006, la RMI aprobó, como carácter de Acuerdo interministerial, el Plan de Acción para la lucha contra la Trata de personas que fuera propuesto por el Foro. 
En sus dieciséis años de existencia, el FEM ha logrado convertirse en un verdadero espacio de debate e intercambio sobre los temas migratorios que atañen a la región y ha logado impulsar la toma de decisiones relevantes en la materia. A saber ${ }^{26}$ :

a) las delegaciones han realizado un seguimiento del estado de situación de los Acuerdos migratorios aprobados en el ámbito del Mercosur;

b) se propusieron diversas reformas como a la Resolución 75/96 "Documentos de cada Estado Parte que habilitan el tránsito de personas en el MERCOSUR" que fue aprobado por la RMI como Acuerdo interministerial, ampliando la anterior norma a los Estados asociados y luego fue elevada al CMC con el Proyecto de Decisión modificatorio de la Resolución mencionada. Otra de las reformas que tuvo origen en el Foro fue al Acuerdo de Recife $(1993)^{27}$ que fue negociada y consensuada por las delegaciones y aprobada por los Ministros del Interior de los Estados Parte que elevaron al CMC el Proyecto de Decisión denominado "Primer Protocolo Adicional al Acuerdo de Recife" aprobado por Decisión $\mathrm{N}^{\circ} 5 / 00$. El mismo tiene por objeto adecuar y complementar el procedimiento de control migratorio en las "Áreas de Control Integrado" a través de la implementación de nuevas modalidades de control, que optimizan la utilización de recursos y agilizan los procedimientos, con el objeto de lograr una circulación más expedita de personas en la frontera. En el año 2014, el CMC aprueba el Acuerdo de Complementación del Acuerdo de Recife en materia migratoria que

tiene por objeto regular el control integrado migratorio, utilizando procedimientos administrativos y operativos compatibles y semejantes en forma simultánea por los funcionarios migratorios de las Partes que actúen en el control adoptando modalidades que complementen y faciliten su funcionamiento, a fin de lograr una circulación expedita de personas en la frontera (art. 1).

Este Acuerdo de complementación aún no ha sido incorporado al ordenamiento jurídico de los Estados Parte.

\footnotetext{
${ }^{26}$ Esta información surge en parte de la memoria institucional del FEM que recoge todos los temas tratados en las reuniones. La memoria se encuentra disponible en línea y la última actualización incorpora hasta la última reunión del año 2014. Consultado en: http://www.migraciones.gov.ar/foro_migratorio/pdf/memoria_institucional_n.pdf [el día 05/12/2020]

${ }^{27}$ También impulsó las modificaciones del Acuerdo llevadas a cabo en el año 2000 (Decisiones ํ 4/00 y N 5/00).
} 
Otra de la propuestas normativas elaboradas por el FEM y aprobadas por la RMI fue el Acuerdo sobre Documentos de Viaje del Mercosur y Estados asociados, cuyo objeto consiste en modificar las Decisiones CMC N 18/08 y N 14/11 sobre Documentos de Viaje, actualizando la nómina de Documentos de Viaje vigentes entre los países del Mercosur ampliado;

c) En el ámbito del Foro se propusieron distintas capacitaciones en materia migratoria, se asumieron posturas para ser presentadas en foros internacionales y se intercambiaron informaciones estadísticas;

d) Por iniciativa de las delegaciones se presentaron nuevos temas de debate como las migraciones por motivos de desastres naturales, climáticos y de carácter humanitario y refugio, reasentamiento y apátridia.

e) Se impulsó la creación de la Red de Especialistas en Seguridad Documental Migratoria del Mercosur y Estados Asociados (Red SEGDOC) que fue aprobada por el CMC por Decisión 25/14 de fecha 16 de diciembre de 2014. Esta red está dedicada al análisis de documentación y a la cooperación entre los funcionarios que integren dicha Red, a fin de prevenir y evitar el fraude documental migratorio en la región.

f) En el año 2014 el FEM elaboró el proyecto Memorando de entendimiento entre el Mercosur y la OIM en materia de cooperación técnica internacional que fue aprobado por Resolución $\mathrm{N}^{\circ}$ 60/14 del Grupo Mercado Común (GMC) con fecha 14 de diciembre de 2014. Si bien el órgano técnico donde se llevaron a cabo los trabajos sobre esta propuesta fue el FEM, el mismo contempla la posibilidad de que cualquier órgano del Mercosur que trabaje sobre alguna cuestión vinculada a las migraciones, pueda trabajar conjuntamente con la OIM en materia de cooperación y asistencia técnica con dicho organismo.

Este acuerdo permitirá una cooperación más estrecha entre los países miembros de la OIM y del Mercosur en aspectos tales como la migración laboral, migración transfronteriza, flujos migratorios mixtos, integración social de los migrantes, gestión de fronteras, estandarización de estadísticas, sistemas de información sobre la migración, trata de personas y tráfico ilícito de migrantes. Otros asuntos que contempla el memorando de entendimiento incluyen la capacitación de funcionarios gubernamentales, leyes y regulaciones migratorias, libre circulación de per- 
sonas, asistencia a ciudadanos en el extranjero y vínculos con los mismos, y derechos de los migrantes.

g) El 20 de diciembre de 2015, el CMC adoptó dos decisiones vinculadas a la circulación de personas. La Decisión $N^{\circ}$ 46/15 que aprobó el Acuerdo sobre documentos de viaje y de retorno de los Estados Partes del Mercosur y Estados Asociados que reconoce la validez de los documentos de identificación personal de cada Estado Parte y Asociado como documentos de viaje hábiles para el tránsito de nacionales y/o residentes regulares del Mercosur por el territorio de los mismos. Y la Decisión N 53/15 que aprobó el Acuerdo sobre Registración Migratoria Electrónica que aprueba la modalidad de registración electrónica de los datos de las personas que se someten al control migratorio que sustituirá progresivamente el formato físico.

h) El 16 de julio de 2019, el CMC aprobó el Acuerdo operativo para la implementación de mecanismos de intercambio de información migratoria entre los Estados Partes del Mercosur que fuera elevado por la Reunión de Ministros del Interior y Seguridad (Decisión № 2/19). Tiene por objeto establecer mecanismos coordinados entre las Partes de consulta, verificación e intercambio de información de personas y otra relacionada, con fines migratorios tendientes a facilitar la movilidad de personas y para fortalecer la cooperación para la prevención de los delitos transnacionales. Este acuerdo aún no entró en vigor.

\section{ii. Declaraciones y comunicados}

En este apartado resumiremos las principales declaraciones y comunicados de los Estados Partes y Asociados del Mercosur referidos a la circulación de personas.

\begin{tabular}{|c|c|c|c|}
\hline Año & Nombre & Tema principal & Objetivos generales \\
\hline 2000 & $\begin{array}{c}\text { Declaración } \\
\text { de Río de } \\
\text { Janeiro }\end{array}$ & Refugiados & $\begin{array}{l}\text { - Declarar la necesidad de una normativa jurídica } \\
\text { específica sobre el refugio que establezca proce- } \\
\text { dimientos armónicos sobre la materia. } \\
\text { - Dicha normativa debería contemplar los princi- } \\
\text { pios generales sobre la recepción, protección y } \\
\text { asistencia a los refugiados- } \\
\text { - No aplicación, a quien haya sido reconocido } \\
\text { como refugiado por otro Estado Parte o asociado, } \\
\text { medidas de retorno forzado al país donde su vida, }\end{array}$ \\
\hline
\end{tabular}




\begin{tabular}{|c|c|c|c|}
\hline & & & $\begin{array}{l}\text { libertad o integridad física están amenazadas por } \\
\text { motivos de raza, nacionalidad, grupo social, opi- } \\
\text { nión política o violación grave y generalizada de } \\
\text { los derechos humanos. }\end{array}$ \\
\hline 2001 & $\begin{array}{l}\begin{array}{c}\text { Declaración } \\
\text { de }\end{array} \\
\text { Asunción }\end{array}$ & $\begin{array}{l}\text { Tráfico de personas y } \\
\text { tráfico ilícito de mi- } \\
\text { grantes }\end{array}$ & $\begin{array}{l}\text { - Condena a la figura del tráfico de personas. } \\
\text { - Garantizar el pleno respeto de los derechos hu- } \\
\text { manos de los migrantes y de sus familias. } \\
\text { - Compromiso de adopción de medidas legislati- } \\
\text { vas punitorias. } \\
\text { - Cooperación a fin de detectar documentos falsi- } \\
\text { ficados. }\end{array}$ \\
\hline 2004 & $\begin{array}{l}\text { Declaración } \\
\text { de } \\
\text { Santiago }\end{array}$ & $\begin{array}{l}\text { Principios migrato- } \\
\text { rios }\end{array}$ & $\begin{array}{l}\text { - Regularización de los flujos migratorios. } \\
\text { - Asegurar el respeto de los derechos humanos de } \\
\text { los migrantes. } \\
\text { - Protección internacional a los refugiados. } \\
\text { - Reunificación familiar. } \\
\text { - Compromiso de combatir el tráfico ilícito de } \\
\text { migrantes. } \\
\text { - Condena a prácticas de xenofobia, deportaciones } \\
\text { en masa y detenciones ilegales. } \\
\text { - Coordinación y cooperación entre organismos } \\
\text { migratorios. } \\
\text { - Necesidad de tratamiento multidisciplinario y } \\
\text { multilateral de las migraciones. }\end{array}$ \\
\hline 2005 & $\begin{array}{l}\text { Declaración } \\
\text { de Montevi- } \\
\text { deo }\end{array}$ & $\begin{array}{l}\text { Trata de personas en } \\
\text { el Mercosur y Esta- } \\
\text { dos asociados }\end{array}$ & $\begin{array}{l}\text { - Condena al delito de trata de personas. } \\
\text { - Prevención y lucha contra la trata en la región. } \\
\text { - Tipificación penal de este delito en las legisla- } \\
\text { ciones de los Estados. } \\
\text { - Fortalecimiento institucional. } \\
\text { - Protección y asistencia a las víctimas } \\
\text { - Campañas de difusión en medios de comunica- } \\
\text { ción. } \\
\text { - Cooperación regional a fin de erradicar la trata. }\end{array}$ \\
\hline
\end{tabular}




\begin{tabular}{|c|c|c|c|}
\hline 2014 & $\begin{array}{l}\text { Comunicado } \\
\text { especial so- } \\
\text { bre los dere- } \\
\text { chos de los } \\
\text { niños, niñas } \\
\text { y adolescen- } \\
\text { tes migrantes } \\
\text { no acompa- } \\
\text { ñados }\end{array}$ & $\begin{array}{l}\text { NNA migrantes no } \\
\text { acompañados }\end{array}$ & $\begin{array}{l}\text { - Preocupación por la detención de NNA migran- } \\
\text { tes no acompañados, procedentes especialmente } \\
\text { de Centroamérica, en la frontera sur de Estados } \\
\text { Unidos. } \\
\text { - Exigencia de los derechos fundamentales de } \\
\text { estos NNA. } \\
\text { - Reconocimiento de la problemática que afecta al } \\
\text { continente americano. } \\
\text { - Defensa de la no criminalización de la condición } \\
\text { migratoria, de la prohibición de detención por } \\
\text { motivos migratorios y el rechazo de las políticas } \\
\text { de deportación automática. }\end{array}$ \\
\hline 2015 & $\begin{array}{l}\text { Declaración } \\
\text { sobre la cri- } \\
\text { sis humanita- } \\
\text { ria de gestión } \\
\text { de movi- } \\
\text { mientos mi- } \\
\text { gratorios }\end{array}$ & $\begin{array}{l}\text { Crisis humanitaria } \\
\text { que afecta a migran- } \\
\text { tes, refugiados y } \\
\text { solicitantes de asilo } \\
\text { de Siria, Eritrea, } \\
\text { Afganistán, Somalia } \\
\text { y Nigeria }\end{array}$ & $\begin{array}{l}\text { - Destacan la necesidad de abordar, desde el enfo- } \\
\text { que de los Derechos Humanos y del principio de } \\
\text { reunificación familiar, las causas de esta crisis } \\
\text { humanitaria. } \\
\text { - Apoyo a los organismos multilaterales y países } \\
\text { involucrados en la solución de la crisis. }\end{array}$ \\
\hline 2015 & $\begin{array}{l}\text { Declaración } \\
\text { sociolaboral } \\
\text { del Mercosur }\end{array}$ & $\begin{array}{l}\text { Desarrollo económi- } \\
\text { co con justicia social }\end{array}$ & $\begin{array}{l}\text { - Los trabajadores cualquiera sea su nacionalidad } \\
\text { tienen derecho a asistencia, información, protec- } \\
\text { ción e igualdad de derechos y condiciones de tra- } \\
\text { bajo. } \\
\text { - Compromiso de adoptar y articular medidas para } \\
\text { establecer normas y procedimientos comunes } \\
\text { relativos a la circulación de trabajadores en la } \\
\text { zona fronteriza. }\end{array}$ \\
\hline
\end{tabular}

Tabla n. ${ }^{\circ}$ 4. Declaraciones de los Estados Partes del Mercosur y Asociados vinculadas a la temática migratoria.

Fuente: elaboración propia a partir de información disponible en la página oficial del Mercosur.

iii. $\quad$ Instituto de Políticas Públicas en Derechos Humanos del Mercosur (IPPDH)

El IPPDH es una instancia técnica que nace en 2009 a través de la Decisión del Consejo del Mercado Común (CMC) No 14/09, bajo el ámbito de la Reunión de Altas Autoridades de Derechos Humanos y Cancillerías del Mercosur y Estados Asociados (RAADH) y con sede permanente en la Ciudad de Buenos Aires, conforme lo establece la Decisión CMC No 32/09.

En el año 2018 presentó la Iniciativa Regional Foco Niñez Migrante "para alertar, articular acciones, identificar buenas prácticas y elaborar propuestas orientadas a dar respuestas a la 
vulneración de los derechos de la niñez migrante con un abordaje regional" (IPPDH, 2019). En el marco de esta iniciativa se publicó en 2019 Protección de niños, niñas y adolescentes en contextos de migración. Manual de aplicación de estándares internacionales y regionales de derechos humanos dirigido a funcionarios y funcionarias de instituciones públicas y privadas que realicen tareas de formulación y gestión de políticas migratorias, control migratorio y protección de los derechos de niños, niñas y adolescentes en contextos de migración.

En mayo de 2019 se llevó a cabo el Diálogo Regional Foco Niñez Migrante donde participaron "actores estratégicos en la materia, intercambiaron información y experiencias de trabajo para identificar las buenas prácticas y los desafíos para la protección y garantía de derechos de este grupo de personas" (IPPDH, 2019a, p. 8). Destacamos la intervención de Julio Croci, Director Nacional de Pluralismo e Interculturalidad de la Secretaría de Derechos Humanos de Argentina, quien afirmó que nuestro país "adaptó sus disposiciones migratorias, incluyendo documentación válida para el ingreso de niñas y niños migrantes los siguientes: 1) Pasaportes vencidos (hasta antes de cumplirse los dos años del plazo de vencimiento), 2) Partida de nacimiento (para los que no cuentan con otra documentación)" (IPPDH, 2019a, p. 15).

En el mismo año, se realizó la VIII Consulta Pública ${ }^{28}$ sobre Movilidad Humana y Desarro1lo. Algunas de las propuestas formuladas por la sociedad civil fueron:

$>$ Garantizar que los trámites de regularización se puedan realizar de forma presencial y virtual en todo el territorio y que toda información al respecto esté disponible al menos en español, portugués e inglés.

$>$ Promover la capacitación y la sensibilización en materia de derechos humanos de los agentes encargados migraciones.

> Garantizar que las personas extranjeras que cumplieron condena o estén cumpliendo, accedan a los trámites de regularización en igualdad de condiciones.

$>$ Garantizar la reunificación familiar como criterio para el ingreso al país de destino y a la regularización migratoria.

$>$ Garantizar que la condición migratoria de madres y padres no resulte en condición apatridia para las hijas y los hijos que nacieron en el país de destino.

\footnotetext{
${ }^{28}$ Las consultas públicas son foros de participación social. organizadas semestralmente con la participación de diversas organizaciones y movimientos sociales de la región para compartir análisis de coyuntura, profundizar temáticas relevantes y construir propuestas regionales de incidencia. Pueden ser presenciales y/o virtuales y han sido promovidas conjuntamente con la Unidad de Participación Social del Mercosur. Más información: https://www.ippdh.mercosur.int/consultas-publicas/
} 
Prohibir las expulsiones que atenten contra la unidad familiar, con especial atención a la protección del interés superior del niño.

$>$ Establecimiento de la misma tipificación del crimen de tráfico de personas en todos los países del Mercosur.

$>$ Formulación de un marco jurídico de defensa de los derechos de los migrantes en los países del Mercosur y Estados Asociados, reconociendo el derecho humano a migrar.

\section{El Caso de ARgentina}

\section{Perfil migratorio}

Conforme el último Censo Nacional de Población, Hogares y Viviendas realizado por el Instituto Nacional de Estadística y Censos (INDEC, 2010) en el año 2010, en los últimos diez años Argentina recibió 274.017 extranjeros, lo que representa un total de 1.805 .957 personas, es decir el 4,5\% de la población total. El 77,7\% proviene de países limítrofes y de Perú. El 11\% proviene de Uruguay, el 29,6\% de Brasil y el 38,2\% de Paraguay, constituyéndose la comunidad paraguaya en la mayor comunidad de extranjeros residentes en el país con un total de 550.713 integrantes. Si bien la población de Bolivia no es la primera extranjería, es la más visible en el área metropolitana donde ha tendido a concentrarse en las últimas décadas (Díez, 2020).

Atendiendo al grupo etario de interés para nuestra investigación, encontramos un total de 53.702 niños y niñas entre 5 y 9 años y 55.911 niños y niñas entre 10 y 14 años nacidos en el extranjero. Considerando el país de origen y el rango etario de 0-14 años de edad, encontramos 3.688 varones y mujeres provenientes de Uruguay, 52.195 provenientes de Paraguay y 3.499 provenientes de Brasil. Como señala Díez (2020), la población extranjera ha asistido a las escuelas desde la fundación del sistema educativo argentino y desde hace ya más de 150 años han estado presentes los migrantes latinoamericanos en porcentajes similares respecto del total de habitantes del país, "variando los países de procedencia, los territorios de asentamiento y su visibilidad (2020, p. 5).

En cuanto al lugar de residencia de los extranjeros, veamos su distribución en el territorio en la siguiente tabla: 


\begin{tabular}{|c|c|}
\hline \multicolumn{2}{|c|}{ Porcentaje de población migrante por provincia } \\
\hline $\begin{array}{l}\text { Citudad Autonoma de Butenos Aires } \\
\text { Santa Crtzz }\end{array}$ & $\begin{array}{r}13.20 \% \\
9.50 \%\end{array}$ \\
\hline Tierra del Fuego. Antartida e Islas del Attántico Sur & $8.88 \%$ \\
\hline Rjo Negro & $7.39 \%$ \\
\hline Netrquén & $6,28 \%$ \\
\hline Chubut & $6,13 \%$ \\
\hline Butenos Aires & $6,00 \%$ \\
\hline Jujtery & $4,39 \%$ \\
\hline Misiones & $3.99 \%$ \\
\hline Formosa & $3,98 \%$ \\
\hline Merdoza & $3,77 \%$ \\
\hline Salta & $2.31 \%$ \\
\hline Cordoba & $1,52 \%$ \\
\hline San Luis & $1,28 \%$ \\
\hline Santa Fe & $1,17 \%$ \\
\hline La Pampa & $1,06 \%$ \\
\hline La Fioja & $0.96 \%$ \\
\hline San Juan & $0.91 \%$ \\
\hline Entre Pjos & $0.84 \%$ \\
\hline Corrientes & $0.77 \%$ \\
\hline Chaco & $0.61 \%$ \\
\hline Tucumân & $0.56 \%$ \\
\hline Catamarca & $0.42 \%$ \\
\hline Santiago del Estero & $0.32 \%$ \\
\hline
\end{tabular}

Tabla n. ${ }^{\circ}$ 5. Porcentaje de población migrante por provincia

Fuente: elaboración propia en base a los datos del Censo 2010 (INDEC)

Según la proyección del Instituto Nacional de Estadística y Censos (INDEC, 2013), la migración internacional en nuestro país para el periodo 2010 - 2020 disminuiría 15 puntos porcentuales. Estas proyecciones fueron elaboradas a partir del método de los componentes, el cual consiste en proyectar cada una de las variables determinantes de la dinámica demográfica (mortalidad, fecundidad, migración) de manera independiente a partir de una población base, que en este caso se trazó para el 1 de julio de 2010. La tasa anual de migración neta para el 2010 equivale a una proporción de 0,37 (37\%), mientras que la proyección realizada para el 2020 equivaldría a una proporción de 0,22 (22\%). Al establecer la diferencia para el periodo 2010 - 2020 obtenemos que la tasa de migración neta disminuye en 15 puntos porcentuales. La tasa de migración 
neta es entendida como el coeficiente entre el saldo neto migratorio ocurrido durante un periodo determinado y la población media de dicho periodo.

\section{La Ley de Migraciones $n^{\circ} 25.871$}

El 21 de enero de 2004 fue publicada la ley 25.871 que fuera reglamentada por el Decreto 616 de 2010. Brevemente señalaremos que al momento de sancionarse esta ley se encontraba vigente la ley 22.439 de 1981 dictada por el gobierno militar del General Videla que incentivaba la inmigración europea y establecía una política restrictiva que permitía la expulsión de los migrantes pues consideraba a la inmigración como una cuestión de seguridad nacional (Novick, 2010). Esta ley se basaba en una concepción represiva que desconocía los derechos de los migrantes y violentaba dos principios fundantes del sistema jurídico argentino: el derecho a la igualdad y a la no discriminación (Domenech, 2007). Posteriormente, en los sucesivos gobiernos, se dictaron decretos de amnistía y recién el 17 de diciembre de 2003, tras largas discusiones, se obtuvo la sanción de la ley 25.871 que establece una nueva política migratoria nacional y que atiende a las transformaciones tanto regionales como internacionales.

Resulta de trascendental importancia su artículo $4^{\circ}$ que establece: "El derecho a la migración es esencial e inalienable de la persona y la República Argentina lo garantiza sobre la base de los principios de igualdad y universalidad". De esta manera se reconoce el carácter de derecho humano a migrar y se establece la obligación del Estado de garantizarlo.

Entre los principales derechos reconocidos a los migrantes podemos destacar: la salud, justicia, trabajo, empleo y seguridad social, bienes públicos (art. $6^{\circ}$ ), pero a los fines del presente trabajo nos referiremos principalmente al derecho a la educación previsto en el artículo $7^{\circ}$. El mismo reza:

En ningún caso la irregularidad migratoria de un extranjero impedirá su admisión como alumno en un establecimiento educativo, ya sea este público o privado; nacional, provincial o municipal; primario, secundario, terciario o universitario. Las autoridades de los establecimientos educativos deberán brindar orientación y asesoramiento respecto de los trámites correspondientes a los efectos de subsanar la irregularidad migratoria (Art. 7, ley 25.871). 
El Decreto reglamentario encarga al Ministerio de Educación de la Nación la tarea de adoptar las medidas necesarias para garantizar a los extranjeros, sin importar la situación de irregularidad migratoria, el acceso a los distintos niveles educativos previsto en la Ley de Educación Nacional (Ley 26.206). Esta ley sancionada y promulgada en diciembre de $2006^{29}$, establece en sus artículos 4 y 143, en consonancia con lo dispuesto en el artículo 7 de la ley migratoria, lo siguiente:

El Estado nacional, las provincias y la Ciudad Autónoma de Buenos Aires tienen la responsabilidad principal e indelegable de proveer una educación integral, permanente y de calidad para todos/as los/as habitantes de la Nación, garantizando la igualdad, gratuidad y equidad en el ejercicio de este derecho, con la participación de las organizaciones sociales y las familias (Art. 4$)^{30}$.

El Estado nacional, las provincias y la Ciudad Autónoma de Buenos Aires deberán garantizar a las personas migrantes sin Documento Nacional de Identidad (DNI), el acceso y las condiciones para la permanencia y el egreso de todos los niveles del sistema educativo, mediante la presentación de documentos emanados de su país de origen, conforme a lo establecido por el artículo $7^{\circ}$ de la Ley No 25.871 (Art. 143).

Un año antes, en 2005, era sancionada y promulgada la ley 26.061 de protección integral de los derechos de los niños, niñas y adolescentes (basada en la Convención sobre los Derechos del Niño). Esta ley destinada a la protección integral de los derechos de los NNA "que se encuentren en el territorio de la República Argentina, para garantizar el ejercicio y disfrute pleno, efectivo y permanente de aquellos reconocidos en el ordenamiento jurídico nacional y en los tratados internacionales en los que la Nación sea parte (...)" (Art. 1, párr. 1). Entre los derechos contemplados por esta ley destacamos el derecho a la documentación, es decir a obtener los documentos públicos que comprueben la identidad (Art. 13) y el derecho a la educación que prevé el "derecho a la educación pública y gratuita, atendiendo a su desarrollo integral, su preparación para el ejercicio de la ciudadanía, su formación para la convivencia democrática y el trabajo, respetando su identidad cultural y lengua de origen, su libertad de creación y el desarrollo má-

\footnotetext{
${ }^{29}$ Ver capítulo III

${ }^{30} \mathrm{El}$ resaltado en este y en los siguientes artículos es nuestro.
} 
ximo de sus competencias individuales; fortaleciendo los valores de solidaridad, respeto por los derechos humanos, tolerancia, identidad cultural y conservación del ambiente" y asegura el acceso y permanencia y en aquellos casos en los que carezcan de "documentación que acredite su identidad, se los deberá inscribir provisoriamente, debiendo los Organismos del Estado arbitrar los medios destinados a la entrega urgente de este documento". No hay causa alguna que pueda restringir el acceso a la educación de los NNA, "debiendo entregar la certificación o diploma correspondiente" (Art. 15).

En el año 2013, el Centro de Derechos Humanos de la Universidad de Lanús y el Fondo de las Naciones Unidas para la Infancia (UNICEF) presentaron un estudio a 10 años de la ley de migraciones $^{31}$. De este documento surge que tanto la ley de migraciones como la ley de protección integral "no definen de manera explícita la condición de la niñez migrante ni de los hijos e hijas de migrantes" (Pinto y Ceriani Cernadas, 2013, p. 12).

De los resultados del estudio, nos gustaría destacar que a pesar de la adecuación normativa (de la ley 26.206 a la 25.871) la práctica muestra que muchos establecimientos educativos exponen objeciones tanto para la inscripción de estudiantes como para la entrega de diplomas sin la presentación del DNI e incluso "algunas instituciones educativas niegan o restringen el acceso, la permanencia o el egreso de niños y niñas migrantes en razón de su condición migratoria" (Pinto y Ceriani Cernadas, 2013, p. 40). Podemos encontrar varios estudios focalizados en este sentido que dan cuenta de estas dificultades que deben enfrentar los NNA migrantes ${ }^{32}$.

De las recomendaciones resultantes del estudio efectuado en el año 2010 (Ceriani Cernadas y Fava, 2010), la coordinación interinstitucional es una de las áreas a considerar como primordial puesto que el diseño de políticas y su aplicación práctica requiere del diálogo permanente entre una pluralidad de organismos públicos a nivel nacional, provincial y municipal. A

\footnotetext{
${ }^{31}$ En el año 2010, el Centro de Derechos Humanos de la Universidad de Lanús elaboró para UNICEF un informe sobre los derechos de niños y niñas migrantes a 5 años de la nueva ley de migraciones, coordinado por Pablo Ceriani Cernadas y Ricardo Fava.

${ }^{32}$ A modo de ejemplo: Mera, G. (2012). Inmigración, distribución y espacio urbano. Debates y desafíos a partir del caso de paraguayos en la Ciudad de Buenos Aires. En Susana Novick (Dir.), Migración y políticas públicas. Nuevos escenarios y desafios (pp. 143-169). Catálogos; Gavazzo, N., Beheren, M. y Novaro, G. (2014). La escolaridad como hito en las biografías de los hijos de bolivianos en Buenos Aires, Revista interdisciplinaria da movilidade humana, 22 (42), 95-118; Carbajal, D. (2011). Los migrantes en la escuela pública. En Movilidad y migraciones (151-162). Instituto Multidisciplinario de Historia y Ciencias Humanas.
} 
partir de 2011, se comenzó a trabajar en tres mesas interinstitucionales ${ }^{33}$ sobre: 1) educación, 2) salud y 3) adecuación normativa, acceso a derechos y prevención de la xenofobia.

Del trabajo de la mesa interinstitucional sobre educación, niñez y migración se identificaron como temas prioritarios que impulsaron las siguientes iniciativas:

a) Las dificultades para obtener títulos de nivel primario y secundario que experimentan NNA en situación migratoria irregular llevó a la Dirección Nacional de Validez de Títulos y Estudios del Ministerio de Educación de la Nación a crear un software por medio del cual se pueden expedir los certificados con pasaporte $\mathrm{u}$ otros documentos, y no necesariamente con DNI. Sin embargo, se informa que persisten las dificultades para los NNA que no poseen DNI. Lo mismo sucede en materia de convalidación y/u homologación de títulos obtenidos en el extranjero.

b) Formación docente en derechos, prevención de la xenofobia e integración de la población migrante. En este aspecto las acciones se limitan a un curso y a la elaboración de una llamada "valija de materiales" de migración para educadores que cuenta con diversas herramientas para trabajar en el aula.

c) Programa de entrega de computadoras: se trata del programa "Conectar igualdad" destinado a estudiantes de escuelas secundarias en todo el país y del programa "Plan S@rmiento BA" destinado a niños/as de escuelas primarias de la Ciudad Autónoma de Buenos Aires. Se ha informado casos de niños/as migrantes o hijos/as de migrantes que no pudieron acceder a estos programas porque ellos y/o sus padres carecían de DNI.

d) Enseñanza de idioma español para niños y niñas migrantes con el propósito con el fin de asegurar que tengan la posibilidad de incorporarse al sistema educativo en todos sus niveles. No hay descripción en el estudio de acciones concretas en este sentido.

\footnotetext{
${ }^{33}$ Cada mesa de trabajo es liderada por un organismo público que actúa como entidad anfitriona para la realización de las reuniones mensuales. Así, la mesa de educación se lleva a cabo en el Ministerio de Educación de la Nación, con la participación del Programa Nacional por los Derechos de la Niñez y Adolescencia que depende de la Coordinación de Programas para la Inclusión Democrática en las Escuelas. Aquí confluyen organismos públicos, universidades, agencias de Naciones Unidas, organizaciones internacionales o intergubernamentales, de la sociedad civil, académicos, etc. Así, estas experiencias lograron reunir en un mismo espacio de trabajo una diversidad de actores, tanto públicos (nacionales, provinciales) como privados, que trabajan a diferentes niveles y con distintos abordajes (Pinto y Ceriani Cernadas, 2013).
} 
Nos gustaría señalar que si bien el artículo 14 inciso a) de la ley 25.871 establece que el Estado favorecerá iniciativas tales como "la realización de cursos de idioma castellano en las escuelas e instituciones culturales extranjeras legalmente reconocidas" (Art. 14), y de allí surge la iniciativa mencionada en el inciso d), no podemos dejar de observar que se trata de una estrategia práctica que responde a un modelo asimilacionista o de integración monocultural (Domenech, 2007) o laissez faire (Martín Rojo, 2003). Este modelo educativo trata que aquellos que se incorporan al sistema escolar, procedentes de la inmigración o de áreas geográficas con una lengua diferente, se asimilen a la mayoría adquiriendo su lengua, para así asegurar su adaptación a la sociedad de acogida y sus posibilidades de progreso social: la submersión lingüística y cultural, que se aplica en el aula común y sin tratamiento diferencial, es una de las principales estrategias (Martín Rojo, 2003). En este mismo sentido, las iniciativas de difusión de información y cursos de formación para promover y lograr la inserción de los migrantes tratan "más bien de metodologías complementarias que pueden servir para el inicio de cambios más significativos y profundos" (Domenech, 2007, p. 14).

Díez (2020) señala, en base a los últimos datos censales, que el sostenimiento de las trayectorias escolares de la población migrante es más difícil que para los estudiantes nativos, "si bien el acceso y permanencia en el nivel primario parece garantizado en términos relativamente igualitarios, la situación cambia en el nivel secundario" (2020, p. 5). En el nivel primario, los niños y niñas migrantes se encuentran bajo formas subordinadas de inclusión. Diez nos explica que los NN

están dentro de las escuelas pero solo en determinados circuitos educativos y conviven con bajas expectativas de sus docentes sobre su desempeño, sostenidas en imágenes devaluadas sobre la escolaridad previa de ellos mismos o de sus progenitores en los países de origen. El nivel secundario, a su vez, ha mostrado dificultades en avanzar sobre la temática de la interculturalidad, lo que supondría reconocer los saberes, repertorios culturales e identitarios de los grupos de referencia de los estudiantes extranjeros, así como también de las posibles trayectorias escolares previas (Díez, 2020, p. 5).

\section{Regularización de la situación migratoria}

Como bien refieren Pinto y Ceriani Cernadas (2013), la ley 25.871 establece que las autoridades migratorias deben implementar medidas que propendan a facilitar la regularización migratoria de 
las personas. Encontramos dos programas en este sentido: (a) la regularización de la situación migratoria de ciudadanos nativos de países fuera de la órbita del Mercosur, que al 30 de junio de 2004 residan de hecho en el territorio nacional (Decreto 1169/2004) y, (b) en el año 2006, la implementación del Programa Nacional de Regularización Documentaria Migratoria, llamado 'Patria Grande', cuyo objetivo era la inserción e integración de los extranjeros residentes en forma irregular en el país provenientes de países del Mercosur y asociados que residían en Argentina antes del 17 de abril de 2006 (Decreto 578/2005 y Disposición DNM 53.253/2005 y modificatorias).

Conforme un estudio ${ }^{34}$ realizado por Cecilia Velázquez (2013), el programa 'Patria Grande'

disminuyó en un 13\% la probabilidad de tener un empleo informal vía un aumento en la probabilidad de tener derecho a jubilación y seguro de salud en el trabajo. Los grupos más beneficiados son los hombres, los más jóvenes (15 a 29 años de edad), y los inmigrantes de bajo nivel educativo (hasta primaria completa). También se encontró un impacto positivo de $7.5 \%$ del programa para los jóvenes en edad de asistir a educación secundaria, luego de Patria Grande se incrementó la probabilidad de asistir a la escuela secundaria o de haber completado el nivel (Velázquez, 2013, p. 38).

Con respecto a 'Patria Grande', Domenech (2007, p. 10) sostiene que el plan de regularización migratoria no solo se basa en las necesidades de los migrantes y sus derechos sino también en los intereses económicos del Estado argentino, recurriéndose en algunos casos a la lógica costo/beneficio.

\section{ReCAPITULACIÓN}

En el presente capítulo proporcionamos un panorama general y particular de los movimientos migratorios internacional, regional y local con el propósito de dar cuenta de la movilidad de la

\footnotetext{
${ }^{34} \mathrm{El}$ panel de datos fue construido a partir de la encuesta de hogares argentina para el período 2004 a 2010, restringiéndonos a la provincia y la ciudad de Buenos Aires. Se trabajó con una submuestra del grupo de beneficiarios potenciales, los inmigrantes de Paraguay, Bolivia y Perú; y como grupo de comparación se consideró a los argentinos que migraron recientemente de ciudad o provincia.
} 
población migrante objeto de estudio: los niños, niñas y adolescentes en edad de escolarización, dando cuenta de una tendencia estable en el desplazamiento intrarregional.

En el recorrido por la normativa internacional y regional hemos advertido la preocupación por parte de los Estados de establecer normas vinculantes que establezcan parámetros para la protección de los migrantes. A pesar de ello, encontramos situaciones de vulneraciones y violaciones a los derechos humanos que impiden el ejercicio de los derechos políticos, económicos, sociales y culturales para los migrantes. Como bien afirma Bogado Bordazar (2020), no caben dudas que el derecho a migrar es un derecho humano, al que se le aplican los principios de universalidad e inalienabilidad, indivisibilidad, interdependencia e interrelación e igualdad y no discriminación y goza, por ello, de la promoción y protección por parte de los Estados y de toda la sociedad internacional.

En el caso de Argentina, los estudios y análisis recopilados evidencian que a pesar de los Acuerdos de Estados Partes y Asociados de convalidación de títulos y diplomas de nivel primerio y secundario del Mercosur, la ley de migraciones y la ley nacional de educación, continúan existiendo dificultades a la hora de la inscripción en los establecimientos educativos y para obtener título/diploma de la escuela primaria y secundaria para los NNA en situación migratoria irregular. 
jonales

\section{residencia, 25.871 , entrat, salir y}

Latinoamérica

Mercosur.

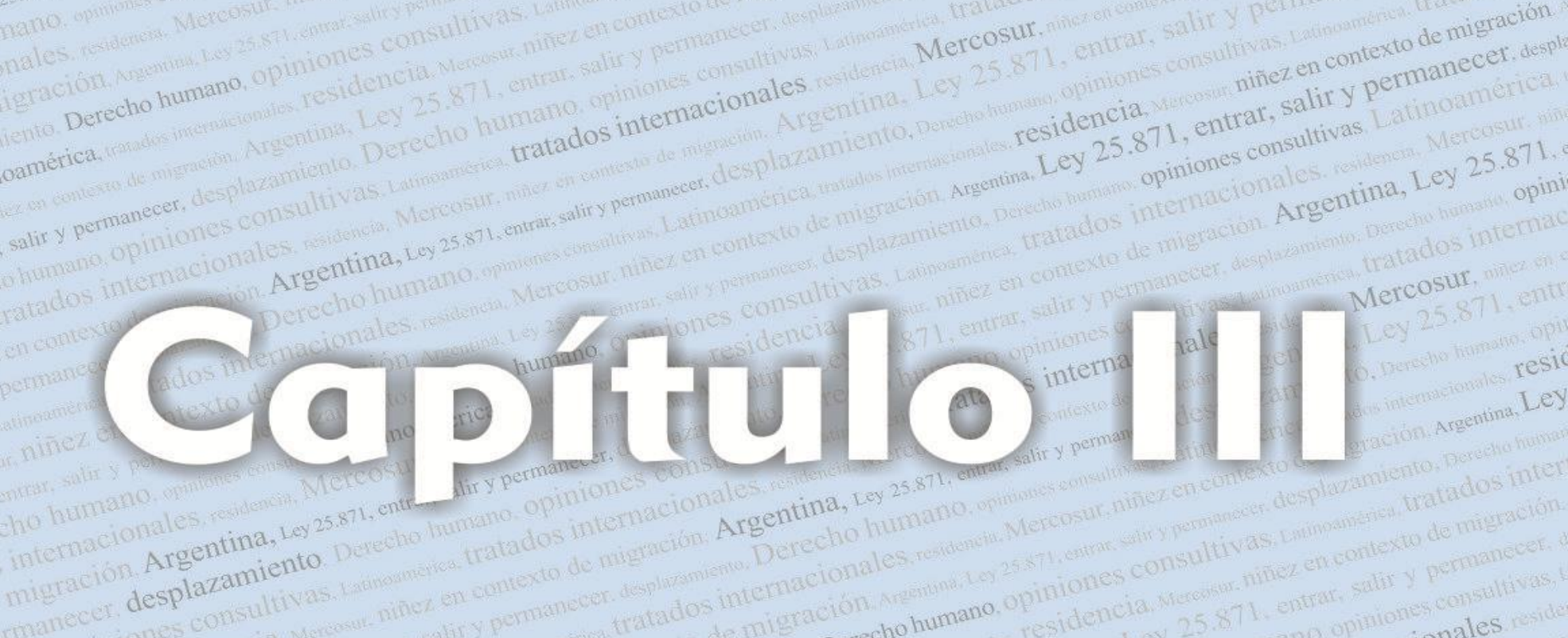




\section{Capítulo III}

\section{Derecho a la educación}

(...) la democracia es un valor fundamental de la educación en la primera infancia, de toda la educación. Con democracia me refiero a una forma de regir, por ejemplo, cómo regimos las escuelas; pero también una forma de vida y de vincularse con los demás. (...) La democracia, entendida de esta forma, se basa en escuchar y dialogar, en la diversidad y la infinidad de perspectivas, en la confrontación y la negociación; y se aprende a través de la acción, de la experiencia vivencial en lugar de ser una materia que se deba enseña.

Peter Moss (CLADE, 2018, p. 55)

Como sostienen Marchesi y Garrido (2014), la educación debe hacer frente a enormes desafíos en un mundo con profundos cambios tecnológicos y sociales entre los que destaca el desarrollo de políticas, programas y experiencias inclusivas que aseguren el derecho de los niños, niñas y adolescentes a una educación de calidad.

La educación es un derecho humano fundamental que se constituye como la garantía para la realización de otros derechos y es, a la vez, un bien social del que nadie puede ser privado porque hace posible el pleno ejercicio de la ciudadanía (CLADE, 2018).

Si bien en este capítulo nos enfocaremos en la niñez y en su derecho a una educación inclusiva, no podemos dejar de señalar que uno de los elementos que lo hace posible es el docente que puede abrir caminos posibilidades y futuros a estos niños, niñas y adolescentes. Como señala Carina Kaplan (Argentina, 2009, p. 56), "cuando la escuela se democratiza, el maestro enseña más a los que menos tienen, confía más en los que menos confían en sí mismos como consecuencia del descrédito social del que son objeto". Cuando la escuela encuentra mecanis- 
mos, discursos y docentes dispuestos a no estigmatizar a sus estudiantes, logar dar voz a los desprotegidos y les abre horizontes vitales, evitando de esta manera el ciclo de reproducción de la pobreza (Argentina, 2009).

En este capítulo continuaremos con la perspectiva multiescalar (Domenech y Pereira, 2017) que pone en relación lo local, lo nacional, lo regional y lo internacional en lo relativo a instituciones, actores, espacios y prácticas vinculados con el derecho a la educación. Proponemos un recorrido por los instrumentos vinculantes y no vinculantes más relevantes en la materia así como también de los espacios de diálogo y construcción de consensos.

\section{EL DERECHO A LA EDUCACIÓN EN EL ORDEN INTERNACIONAL}

En el Estado mundial de la infancia 2016, Anthony Lake (UNICEF, 2016) nos impulsa a enfrentar una verdad incómoda: "la vida de millones de niños están malogradas por el solo hecho de haber nacido en un país, en una comunidad, con un género o en determinadas circunstancias". Los obstáculos para llegar a esos niños y niñas son el compromiso político, los recursos y la voluntad colectiva (Lake en UNICEF, 2016).

En la escala mundial, las cifras son impactantes: el 38\% de los niños terminan la escuela primaria sin aprender a leer, escribir y hacer cálculos aritméticos simples (UNICEF, 2016). Entre 2010 y 2015, el número de niños y niñas sin escolarizar en edad de cursar primaria aumentó en 2,4 millones, llegando a un total de 59 millones (IE de la UNESCO 2015).

\section{Normativa internacional}

\section{Declaración Universal de los Derechos Humanos}

Es indispensable comenzar este apartado afirmando que fue la Carta de San Francisco (1945) la que reconoció al ser humano la titularidad de derechos y libertades fundamentales que los Estados tienen el deber de respetar y proteger. El propósito de cooperación internacional (art. 1.3) de las Naciones Unidas sirve de base para la promoción y protección universal de esos derechos del individuo y en la Carta se confieren competencias a la Asamblea General (AGNU) y al Consejo Económico y Social (ECOSOC) para crear comisiones que ayuden a hacerlos efectivos (Remiro Brotons, 1997). 
La Declaración Universal de Derechos Humanos fue un proyecto elaborado por la Comisión de Derechos Humanos que fue aprobada por la AGNU el 10 de diciembre de 1948. En ese entonces la Declaración carecía de fuerza obligatoria per se pero por el papel que desempeñó y desempeña puede afirmarse, como sostiene Remiro Brotons (1997), que los principios que consagra son reconocidos por unanimidad como Derecho internacional general.

El derecho a la educación está contemplado en el artículo 26 de la Declaración Universal:

1. Toda persona tiene derecho a la educación. La educación debe ser gratuita, al menos en lo concerniente a la instrucción elemental y fundamental. La instrucción elemental será obligatoria. La instrucción técnica y profesional habrá de ser generalizada; el acceso a los estudios superiores será igual para todos, en función de los méritos respectivos.

2. La educación tendrá por objeto el pleno desarrollo de la personalidad humana y el fortalecimiento del respeto a los derechos humanos y a las libertades fundamentales; favorecerá la comprensión, la tolerancia y la amistad entre todas las naciones y todos los grupos étnicos o religiosos, y promoverá el desarrollo de las actividades de las Naciones Unidas para el mantenimiento de la paz.

3. Los padres tendrán derecho preferente a escoger el tipo de educación que habrá de darse a sus hijos.

Del artículo surge que la educación representa un derecho humano inalienable y es el punto de partida para el desarrollo y de formación integral de la persona sin discriminación de ningún tipo. La educación debe asumir el compromiso de desarrollar en las personas una actitud respetuosa y activa en la defensa de los derechos fundamentales porque solo así podrá tener un rol activo en la construcción de una sociedad más justa e igualitaria (Trucco, 2011).

\section{Convención relativa a la lucha contra las discriminaciones en la esfera de la en- señanza}

El 14 de diciembre de 1960, la Conferencia General de la Organización de las Naciones Unidas para la Educación, la Ciencia y la Cultura (UNESCO) adoptó esta Convención que entró en vi- 
gencia el 22 de mayo de $1962^{35}$. Rescatamos como significativa la definición prevista en su artículo 1:

se entiende por "discriminación" toda distinción, exclusión, limitación o preferencia, fundada en la raza, el color, el sexo, el idioma, la religión, las opiniones políticas o de cualquier otra índole, el origen nacional o social, la posición económica o el nacimiento, que tenga por finalidad o por efecto destruir o alterar la igualdad de trato en la esfera de la enseñanza y, en especial: a. Excluir a una persona o a un grupo del acceso a los diversos grados y tipos de enseñanza; b. Limitar a un nivel inferior la educación de una persona o de un grupo; c. A reserva de lo previsto en el artículo 2 de la presente Convención, instituir o mantener sistemas o establecimientos de enseñanza separados para personas o grupos; o d. Colocar a una persona o a un grupo en una situación incompatible con la dignidad humana. 2. A los efectos de la presente Convención, la palabra "enseñanza" se refiere a la enseñanza en sus diversos tipos y grados, y comprende el acceso a la enseñanza, el nivel y la calidad de esta y las condiciones en que se da.

\section{Pacto Internacional de Derechos Económicos, Sociales y Culturales}

El proceso de redacción de un instrumento jurídicamente vinculante que consagrara los derechos mencionados en la Declaración Universal de Derechos Humanos había comenzado inmediatamente después de aprobada la misma (ACNUDH, 2016). El Pacto Internacional Derechos Económicos, Sociales y Culturales (PIDESC) fue aprobado por la Asamblea General de las Naciones Unidas el 16 de diciembre de 1966 y entró en vigencia el 3 de enero de 1976. Como sostiene Corti (2011), el Pacto se propone asegurar los derechos humanos y, para ello, obliga a los Estados a proteger, respetar y cumplir los derechos económicos, sociales y culturales, promoviendo que estos tomen medidas políticas, administrativas, legislativas, financieras, judiciales y de cualquier otra índole con el objetivo de garantizar el pleno goce de estos derechos.

Con respecto al derecho a la educación, el Pacto reitera la redacción utilizada en la Declaración Universal, pero dedica los artículos 13 y 14 a sus diferentes dimensiones, especificando la

\footnotetext{
${ }^{35}$ Son pocos los Estados latinoamericanos que a la fecha (octubre de 2020) no han ratificado o aceptado esta convención: Bolivia, Colombia, El Salvador, Haití y México.
} 
obligación de garantizar la enseñanza primaria obligatoria gratuita y la adopción de medidas para lograr la enseñanza secundaria y superior gratuitas (ACNUDH, 2016).

\section{i. $\quad$ Observaciones Generales $n^{\circ} 11$ y $n^{\circ} 13$ del Comité de Derecho Económicos, So- ciales y Culturales}

El 28 de mayo de 1985 el ECOSOC creó el Comité de Derecho Económicos, Sociales y Culturales para llevar a cabo las funciones de seguimiento asignadas a este Consejo en la Parte IV del PIDESC. Este Comité compuesto por 18 expertos independientes analiza los informes presentados por los Estados y desarrolla informes generales. En 1988 el Comité decidió publicar su interpretación de las disposiciones del Pacto, conocida como observaciones generales. Al día de hoy, lleva 25 observaciones generales publicadas sobre distintos temas del Pacto. Estas observaciones generales:

(...) tienen carácter prescriptivo para los Estados en relación al procedimiento de informes, por cuanto el Comité analizará su comportamiento frente a los derechos consagrados por el Pacto, a la luz de estas interpretaciones, y podrá entender incluso que han existido violaciones del Pacto en relación a determinados derechos (Abramovich y Courtis, 1997 en IIPE UNESCO, 2015).

Nos interesa recuperar la interpretación que el Comité hace de los artículos 13 y 14 del Pacto. En 1999, el Comité publica la Observación general n 11 que destaca:

El derecho a la educación, reconocido en los artículos 13 y 14 del Pacto, así como en otros tratados internacionales, tales como la Convención sobre los Derechos del Niño y la Convención sobre la eliminación de todas las formas de discriminación contra la mujer, es de vital importancia. Se ha clasificado de distinta manera como derecho económico, derecho social y derecho cultural. Es, todos esos derechos al mismo tiempo. También, de muchas formas, es un derecho civil y un derecho político, ya que se sitúa en el centro de la realización plena y eficaz de esos derechos. A este respecto, el derecho a la educación es el epitome de la indivisibilidad y la interdependencia de todos los derechos humanos ${ }^{36}$.

\footnotetext{
${ }^{36}$ El resaltado en nuestro.
} 
En diciembre del mismo año, el Comité analizó en su Observación $n^{\circ} 13$ el artículo 13 del Pacto. El Comité toma la definición de "enseñanza primaria" adoptado por la Declaración Mundial sobre Educación para Todos: "El principal sistema para impartir la educación básica fuera de la familia es la escuela primaria. La educación primaria debe ser universal, garantizar la satisfacción de las necesidades básicas de aprendizaje de todos los niños y tener en cuenta la cultura, las necesidades y las posibilidades de la comunidad" (art. 5). "Si bien enseñanza primaria no es sinónimo de educación básica, hay una estrecha correlación entre ambas".

En esta Observación el Comité incorpora las cuatro dimensiones del derecho a la educación: a) disponibilidad: debe haber instituciones y programas de enseñanza en cantidad suficiente en el ámbito del Estado Parte, b) accesibilidad: las instituciones y los programas de enseñanza han de ser accesibles a todos, sin discriminación, en el ámbito del Estado Parte. Comprende tres dimensiones: la no discriminación, la accesibilidad material y económica, c) aceptabilidad: la forma y el fondo de la educación, comprendidos los programas de estudio y los métodos pedagógicos, han de ser aceptables para los estudiantes y, cuando proceda, los padres, d) adaptabilidad: la educación ha de tener la flexibilidad necesaria para adaptarse a las necesidades de sociedades y comunidades en transformación y responder a las necesidades de los alumnos en contextos culturales y sociales variados.

\section{Convención sobre los Derechos del Niño}

La Convención sobre los Derecho del Niño (CDN) fue adoptada y abierta a la firma y ratificación por la Asamblea General de las Naciones Unidas el 20 de noviembre de 1989 (Resolución 44/25) y entró en vigor el 2 de septiembre de 1990. Esta Convención consolida la educación como un derecho humano de los niños, niñas y adolescentes y establece criterios sobre el funcionamiento de los sistemas educativos en los niveles inicial, básico y medio.

Dedica al derecho a la educación sus artículos 28 y 29: en el primero establece que "los Estados partes reconocen el derecho del niño a la educación", remarcando que se puede ejercer progresivamente y en condiciones de igualdad de oportunidades. Se establece como obligatoria el carácter gratuito tanto de la educación primaria como la enseñanza secundaria (IIPE UNESCO, 2015). El artículo 29 regula los fines de la educación: 
a) Desarrollar la personalidad, las aptitudes y la capacidad mental y física del niño hasta el máximo de sus posibilidades; b) Inculcar al niño el respeto de los derechos humanos y las libertades fundamentales y de los principios consagrados en la Carta de las Naciones Unidas; c) Inculcar al niño el respeto de sus padres, de su propia identidad cultural, de su idioma y sus valores, de los valores nacionales del país en que vive, del país de que sea originario y de las civilizaciones distintas de la suya; d) Preparar al niño para asumir una vida responsable en una sociedad libre, con espíritu de comprensión, paz, tolerancia, igualdad de los sexos y amistad entre todos los pueblos, grupos étnicos, nacionales y religiosos y personas de origen indígena; e) Inculcar al niño el respeto del medio ambiente natural.

Como bien señala el documento del IIPE UNESCO (2015), los derechos previstos en la Convención generan un conjunto de obligaciones para los Estados partes que impactan en la consolidación del derecho a la educación y también en la promoción de las prácticas educativas que se llevan a cabo en un ámbito de pleno ejercicio de los derechos como son el derecho a la libertad de expresión, pensamiento y conciencia religiosa, el derecho a reunirse con amigos, la protección contra toda forma de violencia, el derecho a conocer y apreciar su propia cultura, lengua y religión.

\section{Convenio $n^{\circ} 169$ de la Organización Internacional del Trabajo (OIT) sobre los Pueblos Indígenas y Tribales en Países Independientes}

Siguiendo la propuesta del documento elaborado por el IIPP UNESCO (2015), quisiéremos destacar el Convenio 169 de la OIT de 1989 que se propone eliminar las diferentes formas de discriminación en materia de educación. La parte IV del Convenio está dedicada al acceso a la educación a todos los niveles y en pie de igualdad con el resto de la comunidad nacional. La educación para los pueblos indígenas debe ser desarrollada y aplicada en cooperación con éstos y, debe responder a sus necesidades, abarcar su historia, conocimientos, sistemas de valores y demás aspiraciones sociales, económicas y culturales. (ACNUR, 2009)

El artículo 28 del Convenio dispone: 
1. Siempre que sea viable, deberá enseñarse a los niños de los pueblos interesados a leer y a escribir en su propia lengua indígena o en la lengua que más comúnmente se hable en el grupo a que pertenezcan. Cuando ello no sea viable, las autoridades competentes deberán celebrar consultas con esos pueblos con miras a la adopción de medidas que permitan alcanzar este objetivo. 2. Deberán tomarse medidas adecuadas para asegurar que esos pueblos tengan la oportunidad de llegar a dominar la lengua nacional o una de las lenguas oficiales del país. 3. Deberán adoptarse disposiciones para preservar las lenguas indígenas de los pueblos interesados y promover el desarrollo y la práctica de las mismas.

\section{Otros}

i. Conferencia Mundial sobre la Educación para Todos y su Marco de acción

Ya en el ámbito de los textos con carácter no vinculante, nos encontramos con la Declaración y el Marco de acción para satisfacer las necesidades básicas de aprendizaje que fueron aprobados en el marco de la Conferencia Mundial sobre la Educación para Todos que se llevó a cabo del 5 al 9 marzo de 1990 en Jomtien, Tailandia. Esta Conferencia fue organizada por la Unesco, Unicef, el Programa de las Naciones Unidas para el Desarrollo (PNUD) y el Banco Mundial.

En el artículo 1.1 de la Declaración Mundial sobre la Educación para Todos ya se fija el alcance de las "necesidades básicas de aprendizaje":

Cada persona - niño, joven o adulto- deberá estar en condiciones de aprovechar las oportunidades educativas ofrecidas para satisfacer sus necesidades básicas de aprendizaje. Estas necesidades abarcan tanto las herramientas esenciales para el aprendizaje (como la lectura y la escritura, la expresión oral, el cálculo, la solución de problemas) como los contenidos básicos del aprendizaje (conocimientos teóricos y prácticos, valores y actitudes), necesarios para que los seres humanos puedan sobrevivir, desarrollar plenamente sus capacidades, vivir y trabajar con dignidad, participar plenamente en el desarrollo, mejorar su calidad de vida, tomar decisiones fundamentadas y continuar aprendiendo. 
Como sostiene Haggins (1992), la rapidez del cambio tecnológico y social en todo el mundo están cediendo el paso a un concepto de la educación centrado en la necesidad de "aprender a aprender", dando por supuesto que el aprendizaje es un proceso que dura toda la vida.

Uno de los objetivos de la educación es la transmisión y enriquecimiento de los valores culturales comunes así como el desarrollo cultural y la salvaguardia de la identidad y de las tradiciones culturales. Estos configuran desafíos así como también la necesidad de creación de un ambiente en las escuelas y otras instituciones educativas que facilite la transmisión de la cultura con un criterio positivo y refuerce su naturaleza dinámica (Haggins, 1992).

La Educación para Todos requiere un examen de las necesidades lingüísticas desde el nivel comunitario hasta el nivel nacional. Si bien la alfabetización en la lengua materna, o "casi materna", puede servir muy bien de base para el aprendizaje inicial, es posible que la enseñanza subsiguiente deba realizarse en idiomas nacionales o internacionales, especialmente para evitar los peligros de aislamiento social, cultural y económico. Otro problema que es preciso resolver es el del desarrollo de políticas lingüísticas durables para el enorme número de refugiados y personas desplazadas en todo el mundo (Haggins, 1992, p. 104).

A casi 40 años del artículo 26 de la Declaración Universal, la Conferencia Mundial de Educación para Todos fue una gran oportunidad para identificar y emprender iniciativas destinadas a atender las diversas necesidades de aprendizaje de las personas de todas las edades.

\section{ii. $\quad$ Foro Mundial sobre la Educación en 2000 y 2015}

Otro espacio de actuación de la sociedad civil, de los gobiernos y de las organizaciones internacionales, lo encontramos en el Foro Mundial sobre la Educación que tuvo lugar en Dakar, Senegal en abril del año 2000, diez años después de la Declaración Mundial sobre la Educación para Todos y, en mayo de 2015 en Incheon, Corea.

El Foro de Dakar tenía como propósito presentar los resultados globales de la evaluación de la década de «Educación para Todos» y aprobar un nuevo Marco de Acción, fundamentalmente para continuar la tarea. El Marco de Acción aprobado en Dakar esencialmente «reafirma» la visión y las metas acordadas en Jomtien en 1990 y reafirman el compromiso de lograr la edu- 
cación pata todos en el año 2015. Como sostiene Torres (2001), mientras que en Jomtien la noción de educación básica dejaba abierta la posibilidad de incluir dentro de ésta la educación secundaria, en Dakar el tope es claramente la escuela primaria, aunque el tema de la equidad de género se extiende al ámbito de la educación secundaria.

Al igual que en Jomtien, se identificaron seis metas en Dakar que, como sostiene Torres (2001), son esencialmente una ratificación de las metas acordadas diez años atrás aunque hay variaciones de contenido y de forma:

esta vez se habla de la educación como un derecho y se enfatiza expresamente la gratuidad, obligatoriedad y calidad de la escuela primaria; se recuerda que los resultados de aprendizaje deben ser visibles y medibles; se pone mayor énfasis en la eliminación de las disparidades de género tanto en la educación primaria como secundaria, teniendo como referente a la niña; y se pide que la educación de adultos se integre de lleno a los sistemas educativos nacionales (Torres, 2001).

En 2015 se llevó a cabo un nuevo Foro Mundial de Educación en el que se aprueba la Declaración de Incheon donde se promueve que:

se proporcione educación primaria y secundaria de calidad, equitativa, gratuita y financiada con fondos públicos, durante 12 años, de los cuales al menos nueve serán obligatorios, consiguiendo así resultados de aprendizaje pertinentes. Alentamos también a que se imparta al menos un año de enseñanza preescolar de calidad, gratuita y obligatoria y a que todos los niños tengan acceso a una educación, atención y desarrollo de la primera infancia de calidad (párrafo 6 de la Declaración).

\section{iii. $\quad$ El Objetivo de Desarrollo Sostenible (ODS) 4}

El Objetivo de Desarrollo Sostenible 4 se propone Garantizar una educación inclusiva, equitativa y de calidad y promover oportunidades de aprendizaje durante toda la vida para todos. Las metas del ODS 4 que conciernen a nuestra investigación son: 
4.1 De aquí a 2030, asegurar que todas las niñas y todos los niños terminen la enseñanza primaria y secundaria, que ha de ser gratuita, equitativa y de calidad y producir resultados de aprendizaje pertinentes y efectivos.

4.2 De aquí a 2030, asegurar que todas las niñas y todos los niños tengan acceso a servicios de atención y desarrollo en la primera infancia y educación preescolar de calidad, a fin de que estén preparados para la enseñanza primaria

4.5 De aquí a 2030, eliminar las disparidades de género en la educación y asegurar el acceso igualitario a todos los niveles de la enseñanza y la formación profesional para las personas vulnerables, incluidas las personas con discapacidad, los pueblos indígenas y los niños en situaciones de vulnerabilidad.

4.7 De aquí a 2030, asegurar que todos los alumnos adquieran los conocimientos teóricos y prácticos necesarios para promover el desarrollo sostenible, entre otras cosas mediante la educación para el desarrollo sostenible y los estilos de vida sostenibles, los derechos humanos, la igualdad de género, la promoción de una cultura de paz y no violencia, la ciudadanía mundial y la valoración de la diversidad cultural y la contribución de la cultura al desarrollo sostenible

4.a Construir y adecuar instalaciones educativas que tengan en cuenta las necesidades de los niños y las personas con discapacidad y las diferencias de género, y que ofrezcan entornos de aprendizaje seguros, no violentos, inclusivos y eficaces para todos.

Al finalizar el ciclo lectivo 2018, según informa el Instituto de Estadística de la UNESCO $(\mathrm{IEU})^{37}$, alrededor de 258 millones de niños, niñas y adolescentes aún estaban fuera de la escue$\mathrm{la}^{38}$, lo que representa cerca de una quinta parte de la población mundial de ese grupo de edad. Más de la mitad de todos los NNA de todo el mundo no están alcanzando los estándares mínimos de competencia en lectura y matemáticas. Si esta situación continúa, se proyecta que un niño de cada diez de entre 6 y 17 años de edad no estará escolarizado en 2030.

\footnotetext{
${ }^{37}$ Información disponible en: http://uis.unesco.org/fr/topic/enfants-et-jeunes-non-scolarises [Consultado: 18/11/2020]

${ }^{38}$ Sobre un total de 59 millones de niños en edad de asistir a la escuela primaria, 62 millones en edad de asistir el primer ciclo de la escuela secundaria y 138 millones de niños en edad de asistir el segundo ciclo de la escuela secundaria. Información disponible en: http://uis.unesco.org/fr/topic/enfants-et-jeunes-non-scolarises [Consultado: 18/11/2020]
} 
Según el Informe de seguimiento de la Educación en el Mundo 2019 (UNESCO, 2018), la tasa de asistencia a la escuela primaria no ha cambiado prácticamente desde el año 2008. Para lograr la finalización universal de la educación secundaria en 2030, "todos los niños de la cohorte 2018 deben ingresar en la escuela primaria a tiempo" (UNESCO, 2018, p. 51).

\section{EL DERECHO A LA EDUCACIÓN EN AMÉRICA LATINA Y EL CARIBE}

En catorce de los dieciocho países de la región latinoamericana considerados ${ }^{39}$ más del $97 \%$ de los niños y niñas de 6 a 11 años han completado el nivel de la educación primaria. El nivel primario forma parte de la educación básica y es el segundo tramo educativo de los sistemas nacionales de educación de la región. El nivel primario abarca a los niños y niñas de entre 6 y 12 años. Este grupo poblacional representa el $12 \%$ de la población total latinoamericana, es decir 74,5 millones de niñas y niños (SITEAL, 2019).

Las tasas de analfabetismo presentan variaciones importantes entre los países de América Latina y el Caribe. Del total de la región, cuatro países registran tasas de analfabetismo menores o iguales al 5\%; seis tienen tasas entre el 5\% y el 10\%; cinco alcanzan porcentajes de analfabetismo entre el $10 \%$ y el $20 \%$; y tres presentan tasas iguales o superiores al $20 \%$. Es decir, mientras que en Cuba, Argentina, Chile y Costa Rica se ha logrado alfabetizar a casi el total de la población, en Nicaragua y El Salvador alrededor de una quinta parte de la población es analfabeta, y en Guatemala, casi un tercio de la población se encuentra en esta situación (LLECE, 2008).

Conforme surge del Segundo Informe regional comparativo y explicativo (LLECE, 2008), los sistemas educativos de la región latinoamericana tienen en su organización y estructuras analogías pero también grandes variaciones a tal punto que se afirma que de los diecinueve países de la región no hay dos que posean la misma estructura.

La enseñanza primaria es obligatoria en toda América Latina y el Caribe y cada vez hay más Estados que incluyen la educación secundaria inferior en su régimen obligatorio. Argentina y Chile son los países que presentan la media más alta de educación obligatoria (13 años), México y Perú siguen con 12 años.

\footnotetext{
${ }^{39}$ Países latinoamericanos considerados en el Documento de SubEje: Argentina, Bolivia, Brasil, Chile, Colombia, Costa Rica, Cuba, Ecuador, El Salvador, Guatemala, Honduras, México, Nicaragua, Panamá, Paraguay, Perú, República Dominicana, Uruguay y Venezuela.
} 
Solo Colombia, Nicaragua, Paraguay y República Dominicana presentan tasas netas de matrícula en educación primaria inferiores a 90\%. Mientras que en Argentina, Ecuador, México y Panamá la totalidad de los estudiantes en edad oficial de cursar la primaria asisten a la escuela. En promedio, el 75,4\% de los niños y las niñas de la región en edad de ingresar en la primaria lo hacen oportunamente. Es posible encontrar el 100\% de cobertura oportuna en primer grado en Cuba y Argentina, y algo menos del 50\% en Nicaragua (LLECE, 2008).

Desde el punto de vista de las legislaciones latinoamericanas vigentes que regulan el derecho a la educación, podemos destacar que, de una manera u otra, todas se refieren a la educación como un derecho humano y el Estados es el garante, estableciendo cómo se materializa esta función de garantía. Se pueden identificar tres formas distintas en que el Estado asume la función de garante de este derecho: en un primer momento, la normativa no contenía un referencia explícita sino que se expresaba de manera imprecisa esta obligación del Estado; recién en los años noventa aparece de forma explícita la garantía estatal del derecho a la educación; en la normativa de Brasil (1996) se suma a la descripción de las obligaciones estatales la idea de su exigibilidad, siendo este país el único que lo hace en forma expresa y en la legislación de Ecuador (2012), se operacionaliza la noción de garantía y se detallan los alcances de esta función (IIPE UNESCO, 2015).

\section{Normativa regional}

\section{Declaración Americana de los Derechos y Deberes del Hombre}

En el ámbito del continente americano nos encontramos, en primer lugar, con el texto de la Declaración Americana de los Derechos y Deberes del Hombre (DADDH) que fue aprobada el 2 de mayo de 1948 junto con la Carta de Bogotá que dio nacimiento a la Organización de Estados Americanos (OEA).

La Declaración comprende una amplia gama de prerrogativas y libertades y determina la interdependencia e indivisibilidad de los derechos humanos. Con el paso del tiempo y en la actualidad, la Declaración ha devenido de observancia inexcusable para todos los Estados Parte de la OEA que de esta manera se encuentran sometidos, al menos, a un instrumento de derechos humanos en el sistema interamericano (Rodríguez, 2011). 
El derecho a la educación está contemplado en el artículo 12 de la DADDH. Surge de este texto que toda persona tiene un derecho fundamental a educarse teniendo garantizada, por lo menos, la gratuidad de la educación primaria. La educación capacita a las personas para que puedan lograr una subsistencia digna, mejoren el nivel de vida y pueda aportar a la construcción de la sociedad.

Como sostiene Rodríguez (2011, p. 150), "la Declaración Americana y la Declaración Universal contemplan tres aspectos diferentes de la educación: el acceso, el contenido y la preferencia. El Pacto Internacional afirma conceptos similares aunque añade el componente de la promoción de la educación para adultos y las becas.”

\section{Convención Americana sobre Derechos Humanos}

La Convención Americana sobre Derechos Humanos (CADH), también llamada Pacto de San José de Costa Rica, fue adoptada y firmada el 22 de noviembre de 1969 y entró en vigencia el 18 de julio de 1978. La Convención cuenta con dos protocolos adicionales. El Protocolo Adicional en Materia de Derechos Económicos, Sociales y Culturales o "Protocolo de San Salvador", adoptado el 17 de noviembre de 1988 y entró en vigor el 16 de noviembre de 1999. Y el Protocolo relativo a la Abolición de la Pena de Muerte que fue suscrito el 8 de junio de $1990^{40}$. La Convención es un tratado internacional vinculante que actualmente obliga a 23 Estados americanos ${ }^{41}$.

Debemos leer de manera conjunta los artículos 19 y 26 de la CADH. Por su parte, el art. 19 establece que "todo niño tiene derecho a las medidas de protección que su condición de menor requieren por parte de su familia, de la sociedad y del Estado." Este derecho, junto a otros, no es susceptible de suspensión lo que implica que está protegido por normas imperativas de Derecho internacional de los derechos humanos.Y el artículo 26 insta a los Estados a promover el desarrollo progresivo "de los derechos que se derivan de las normas económicas, sociales y

\footnotetext{
40 Información consultada en la página oficial de la Corte Interamericana de Derechos Humanos: https://www.corteidh.or.cr/que_es_la_corte.cfm, el 23 de octubre de 2020.

${ }^{41}$ Estos estados son: Argentina, Barbados, Bolivia, Brasil, Chile, Colombia, Costa Rica, Dominica, Ecuador, El Salvador, Granada, Guatemala, Haití, Honduras, Jamaica, México, Nicaragua, Panamá, Paraguay, Perú, República Dominicana, Surinam y Uruguay.

Venezuela y Trinidad y Togado denunciaron la Convención en 2012 y en 1998, respetivamente.
} 
sobre educación, ciencia y cultura, contenidas en la Carta de la Organización de los Estados Americanos, reformada por el Protocolo de Buenos Aires" en la medida de sus posibilidades.

El Protocolo de San Salvador viene a individualizar los derechos económicos, sociales y culturales. En su artículo 13 contempla el derecho a la educación. Es más amplio que la DADDH en el sentido que establece que el derecho a la educación "deberá orientarse hacia el pleno desarrollo de la personalidad humana y del sentido de su dignidad y deberá fortalecer el respeto por los derechos humanos, el pluralismo ideológico, las libertades fundamentales, la justicia y la paz”. Destacamos que el inciso 3 establece:

a. la enseñanza primaria debe ser obligatoria y asequible a todos gratuitamente; (...) c. la enseñanza superior debe hacerse igualmente accesible a todos, sobre la base de la capacidad de cada uno, por cuantos medios sean apropiados y en particular, por la implantación progresiva de la enseñanza gratuita; $d$. se deberá fomentar o intensificar, en la medida de lo posible, la educación básica para aquellas personas que no hayan recibido o terminado el ciclo completo de instrucción primaria; e. se deberán establecer programas de enseñanza diferenciada para los minusválidos a fin de proporcionar una especial instrucción y formación a personas con impedimentos físicos o deficiencias mentales (...).

\section{Otros}

En este apartado analizaremos diversas instancias de reflexión y construcción de la educación como derecho humano fundamental en la región latinoamericana.

\section{i. $\quad$ Compromiso de las Américas}

Las Cumbres de las Américas es un espacio que reúne a los Jefes de Estado y de Gobierno de los Estados Miembros del continente americano para debatir sobre aspectos políticos compartidos, afirmar valores comunes y comprometerse a acciones concertadas a nivel nacional y regional con el fin de hacer frente a desafíos presentes y futuros que enfrentan los países de la región. Hasta el momento se han celebrado diez Cumbres, ocho ordinarias y dos extraordinarias ${ }^{42}$.

\footnotetext{
${ }^{42}$ Información disponible en http://www.summit-americas.org/defaults.htm [consultada el 23 de octubre 2020].
} 
En el marco de las Cumbres se organizaron numerosas reuniones ministeriales con el propósito de permitir un efectivo seguimiento de los mandatos de las Cumbres en cada una de las áreas -agricultura, comercio, trabajo, educación, desarrollo sostenible, salud, etc.-, así como de generar ámbitos propicios para el intercambio y el logro de acuerdos regionales en las distintas carteras (Feldfeber et al., 2005). En el ámbito educativo, se realizaron reuniones ministeriales en el marco del Consejo Interamericano para el Desarrollo Integral: I reunión en 1998 en Brasil, la II reunión en 2001 en Uruguay, la III reunión en 2003 en México, la IV en 2005 en Trinidad y Tobago, la V en 2007 en Colombia, la VI en 2009 en Ecuador, la VII en 2012 en Suriname, la VIII en 2015 en Panamá y la IX en 2017 en Bahamas ${ }^{43}$.

Feldfeber, Saforcada y Jaimovich (2005) afirman que la educación ha ocupado diversas posiciones en las Declaraciones finales de las Cumbres. Estos autores analizan la I Cumbre realizada en Miami en 1994, la II Cumbre que tuvo lugar en Santiago de Chile en 1998, la III Cumbre en Quebec en 2001 y la Cumbre extraordinaria llevada a cabo en Monterrey en 2005. En este proceso de Cumbre en un primer momento, la educación fue considerada como un servicio comercial más y lo vemos claro en acciones relacionadas con la capacitación de recursos humanos, la economía global del conocimiento y el desarrollo de capacidades que aseguren la competitividad y la productividad. Por otro lado, las Cumbres impulsan acuerdos en los que la educación se centra en ciertas problemáticas como la discriminación o la pobreza sin integrase a un proyecto social más amplio.

Sin embargo, como sostienen Feldfeber, Saforcada y Jaimovich (2005),

en la Cumbre de Quebec comienza a enfatizarse una línea de política que intenta recuperar un mayor espacio para las políticas sociales. Los compromisos y responsabilidades que los Estados asumen ya no son definidos exclusivamente en términos económicos, ni se reducen a la atención de grupos prioritarios, sino que se expresa una preocupación por garantizar mayores niveles de igualdad. Las líneas anteriores de mercantilización y focalización de la educación se sostienen, pero se articulan con este nuevo discurso (2005, p. 21).

\footnotetext{
${ }^{43}$ Información disponible en http://www.oas.org/es/cidi/ministros educacion.asp [consultada el 15 de noviembre de 2020].
} 
Si avanzamos en poco en el tiempo, nos encontramos con la IX Reunión Interamericana de Ministros de Educación llevada a cabo los días 9 y 10 de febrero de 2017 en Nassau, Bahamas donde fue adoptada la Declaración titulada "La Agenda Educativa Interamericana: Construyendo alianzas y avanzando hacia los objetivos del desarrollo sostenible”. Esta reunión ministerial adopta y crea la Agenda Educativa Interamericana (AEI) que había sido encomendada en 2015 a la Comisión Interamericana de Educación (CIE). Con esta AEI, "los Estados Miembros de la OEA están expresando claramente su compromiso con los objetivos y metas globales ya establecidos y definiendo acciones hemisféricas específicas que apoyarán su exitosa implementación" (OEA, 2018, p. 145).

Con el propósito de contribuir a alcanzar las metas del ODS 4, esta Agenda brindará su apoyo a los Estados parte de la OEA, que así lo solicitaren, para avanzar en tres áreas prioritarias: 1) educación de calidad, inclusiva y con equidad, 2) fortalecimiento de la profesión docente y 3) atención integral a la primera infancia. Esta Agenda será implementada por un período de cinco años (a partir de 2017) y luego será revisada por los Estados Parte.

En el marco de la VII Cumbre de las Américas se adopta el 14 de abril de 2018, se adopta el Compromiso de Lima titulado "Gobernabilidad democrática frente a la corrupción" donde encontramos dos párrafos dedicados a la educación: promueve la iniciativa hemisférica de la Agenda Educativa Interamericana bajo el respeto a la diversidad regional y el desarrollo de

una cultura de transparencia, participación ciudadana y prevención de la corrupción para el fortalecimiento de los valores democráticos y cívicos desde la primera infancia y a lo largo de toda la vida, implementando programas de enseñanza y aprendizaje en los diferentes niveles de los sistemas educativos, así como programas de educación continua (Compromiso de Lima, 2018, párrafo 4).

\section{ii. Metas Educativas 2021 de la OEI}

En diciembre del año 2010 la Organización de Estados Iberoamericanos (OEI) aprobó las Metas Educativas 2021: "la educación que queremos para la generación de los Bicentenarios" en el 
marco de la XX Cumbre Iberoamericana de Jefes de Estado y de Gobierno celebrada en la ciudad de Mar del Plata, Argentina.

Entre estas Metas destacamos la meta específica 2 "garantizar el acceso y la permanencia de todos los niños en el sistema educativo mediante la puesta en marcha de programas de apoyo y desarrollo de las familias para favorecer la permanencia de sus hijos en la escuela", la meta específica 8 "asegurar la escolarización de todos los niños en la educación primaria y en la educación secundaria básica en condiciones satisfactorias", la meta específica 14 "ampliar el número de las escuelas de tiempo completo en primaria" y la meta específica 20 "mejorar la formación inicial del profesorado de primaria y de secundaria" (OEI, 2010).

En el marco del Proyecto Metas Educativas 2021, se creó el Instituto de Evaluación de la OEI (IESME) cuyo objetivo fundamental fue el seguimiento del conjunto de indicadores definidos en las Metas. Desde 2011 publica anualmente el Informe Miradas donde se hace una revisión de los indicadores de las Metas 2021. El Informe de 2018 da cuenta de dos procesos simultáneos: 1) continuar con el seguimiento de las Metas 2021, mejorando los indicadores existentes, 2), iniciar la reflexión y el debate que hagan posible la definición, la concreción y el acuerdo sobre las Metas para la década 2021-2030, en el marco de los ODS, buscando establecer las sinergias con los compromisos definidos en la agenda educativa internacional (OEI, 2018).

\section{iii. Reunión Regional de Ministros y Ministras de Educación de América Latina y el Caribe | Declaración de Lima de 2014 y de Buenos Aires de 2017}

En la Reunión de Ministros y Ministras de Educación de América Latina y el Caribe (ALC) 1levada a cabo los días 30 y 31 de octubre de 2014 llamada "Educación para Todos (EPT) en América Latina y el Caribe: balance y desafíos post-2015” se adoptó la Declaración de Lima. Entre las áreas prioritarias para ALC, la Declaración insta a asegurar un acceso inclusivo y equitativo al aprendizaje de calidad para todos, niños, niñas, jóvenes y personas adultas, en todos los niveles del sistema educativo, desde la primera infancia, hasta la educación terciaria y superior. Se recomienda "la provisión de al menos doce años de educación formal gratuita, obligatoria y de calidad para todos/as al 2030, de los cuales al menos uno debe ser de educación preprimaria" (Declaración de Lima, 2014, párrafo 11). 
Asimismo, en su párrafo diez, se destaca la interculturalidad como un aspecto indispensable de la educación de calidad. Es sistema escolar requiere del apoyo de las familias, las organizaciones sociales, las comunidades y los medios de comunicación, y que todos ellos asuman la responsabilidad educativa.

Ya en el marco del proceso de seguimiento a la implementación de la Agenda 2030, los ministerios de educación de la región de ALC, reunidos en la ciudad de Buenos Aires, los días 24 y 25 de enero de 2017, adoptaron la Declaración de Buenos Aires donde reafirman que:

el principio rector de la agenda educativa al 2030 debe ser velar por que todas las niñas y todos los niños terminen los ciclos de la enseñanza primaria y secundaria, que ha de ser gratuita, equitativa y de calidad, y producir resultados escolares pertinentes y eficaces (Declaración de Buenos Aires, 2017, preámbulo).

En su párrafo 16 se reconoce el carácter multicultural y plurilingüe de la región y que se requiere de un enfoque propio que refuerce esa diversidad para que los pueblos puedan enfrentar los desafíos que se presenten. Proponen una educación multicultural con énfasis en la educación en lengua materna y el aprendizaje de una segunda lengua.

\section{iv. Opinión Consultiva OC-17/02 de la Corte Interamericana de Derechos Humanos}

El 28 de agosto de 2002 la Corte Interamericana de Derechos Humanos (CIDH) emitió, en ejercicio de su función consultiva, a pedido de la Comisión Interamericana de Derechos Humanos, la Opinión Consultiva 17 a la que denominó "Condición Jurídica y Derechos Humanos del Niño".

Esta opinión consultiva es de gran importancia porque por primera vez la Corte reconoció que los niños son titulares de derecho y no solo objeto de protección y que "la verdadera y plena protección de los niños significa que éstos puedan disfrutar ampliamente de todos sus derechos, entre ellos los económicos, sociales y culturales, que les asignan diversos instrumentos internacionales" (OC-17/02, párrafo 8, página 86).

Nos interesa destacar de esta opinión consultiva las afirmaciones de la Corte contenidas en los párrafos 84 y 44: el derecho a la educación tiene un rol destacado en el artículo 19 de la 
Convención Americana porque favorece la posibilidad de gozar de una vida digna y colabora en prevenir situaciones desfavorables para el menor y para la sociedad. Es efectivamente a través de la educación que gradualmente se supera la vulnerabilidad de los niños.

El juez Antônio A. Cançado Trindade acompañó a la opinión consultiva con un voto concurrente en el que sostiene que no basta con afirmar que el niño es sujeto de derecho, es fundamental que él lo sepa y, de allí, surge la gran importancia de la educación en general y de la educación en derechos humanos en particular. El juez manifiesta que "todo niño tiene efectivamente el derecho de crear y desarrollar su propio proyecto de vida. A mi juicio, la adquisición del conocimiento es una forma - quizás la más eficaz - de emancipación humana, e imprescindible para la salvaguarda de los derechos inherentes a todo ser humano" (párrafo 52 de su voto concurrente).

\section{El DeRECHO a la EdUCACión EN EL ÁMbito del MerCosur}

La educación como variable integradora fue incluida de manera temprana en el Mercosur cuando, desde los ministerios de educación de la región, se propone la creación de la Reunión de Ministros de Educación ${ }^{44}$ la cual que se concretó en enero de1992 y funciona en el ámbito del Consejo del Mercado Común (CMC). Es así que la agenda educativa va tomando forma y adopta una estructura institucional específica que se denominó "Sector Educativo del Mercosur" (SEM) o "Mercosur educativo".

Como sostiene Piñón (1998), para que el proceso de integración sea efectivo debe contemplar la totalidad de sus elementos constitutivos: allí la educación debe tener un papel central en las estrategias de desarrollo. Destaca este autor la importancia de llevar a cabo amplios acuerdos nacionales para afrontar la transformación educativa que involucre a todos los actores, los sectores y agencias vinculados al desarrollo educativo permitiendo así nuevas coaliciones que propendan a las coordinación de iniciativas (Piñón, 1998).

Terigi (2009) nos advierte que la estadística educativa que llevan los países de la región no cuenta con ninguna herramienta consolidada que permita realizar el seguimiento de las trayectorias escolares porque se contabilizan sujetos pero ellos no son el foco de información.

\footnotetext{
${ }^{44}$ Se institucionalizó con la Decisión del CMC N ${ }^{\circ}$ 7/91.
} 
La autora identifica como prioridad de la política educativa de la región el ciclo de alfabetización de la escuela primaria porque "el análisis de las trayectorias escolares muestra que las primeras detenciones e interrupciones se experimentan en los primeros grados de ese nivel, bajo las formas de repitencia reiterada y de aprendizajes poco consolidados que producen una base endeble para la trayectoria de los niños y niñas concernidos" (Terigi, 2009, p. 46).

Desde el Mercosur educativo contamos con información estadística elaborada por la Dirección Nacional de Información y Evaluación de la Calidad Educativa del Ministerio de Educación de la Nación Argentina para el año 2012.

\begin{tabular}{|c|c|}
\hline Tasa & Primario \\
\hline \multicolumn{2}{|c|}{ Tasa de aprobación } \\
\hline Argenina & 94,9 \\
\hline Brasil & 91,7 \\
\hline Chile & 94,9 \\
\hline Paraguay & 92,2 \\
\hline Uruguay & 95,1 \\
\hline \multicolumn{2}{|c|}{ Tasa de reprobación } \\
\hline Argenina & 4,2 \\
\hline Brasil & 6,9 \\
\hline Chile & 3,9 \\
\hline Paraguay & 4,3 \\
\hline Uruguay & 4,9 \\
\hline \multicolumn{2}{|c|}{ Tasa de abandono } \\
\hline Argenina & 0,8 \\
\hline Brasil & 1,4 \\
\hline Chile & 1,1 \\
\hline Paraguay & 3,6 \\
\hline Uruguay & 0,0 \\
\hline
\end{tabular}

Tabla n. ${ }^{\circ}$ 6. Tasa de aprobación, reprobación y abandono en el nivel primario Fuente: elaborado a partir de información estadística para el Mercosur educativo (Argentina, 2012).

En el próximo aparatado haremos una recorrida por las decisiones más relevante en materia de educación en el nivel primario y determinaremos qué espacio ocupa la misma en los planes de acción del Mercosur educativo y definiremos la estructura orgánica del SEM.

\section{El Sector Educativo del Mercosur}

Comenzaremos con un recorrido por la normativa mercosureña relevante para el nivel de la enseñanza primaria. En primer lugar, encontramos el Protocolo de integración educativa y reco- 
nocimiento de certificados, títulos y estudios de nivel primario y medio no técnico firmado por los Estados Partes del bloque el 4 de agosto de 1994. Conforme a su artículo 10 "Los Estados Partes reconocerán los estudios de educación primaria y media no técnica y otorgarán validez a los certificados que los acrediten expedidos por las instituciones oficialmente reconocidas por cada uno de los Estados Partes, en las mismas condiciones que el país origen establece para los cursantes o egresados de dichas instituciones" promoviendo de esta forma la continuidad de los estudios de los migrantes en dichos niveles. Asimismo se creó como anexo al Protocolo una Tabla de Equivalencias que deberá ser actualizada ante el cambio del sistema educativo en los Estados Partes. La última actualización de la Tabla de Equivalencias es del año $2015^{45}$.

Argentina aprobó el Protocolo de integración educativa en 1996 a través de la promulgación de la Ley 24.676. Paraguay y Uruguay lo hicieron en 1995 y Brasil en 1998. En el año 2002, los Estados Partes del Mercosur firman un Protocolo ${ }^{46}$ de las mismas características con la República Bolivia y la República de Chile al que se adhiere la República de Ecuador en el año $2008^{47}$.

En el año 2006 del Consejo Mercado Común aprobó el Mecanismo de Implementación del Protocolo de integración educativa ${ }^{48}$. Entre sus disposiciones el Mecanismo prevé: la adopción de criterios flexibles acerca de la documentación de identidad necesaria a los efectos de la continuación de estudios de educación básica, aceptando la documentación de identidad del país de origen, hasta tanto concluya los trámites relativos a la documentación migratoria; eliminación de la exigencia de traducción para la documentación relativa a estudios cursados en los países del bloque; la admisión del alumno con estudios incompletos hasta el inicio del último periodo lectivo de cada país con la finalidad que el educando este escolarizado; la facilitación de la movilidad de los estudiantes en edad escolar teniendo en cuenta los 12 años de escolarización, siempre y cuando el sistema educativo al que se incorpore tenga esta duración; entre otras cuestiones.

\footnotetext{
${ }^{45}$ MERCOSUR/RME/XXV CTR DE PROTOCOLO/Acta N ${ }^{\circ}$ 01/15 Anexo X

${ }^{46}$ MERCOSUR/CMC/DEC. $\mathrm{N}^{\circ}$ 26/02

${ }^{47}$ MERCOSUR/CMC/DEC. $\mathrm{N}^{\circ}$ 20/08

${ }^{48}$ MERCOSUR/CMC/DEC. N $^{\circ}$ 06/06
} 
En la misma dirección, se firmó tres años antes, en 2003, el Acuerdo por canje de notas sobre simplificación de legalizaciones en documentos públicos entre la República Argentina y la República Federativa del Brasil. Según este acuerdo las partes eximirán de toda forma de intervención consular a la legalización de los documentos públicos contemplados en el punto 1) del acuerdo, a saber: a) Los documentos administrativos emitidos por un funcionario público en ejercicio de sus funciones. b) Las escrituras públicas y actos notariales. c) Las certificaciones oficiales de firma o de fecha que figuren en documentos privados. La única formalidad exigible es la intervención gratuita de las autoridades centrales de ambos países, esto es las Cancillerías, no siendo necesaria la intervención consular posterior.

El CMC adopta en el año 2007 el Convenio Complementario de Cooperación entre los Estados Partes del Mercosur y el Convenio Andrés Bello ${ }^{49}$ sobre reconocimiento de estudios, títulos y certificados de educación primaria/básica y media/secundaria no técnica. La inclusión social y escolar es un derecho fundamental de todos los niños y jóvenes por lo que resulta necesario adoptar las medidas necesarias para garantizar el acceso y la permanencia de los estudiantes en los distintos sistemas educativos. Conforme al artículo 1 del Convenio, los países reconocerán los estudios, títulos y certificados de los niveles señalados y les otorgarán validez en las mismas condiciones establecidas para los cursantes o egresados de sus respectivos países, sobre la base de una tabla de equivalencias acordada y los ajustes que fueran necesarios para su implementación.

\footnotetext{
${ }^{49}$ La Organización del Convenio Andrés Bello de Integración Educativa, Científica, Tecnológica y Cultural, es un organismo intergubernamental, con personería jurídica internacional, creado en virtud del Tratado suscrito en Bogotá, el 31 de enero de 1970, sustituido en Madrid en 1990. Los países que conforman la Organización del Convenio Andrés Bello son: Bolivia, Chile, Colombia, Cuba, Ecuador, España, México, Panamá, Paraguay, Perú, República Dominicana y Venezuela. Información disponible en: http://convenioandresbello.org/cab/que-es-el-cab/ [Consultado el 3/11/2020]
} 


\section{Organización del sistema educativo en el Mercosur}

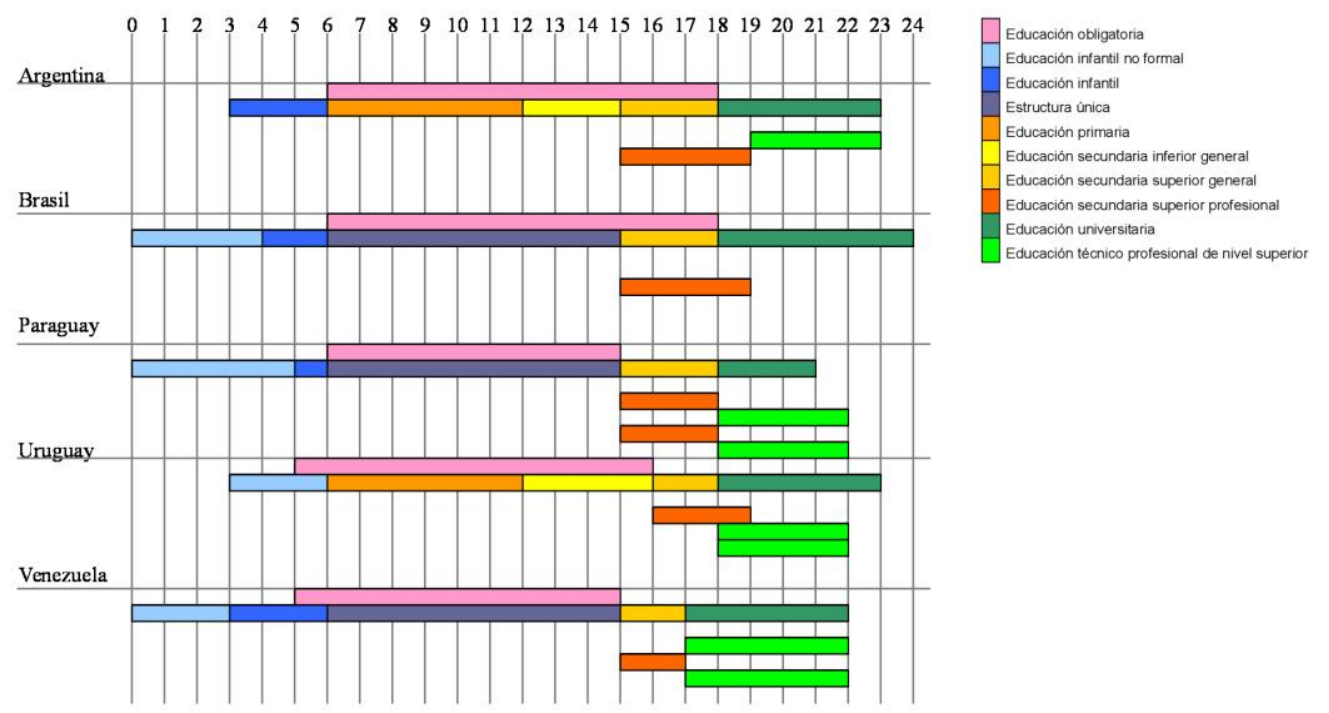

Esquema n. ${ }^{\circ}$ 1. Organización de los niveles educativos del SEM

Fuente: en base al gráfico 2.6 de la organización del sistema educativo escolarizado (LLECE, 2008)

La política regional más dinámica del SEM es la de la educación superior tal como afirma Perrotta (2013). Esta autora esgrime como justificativos:

la formación de un mercado común donde los trabajadores y profesionales se muevan libremente; tendencias globales en pos de la mercantilización de la educación y privatización del conocimiento mientras se conforma un mercado internacional redituable para los servicios de educación superior; procesos de reforma neoliberal que incorporan como una de sus políticas estrella a la evaluación y la acreditación; el desfinanciamiento y la regulación del sector universitario,(...) la desestimación de la enseñanza técnica (Perrotta, 2015, pp. 226-227), entre otras.

Incluso si consultamos hoy ${ }^{50}$ el sitio web oficial del Mercosur educativo vamos a encontrar que en el índice desplegable ubicado en la parte izquierda figura la opción "Programas y

\footnotetext{
${ }^{50}$ Consulta efectuada el 31 de octubre de 2020: http://edu.mercosur.int/es-ES/programas-e-projetos.html
} 
Proyectos" que nos lleva únicamente a los programas y proyectos vigentes en el área de la educación superior.

\section{Estructura del SEM}

La misión del Sector Educativo del Mercosur (SEM) o Mercosur Educativo es:

Conformar un espacio educativo común, a través de la concertación de políticas que articulen la educación con el proceso de integración del MERCOSUR, estimulando la movilidad, el intercambio y la formación de una identidad y ciudadanía regional, con el objeto de lograr una educación de calidad para todos, con atención especial a los sectores más vulnerables en un proceso de desarrollo con justicia social y respeto a la diversidad cultural de los pueblos de la región ${ }^{51}$.

Actualmente $^{52}$ la estructura del SEM se compone de la Reunión de Ministros de Educación (RME), instancia máxima de decisión, el Comité Coordinador Regional (CCR), las cuatro Comisiones de Área (CA), que atienden cuatro áreas específicas: Educación Básica (CA-EB), Educación Tecnológica (CA-ET), Educación Superior (CA-ES) y Formación Docente (CAFD $)^{53}$. Cuenta con el apoyo del Comité de Gestión del Sistema de Información y Comunicación (CGSIC), responsable de suplir las necesidades de comunicación, gestión de conocimiento, información y trabajo cooperativo en el ámbito del SEM. En 2006, se creó la Red de Agencias Nacionales de Acreditación (RANA). En junio de 2008 se creó el Fondo de Financiamiento del SEM (FEM) con el propósito de financiar los programas y proyectos del área educacional que fortalezcan el proceso de integración regional.

A esta estructura se suman: el Comité Asesor del FEM (CAFEM), el Comité Técnico de Evaluación (CTE) que establece los lineamientos para definir los criterios de la evaluación de la calidad de la educación en la región, los Grupos de Trabajo (GT) integrados por expertos que asesoran al CCR o CRCA, los Grupos Gestores de Proyectos (GGP) que son instancias temporales específicas convocadas ad hoc por el CCR por iniciativa propia o por sugerencia del Comité

\footnotetext{
${ }^{51}$ Plan de acción del Sector Educativo del Mercosur para el período 2011-2015.

${ }^{52}$ La última modificación del organigrama del SEM fue en el año 2017. Ver MERCOSUR/CMC/DEC. N 18/17.

${ }^{53}$ Creado en el primer semestre de 2011 con el Plan de acción del Mercosur Educativo para el período 2011-2015.
} 
de Coordinadores de Área de perfiles para definir y desarrollar los proyectos aprobados en el marco del SEM / FEM, los Comité ad hoc y los Comités de gestión.

A pesar de contar con una estructura institucional propia y compleja que incluye un Fondo específico, la cuestión financiera no se encuentra solucionada lo que limita la posibilidad de implementar las actividades (Perrotta, 2013).

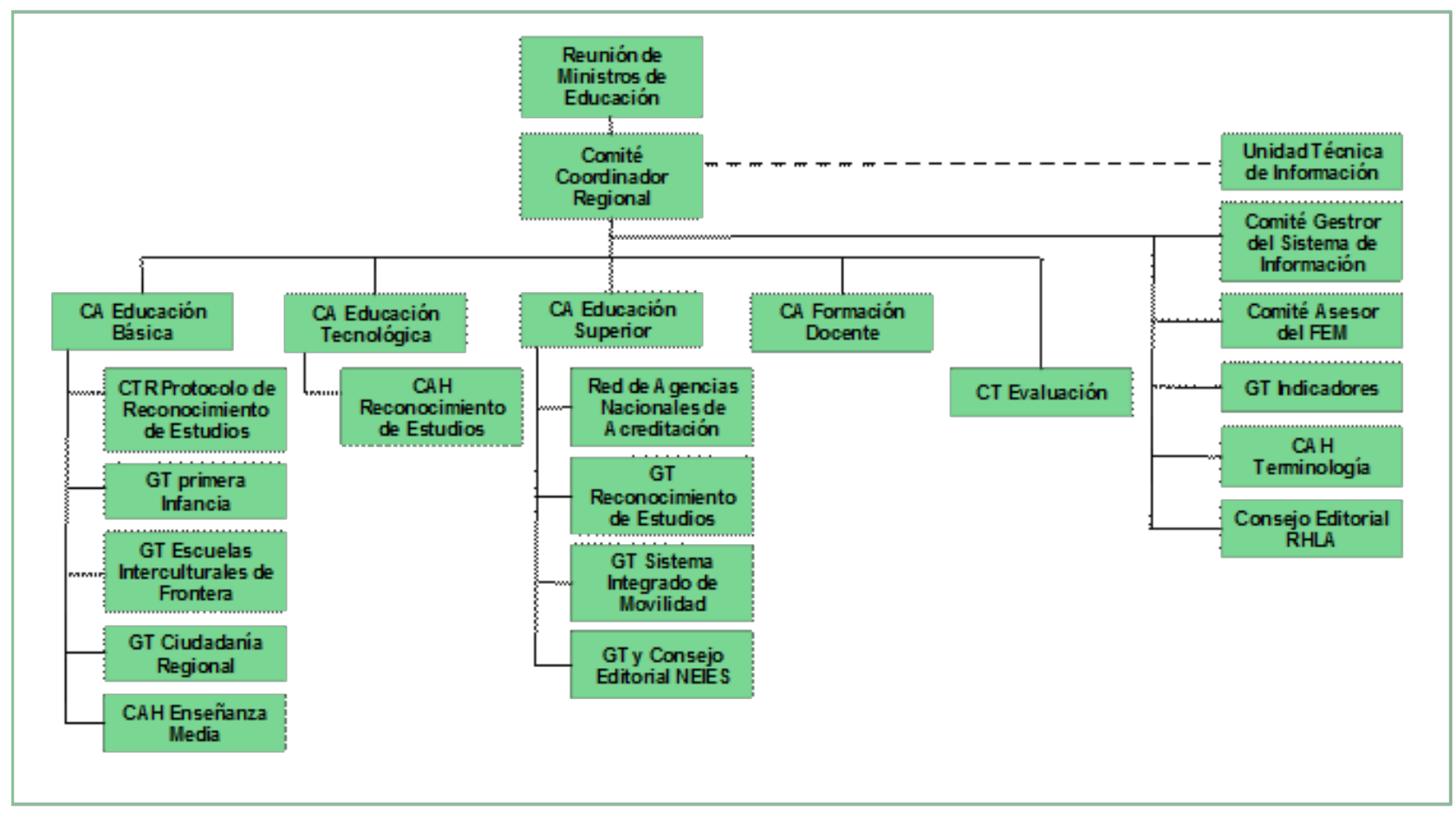

Esquema n. ${ }^{\circ}$ 2. Organigrama del SEM

Fuente: elaboración propia en base a la Decisión $\mathrm{N}^{\circ} 18 / 17$ del CMC

El área de interés de nuestra investigación es la educación básica ${ }^{54}$ que comprende la educación primaria y media y orgánicamente está a cargo de:

\section{Comisión de Área de Educación Básica (CAEB)}

Comisión Técnica Regional de Protocolo de Reconocimiento de Estudios (CTR)

Grupo de Trabajo de Escuelas de Fronteras (GTEF)

\footnotetext{
${ }^{54}$ Un nivel de enseñanza uniforme para los cinco países del Mercosur denominado Enseñanza Básica que incluye los niveles Primario y Primer Ciclo de Educación Secundaria (CINE 1 y CINE2), como CINE12.
} 


\section{Grupo de Trabajo de Ciudadanía Regional (GTCR) \\ Grupo de Trabajo de Primera Infancia (GTPI) \\ Comisión ad hoc de Educación Media (CAHEM)}

\section{Planes de acción del SEM}

Podemos identificar con precisión los contenidos de los planes de acción trienales del SEM a partir de los períodos 1998-2000, 2001-2005, 2006-2010, 2011-2015 y 2016-2020. El 27 de junio de 1992, el CMC aprobó la Decisión No 7 que adoptaba el "Plan Trienal para el Sector Educación en el Contexto del Mercosur" que constaba de tres programas que buscaban la formación de la conciencia ciudadana favorable al proceso de integración, la capacitación de recursos humanos y la compatibilización y armonización de los sistemas educativos de los Estados Partes. Este Plan fue prorrogado por igual período en diciembre de 1994 y, a su término en diciembre de 1997, nuevamente hasta junio de 1998.En el año 1996 se adopta el "Programa MERCOSUR 2000 - Metas y Desafíos para el Sector Educativo"55 que aborda una serie de programas de cooperación universitaria, sistemas de información en educación, formación de administradores de la educación, innovación en la gestión de instituciones educativas, evaluación educativa y, por último, un programa multidisciplinario de temas especiales.

Veamos ahora los contenidos específicos de los planes de acción dedicados al nivel de enseñanza objeto de nuestra investigación.

\section{Planes de acción del SEM}

\footnotetext{
${ }^{55}$ MERCOSUR/RME/ACTA No 01/96 Anexo I.
} 
El plan trienal 1998-2000 no contiene estrategias ni líneas de acción específicas para la educación básica. Se establecen dos áreas prioritarias: el desarrollo de la identidad regional y la promoción de políticas regionales de capacitación de recursos humanos y mejoramiento de la calidad de la educación.

En el plan para el período 2001-2005, el SEM asume el desafío en el área de la Educación Básica de mejorar el aprendizaje y plantea como fundamental la interacción de las escuelas con diferentes instituciones y actores sociales. Como estrategias se propone revertir el fracaso escolar que afecta los primeros años de escolaridad y a la transición de ciclos y/o niveles y la atención prioritaria a los grupos más vulnerables a fin de garantizar el acceso, la permanencia y la promoción de la educación. Se identifican como grupos vulnerables los integrados por niños y niñas con necesidades especiales de aprendizaje, en situaciones de pobreza, urbano-marginal y rural, grupos indígenas y otros sectores poblacionales en situación de marginalidad social, cultural y económica.

El plan de acción 2006-2010 se diseña en consonancia con los objetivos de Educación para Todos y los Objetivos del Milenio. Las metas que se plantean para la educación básica son: la inclusión de contenidos comunes que favorezcan la integración regional prioritariamente en el trayecto de la educación básica (historia y geografía e incorporar contenidos vinculados a temáticas del bloque), llevar a cabo reuniones de diseño y monitoreo de las políticas que se implementan en las escuelas en de derechos humanos, medio ambiente y educación para la paz, instalar las Bibliotecas Escolares Mercosur y ampliar el número de escuelas beneficiarias del proyecto, la realización de encuentros bienales de intercambio y reflexión sobre alguna(s) de las temáticas priorizadas para los diferentes niveles y modalidades de formación docente, la actualización permanente de las tablas de equivalencias, entre las más relevantes para nuestra área de estudios.

El plan de acción 2011-2015 del SEM está en sinergia con el Programa "Metas 2021: la educación que queremos para la generación de los Bicentenarios". Entre las metas destacamos: el fortalecimiento de la organización institucional para la gestión democrática de la escuela pública, garantizando la participación de todos los actores involucrados en el ámbito escolar, y de los mecanismos de participación de los jóvenes en el proceso de promoción de ciudadanía regional (Parlamento Juvenil del Mercosur, concurso histórico 
literario "Caminos del Mercosur), la consolidación de las escuelas interculturales de frontera como una política de los Ministerios de Educación de los países miembros y asociados del Mercosur, la profundización de las estrategias para garantizar la igualdad de oportunidades de acceso, permanencia y conclusión con calidad, en tiempo oportuno, de los niños y jóvenes en los sistemas de enseñanza de la región, el fortalecimiento de las prácticas pedagógicas de enseñanza y aprendizaje a nivel institucional y en la sala de clase de los servicios educativos de la educación obligatoria en la región, la facilitación de las condiciones de movilidad de los estudiantes de Educación Básica PrimarialFundamental y MedialSecundaria, la ampliación de la cobertura del programa original bilingüe a partir de la transformación del mismo, en otro que pueda incluir todas las escuelas de fronteras ${ }^{56}$, entre otras.

En el plan de acción 2016-2020 advertimos la coordinación de la agenda del SEM con el Plan estratégico de acción social del Mercosur (PEAS), el plan de acción de la Unasur y con la Agenda 2030 de las Naciones Unidas. Se estableció como objetivos específicos facilitar los procesos de legalización de certificados y títulos y actualizar la tabla de equivalencia y el mecanismo de aplicación en el nivel primario/básico y medio/secundario, con el objetivo de fortalecer la movilidad regional de los estudiantes, docentes y profesionales para promover la integración regional entre los sistemas educativos de los países miembros y asociados del bloque. En el eje Inclusión y participación social, se establece como prioridad la institucionalización y consolidación de los Programas Regionales: Parlamento Juvenil del Mercosur (PJM), Caminos del Mercosur y Escuelas Interculturales de Frontera (PEIF), pero las actividades concretas programadas están dedicadas más claramente a fortalecer el proyecto Caminos del Mercosur y el PJM (a cargo del GT Ciudadanía regional). Cabe aclarar que el único de estos programas destinados al nivel de la educación primaria es el de PEIF que abordaremos en el próximo capítulo. Las actividades previstas para este programa son: incorporar el uso de las TIC como herramienta para alumnos y docentes, un anexo con glosario terminológico referido a la educación intercultural en región de fronteras y un plan de trabajo que prioriza objetivos del plan de acción, incorporar

\footnotetext{
${ }^{56}$ De esto conversé con los funcionarios del Ministerio de Educación de la Nación pero lo planteaban como algo de este año y se planteó para el periodo 2011-2015
} 
nuevas escuelas al programa y seleccionarlas de acuerdo con las variables pertinentes a cada zona trabajando con los estados, departamentos y municipios, realizar encuentros virtuales de trabajo para el diseño del plan de acción anual y llevar a cabo al menos una jornada para la formación en servicio, acompañamiento docente (supervisión) y producción conjunta de conocimiento en temáticas relacionadas a PEIF, para la promoción de la integración hasta 2020 (a cargo del GT Escuelas Interculturales de Frontera).

\section{El derecho a LA EDUCACIÓn EN ARgentina}

En este apartado no haremos un recorrido histórico de la normativa argentina regulatoria del derecho a la educación porque excedería los límites del presente trabajo, solo diremos que nuestro país cuenta con un sistema educativo tradicionalmente de gestión centralizada y organizado en cuatro niveles de enseñanza que en los últimos años experimentó un gran proceso de transformación. La promulgación de las leyes de transferencia de los servicios educativos a las provincias (1992), la Ley Federal de Educación (1993) y de Educación Superior (1995) constituyen parte del marco legal de este proceso. "La primera ley transfiere las escuelas aun dependientes del gobierno nacional a las provincias, la segunda establece los lineamientos básicos de organización de la educación inicial, primaria y secundaria y la tercera contiene los lineamientos generales de organización del nivel terciario, universitario y no universitario" (Argentina, 2012, p. 9). Nos enfocaremos en la Ley de Educación Nacional promulgada el 27 de diciembre de 2006 que extendió la educación obligatoria a 13 años.

Para ejercer de manera plena el derecho a la educación, es condición necesaria pero no suficiente, que el Estado ponga a disposición una oferta educativa a la cual poder acceder (IIPE UNESCO, 2015). En este sentido, la Ley de Educación nacional n 26.206 (2006) dispone en su artículo 17:

La estructura del Sistema Educativo Nacional comprende cuatro (4) niveles — la Educación Inicial, la Educación Primaria, la Educación Secundaria y la Educación Superior, y ocho (8) modalidades. A los efectos de la presente ley, constituyen modalidades del Sistema Educativo Nacional aquellas opciones organizativas y/o curriculares de la educación común, dentro de uno o más niveles educativos, que procuran dar respuesta a requeri- 
mientos específicos de formación y atender particularidades de carácter permanente o temporal, personales y/o contextuales, con el propósito de garantizar la igualdad en el derecho a la educación y cumplir con las exigencias legales, técnicas y pedagógicas de los diferentes niveles educativos. Son modalidades: la Educación Técnico Profesional, la Educación Artística, la Educación Especial, la Educación Permanente de Jóvenes y Adultos, la Educación Rural, la Educación Intercultural Bilingüe, la Educación en Contextos de Privación de Libertad y la Educación Domiciliaria y Hospitalaria ${ }^{57}$.

En su artículo 3, la Ley afirma que "la educación es una prioridad nacional y se constituye en política de Estado para construir una sociedad justa, reafirmar la soberanía e identidad nacional, profundizar el ejercicio de la ciudadanía democrática, respetar los derechos humanos y libertades fundamentales y fortalecer el desarrollo económico-social de la Nación”.

En nuestro país ${ }^{58}$, la educación primaria, nivel educativo objeto de estudio de la presente tesis, es obligatoria y está destinada a los niños y niñas a partir de los seis años de edad (art. 26 de la Ley $n^{\circ}$ 26.206). Comprende seis o siete años y entre los objetivos de este nivel de enseñanza destacamos: garantizar el acceso a un conjunto de saberes comunes que les permitan participar de manera plena y acorde a su edad en la vida familiar, escolar y comunitaria, ofrecer las condiciones necesarias para un desarrollo integral de la infancia, brindar oportunidades equitativas para el aprendizaje de saberes significativos en los diversos campos del conocimiento, en especial la lengua y la comunicación, las ciencias sociales, la matemática, las ciencias naturales y el medio ambiente, las lenguas extranjeras, el arte y la cultura y la capacidad de aplicarlos en situaciones de la vida cotidiana, ofrecer los conocimientos y las estrategias cognitivas necesarias para continuar los estudios en la Educación Secundaria, entre otros regulados en el artículo 27 de la Ley $n^{\circ} 26.206$.

En esta instancia de este apartado, queremos recuperar la afirmación de Terigi (2006, p. 198) "existe una considerable diversidad entre las escuelas primarias argentinas" porque esta realidad no solo será importante para analizar la situación de la enseñanza primaria en nuestro

\footnotetext{
${ }^{57}$ El resaltado en nuestro.

${ }^{58}$ La enseñanza primaria es obligatoria en los cinco países del Mercosur. En Argentina, Uruguay y Venezuela se denomina 'primaria', en Brasil 'enseñanza fundamental' y en Paraguay 'educación escolar básica. En todos los casos, este nivel está destinado a niños y niñas a partir de los 6 años de edad (SITEAL, 2019).
} 
país sino que se extiende a todos los países de la región y, nos permite adelantarnos y así comprender, las dificultades de proyectar un único programa "normalizador" de educación primaria para los niños, niñas y adolescentes de los países del Mercosur.

En nuestro país es imposible hablar de una única realidad y de "la escuela primaria", porque la desigualdad es innegable en las condiciones en que se lleva a cabo la enseñanza primaria en las distintas regiones, entre provincias de una misma región y, a su vez, dentro de cada jurisdicción (Terigi, 2006). Existen las escuelas primarias inclusivas, internacionales, en contexto de encierro, rurales, urbanas, de frontera, los programas de aceleración ${ }^{59}$, de turnos reducidos, de jornada completa y, como afirma Terigi (2006), el plurigrado o multigrado de las escuelas rurales.

Los resultados de la comparación de los Informes SERCE y TERCE en nuestro país muestran que, tanto en $3^{\circ}$ como en $6^{\circ}$ año de las escuelas primarias, los estudiantes argentinos mejoraron su desempeño escolar, con una diferencia que es estadísticamente significativa y se encuentran por encima del promedio de la región (Leones et al., 2016). Otro dato estadístico que queremos considerar es el proporcionado por el Informe Aprender 2018 sobre resultados nacionales de $6^{\circ}$ año del nivel primario $(2019)^{60}$. En el capítulo cuarto se analiza el desempeño de los estudiantes de $6^{\circ}$ año según su pertenencia a hogar migrante. El 11\% de los estudiantes declara que pertenece a un hogar en donde él, su madre o su padre nacieron fuera de Argentina. Al analizar la condición migratoria del hogar según el nivel socioeconómico se observa que la proporción de estudiantes que viven en hogares migrantes es mayor a medida que disminuye el nivel socioeconómico (Argentina, 2019).

Somos conscientes de que este tipo de informes responden a un paradigma educativo que “impugna sistemáticamente la posición de los discursos educativos críticos alrededor del mundo, colocando a los resultados de las pruebas aplicadas como único parámetro legítimo para dar cuenta de una buena escolarización” (Martínez y Seoane, 2020, p. 23). Y la consecuencia de ello

\footnotetext{
${ }^{59}$ Mónica Escobar, profesora de la Facultad de Humanidades y Ciencias de la Educación (UNLP), entrevista por videollamada, 3 de septiembre de 2020 .

${ }^{60}$ En el Informe Aprender 2018 participó el 94,4\% de las escuelas del nivel primario de todo el país y el 78,7\% de los estudiantes de $6^{\circ}$ año.
} 
es que los sistemas de evaluación se convierten en dispositivos de control de docentes y de estudiantes. Solo los consideramos a modo ilustrativo y no como marco de referencia.

De las ocho modalidades ${ }^{61}$ previstas en la Ley ${ }^{\circ} 26.206$, nos interesa repasar la de Educación Intercultural Bilingüe (EIB). Esta modalidad tiene el desafío de contemplar la pluralidad etnolingüística $^{62}$ de Argentina como también la vulnerabilidad socioeconómica de las poblaciones indígenas (Hecht, 2015). Ley de Educación nacional dispone:

La Educación Intercultural Bilingüe es la modalidad del sistema educativo de los niveles de Educación Inicial, Primaria y Secundaria que garantiza el derecho constitucional de los pueblos indígenas, conforme al artículo 75 inciso 17 de la Constitución Nacional, a recibir una educación que contribuya a preservar y fortalecer sus pautas culturales, su lengua, su cosmovisión e identidad étnica; a desempeñarse activamente en un mundo multicultural y a mejorar su calidad de vida. Asimismo, la Educación Intercultural Bilingüe promueve un diálogo mutuamente enriquecedor de conocimientos y valores entre los pueblos indígenas y poblaciones étnica, lingüística y culturalmente diferentes, y propicia el reconocimiento y el respeto hacia tales diferencias (art. 52 de la Ley ${ }^{\circ} 26.206$ ).

Como señalamos en el texto del artículo, esta definición reduce la EIB a los pueblos indígenas y en los tres primeros niveles del sistema educativo. Aquí retomamos dos cuestionamientos que hace Hecht (2015) a la ley: 1) en primer lugar, que solo los indígenas sean los destinatarios de la EIB hace que se pierda de vista la transversalidad que estas propuestas deberían tener, excluyendo así a los estudiantes migrantes y no-indígenas, 2) y en segundo lugar, se percibe un desinterés por esta modalidad en los niveles más altos de educación e inclusive negando al superior, olvidando que se trata de trayectorias escolares.

En este mismo sentido, Thisted (2014) afirma que suele prevalecer la concepción de la EIB como una política cuyo foco son los indígenas que viven en situaciones comunitarias, mayormente rurales, se limita a la educación obligatoria y se centra en la cuestión lingüística. En la

\footnotetext{
${ }^{61}$ Se entiende por modalidad educativa a las orientaciones, modos, reglas y mecanismos formales con que los sistemas de la región se organizan para garantizar el derecho a la educación. Así, la EIB entendida como modalidad educativa indica el formato oficial con que el Estado garantiza la educación en la lengua y en la cultura del pueblo en cuestión (Corbetta et al., 2018, p. 12).

${ }^{62}$ En Argentina además del español y de las lenguas de migración, se hablan catorce lenguas indígenas con diferentes grados de vitalidad (Hecht, 2015).
} 
misma línea, Beheran (2012, p. 216) destaca que "la modalidad [EIB] continúa sin contemplar la presencia de estudiantes inmigrantes en los distintos niveles del sistema educativo y las necesidades educativas de esta población”. Padawer y Díaz (2015), afirman que las políticas educativas interculturales en nuestro país atienden de manera predominante a comunidades originarias y rurales y no involucran "al resto de la población escolar (...), a los indígenas urbanos ni a otros grupos que podrían ser definidos como minorías culturales, tales como la población inmigrante latinoamericana o la población indígena extranjera” (2015, p. 74).

Si bien la Resolución n 119/10 del Consejo Federal de Educación establece la necesidad de "la gradual y progresiva incorporación de la modalidad de Educación Intercultural Bilingüe en la política curricular de los distintos niveles y modalidades del sistema educativo" (art. 3) y se propone "garantizar en forma gradual y progresiva la formación docente en y para la Educación Intercultural Bilingüe específica, inicial y continua en los distintos niveles del sistema educativo" (art. 5), sigue enfocándose en los niveles inicial, primario y secundario y en los pueblos y comunidades indígenas, a pesar de que en el Anexo 1 de dicha resolución en el párrafo 22 aparecen entre paréntesis los "migrantes recientes" al referirse a la situación educativa actual que se caracteriza por el bilingüismo o multilingüismo tanto en zonas rurales como urbanas (Argentina, 2011).

Las poblaciones migrantes no son vistas como potenciales destinatarias de esta modalidad. Es así que los estudiantes migrantes son invisibilizados, produciéndose "formas sutiles de discriminación en el marco de una política que se propone inclusiva” (Hecht, 2015, p. 26).

María Eugenia Martínez ${ }^{63}$, docente, investigadora y especialista en educación intercultural, nos propone abordar la interculturalidad como perspectiva. En este sentido, Corbetta et al. (2018), marcan la diferencia entre la EIB como modalidad y la interculturalidad como enfoque en las políticas públicas. Afirman:

(...) la interculturalidad como enfoque es una educación para todos destinada a desactivar las relaciones y las posiciones asimétricas en nuestra sociedad. (...) tiene como consecuencia la interculturalización de la totalidad del sistema con el objetivo de generar una

\footnotetext{
${ }^{63}$ María Eugenia (Mae) Martínez, co-coordinadora de la Red Latinoamericana de Estudios sobre Trabajo Docente, videoconferencia por zoom, 15 de diciembre de 2020 .
} 
educación que alcance también a los grupos hegemónicos y étnicamente desmarcados (Corbetta et al., 2018, p. 17).

Como señalan los autores arriba mencionados, la interculturalidad no debería limitarse al campo educativo aislado de los ámbitos social, cultural, económico y cultural sino ser transversal a todas las políticas públicas (Corbetta et al., 2018). Es por ello que Díez (2013) toma el concepto de interculturalidad extendida que refiere a la educación intercultural para toda la sociedad y no solo para los pueblos originarios que intenta ir más allá de lo educativo, ubicándose como estrategia general para hacer frente a las políticas monoculturales de los Estados latinoamericanos.

Mae Martínez ${ }^{64}$ nos recuerda que la interculturalidad, al interior de nuestro país, se vincula con las relaciones que a lo largo de la historia han mantenido los distintos pueblos originarios con el Estado nacional. Y esas articulaciones pueblos originarios-Estado son complejas y difieren de una región a otra.

Como afirman Diez y Hecht (2013 en Diez, 2013), la EIB surge en nuestro país como política educativa focalizada originada en el contexto neoliberal que se propone contener a los niños y niñas indígenas "quienes no solo se encuentran interpelados por un sistema educativo que no contempla la diversidad sociocultural y lingüística de sus destinatarios sino que además se encuentran en contextos socioculturales marcados por situaciones de extrema desigualdad y pobreza estructural" (Diez, 2013, p. 14).

Retomaremos el concepto polisémico de interculturalidad en el capítulo IV del presente trabajo de investigación para analizarlo en el contexto del Programa de Escuelas Interculturales Bilingües de Frontera (PEIBF) del Mercosur. Y así poder establecer semejanzas y diferencias con la propuesta intercultural de la legislación argentina.

\section{RECAPITULACIÓN}

El recorrido normativo llevado a cabo en este capítulo nos permite afirmar que la educación se ha consolidado como derecho humano fundamental e inalienable en todos los niveles educativos.

\footnotetext{
${ }^{64}$ María Eugenia (Mae) Martínez, co-coordinadora de la Red Latinoamericana de Estudios sobre Trabajo Docente, videoconferencia por zoom, 15 de diciembre de 2020.
} 
La instrucción primaria debe ser gratuita, de calidad, equitativa, inclusiva y no discriminatoria, debe tener por objeto el desarrollo de la personalidad y de la identidad cultural y, así lograr un rol activo en la construcción de una sociedad más justa e igualitaria. A ello sumamos, el reconocimiento del carácter multicultural y plurilingüe de la región latinoamericana.

Hemos identificado avances normativos en todos los niveles muy importantes y el desarrollo de muchas herramientas disponibles, sin embargo advertimos una falta apropiación de estas herramientas por parte del campo educativo y de la sociedad en su conjunto para garantizar el pleno ejercicio del derecho a la educación (CLADE, 2015).

Coincidimos con la UNESCO (2019) en que "la migración y los desplazamientos interactúan con la educación a través de relaciones mutuas y complejas que afectan a los que migran, los que se quedan y los que acogen o pueden acoger a migrantes y refugiados”. En este contexto, el sistema educativo del Estado receptor debe dar respuestas atendiendo a la diversidad cultural que florece en el aula. Y es aquí donde el sistema educativo debe evitar ser homogeneizador (Terigi, 2006).

Ya en el orden mercosureño, pudimos identificar un gran desarrollo a nivel regional del nivel de la educación superior en detrimento del nivel primario: sin educación primaria universal y de calidad es imposible el desarrollo de las trayectorias escolares que permitan el acceso a los niveles superiores (terciario e universitario).

Por otra parte, advertimos que en el SEM no hay un Grupo de Trabajo o Comisión Ad Hoc para la educación primaria solo para la primera infancia y la enseñanza media. Pareciera que el único tema relevante vinculado a este nivel educativo refiere a las tablas de equivalencia (CTR de Protocolo de reconocimiento de títulos). Sin dudas, asegurar la movilidad de los niños, niñas y adolescentes de la región es fundamental pero es solo el primer paso para garantizar el acceso a la educación. Las acciones están dirigidas a fortalecer la ES, la ET y la Primera Infancia.

En el caso de Argentina, encontramos que la Educación intercultural se encuentra limitada a ser una de las ocho modalidades reguladas por la ley de educación y no se configura como un enfoque de política pública. Es así que existe una gran diversidad en la implementación de esta modalidad por cada jurisdicción dado el sistema federal de organización del Estado argentino, incluso a nivel municipal. Coincidimos con Tubino (en Corbetta et al., 2018, p.17) en que 
considerar a la interculturalidad como modalidad "encubre la importancia de las injusticias estructurales, la distribución inequitativa de la riqueza y las relaciones de prestigio y poder entre culturas para entender las relaciones interculturales". 


\section{español}




\title{
Capítulo IV
}

\section{El Programa de Escuelas Interculturales Bilingües de Frontera}

\author{
"La frontera separa, la frontera se ocupa, la frontera se cruza y se vive". \\ Jelin (2000, p. 334) \\ “Las migraciones son simultáneamente un tema de enseñanza y experiencias vividas". \\ Díez (2020,p. 6)
}

\section{EN BÚSQUEDA DE PROGRAMAS/POLÍTICAS EDUCATIVAS Y MIGRATORIAS DESTINADAS A LA NIÑEZ Y JUVENTUD MIGRANTE EN EL NIVEL DE LA ENSEÑANZA PRIMARIA}

A lo largo de la tesis hemos buscado construir una perspectiva multiescalar (Domenech y Pereira, 2017) que ponga en relación lo local, lo nacional, lo regional y lo internacional en lo relativo a instituciones, actores, espacios y prácticas vinculadas a las migraciones y a la educación. En esta instancia, la búsqueda se centra en encontrar en la escala regional mercosureña normativas, instituciones y actores que aborden la problemática de la inserción de la niñez migrante intrabloque en los niveles de la enseñanza primaria. Es decir, integrar las dos temáticas en el ámbito regional.

La realidad es que por primera vez en la edición 2019 del Informe de seguimiento de la educación en el mundo de la Unesco se trata con profundidad los efectos considerables que los desplazamientos pueden tener sobre los sistemas educativos en todas partes del mundo (Azoulay en Unesco, 2019). El reciente abordaje conjunto de estas problemáticas por una institución internacional nos da la pauta de que será difícil encontrar un similar tratamiento en la región. 
De hecho, podemos constatar que no existe en el Mercosur una política regional educativa que tenga como destinatarios a los niños y niñas migrantes intrabloque con el objetivo de garantizar su efectivo derecho a la educación en el nivel de la enseñanza primaria. Si bien en el Acuerdo de Residencia (2002) reconoce a los hijos de los migrantes el "derecho fundamental de acceso a la educación en condiciones de igualdad con los nacionales del país de recepción" (art. 9) presenta la limitación de ser una herramienta normativa y no una política pública regional. Como veremos en este capítulo, las dificultades -en el caso de Misiones- y la imposibilidad -en el caso de Corrientes- para sostener en el tiempo el único Programa existente en el nivel de la enseñanza primaria, la poca de capacidad de ejecución multinacional del mismo y la falta de articulación con otras políticas del sector, así como la falta de evaluación a nivel nacional y regional de su implementación, son elementos clave, en términos de Luján (2012), para la configuración de una política pública regional. Sin embargo, podemos afirmar que sienta las bases del régimen internacional migratorio y educativo del Mercosur.

Ahora bien, en el ámbito de la educación primaria y secundaria del SEM, nos encontramos con tres programas destinados a niñas, niños y jóvenes de la región mercosureña: Parlamento Juvenil del Mercosur (PJM), Caminos del Mercosur y Escuelas Interculturales de Frontera. El Parlamento Juvenil surge en 2008 y se implementa por primera vez en el año 2010 y hasta el día de hoy cuenta con cinco encuentros. Este programa tiene lugar en las escuelas secundarias de Argentina, Brasil, Paraguay y Uruguay para promover espacios de participación y debate estudiantil sobre seis ejes posibles: Inclusión Educativa, Género, Jóvenes y Trabajo, Participación Ciudadana, Derechos Humanos e Integración Latinoamericana. En el marco de la XXXIV Reunión de la Comisión de Área de Educación Básica (CAEB) realizada en Asunción en abril de 2018, el Grupo de Trabajo de Ciudadanía Regional manifestó su preocupación por la sustentabilidad del programa.

Caminos del Mercosur es un concurso histórico-literario destinado a jóvenes de 16 y 17 años que pretende "busca estimular y fortalecer la interacción entre los/as estudiantes secundarios de la región, permitiéndoles ampliar sus conocimientos, vivenciar y apreciar la integración de los pueblos y consolidar una identidad del Mercosur, respetando la diversidad cultural y pro- 
moviendo la participación" ${ }^{\circ 5}$. En la 14 edición del concurso (2018) fueron distinguidos 24 estudiantes por sus relatos sobre la transformación de la educación superior en toda Latinoamérica en las primeras décadas del siglo XX. En 2020 el concurso se tituló “Un viaje en el tiempo hacia la libertad". En esta oportunidad, los jóvenes podrán optar entre dos temáticas al momento de elaborar sus relatos: las mujeres que protagonizaron los procesos independentistas en los países mercosureños; o la participación de los pueblos originarios y las comunidades afrodescendientes en esos mismos movimientos. En esta ocasión, el país organizador fue Colombia bajo la coordinación del Ministerio de Educación Nacional (cierre de la convocatoria prevista para noviembre de 2020).

En junio de 2018 la Reunión de Ministros de Educación (Acta $N^{\circ}$ 01/18) decidió que estos dos programas se realicen en años alternados. La frecuencia en la implementación para el caso del PJM (cinco encuentro en doce años) y el limitado alcance de la participación para el concurso literario podrían ser algunos de los motivos que nos llevan a considerar que no pueden configurarse como una política regional pero no nos detendremos a analizar los motivos de su creación ni los impactos dado que se ubican por fuera de nuestro objeto de estudio, al tratarse de dos programas destinados a estudiantes del nivel de la educación media en tanto que nuestro trabajo se enfoca en la educación primaria. Por otra parte, ambos programas se encuentran bajo la órbita del Grupo de Trabajo Ciudadanía Regional (GTCR) mientras que el tercer programa está en la órbita del Grupo de Trabajo de Escuelas Interculturales de Frontera (GTEIF).

Finalmente nos encontramos con las Escuelas Interculturales Bilingües de Frontera que tienen como destinatarios a los niños y niñas del nivel de la educación primaria y las abordaremos en el próximo apartado. La limitación que presenta este programa podemos identificarla en su propia denominación: solo tiene lugar en algunas zonas fronterizas.

\section{Revisión de los conceptos de frontera y de interculturalidad}

En esta etapa de la investigación, nos sentimos impulsados a revisar algunos conceptos desde una mirada multidisciplinar: la frontera y la interculturalidad. Recuperaremos aportes de los Es-

\footnotetext{
${ }^{65}$ Información disponible en http://edu.mercosur.int/es-ES/mais-noticias/204-caminos-del-mercosur.html [Consultado en diciembre de 2019]
} 
tudios Culturales, de la Etnografía, de la Sociología, de la Filosofía y del Derecho internacional con el propósito de comprender de manera más completa el fenómeno que se describe en el próximo apartado.

Frontera es un concepto evolutivo (Remiro Brotons, 1997) y una noción polisémica (Jelin, 2000; Briones y del Cairo, 2015; Grimson, 2011). Se trata de un concepto que evoluciona conforme las necesidades de separación o acercamiento de los Estados vecinos, entendiendo a la frontera como un límite lineal o como una zona de cooperación. En el mismo sentido, la frontera no tiene un único significado: pueden ser considerados como espacios marginales donde el Estado está ausente (frontier), como espacios que invitan a ser cruzados (boundary) y como espacios en los que se vive (border), este último es la zona fronteriza (Jelin, 2000). Estas zonas de frontera “definen la pertenencia y/o exclusión de los grupos” (Hirsch, 2000, p. 279).

Grimson (2011) señala que es importante distinguir a) la frontera jurídico-política que se materializa con la presencia de las aduanas, los controles migratorios y las fuerzas de seguridad, b) la frontera económica que a veces separa los sistemas productivos, diferencia precios e impuestos, c) la frontera soberana que otorga derechos de ciudadanía diferenciados y determina el ámbito de actuación del poder estatal, d) la frontera identitaria que es aquella vinculada a las categorías de adscripción de personas o grupos.

En los Estados-nación la frontera es concebida como una línea que abarca el territorio, donde se expresa su soberanía y fija el alcance espacial de sus competencias (Remiro Brotons, 1997), es allí donde emerge lo regional y confluye lo transnacional (Hirsch, 2000). Estas fronteras terrestres o interestatales son el resultado de acuerdos históricos que surgieron de las relaciones de fuerza entre los Estados y las poblaciones locales (Grimson, 2000). Según este autor,

la convivencia cotidiana en una zona de frontera no se traduce necesariamente para la población local en una identificación compartida, en una "identidad fronteriza", sino que la propia dinámica de la interacción cotidiana plantea en muchos casos, por el contrario, un crecimiento de los roces y los conflictos (Grimson, 2000, p. 20).

En América Latina, la frontera es la productora de la diferencia cultural mucho más de lo que es producto de ella. Son muchos los espacios fronterizos donde las diferencias solo son producidas por la frontera (medios de comunicación, sistemas escolares, entre otros). "Como las 
fronteras culturales e identitarias pueden competir con las fronteras políticas, los estados muchas veces desarrollan políticas de nacionalización para intentar hacerlas coincidir: instalan escuelas de frontera, procuran alcanzarlas con medios de comunicación, envían regimientos militares" (Grimson, 2000, p. 31).

Señala Grimson (2005) que en los procesos de regionalización en el Cono Sur como es el caso del Mercosur, las fronteras se redefinen a pesar de que de las investigaciones surge que continúan siendo barreras arancelas, migratorias e identitarias. Esta redefinición implica resignificar y recrear "las asociaciones de la noción de frontera no sólo con categorías de diferencia, sino con otras que se refieren a superior-inferior, pobres-ricos, orden-desorden" (2005, p. 138). Las zonas fronterizas presentan una gran diversidad de situaciones vinculadas a historias diferentes y a contextos específicos.

Massey (2012) analiza el fenómeno de la comprensión espacio-temporal "que refiere al movimiento y la comunicación a través del espacio, a la extensión geográfica de las relaciones sociales y a nuestra experiencia de todo ello" (p. 114). La autora plantea que un problema del concepto de lugar es que parece exigir el trazado de fronteras que separa un interior de un exterior y que podría ser una manera fácil de construir una contraposición entre "nosotros" y "ellos". Propone una interpretación alternativa del lugar: lo que lo caracteriza es el hecho que se construyó a partir de una red determinada de relaciones sociales que se encuentran y se entretejen en un sitio particular. Los lugares son momentos articulados en redes de relaciones e interpretaciones sociales que implican una conciencia de esos vínculos con todo el mundo y que integra lo global y lo local (Massey, 2012).

Destacamos dos aspectos del lugar propuestos por la autora: los lugares no son estáticos sino que son procesos y no tienen identidades únicas y específicas sino que están llenos de conflictos internos (Massey, 2012, pp. 127-128).

Abordemos ahora la noción de interculturalidad que también resulta tener carácter polisémico. El fenómeno de la interculturalidad no es reciente: a lo largo de la historia de la humanidad, los encuentros entre culturas y civilizaciones ha sido una constante (Parker, 2007). La constitución histórica de América Latina ha sido y continúa siendo intercultural pues han convivido y conviven diferentes pueblos ya sea de un modo pacífico o conflictivo (Picotti, 2007). Según Par- 
ker (2007), los proceso de integración latinoamericanos pueden comprenderse "como complejos procesos en los cuales se desafian a las identidades en contextos crecientemente interculturales" (p.78).

Como sostiene Parker (2007), la interculturalidad va más allá del contacto o apertura entre dos o más culturas distintas, nos remite a condiciones de posibilidad de una interacción que "sobre la base de principios realistas, asumiendo la complejidad y conflictividad, apunte hacia el reposicionamiento de unas culturas hacia otras y viceversa" (p. 63). La interculturalidad supone entonces procesos de autorreconocimiento de los sujetos involucrados en la interacción, de representaciones colectivas y de espacios que posibiliten las mediaciones, comunicaciones, diálogos, negociaciones y búsquedas de consensos hacia el restablecimiento de relaciones interculturales en nuevas fases y espacios para el entendimiento y desarrollo (Parker, 2007).

Díez (2013) señala dos aproximaciones al término interculturalidad: como categoría descriptiva y como categoría propositiva. En tanto categoría descriptiva, la interculturalidad "puede pensarse como una situación de hecho que da cuenta de las particularidades con que se definen las relaciones entre agrupamientos en distintos espacios de interacción social" (2013, p. 7), la descripción variará según el contexto histórico y social y la concepción de cultura de la que se parta. Como categoría prepositiva, la interculturalidad se piensa como proyecto que toma forma a partir de acciones colectivas y de diseño de políticas que buscan producir un cambio sobre la realidad.

Por su parte, Catherine Walsh (2009) nos propone el concepto de interculturalidad crítica que entiende a la interculturalidad como proyecto político, social epistémico y ético. Y la distingue de la interculturalidad funcional que

asume la diversidad cultural como eje central, apuntalando su reconocimiento e inclusión dentro de la sociedad y el Estado nacionales (uninacionales por práctica y concepción) y dejando por fuera los dispositivos y patrones de poder institucional-estructural -las que mantienen la desigualdad-, la interculturalidad crítica parte del problema de poder, su patrón de racialización y la diferencia (colonial no simplemente cultural) que ha sido construida a función de ello. El interculturalismo funcional responde a y parte de los intereses y necesidades de las instituciones sociales; la interculturalidad crítica, en cambio, es una 
construcción de y desde la gente que ha sufrido una historia de sometimiento y subalternización (Walsh, 2009, p. 9).

La autora propone entender la interculturalidad como proceso y como proyecto dirigido hacia la construcción de "otros modos de poder, saber, ser y vivir" que permite superar los supuestos actuales de la educación intercultural, la educación intercultural bilingüe o la filosofía intercultural (Walsh, 2009, p. 11). Concebir la interculturalidad de esta manera implica superar la discusión sobre la relación entre grupos, prácticas o pensamientos culturales, la incorporación de los excluidos en las estructuras educativas o la implementación de programas especiales para lograr una educación normal y universal, tal como sostiene Walsh. Significa "señalar la necesidad a visibilizar, enfrentar y transformar las estructuras e instituciones que diferencialmente posicionan grupos, prácticas y pensamientos dentro de un orden y lógica que, a la vez y todavía, es racial, moderno-occidental y colonial” (Walsh, 2009, p. 12).

\section{Las Escuelas Interculturales BiLingües de Frontera (EIBF)}

Este programa surge bajo el nombre Escuelas Bilingües de Frontera para transformarse un tiempo después en Escuelas Interculturales Bilingües de Frontera y actualmente se lo llama Escuelas Interculturales de Frontera. Nos ocuparemos de la noción de interculturalidad en esta sección porque resulta significativa su incorporación en el nombre del programa y analizaremos si logró pasar de la palabra a la acción. El otro concepto clave que destaca en este programa es el de frontera porque se inserta en el marco de un proceso de integración.

Como adelantáramos en el "Diseño metodológico" no hemos podido trasladarnos a la zona fronteriza objeto de estudio para realizar trabajo de campo, en primer lugar, por un motivo de financiación y, en segundo lugar, debido a la pandemia del SARS-CoV-2 que restringió la circulación durante el año 2020. Debemos tener en cuenta la extensa zona geográfica que abarca el programa incluso si nos limitamos a la frontera argentino-brasileña. Es por ello que nos proponemos estudiar a las EIB a partir de la lectura y análisis de las actas de los órganos del Mercosur involucrados, las normas de las provincias intervinientes, los resultados de los estudios etnográficos existentes y, principalmente, las experiencias de quienes tienen información relevante, son accesibles socialmente y están dispuestos a cooperar (Marradi et al., 2018), estos fueron: las 
autoridades de los ministerios de educación provinciales, los asesores pedagógicos, los directores y los maestros que trabajan en las escuelas asociadas al programa. No cabe duda que entrevistar a los estudiantes, destinatarios directos del programa, hubiera sido lo óptimo pero la inaccesibilidad física se trasformó en una real limitante así como también el hecho de que el programa estuvo vigente por 15 años lo que implica que hablamos de niños y niñas que han finalizado su ciclo de formación educativa.

\section{Un poco de historia sobre las EIB}

Nos parece importante destacar en esta instancia las dificultades que hemos tenido para obtener información sobre el origen, la implementación y, sobre todo, de la evaluación de resultados de las EIB en el ámbito del Mercosur Educativo ${ }^{66}$. En el caso de Argentina, nuestra dimensión espacial de estudio, el Ministerio de Educación de la Nación no posee información recopilada sobre la historia y la implementación de las EIB: no existe información disponible en su portal web lo que nos llevó a comunicarnos telefónicamente con el Área de Cooperación internacional y de Educación Rural donde nos informaron que efectivamente no cuenta con información sistematizada sobre el programa ${ }^{67}$. Esto nos llevó a contactar a los responsables del programa en los ministerios de educación de las provincias involucradas y, a través de ellos, pudimos contactar a asesores pedagógicos, directores y maestros de algunas de las escuelas asociadas.

En la plataforma web del Mercosur, a través de la Sección Documentos oficiales, tuvimos acceso a las actas y sus anexos de las Reuniones de Ministros de Educación (RME) ${ }^{68}$, de la Comisión de Área de Educación Básica (CAEB) y de los distintos grupos de trabajo que operan bajo su órbita. Cabe señalar que en marzo de 2019 el Grupo Técnico Escuelas Interculturales de Frontera (GTEIF) solicitó al CAEB incluir en la página web del Mercosur las experiencias de las escuelas incluidas en el GT (Acta $\mathrm{N}^{\circ} 01 / 19$ ). Las evaluaciones sobre las dificultades en la ejecu-

\footnotetext{
${ }^{66}$ Mercosur Educativo: http://edu.mercosur.int [Consultado en diciembre de 2019]

${ }^{67}$ Encargadas del Área de Cooperación internacional y de Ruralidad, Ministerio de Educación de la Nación Argentina, conversación telefónica, 6 y 7 de febrero de 2020 respectivamente.

${ }^{68}$ En varias ocasiones nos encontramos con que las actas y sus anexos no estaban disponibles, es por ello que nos pusimos en contacto por correo electrónico con la Secretaría del Mercosur que subió a la página web los documentos faltantes.
} 
ción del programa las encontramos reflejadas únicamente en las Actas ${ }^{69}$ redactadas por los distintos Comité de integración fronteriza argentino-brasileros ${ }^{70}$ y por el Grupo de Trabajo de Escuelas Interculturales de Frontera ${ }^{71}$.

En este marco normativo que pudimos reconstruir destacamos dos documentos: uno de ellos es una publicación conjunta de los ministerios de educación argentino y brasileño de 2007 y el otro figura como anexo a la RME de 2018 (Acta $N^{\circ} 1 / 18$ Anexo V). Estos documentos presentan ciertas incongruencias puesto que la información sobre el surgimiento del programa no se corresponde en su integridad con las resoluciones disponibles y creemos que faltan algunos elementos normativos. Si bien se trata de documentos que reproducen en buena medida su contenido, sobre todo en la introducción histórica, ya desde las primeras páginas advertimos el cambio en el enfoque del programa:

Documento conjunto elaborado por el Ministerio de Educación, Ciencia y Tecnología de Argentina y el Ministerio de Educación de Brasil (2007) titulado Programa Escuelas Bilingües de Frontera (PEBF):

Modelo de enseñanza común en escuelas de zona de frontera, a partir del desarrollo de un programa para la educación intercultural, con énfasis en la enseñanza del portugués y el español. Un esfuerzo binacional argentino-brasileño para la construcción de una Identidad Regional Bilingüe e Intercultural en el marco de una cultura de paz y de cooperación interfronteriza.

Anexo V al Acta $\mathrm{N}^{\circ}$ 01/18 de la RME titulado Programa de Escuelas Interculturales ${ }^{72} \mathrm{Bi}^{-}$ lingües de Frontera (PEBF):

\footnotetext{
${ }^{69}$ Estas actas están disponibles a partir de las reuniones realizadas en 2010 hasta 2018 en la Biblioteca Digital de Tratados de la Cancillería Argentina: https://tratados.cancilleria.gob.ar/ y en la página la https://integrac-fronteriza.cancilleria.gob.ar/ se encuen$\underline{\text { tran disponibles actas desde } 2014 .}$

${ }^{70}$ El Acta de Uruguayana del 22 de agosto de 1989 firmada por los Presidentes de la República Argentina, Carlos Saúl Menem, y de la República Federativa del Brasil, José Sarney inaugura las comité de frontera creados por el Protocolo $\mathrm{N}^{\circ} 23$ : Regional Fronterizo, del programa de Integración y Cooperación Económica Argentina-Brasil, firmado en Buenos Aires el 29 de noviembre de 1988. Como podemos advertir, la integración fronteriza argentino-brasilera precede al Mercosur pues estuvo presente en la voluntad política de ambos países. Los Comités tienen como objetivo facilitar la circulación de personas, bienes y servicios en el área de frontera, promover el desarrollo conjunto y la integración de las localidades vecinas de ambos países. Estos se establecieron en las siguientes ciudades fronterizas: Puerto Iguazú y Foz de Iguazú (1989); Bernardo de Irigoyen y Dionisio Cequeira (2009); Paso de los Libres y Uruguayana (2006); Santo Tomé y Sao Borja (2018).

${ }^{71}$ Este Grupo Técnico surge en el año 2004.
} 
Modelo de enseñanza común en escuelas de zona de frontera a partir del desarrollo de un programa para la educación intercultural, con énfasis en la enseñanza de las lenguas predominantes en la región. ${ }^{73}$

El Programa de Escuelas Interculturales Bilingües de Frontera surge en la búsqueda de estrechar lazos de interculturalidad entre ciudades vecinas de Argentina y Brasil. Encontramos como punto de partida el Tratado de Asunción que establece en su artículo $17^{74}$ como idiomas oficiales al español y al portugués y en 2006 se introduce el guaraní como idioma del Mercosur (Dec. 35/06 CMC). El Protocolo de Ouro Preto establece en su artículo 46 que la versión oficial de los documentos de trabajo será la del idioma del país sede de cada reunión y reafirma que los idiomas oficiales del Mercosur son el español y el portugués.

A continuación se ofrece un esquema que describe cronológicamente los hechos que dan nacimiento al Programa de Escuelas Interculturales Bilingües de Frontera.

\footnotetext{
72 La palabra "intercultural" se incorpora al nombre del programa a partir de 2009 impulsada a partir de una reunión entre el Ministerio de Educación de Brasil y una institución asesora, el Instituto de Investigação e Desenvolvimento em Política Lingüística (IPOL), donde se comprendió la importancia de explicitar los aspectos interculturales en y del programa (Sagaz, 2013, p. 41). El IPOL ha tenido un rol muy importante en el diseño del Programa y ha colaborado en su implementación a través de asesoramiento y asistencia técnica.

${ }^{73}$ El subrayado es nuestro con el propósito de destacar la evolución en cuanto al alcance geográfico y conceptual del programa.

${ }^{74}$ El artículo 17 del Tratado de Asunción dispone: "Los idiomas oficiales del Mercado Común serán el español y el portugués y la versión oficial de los documentos de trabajo será la del idioma del país sede de cada reunión."
} 


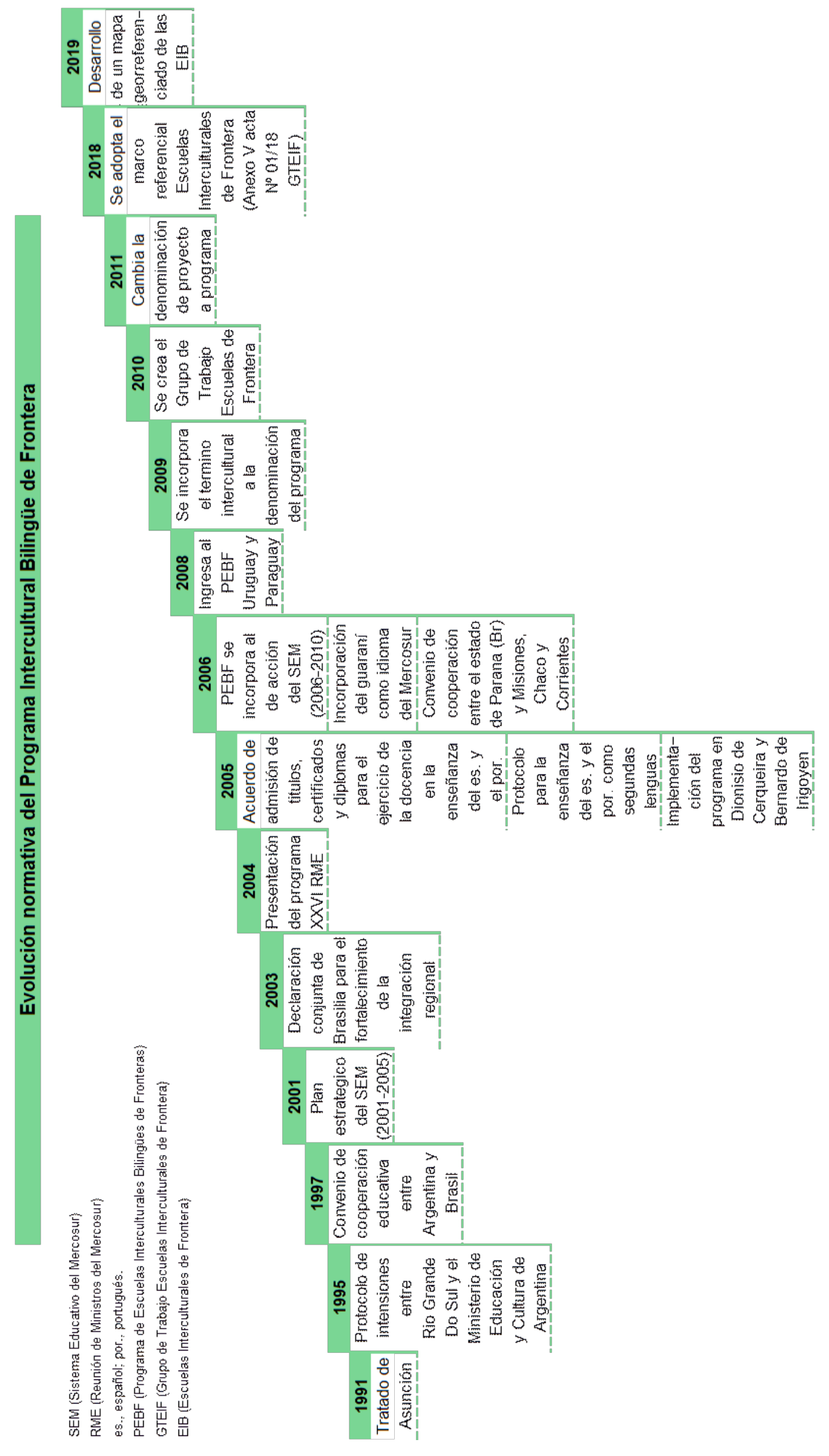


Esquema n. ${ }^{\circ}$ 3. Línea del tiempo que da cuenta del surgimiento del PEIBF

Fuente: elaboración propia a partir de la normativa recopilada.

El 10 de agosto de 1995 se firma el Protocolo de intenciones entre el Estado de Rio Grande do Sul y el Ministerio de Cultura y Educación de la República Argentina con el objeto de promover la cooperación para el desarrollo de acciones destinadas a la enseñanza de las lenguas portuguesa y española así como el intercambio cultural por medio de cursos, prácticas, estudios conjuntos, asesorías, seminarios, festivales y muestras (Cláusula primera). En la firma de este documento se tuvo en cuenta que la lengua, la cultura y la educación son factores fundamentales para la expresión, preservación, comunicación y aproximación de la identidad y que la promoción del intercambio cultural y educacional beneficiaría el desarrollo de las propuestas del Mercosur plasmadas en el Tratado de Asunción.

Dos años después, Argentina y Brasil celebraron el Convenio de Cooperación educativa $(10 / 11 / 1997)^{75}$ en una búsqueda de dar respuesta a los desafíos de la consolidación de la democracia en un contexto de integración, de transformaciones productivas y de avances científicos y tecnológicos. Los Estados se obligaron a promover la enseñanza del idioma oficial de la otra parte en los cursos de educación básica y/o media, a incluir contenidos referidos a la integración regional en los distintos niveles educativos y a crear en grado y postgrado asignaturas que aborden la historia, literatura, cultural, economía, realidad política, tecnológica y social de la otra parte (Artículo 4).

En el plano institucional mercosureño, en la Reunión de Ministros de Educación realizada en el año 2001 se aprueba el Plan Estratégico 2001-2005 del SEM. En este documento destacamos dos de los principios orientadores que se plantean: (1) "la educación como espacio cultural para el fortalecimiento de una conciencia favorable a la integración que valore la diversidad y la importancia de los códigos culturales y lingüísticos" y (2) "el proceso de integración se fortalece en la institución educativa para impactar fuertemente en las instituciones educativas, especialmente en los niveles primarios y medios" (RME, 2001).

\footnotetext{
${ }^{75}$ Este Convenio entró en vigencia el 15 de junio de 2000.
} 
Ya en el área de la Educación Básica, se considera a las escuelas del Mercosur "como espacios donde culturas e identidades regionales pueden constituirse y actuar en el sentido de una efectiva conciencia de integración regional y de sus correspondientes prácticas sociales" (RME, 2001). Entre las metas propuestas rescatamos la intención de consolidar la enseñanza sistemática del idioma oficial extranjero en todos los países y de consolidar un sistema de movilidad de profesores de las lenguas oficiales entre los países del Mercosur.

No bien inicia el siglo XXI, la preocupación por los códigos interculturales y lingüísticos como necesarios para el fortalecimiento de la integración regional deja de ser únicamente bilateral y se convierte en regional. Así se vislumbra en el segundo plan de acción del SEM que busca sensibilizar sobre la necesidad del aprendizaje de los dos idiomas oficiales del Mercosur. Sin embargo, advertimos que la celebración de acuerdos a nivel local -estadual, provincial, ministerial, consular- seguirá siendo el punto de partida en la búsqueda de la identidad regional.

En noviembre de 2003 en Brasilia, el ministro de educación argentino, Daniel Filmus y el entonces ministro brasileño, Cristovam Buarque, reunidos en ocasión del Seminario Internacional Universidad XXI, firmaron la "Declaración Conjunta del Ministerio de Educación de Brasil y del Ministerio de Educación, Ciencia y Tecnología de la República Argentina para el Fortalecimiento de la Integración Regional" con el propósito de afianzar los lazos en el área educativa y, a partir de ese momento, equipos técnicos de Argentina comenzaron a trabajar en un borrador del proyecto piloto (RME, Acta 1/2018). Ambos representantes ministeriales reafirmaron la gran importancia de la enseñanza del español en Brasil y del portugués en Argentina.

El 9 de junio de 2004 los ministros de educación de Argentina, Daniel Filmus y de Brasil, Tarso Genro, firman una Declaración Conjunta que incluía un Plan de Trabajo donde se prevé la creación en región de frontera de tres escuelas en cada país con modelo bilingüe intercultural (Sagaz, 2013).

Según surge de la publicación conjunta de los ministerios de educación argentino y brasileño (2007) y del Anexo V del Acta $\mathrm{N}^{\circ} 1$ de la RME (2018), el Programa de Escuelas Interculturales Bilingües de Frontera fue presentado en el marco de la XXVI RME del Mercosur, Bolivia y Chile realizada en Buenos Aires el 10 de junio de 2004. Sin embargo, no encontramos en el Acta labrada en dicha reunión ni en sus Anexos rastro alguno del PEBF. 
El 19 de junio de 2005 el Consejo del Mercado Común adopta la Decisión № 09/05 por la cual se adopta el Acuerdo de admisión de títulos, certificados y diplomas para el ejercicio de la docencia en la enseñanza del español y del portugués como lenguas extranjeras en los Estados partes. El propósito del Convenio, aún vigente, es facilitar la movilidad de docentes de los idiomas oficiales del Mercosur de instituciones de educación primera y media de la región para compensar las carencias existentes en los Estados partes respecto de la potencial demanda de recursos humanos calificados para enseñar los idiomas oficiales del bloque.

El 30 de noviembre de 2005, los ministros de educación de Argentina y Brasil firmaron un Protocolo para la promoción de la enseñanza del español y del portugués como segundas lenguas entendiendo que de esta manera se consolida la integración regional en el marco de la diversidad. Este acuerdo está dirigido a capacitar a formadores de profesores brasileños de español y de profesores argentinos de portugués. Es el paso previo a poder volver obligatoria la enseñanza de estas lenguas en las escuelas.

Ese mismo año se lanzó oficialmente el 4 de marzo en la localidad de Dionísio Cerqueira (Santa Catarina, Brasil) y en Bernardo de Irigoyen (Misiones, Argentina) el Programa de Escuelas Bilingües de Frontera a través de la Coordinación de formación continua del Departamento de Políticas de Educación infantil y de Enseñanza fundamental de la Secretaría de Educación Básica del Ministerio de Educación de Brasil junto al Ministerio de Educación, Ciencia y Tecnología de Argentina (Sagaz, 2013).

El 9 de febrero de 2006, la Secretaría de Cultura del Estado de Paraná (Brasil) y las Provincias de Chaco, Misiones, Formosa y Corrientes (Argentina) firmaron un convenio marco de cooperación con el propósito de establecer mecanismos de cooperación e intercambio de experiencias orientados a la promoción, difusión y para asegurar los vínculos culturales de la región, mediante cursos, seminarios, becas, conferencias, formaciones, espectáculos, entre otras actividades.

Por Decisión N 35 del Consejo del Mercado Común del día 15 de diciembre de 2006, se incorporó el guaraní como uno de los idiomas del Mercosur y se establece que los idiomas de trabajo son los oficiales (español y portugués). 
El PEBF se incorpora en el ámbito de las acciones del Mercosur en 2006, conforme al Plan de Acción 2006-2010 cuando pasa a formar parte de la agenda de trabajo del SEM. El Plan operativo se plantea en el Área de la Educación Básica como meta la "promoción de un programa de escuelas gemelas por país, priorizando en una primera etapa las fronteras bilingües, partiendo de la experiencia existente entre Argentina y Brasil y alcanzando progresivamente la presencia en todas las fronteras" (RME, 2006). Las acciones se proyectaron en dos etapas: (1) iniciar y/o ampliar un programa de escuelas gemelas que incluya a Argentina, Brasil, Paraguay y Uruguay, y (2) extender a los países limítrofes de lengua española (Chile, Bolivia y otros).

Según surge del Anexo V del Acta $N^{\circ} 1$ de la RME (2018) y, que posteriormente, fuera confirmado por funcionarios del Ministerio de Educación y Cultura de Uruguay ${ }^{76}$, el Programa de Escuelas Interculturales de Frontera se inició en el año 2008 con dos escuelas pertenecientes a los departamentos Cerro Lago (Río Branco) y Rocha (Chuy) y las “escuelas espejo” del programa en Brasil pertenecientes al estado de Río Grande del Sur (Yaguarón y Chuí). Según surge del acta de la VI Reunión técnica del Programa llevada a cabo los días 13 y 14 de abril de 2009, iniciaría la tercera semana de abril de ese año el intercambio docente luego del estudio sociolingüístico que tuvo lugar en octubre del año anterior en Yaguarón/Río Branco y Chuy/Chui. Más adelante, abordaremos la aplicación del programa en la frontera uruguaya.

En el segundo semestre de ese mismo año se dio inicio a las actividades en la frontera paraguayo-brasileña, en las comunidades educativas del departamento de Pedro Juan Caballero (Amambay) y en el estado de Mato Grosso (Ponta Pôra) ${ }^{77}$ y en marzo de 2009 inicia el intercambio docente (RME, 2018).

Rescatamos las actas de las Reuniones Técnicas del Proyecto de Escuelas Interculturales Bilingües de Frontera del año 2010 puesto que dan cuenta de la puesta en marcha del proyecto en las fronteras Argentina-Brasil, Brasil-Uruguay, Brasil-Venezuela ${ }^{78}$, Brasil-Paraguay y se mani-

\footnotetext{
${ }^{76}$ Lauren Dimperio, Profesora coordinadora del Departamento de Segundas Lenguas y Lenguas Extranjeras, C.E.I.P., Ministerio de Educación y Cultura de Uruguay, correo electrónico, 4 de diciembre de 2019.

${ }^{77}$ Escuela EE Jao Brembatti en la localidad de Ponta Pôra y Escuela Calvoso en el departamento Pedro Juan Caballero (Mendes Thomaz, 2011, p. 332).

${ }^{78}$ Escuelas EM Alcides da Conceição Lima en la localidad de Pacaraima (Brasil) y EIB San Antonio de Morichal y EIB El Salto en la localidad de Santa Helena de Uairén (Venezuela) (Mendes Thomaz, 2011, p. 333).
} 
fiesta la intención de llevar a cabo la primera reunión Argentina-Paraguay. En reuniones posteriores Paraguay manifiesta un impase en la implementación del programa (2015) y, si bien presenta un breve análisis de sus escuelas de fronteras y de las dificultades de sus estudiantes (2016), nunca llega a implementar el programa en la frontera con Argentina.

En la reunión del Grupo Técnico de 2011, se propone cambiar la denominación: deja de llamarse "Proyecto" y pasa a ser "Programa de Escuelas Interculturales de Frontera" (Acta $\mathrm{N}^{\circ}$ 01/11 GTEIF).

En 2014, en la reunión del GT de Escuelas de Frontera, los representantes de Argentina, Brasil y Uruguay proponen que el enfoque intercultural de las escuelas de frontera adquiera el reconocimiento como política pública, sustentando esta propuesta sobre la base que: a) la interculturalidad es una característica inherente a las zonas de frontera, b) no es suficiente trabajar sobre el bilingüismo cuando se trata de abordar la interculturalidad y c) existe un gran número de escuelas en condición fronteriza lo que dificulta pensar en una sola alternativa de interacción uno a uno. En esa misma reunión se sugiere cambiar por "escuelas vecinas" la anterior denominación de "escuelas gemelas o espejo" (Acta $\mathrm{N}^{\circ}$ 01/14 GTEIF). Sin embargo, a lo largo de nuestra investigación constatamos, tanto en diferentes informes como en las entrevistas realizadas, la persistencia en la denominación de estas escuelas como "gemelas" o incluso "escuelas hermanas".

En abril de 2018, el GTEIF aprueba el documento titulado "Marco referencial Escuelas Interculturales de Frontera" (Anexo IV Acta № 01/18 GTEIF), que luego será aprobado el 15 de junio de ese mismo año por la Reunión de Ministros de Educación como Anexo V Acta 1/18, documento que ya hemos mencionado más arriba.

En la reunión del GTEIF por videoconferencia llevada a cabo en marzo 2019, Argentina señaló que se encontraba desarrollando un mapa georreferenciado de las escuelas que forman parte del grupo de trabajo. Este mapa lo podemos visualizar en el siguiente enlace: $\underline{\text { http://mapa.educacion.gob.ar/maps/escuelas-programa-integracion-regional }}{ }^{79}$ pero lamentablemente se encuentra incompleto y desactualizado.

\footnotetext{
${ }^{79}$ Última visita 10 de septiembre de 2020.
} 
En esa misma reunión el GTEIF estableció temáticas para trabajar semestralmente en las escuelas de frontera ("Yerba mate" para el primer semestre de 2019), y solicitó a la Comisión de Área Educación Básica (CAEB) la inclusión de un espacio digital dentro del sitio web del Mercosur para dar cuenta de las experiencias de las escuelas incluidas en el GT.

El Subgrupo de Trabajo $\mathrm{N}^{\circ} 18$ de Integración Fronteriza (SGT No ${ }^{\circ}$ ) que funciona en la órbita del Grupo Mercado Común (GMC) tuvo su primera reunión en mayo de 2016. Nos interesa tomar en cuenta su labor porque justamente en su primera reunión de 2017 reitera a la Secretaría del Mercosur la necesidad de tomar conocimiento de los temas fronterizos abordados por los órganos del bloque.

El Anexo IV Acta $\mathrm{N}^{\circ} 1 / 18$ del SGT $\mathrm{N}^{\circ} 18$ contiene un relevamiento de las Acuerdos de Localidades de Fronteras Vinculadas vigentes en Brasil. En la frontera con Argentina y Uruguay se establecen áreas de cooperación entre las partes para llevar adelante trabajos conjuntos en materia educativa, incluido el intercambio de docentes, alumnos y material educativo. En la segunda reunión de 2018, el Comité de frontera Brasil-Uruguay (Anexo IV Acta $\mathrm{N}^{\circ} 2 / 18$ ) propone varias acciones en las ciudades gemelas relacionados con la cultura y la educación entre las que destacamos la continuidad y coordinación del Programa de Escuelas Interculturales de Frontera, generar salidas didácticas entre las fronteras, la enseñanza del español y del portugués en la frontera, la necesidad de implantación de bibliotecas bilingües, la necesidad de elaborar mecanismos continuos de integración, entre otras.

Es recién en octubre de 2019 que el Sector de Asesoría Técnica de la Secretaría del Mercosur presenta un mapeo temático y normativo de la integración fronteriza (Anexo VII Acta $\mathrm{N}^{\circ}$ 3/19 SGT No 18) que abarca el período 2018 y primer semestre 2019 e identifica los órganos y foros del Mercosur y la normativa aprobada vinculada a la integración fronteriza. El propósito del mapeo es ayudar al SGT $N^{\circ} 18$ a identificar los temas prioritarios. De esta presentación (se trata de una presentación de PowerPoint), surge que las temáticas de educación, cultura y migración han tenido el mismo desarrollo para el período informado en el ámbito del Consejo Mercado Común: educación y cultura en el ámbito de la Reunión de Ministros de Educación (RME), el Comité Coordinador Regional Comisión de Área de Educación Básica (CRC-EB), el Grupo Técnico de Escuelas de Frontera (GTEF) y la cuestión migratoria en el ámbito de la Reunión de 
Ministros del Interior y de Seguridad (RMI). A ello sumamos lo dicho un poco más arriba, el SGT N 18 de Integración Fronteriza funciona en el ámbito del Grupo Mercado Común.

\section{EI PEBF: de la propuesta a su implementación}

En este apartado vamos a analizar de la propuesta del Programa Escuelas Interculturales Bilingües de Frontera (PEBF) según surge del documento conjunto de los ministerios de educación argentino y brasileño (2007) y del Anexo V del Acta $N^{\circ} 1$ de la RME (2018). Si bien no nos vamos a detener en estos dos documentos que son muy similares a pesar de haber sido redactados con once años de diferencia, nos gustaría rescatar las bases para luego detenernos en la implementación efectiva en las provincias argentinas. Y dado que hemos tenido la oportunidad de acceder a la información, dar cuenta del programa en la frontera uruguayo-brasilera.

Según estos documentos, la zona fronteriza de países con diferentes lenguas es una zona de indefinición (2007), inestabilidad y de contacto-conflicto (2018) sociolingüístico. En 2004 se llevaron a cabo diagnósticos sociolingüísticos que dieron cuenta de la diferencia de la presencia del portugués y del español en las ciudades-gemelas y en toda la frontera en general. En el lado argentino de la frontera, la presencia del portugués es relativamente constante y es considera una lengua de "prestigio", mientras que del lado brasilero la presencia del español no es generalizada en niños escolarizados ni en sus familiares.

En la frontera paraguayo-brasilera, el portugués es la lengua mayoritaria que posibilita la comunicación y la convivencia. En Paraguay se habla con facilidad español, portugués y guaraní; los brasileros en cambio presentan algunas dificultades con el uso del guaraní y del español en la comunicación diaria.

Por su parte, la frontera uruguayo-brasilera se caracteriza por la presencia del español y del portugués convirtiéndola en una zona de bilingüismo social. También está presente otra variedad lingüística denominada "portuñol”, de ello hablaremos más adelante.

Quisiéramos recuperar las dos dimensiones del concepto de interculturalidad utilizados en el programa: a) la dimensión de las vivencias, que implica un conjunto de prácticas sociales relacionadas con el estar con el otro, entenderlo, trabajar con él y producir sentido de manera conjun- 
ta; b) la dimensión informacional, que implica tener conocimientos sobre el otro, su país, sus formas históricas de constitución y de organización, conocimientos que deben estar presentes en los proyectos de aprendizaje.

Otro de los conceptos que estructuran el programa es el de cooperación interfronteriza que es entendida como:

la oportunidad de superar la idea de frontera nacional como barrera -“en donde el país se termina"- sino al contrario, de entenderla como la visualización del acceso a oportunidades sociales, personales, educativas, culturales, económicas nacidas de la presencia y de la interacción con el otro. Superar también los prejuicios, conflictos y disputas originadas en un pasado o la afirmación del Estado nacional como instancia única de atribución de identidad en la que el "otro" es presentado como amenaza o como negación (Anexo V del Acta $\mathrm{N}^{\circ} 1$ de la RME, 2018, sección enseñanza a través de los proyectos de aprendizaje, párrafo 2).

El programa se propone el desarrollo de un modelo de enseñanza común en las escuelas de frontera. Teniendo en cuenta que existe una pluralidad de escuelas primarias, cada sistema escolar y cada escuela elabora un proyecto educativo institucional propio. Se considera que la enseñanza a través de "proyectos de aprendizaje" es un instrumento para la construcción de la cooperación interfronteriza. Los proyectos de aprendizaje surgen de los intereses manifestados por los alumnos involucrados y son consensuados entre los docentes de ambos países. Veremos en los próximos apartados la forma que adoptó en cada provincia.

Como afirma Lipski (2018), en la frontera brasilera con los países hispanohablantes se producen contactos lingüísticos entre el español y el portugués. En las ciudades fronterizas son pocos los hispanohablantes que dominan completamente la lengua portuguesa con excepción de dos regiones, donde hay comunidades de habla portuguesa dentro de dos naciones hispanohablantes: en el norte de Uruguay y en la provincia argentina de Misiones.

\section{El caso de Uruguay}

Tomamos la decisión de incorporar información sobre el PEIB en la frontera uruguaya por las características lingüísticas e identitarias que presenta y por la factibilidad de acceder a la infor- 
mación que nos fue proporcionada por la Administración Nacional de Educación Pública (ANEP), ente autónomo responsable de la planificación, gestión y administración del sistema educativo público en sus niveles de educación inicial, primaria, media, técnica y formación en educación terciaria en todo el territorio uruguayo ${ }^{80}$.

El Programa de Escuelas Interculturales de Frontera se inició en la República Oriental del Uruguay en el año 2008 en los departamentos de Cerro Largo (Río Branco), Rocha (Chuy), luego se incorporó Rivera y, en 2018, se sumó el departamento de Artigas (Bella Unión) ${ }^{81}$. Según surge del informe que nos enviara por correo electrónico la Coordinadora del Departamento de Segundas Lenguas y Lenguas Extranjeras del Consejo de Educación Inicial y Primaria (CEIP), la maestra Laurem Dimperio, al 26 de agosto de $2020^{82}$, once escuelas participa del programa en todo el territorio uruguayo con 84 docentes involucrados. En el departamento de Artigas: Escuela N³7 y Escuela N78 (Bella Unión); en Cerro Largo: Escuela N5 (Río Branco), Escuela N¹2 (Río Branco) y Escuela N74 (Aceguá); en Rivera: Escuela N5, Escuela N9 y Escuela N¹34 y en el departamento den Rocha: Escuela N²8, Escuela No 74 y Escuela No110 (Chuy).

En cada escuela, los proyectos son llevados adelante por un equipo de docentes integrado por un/a Maestro/a Director/a, el profesor/a de portugués, maestros/as de clase y profesores de otras áreas como ser Arte o Física. Se trabaja de manera conjunta con la "escuela espejo" en Brasil que ha sido seleccionada por proximidad o por poseer contactos con alguna escuela de la zona fronteriza. Los proyectos abarcan desde $1^{\circ}$ grado hasta $6^{\circ}$ grado de acuerdo a los docentes que estén involucrados. Según el informe, en el año 2019 se abordó la temática de la yerba mate y se realizaron actividades muy productivas en todas las escuelas y encuentros de intercambio con escuelas de Brasil y Argentina, logrando la unión de la triple frontera.

La zona fronteriza del norte de Uruguay se caracteriza por la presencia de dos lenguas, el español y el portugués. Además en esta región se hablan otras variedades lingüísticas que han

\footnotetext{
${ }^{80}$ Para más información sobre la ANEP, consultar: https://www.anep.edu.uy/acerca-anep

${ }^{81}$ Según información brindada por Lauren Dimperio, Coordinadora del Departamento de Segundas Lenguas y Lenguas Extranjeras, Consejo de Educación Inicial y Primaria (CEIP), ANEP, en correo electrónico, el 4 de diciembre de 2019.

${ }^{82}$ Informe PEIF-Uruguay, elaborado por Lauren Dimperio, Coordinadora del Departamento de Segundas Lenguas y Lenguas Extranjeras, Consejo de Educación Inicial y Primaria (CEIP), ANEP, correo electrónico, 26 de agosto de 2020.
} 
sido llamadas "portuñol", "fronterizo", "bayano" o "brasilero". Estas variedades dialectales tienen base portuguesa, influidas por el contacto con el español. Variedades fronterizas que han sido denominadas: portugués del Uruguay (Brovetto, 2010). Esta variedad no se encuentra escrita y se transmite oralmente a través de las generaciones. Lingüísticamente posee características únicas, incluso hay vocablos que no existen por fuera del portuñol ${ }^{83}$.

En el programa de escuelas interculturales de frontera se incluyó el portugués standard, según nos informó Aldo García ${ }^{84}$, a cargo de la Dirección de Políticas Lingüísticas de la ANEP. Esta incorporación responde a una integración de tipo geográfica y política planteada desde el Mercosur, más que a aspectos estrictamente lingüísticos e identitarios ${ }^{85}$. Según Brovetto (2010), las razones y motivaciones de la introducción del portugués en la educación fronteriza que responden a los compromisos asumidos en el marco del Mercosur, más allá de su importancia, se refieren al portugués como lengua oficial de Brasil y se opone a la justificación para la educación bilingüe de frontera cuyo centro de definición es la inclusión del portugués del Uruguay.

\footnotetext{
${ }^{83}$ Aldo García, Director de la Dirección de Políticas Lingüísticas, ANEP, correo electrónico, 23 de enero de 2020.

${ }^{84}$ Ibídem.

${ }^{85}$ Claudia Brovetto, ANEP, correo electrónico, 22 de enero de 2020.
} 


\section{Las EIB del lado argentino}

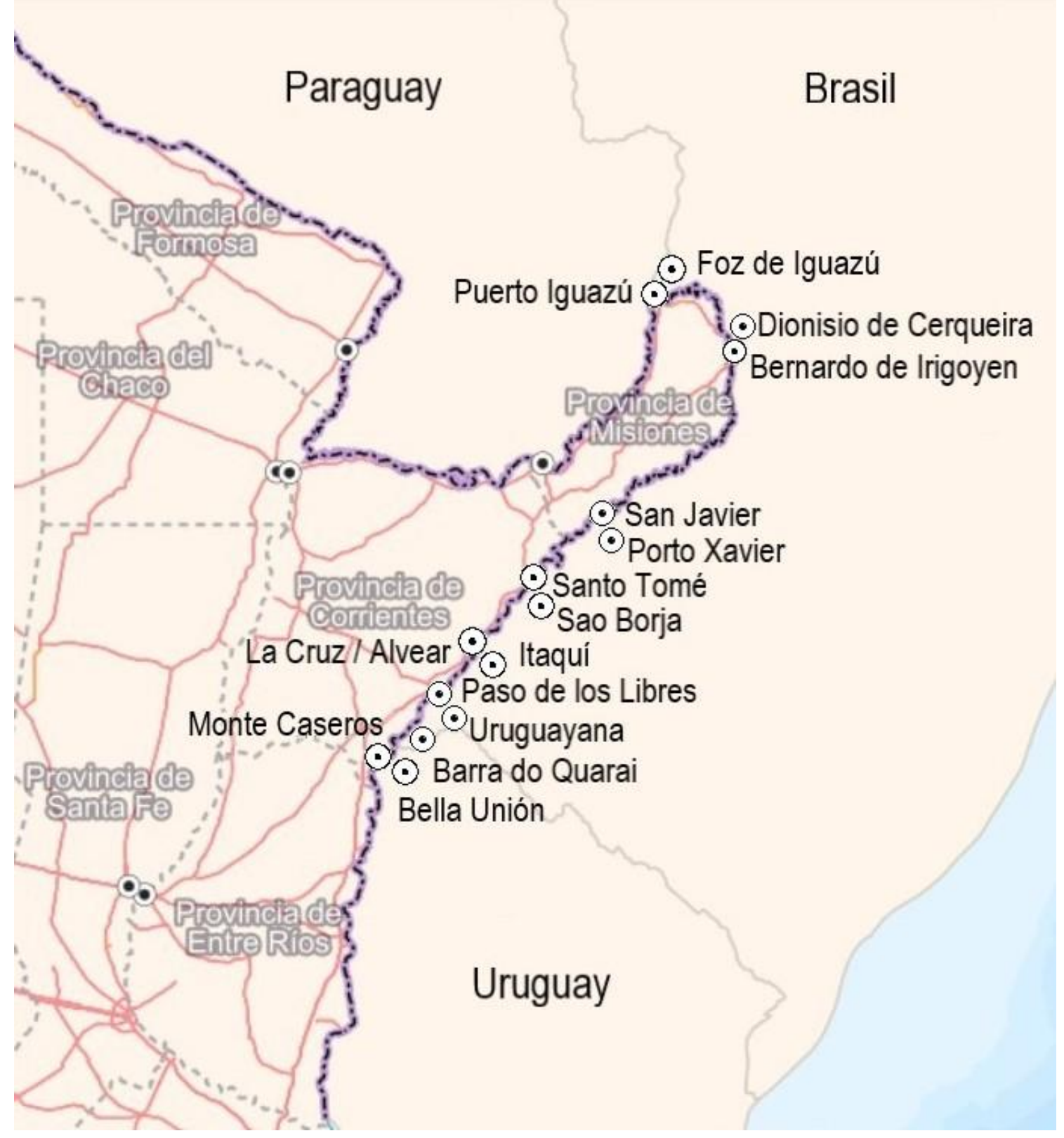

Mapa \#2. Ubicación de las ciudades espejo involucradas en el PEBF.

Fuente: elaboración propia en base a mapa disponible en el Instituto Geográfico Nacional ${ }^{86}$ e información proporcionada por los ministerios de educación de Misiones y Corrientes

86 El Instituto Geográfico Nacional depende del Ministerio de Defensa de la Nación. Mapa disponible en: https://ide.ign.gob.ar/portal/apps/webappviewer/index.html?id=96debf32a6cd4c27b4e445681f535ec0 
La información que pudimos recabar para este aparatado proviene directamente de los gobiernos provinciales participantes y de los actores involucrados como son directivos de área, asesores pedagógicos, directores de escuelas y maestros. Salvo en el caso de Misiones, en este apartado no pretendemos dar un panorama completo de la situación del programa en cada una de las escuelas sino dar cuenta de la evolución de la implantación del programa en alguno de los establecimientos con los que pudimos entablar contacto.

\section{El PEBF en la Provincia de Misiones}

La Provincia de Misiones es la que más desarrollo ha tenido ${ }^{87}$ en el marco del programa de EIB y la única que ha podido mantener la modalidad a lo largo de 15 años tal como afirma Liliam Prytz Nilsson, directora del Instituto de Políticas Lingüísticas (Daviña, 2018, p. 53) y Vivian Eich ${ }^{88}$, asesora técnica pedagógica de la misma institución provincial. Se implementó en dos escuelas de las localidades de Bernardo de Irigoyen (EIB $\mathrm{N}^{\circ} 1$ Escuela $\mathrm{N}^{\circ}$ 604) cuya escuela hermana se encuentra en el municipio de Dionisio de Cerqueira, Brasil (Escuela "Doutor Theodureto") y en Puerto Iguazú (EIB No 2 Escuela $\mathrm{N}^{\circ} 164$ "Mayor Juan Leonetti”) cuya escuela hermana se encuentra en el municipio de Foz de Iguazú (Escuela "Adele Zonotto Scalco"). Se hizo el intento de incorporar a la Escuela $\mathrm{N}^{\circ} 109$ de la localidad de San Javier que tuvo contacto con Porto Xavier pero se limitó al ámbito de investigación y a la preparación de material de enseñanza. El cruce en esta escuela no fue posible por no tratarse de una frontera seca (frontera húmeda) y el seguro no lo cubre.

Se trata de escuelas primarias ubicadas en la frontera seca que no son rurales a pesar de que están emplazadas en ciudades que no son grandes cascos urbanos. En 2005, la escuela de Bernardo de Irigoyen fue la primera en participar del programa. En 2007, por Resolución $\mathrm{N}^{\circ}$ 1087 del Consejo General de Educación de Misiones se estableció la modalidad de trabajo para los docentes de las EIBF y se determinó que la unidad de trabajo son las "escuelas hermanas" que realizan el cruce semanal.

\footnotetext{
${ }^{87}$ Encargada del Área de Ruralidad, Ministerio de Educación de la Nación Argentina, conversación telefónica, 6 de febrero de 2020 .

${ }^{88}$ Vivian Eich, Asesora técnica pedagógica, Instituto de Políticas Lingüísticas, Ministerio de Cultura Ciencia, Educación y Tecnología de la Provincia de Misiones, entrevista por videoconferencia, 8 de septiembre de 2020.
} 
Debemos aclarar que el presupuesto para el funcionamiento del programa (material, salarios, viáticos, etc.) tiene un origen diferente a cada lado de la frontera: en el caso argentino, el presupuesto es enviado por el gobierno nacional, mientras en que el caso brasilero, nos encontramos con escuelas municipales cuyos docentes son contratados por el municipio involucrado. En el año 2019, los maestros brasileros pagaron por su cuenta el cruce para darle así continuidad al programa.

Por otra parte, en Brasil el acompañamiento pedagógico fue transferido en 2013 a las universidades de la región - Universidade Federal da Integração Latino-Americana, (UNILA)/Universidade Federal da Fronteira Sul (UFFS) -, mientras que en Argentina se trabaja con equipos técnicos dentro de los ministerios. Según Prytz Nilsson (Daviña, 2018), esta situación afecta el grado de institucionalización de la propuesta pero también proporciona una mayor diversificación en las perspectivas que planifican y monitorean el proyecto.

Como señaláramos más arriba, el programa se basa en proyectos de aprendizaje interdisciplinar y situado en las necesidades, intereses y motivaciones de los niños y sus familias: durante los primeros quince días se lleva a cabo una sensibilización, en un segundo momento se relevan los intereses de los estudiantes a través de preguntas y es así que se elabora un proyecto interdisciplinario consensuado con el par pedagógico.

La escuela de Puerto Iguazú cuenta con 35 maestros, el equipo del programa EIB está integrado por dos maestros y un asesor pedagógico, mientras que la escuela de Bernardo de Irigoyen cuenta con 35-40 maestros y el equipo se compone de cuatro maestros y dos asesores pedagógicos. Los maestros cruzan la frontera dos veces por semana, martes y jueves, en jornada completa (de 7 a 18 hs.). Los días lunes y miércoles narran sus experiencias y las comparten en ateneos y los días viernes comparten otras aulas.

Los niños, niñas y adolescentes del lado argentino logran ser bilingües reales y no aditi$\operatorname{vos}^{89}$, no sucede lo mismo con los estudiantes brasileros. Lipski (2018, p. 175) en su estudio con-

\footnotetext{
${ }^{89}$ Se habla de bilingüismo aditivo cuando un individuo añade una nueva lengua a su repertorio verbal sin que su primera lengua corra peligro de ser sustituida, al tratarse de una lengua de prestigio. Ver: Palacios Martínez, Ignacio (dir.), Rosa Alonso Alonso, Mario Cal Varela, Yolanda Calvo Benzies, Francisco Xabier Fernández Polo, Lidia Gómez García, Paula López Rúa, Yonay Rodríguez Rodríguez \& José Ramón Varela Pérez. 2019. Diccionario electrónico de enseñanza y aprendizaje de lenguas. (Disponible en línea en https:/www.dicenlen.eu/es/diccionario/entradas/bilinguismo-aditivo, con fecha de acceso 29/10/2020).
} 
firma que "el hilo común que vincula todas las comunidades argentinas de la franja fronteriza misionera es el empleo de la lengua portuguesa como lengua de preferencia entre muchos individuos nacidos y criados dentro del territorio argentino".

Según la asesora pedagógica consultada ${ }^{90}$, siempre existieron problemas con Brasil en la implementación del programa. Uno de los inconvenientes es que la EIB no está institucionalizada como modalidad en los municipios involucrados. En 2011, los problemas concretos estuvieron vinculados a la falta de financiación del programa y, como mencionáramos más arriba, en 2019 fueron los propios maestros quienes financiaron el desplazamiento por falta total del apoyo del gobierno brasilero.

Del lado argentino el problema es otro, la falta de interés por parte del gobierno provincial y del nacional en el programa. Quienes trabajan en el Instituto de Políticas Lingüísticas deben luchar "día a día" por defender el programa, buscando reconocimiento y justificando por qué el mismo debe continuar.

\section{El PEBF en la Provincia de Corrientes}

La primera escuela que participó en el programa estaba ubicada en la localidad de Pasos de los Libres (Escuela ํ 667 "Vicente Eladio Verón”) cuya ciudad gemela es Uruguayana (Estado Río Grande del Sur). En 2006, el programa se amplió a las localidades de Santo Tomé (Escuela No 554 “Josefa Fernández Dos Santos” y Escuela No 484 "República Federativa de los Estados Unidos del Brasil") cuya ciudad gemela es Sao Borja (Estado Río Grande del Sur) y en las localidades de La Cruz/Alvear (Escuela No 478 "Gobernación de Tierra del Fuego" de La Cruz y Escuela № 123 "José Carmelo Belmont" de Alvear) cuya ciudad gemela era Itaquí (Estado Río Grande del Sur).

Según el informe titulado "Escuelas de Frontera" (2016) que nos fuera compartido por correo electrónico por la Dirección de Educación Intercultural Bilingüe ${ }^{91}$ del Ministerio de Educa-

\footnotetext{
${ }^{90}$ Vivian Eich, Asesora técnica pedagógica, Instituto de Políticas Lingüísticas, Ministerio de Cultura Ciencia, Educación y Tecnología de la Provincia de Misiones, entrevista por videoconferencia, 8 de septiembre de 2020.

${ }^{91}$ Valeria Solis, Asesora pedagógica, Dirección de Educación Intercultural Bilingüe, Ministerio de Educación de la Provincia de Corrientes, correo electrónico, 20 de noviembre de 2019.
} 
ción de la Provincia de Corrientes, el programa fue interrumpido luego de ocho años de vigencia por cuestiones políticas, económicas y de seguridad tanto para docentes como para alumnos. Semanalmente cada escuela argentina enviaba docentes a dictar clases de español en lo que en ese momento se definía como una "escuela gemela" en la localidad que tuvieran enfrente, y las autoridades del vecino país, realizaban la misma acción, comúnmente esto se denominaba “cruce”.

En el año 2013 se crea la Dirección de Educación Intercultural Bilingüe con el propósito de retomar las tareas de acompañamiento pedagógico a los docentes que habían sido nombrados para trabajar en el programa. A partir de allí se retoman las tareas de diagnóstico de carácter administrativo y pedagógico. Por Disposición 594/14 del Consejo General de Educación de la Provincia de Corrientes se institucionaliza el programa y se crea la jurisdicción Escuelas de Frontera.

Teniendo en cuenta que Corrientes no solo limita con Brasil sino también con Paraguay y Uruguay fue necesario incluir otras instituciones de nivel primario que serían llamadas Escuelas Interculturales Bilingües de Frontera. De este modo se oficializa la Disposición 452/15 del Consejo General de Educación, incluyendo escuelas y jardines de la localidad de Monte Caseros (Escuelas $\mathrm{N}^{\circ} 88$ y $\mathrm{N}^{\circ} 89$, Jardines de Infantes Nucleados $\mathrm{N}^{\circ} 61$ y $\left.\mathrm{N}^{\circ} 14\right)$, de Paso de los Libres (Escuela $\mathrm{N}^{\circ} 619$ ), todas sobre el margen del Río Uruguay. Y sobre el margen del Río Paraná, en la localidad de Ituzaingó en la Isla Apipé (Escuela $\mathrm{N}^{\circ} 419$ ), que posee un rico y variado enlace con Paraguay y su relación ya no es con el portugués sino con el guaraní.

Tuvimos la oportunidad de entrevistarnos con dos actores de este programa que nos permitieron conocer la realidad del programa en sus respectivas localidades: Claudia Aun, maestra en Escuela $N^{\circ} 554$ “Josefa Fernández Dos Santos” en la localidad de Santo Tomé y María Rosa Carbonara, directora de la Escuela $N^{\circ} 88$ "Del Centenario" en la localidad de Monte Caseros.

Santo Tomé es una localidad cabecera del departamento homónimo ubicada a orillas del río Uruguay. Allí se ubica la Escuela $\mathrm{N}^{\circ} 554$ clasificada como urbana donde trabaja Claudia Aun $^{92}$ que al momento de la entrevista se encontraba sin directora (por licencia médica). La escuela se incorpora al programa en el año 2006 con tres maestras y a la fecha cuenta con la participación de cinco o seis maestras más la directora y llegaron a ser ocho docentes los que partici-

\footnotetext{
${ }^{92}$ Claudia Aun, maestra en la Escuela N 554 “Josefa Fernández Dos Santos” y vicedirectora de la Escuela N 484 "República de los Estados Unidos del Brasil”, Santo Tomé, Corrientes, entrevista telefónica, 4 de diciembre de 2019.
} 
paron a lo largo de los años. En sus inicios, el programa comienza con los niños y niñas de $1^{\circ}$ grado y se fue proyectando hasta el $3^{\circ}$ y $4^{\circ}$ grado. Hasta el año 2011/2012 se efectuaba el cruce de los maestros a la "escuela espejo" en la localidad de San Borja en el Estado de Rio Grande del Sur (en primer lugar, participó la escuela municipal "Aparicio Mariense” y, en un segundo momento, la escuela municipal "Ubaldo Sorrilha da Costa"). Al inicio del año escolar planificaban junto a las maestras de la escuela brasilera los contenidos y las actividades. En el cruce las maestras argentinas enseñaban a los estudiantes brasileros el contenido, lengua o ciencias, en español, no enseñaban la lengua española y a la inversa las maestras brasileras en territorio correntino. La lengua española debía aprenderse como Lengua 2 y no como lengua extranjera ${ }^{93}$. El propósito era formar "ciudadanos de la frontera", lograr una sociedad unificada, afirma Claudia.

Del lado brasilero siempre hubo mayor resistencia a la lengua española mientras que los estudiantes argentinos son mucho más receptivos a la lengua portuguesa. La zona de Santo Tomé es muy particular, los niños consumen la televisión y la radio brasilera que está prácticamente en todos los hogares y es muy común que mezclen las dos lenguas (portuñol). A ello se suma el comercio, los correntinos cruzan la frontera para comprar vestimenta y comestibles. Este contacto con Brasil siempre fue así, según nos cuenta Claudia. Hace tiempo, comprar en San Borja era mucho más barato, se trata de una ciudad más grande que Santo Tomé y con más opciones (por ejemplo, consultorios odontológicos). Hoy en día, a pesar que la creación del puente internacional tuvo repercusiones en el tipo de cambio, los correntinos continúan con la costumbre de cruzar para consumir del otro lado.

Según relata Claudia, las reuniones de trabajo en Brasil se llevaban a cabo de una manera distinta, la tarea docente es reconocida y valorada. La estructura edilicia de las escuelas, el no uso de guardapolvo por las maestras, la disponibilidad del material de estudios para los chicos, el trato interpersonal entre los docentes y directivos, los espacios de recreación de los docentes y de

\footnotetext{
${ }^{93}$ La lengua segunda (L2) sería la lengua más próxima a la lengua materna (L1), concebida como sustituta cercana de la lengua materna, y estrechamente relacionada con los ámbitos de trabajo y estudio, sobre todo. Por el contrario, la lengua extranjera (LE) no deja de ser 'extranjera', si el aprendiente no siente un acercamiento cultural verdadero ni una identificación con los hablantes de la lengua que está estudiando, o que ya ha aprendido. En efecto, es un hecho comprobado que cuando el alumno no se siente identificado ni con la cultura ni con la sociedad que habla esa otra lengua, la siente como lejana y distante. Por el contrario, cuando el alumno se siente fuertemente identificado social y culturalmente con la lengua meta la suele denominar como su L2. Pato, E. y Fantechi, G. (2012). Sobre los conceptos de lengua extranjera (LE) y lengua segunda (L2). Re lingüística aplicada. Disponible en: http://relinguistica.azc.uam.mx/no010/a11.htm
} 
los estudiantes, eran distintos y generaba asombro a las maestras que cruzaban la frontera. Los años en los que duró el cruce fueron tan ricos que incluso generó un cambio en la forma de dar clases de las maestras correntinas.

Por otra parte, los estudiantes esperaban el día del cruce, la llegada de las maestras brasileras al aula. Ellas tenían una forma distinta de enseñar y "aprendimos mucho de ellas", nos cuenta Claudia.

Luego, una vez finalizados los cruces, se comenzó a implementar talleres en el contraturno en los que se trabaja la lengua-cultura portuguesa (fechas patrias, fiestas juninas, entre otros para el año 2019 por directivas del Ministerio de Educación provincial) y algunos días se hace apoyo escolar. Ya no cuentan con el material que antes sí les proporcionaban. Durante la época de cruce, las maestras redactaban relatos de experiencia con frecuencia y desde la suspensión, solo esporádicamente se llevan a cabo estos registros.

En el año 2008, se incorporó al programa la Escuela N 484 "República de los Estados Unidos del Brasil" también ubicada en Santo Tomé, donde Claudia se desempeña como vicedirectora. Durante un tiempo, el cruce se llevó a cabo. Ahora esta escuela cuenta con jornada extendida (por la tarde) y solo dos maestras participan dando apoyo escolar, no trabajan con la lengua-cultura portuguesa.

Claudia nos cuenta al final de la entrevista que:

"desde que tengo memoria, la frontera siempre fue como una forma diferente de vivir, una forma diferente de contactarnos con la otra persona [...] desde el momento en que hablamos, mezclamos muchísimo el portugués [...] El consumo de la televisión en las casas, la mayoría no tiene el cable, tiene una antena y vive Brasil [...]" (Claudia Aun, entrevista telefónica, 4 de diciembre de 2019, minuto 00:28:38).

María Rosa Carbonara ${ }^{94}$ es directora de la Escuela Cabecera Departamental No 88 "Del Centenario" ubicada en la localidad de Monte Caseros. Se trata de una escuela primaria urbana que tiene la particularidad de estar ubicada en la triple frontera: linda con la localidad de Bella

\footnotetext{
${ }^{94}$ María Rosa Carbonada, directora de la Escuela № 88 "Del Centenario”, Corrientes, entrevista telefónica, 26 de noviembre de 2019.
} 
Unión (Uruguay) y con Barra do Quarai (Brasil). Nos dice que se trata de una escuela urbana grande que tiene anexados jardines de infantes. Luego de la interrupción de los cruces docentes, las tareas consistieron en trabajar leyendas compartidas y en la elaboración colaborativa de carteleras. Llevaron a cabo cinco ateneos didácticos dedicados a trabajar "Cuentos de la selva" de Horacio Quiroga como punto de encuentro tripartito que finalizó con la realización de un radio teatro.

También tuvimos la oportunidad de entrevista a Valeria Solis ${ }^{95}$, asesora pedagógica en la Dirección de Educación Intercultural Bilingüe del Ministerio de Educación de la Provincia de Corrientes desde el año 2019. Nos cuenta que cuando ingresó a trabajar el intercambio físico (el cruce de la frontera) desde hacía varios años que no estaba vigente (el cruce se interrumpió en $\left.2013^{96}\right)$.

Si bien Valeria dejó muy en claro que la forma de trabajar la interculturalidad ha variado y que se proponen nuevos abordajes desde la Dirección de EIB, en diversas reuniones de trabajo con maestras, maestros y directivos, se plantea el deseo de los mismos de retornar a esa modalidad suspendida por cuestiones económicas y políticas, según nos comenta. Recordemos que el programa tiene como base el intercambio docente a partir de la disponibilidad de equipos en ambos países y que actúan en las escuelas involucradas y la planificación conjunta de las tareas lo que propicia la comunicación entre todas las instancias de la organización del trabajo (Anexo V del Acta $\mathrm{N}^{\circ} 1 / 18$ de la RME).

En el transcurso de la entrevista nos informa que a comienzos del año 2020, la Dirección de Educación Intercultural Bilingüe publicó un libro que se encuentra disponible en Internet titulado "Educar en Contexto de Interculturalidad y Plurilingüismo en Corrientes" que daría cuenta de la experiencia de esta provincia en el PEBF. Sin embargo, luego de tomar contacto con el mismo advertimos que si bien desde su portada identificamos la temática del Yerba mate propuesta por el GTIEF como temática para trabajar en el primer semestre de 2019 en las escuelas de frontera, las experiencias relatadas no se corresponden, al menos no su totalidad, con la pro-

\footnotetext{
${ }^{95}$ Valeria Solis, Asesora pedagógica, Dirección de Educación Intercultural Bilingüe, Ministerio de Educación de la Provincia de Corrientes, entrevista telefónica, 27 de noviembre de 2020.

${ }^{96}$ Entrevista a referente técnica de la Dirección de Educación Intercultural Bilingüe, Ministerio de Educación de la Provincia de Corrientes efectuada por Fagaburu (2020, p. 116).
} 
puesta del PEBF. Luego de la lectura y de la entrevista con la asesora, se genera una confusión entre la pertenencia de las instituciones educativas que adoptan la modalidad de educación intercultural bilingüe con la pertenencia de las mismas al programa de Escuelas de Frontera del Mercosur. Ello se debe a que las experiencias relatadas en la publicación incluyen jardines de infantes $^{97}$, escuelas secundarias (con orientación en lenguas) ${ }^{98}$ y escuelas con un maestro intercultural bilingüe $^{99}$ y no se advierte en ningún momento el planeamiento conjunto entre las escuelas y asesores técnicos de Argentina, Brasil y Paraguay ${ }^{100}$ en los proyectos de aprendizaje.

En el año 2013 se creó la Dirección de Educación Intercultural Bilingüe dependiente del Ministerio de Educación correntino donde se retomaron las tareas que implicaban acompañar pedagógicamente a los docentes que habían sido nombrados para trabajar en el PEBF. El Consejo General de Educación de dicho ministerio por Disposición 594/14 reconoció como escuelas de frontera a las primeras cinco correntinas involucradas en el programa, otorgando a estas escuelas un marco legal del que carecían. Y en 2015 se reconocieron nuevas escuelas por Disposición 452/15. La educación intercultural bilingüe está regulada en la Ley de educación provincial (Art. 83 de la Ley n ${ }^{\circ}$ 6475/2018) en consonancia con la Ley de Educación Nacional.

Es así que interrumpido el cruce de docentes en 2013, Corrientes continúa el trabajo en las escuelas de frontera con la modalidad intercultural bilingüe pero no ya en el marco del programa de Escuelas de Frontera del Mercosur sino como una iniciativa provincial.

\section{El caso de la Provincia de Formosa}

\footnotetext{
${ }^{97}$ El J.I.N N 49 (Paso de los Libres), el J.I.N. ํo 46 (La Cruz), el J.I.N. Nº 35 (Alvear), el J.I.N. No 61 y el E.J.I. N 14 (Monte Caseros).

${ }^{98}$ El Colegio Secundario “José María Ponce” y el Colegio "Santa Ana” (Capital) y la Escuela Normal "Ramón Milciades Gómez" (San Cosme).

${ }^{99}$ La Escuela $N^{\circ} 41$ (Manuel Derqui), la Escuela Nº 755 (San Luis del Palmar), la Escuela ํo 609 (Mburucuyá) y la Escuela N 487 (Manantiales).

${ }^{100}$ Recordemos que no existe constancia en ningún instrumento vinculado a las Escuelas de Frontera del Mercosur donde conste que Paraguay se haya incorporado al programa, solo encontramos la voluntad del aquel país en hacerlo. En la frontera con Argentina se generó cierto consenso acerca de metodologías y conceptos para las zonas de frontera (Acta GT-EF $\mathrm{N}^{\circ} 01 / 15$ y Nº $02 / 15$ ). En la frontera con Brasil, en el año 2007 Paraguay se incorporó a las reuniones técnicas multilaterales para definir las escuelas que podrían participar del programa.
} 
Decidimos abordar la situación en la Provincia de Formosa porque su inclusión o posible inclusión fue mencionada en la entrevista ${ }^{101}$ que mantuviéramos con la encargada del Área de Ruralidad del Ministerio de Educación de la Nación y figura la presentación de las experiencias de las escuelas de frontera en esa provincia junto a los casos de Misiones y Corrientes en el marco de la reunión de trabajo del GTEIF de mayo de 2019 por parte de los representantes del Ministerio de Educación de nuestro país y, luego retomada la intervención de los representantes de estas tres provincias en la reunión de la CAEB de ese mismo mes (Acta N 02/19 Reunión XL).

Para comprender la situación real de la participación formoseña en el programa, tuvimos la oportunidad de entrevistar al Coordinador de la Modalidad de Educación Intercultural Bilingüe del Ministerio de Cultura y Educación de la Provincia de Formosa ${ }^{102}$. Esta provincia cuenta con 50 años de trayectoria en escuelas de frontera ${ }^{103}$ y más de 30 años en educación intercultural.

En los años 2018 y 2019, el Paraguay se vio afectado por situaciones hídricas severas. Las inundaciones en la Cuenca del Alto Paraguay hizo imposible el desarrollo normal de las clases. Es por ello que contando con el apoyo del gobierno formoseño, las escuelas paraguayas se trasladaron a territorio argentino, especialmente en la ciudad de Clorinda. El estado provincial garantizó la continuidad de la tarea educativa, facilitando la instalación de las escuelas dando asistencia de esta manera a la población que tuvo que ser evacuada (niños y niñas con sus familias). Este traslado a territorio formoseño implicó también el traslado de directivos y docentes.

El contacto de Formosa con Paraguay se ha limitado hasta hoy a intercambiar indicadores sobre experiencias de organización curricular e institucional, focalizándose en la población crio1la. El gobierno paraguayo estaba muy interesado en la experiencia formoseña en educación intercultural bilingüe. Solo participaron de una serie de reuniones preparatorias.

\footnotetext{
${ }^{101}$ Encargada del Área de Ruralidad, Ministerio de Educación de la Nación Argentina, conversación telefónica, 6 de febrero de 2020 .

${ }^{102}$ Adrián Aranda, Coordinador de la Modalidad de Educación Intercultural Bilingüe del Ministerio de Cultura y Educación de la Provincia de Formosa, entrevista telefónica, 21 de septiembre de 2020.

${ }^{103}$ Adrián Aranda, Coordinador de la Modalidad de Educación Intercultural Bilingüe del Ministerio de Cultura y Educación de la Provincia de Formosa, correo electrónico, 22 de septiembre de 2020.
} 


\section{RECAPITULACiÓN}

En el presente capítulo hicimos un recorrido normativo que nos permitió conocer las bases políticas y sociolingüísticas- del Programa de Escuelas Interculturales Bilingües de Frontera que hemos identificado como el único programa existente y, aún vigente, que tiene como destinatarios a los niños y niñas del nivel de la educación primaria de la región mercosureña. El estudio normativo fue complementado con las experiencias relatadas por algunos de los actores que han participado en la implementación del programa desde su surgimiento hasta la actualidad.

Si bien en el año 2011, las EIB dejaron de ser "proyecto" para convertirse en "programa", consideramos que esta propuesta continúa siendo un proyecto: la falta de continuidad de los cruces en el caso correntino, la limitación del alcance del programa a pocas escuelas y, en consecuencia, a pocos niños y niñas en situación de escolarización a ambos lados de la frontera, la imposibilidad de expansión en el caso misionero, la falta de coordinación a nivel nacional y regional, la falta de presupuesto y las tratativas prolongadas e inconclusas de asociar a las escuelas en la frontera argentino-paraguaya, dan cuenta de ello. Quedaron en el camino, hace ya mucho tiempo atrás, las intenciones de convertir a las EIB en una política pública regional.

Como analizamos en el capítulo precedente dedicado al derecho a la educación, las acciones del SEM en el nivel de la enseñanza primaria se limitan al reconocimiento y reválida de certificados, diplomas y títulos y a tablas de equivalencias, que como bien señala Parker (2007, p. 81) da cuenta de los procesos de movilidad laboral y de la internacionalización de los sistemas educativos pero poco dice del proceso de integración intercultural.

La propuesta de educación intercultural bilingüe del Mercosur nace con lo que hemos consideramos una gran restricción: circunscribirse a la zona de frontera y solo a algunas localidades fronterizas. El español, el portugués y el guaraní son lenguas oficiales del Mercosur: si bien entendemos que las fronteras son laboratorios privilegiados para encarar políticas de integración como bien sostiene Sassone (2004), también debemos comprender que el contacto lingǘstico no se limita a la zona de frontera y la creciente migración paraguaya en Argentina de los últimos años y la movilidad migratoria de la región en su conjunto dan cuenta de ello.

La experiencia del PEBF en la Provincia de Misiones es la única que podemos considerar como 'exitosa' por ser la que ha podido sostenerse en el tiempo a pesar de que luego de quince 
de implementación solo ha podido alcanzar a los $\mathrm{NN}$ dos escuelas en dos localidades fronterizas (en Bernardo de Irigoyen hasta el $4^{\circ}$ grado y en Puerto Iguazú hasta $5^{\circ}$ grado). Exitosa en términos relativos porque como nos relata Vivian Eich $^{104}$ en la entrevista, en esa provincia las escuelas de frontera siempre existieron y desde la década de 1970 han servido para defender la frontera y defender el español como idioma nacional y padecen del estigma de frontera como espacio de defensa nacional y la labor llevada a cabo en estas dos escuelas no es reconocida por el propio gobierno provincial y, en consecuencia, tampoco por el nacional y, mucho menos por el bloque regional. Esto dificulta superar ese estigma con el que cargan que se ve reforzado por la superioridad de la lengua cultura portuguesa. De esta manera como afirma Jelin (2000, p. 335), parecería que en el proceso de integración, paradójicamente, se fortalecen las marcas de la territorialidad nacional. Retomaremos este análisis en el último capítulo de esta investigación.

Coincidimos con Fagaburu (2020) que la sostenibilidad del Programa se vio afectada por obstáculos de carácter financiero (recorte y/o suspensión de presupuesto por parte de Brasil), político (voluntad del gobierno de turno por apoyarlo o no, tanto provincial o estadual como nacional) e institucional (distinta lógica de funcionamiento de los sistemas educativos de cada país y la falta de coordinación bajo el amparo del SEM).

El recorrido que trazamos nos permitió advertir un mayor intercambio y cooperación en los niveles de los grupos técnicos donde encontramos mayor información disponible, mientras que a nivel nacional y regional identificamos poca definición e intercambio de información, experiencias y evaluación de las mismas, así como falta de acceso a la misma. En el caso de la provincia de Misiones y los municipios de Foz de Iguazú y Dionisio de Cerqueira, identificamos un gran esfuerzo por el sostenimiento del programa a nivel personal de los/las asesores pedagógicos, directores y maestros/as involucrados en el programa.

\footnotetext{
${ }^{104}$ Vivian Eich, Asesora técnica pedagógica, Instituto de Políticas Lingüísticas, Ministerio de Cultura Ciencia, Educación y Tecnología de la Provincia de Misiones, entrevista por videoconferencia, 8 de septiembre de 2020.
} 


\section{Capítulo V}

\section{Conclusiones}

Comenzamos este último capítulo recordando que hemos llevado a cabo en esta investigación un recorrido multiescalar sobre la normativa que regula el derecho a migrar y el derecho a la educación de los niños, niñas y adolescentes y sobre los flujos migratorios, también con una perspectiva multiescalar, que nos permitió comprender la situación de los NNA migrantes intrabloque en Argentina y su inserción en el contexto del Mercosur, más precisamente en el Mercosur Educativo. Partimos entonces del caso de Argentina y de su participación en el Programa de Escuelas Interculturales Bilingües de Frontera.

Concluimos que este programa es el único que existe destinado al nivel de la enseñanza primaria y que se encuentra limitado a un espacio fronterizo pero no a lo largo de todas las fronteras de los Estados mercosureños sino a determinadas ciudades gemelas y no está destinado a la niñez migrante intramercosur en particular sino a los NNA en edad de escolarización. Si analizamos los datos estadísticos del último censo poblacional (INDEC, 2010), podemos advertir que dentro de las diez jurisdicciones con mayor porcentaje de población migrante, encontramos a Misiones anteúltima en la lista y a Corrientes recién en el número 20 (Tabla n. ${ }^{\circ}$ 5). Lo que con-

firma que el programa no se implementa en las provincias con mayor número de residentes migrantes.

El PEBF surge en 2005 como un acuerdo bilateral entre Argentina y Brasil y se convierte en junio de 2006 en un proyecto multilateral al incorporarse al Sector Educativo del Mercosur. Del Anexo V Acta 1/18 de la RME y de las entrevistas llevadas a cabo surge que el español debía enseñarse en Brasil como segunda lengua (L2) y no como lengua extranjera. En consonancia con el programa, en el año 2005 entra en vigencia en Brasil la Ley del Español n ${ }^{\circ} 11.161$ de la mano del entonces presidente Luiz Inacio Lula Da Silva que vuelve obligatoria su enseñanza 
como L2 a pesar de que muchos estados lo consideraban como lengua extranjera y otros ni siquiera la aplicaban porque la ley requería reglamentación. Fue una clara política exterior brasilera que apuntaba a reforzar el proceso de integración. En 2017, durante la presidencia de Miche Temer, se dicta la Ley $\mathrm{n}^{\circ} 13.415$ que deroga la Ley del Español y modifica el artículo 35 de la Ley 9394/96 y establece la enseñanza obligatoria de la lengua inglesa y relega la enseñanza del español que adquiere el estatus de lengua extranjera optativa. Esto da cuenta de la tendencia de Brasil a ser un país monolingüe y a olvidar que las lenguas oficiales primigenias del Mercosur son dos: el español y el portugués (el guaraní se incorpora luego). Aquí podemos ver claramente los distintos niveles de heterogeneidad que existen entre los Estados en el proceso de regionalismo seguido por el bloque y que se mencionaron en el Capítulo I de la presente tesis.

Creemos que la 'frontera' concebida en los términos del programa es la denominada por Grimson (2011) como 'frontera identitaria' pero no ya con el propósito de distinguir grupos sino para impulsar el proceso de integración a partir de una identidad regional. En la búsqueda de borrar la frontera política, entendemos que se produjo un refuerzo de la misma. De las entrevistas llevadas a cabo en esta tesis aparece el portugués como lengua superior acompañada de una política brasilera unilateral de comunicación en la frontera del lado argentino. Transcurridos 15 años de la implementación del programa en Misiones, no se logra revertir esta situación. A la población brasilera fronteriza no le interesa el español, no están embebidos de la cultura argentina como sí lo están los niños y la población en general de la lengua-cultura brasileña en la provincia misionera. Esto surge también de diferentes trabajos de investigación lingüísticos y etnográficos. Cuando la maestra correntina percibe como "superiores" a las maestras brasileras, sus escuelas, su forma de vestir, su manera de enseñar, su manera de "ser" y la percepción general (maestros, alumnos y población fronteriza) del portugués como una lengua "mejor" que el español, se produce una marcación de la alteridad (Jelin, 2000). Y pareciera que el proceso de integración, como nos dice Jelin, fortalece las marcas de la territorialidad nacional. Y así podemos afirmar estar frente a una frontera identitaria en los términos de Grimson.

Como se trabajó en el capítulo IV de esta tesis, concluimos que las fronteras son laboratorios privilegiados para encarar políticas de integración como bien afirma Sassone (2004). RhiSaus y Oddone (2013) sostienen que las áreas fronterizas son prioritarias en los procesos de cooperación e integración regional y que el rol de las unidades subnacionales es fundamental en 
la construcción de una institucionalidad específica y eficaz para estas áreas. Fagaburu (2020) considera que el PEBF se concibió y se implementó como una iniciativa de cooperación Sur-Sur al desarrollo. Coincidimos parcialmente con los dos primeros autores: en primer lugar, porque luego de 15 años de implementación del programa y casi 30 años de existencia del Mercosur, la integración intercultural no debería limitarse a las zonas de fronteras ya que el contacto lingüístico e intercultural no se limita a un área geográfica determinada, de ello da cuenta la movilidad migratoria en nuestro país, en el bloque y en la región. En segundo lugar, porque si bien la planificación del programa involucró a las provincias argentinas y a los municipios brasileros, como unidades subnacionales, el esfuerzo por la continuidad -en el caso de Misiones- supera la actuación de los ministerios de educación y las direcciones específicas, recae en asesores, directores y maestros quienes con el esfuerzo personal 'día a día' logran poner en marcha el programa año tras año. En este sentido se produce una vinculación/confusión de política doméstica con política internacional (o en este caso regional), que se mantiene fundamentalmente -como se expresógracias al impulso de los recursos humanos locales involucrados.

Concluimos que en el año 2009 se incorporó a la denominación del programa la "interculturalidad" (PEIBF). Sin embargo, muchas veces se utiliza la sigla sin el término 'Interculturales'. Con su incorporación se buscó ampliar el programa porque las lenguas no son solo una parte de la cultura sino también el vehículo fundamental a través de las cuales se expresan las prácticas culturales y las creencias de los grupos y sus representaciones sociales (Gramuglia, 2016). Conforme a los alcances del término en el marco del programa (Anexo V Acta 1/18 RME), podemos afirmar que se trata de una expresión de la interculturalidad funcional o neoliberal (Walsh, 2009). El programa se limita a 'conocer al otro', a 'estar con el otro', a 'entenderlo' pero no busca producir cambios en la realidad, es decir ni un mejoramiento o transformación de las relaciones asimétricas entre las culturas, promueve el diálogo sin abordar las causas de la asimetría cultural (Tubino, 2004). Para superarlo, Walsh (2009) propone entender la interculturalidad como proceso y como proyecto dirigido hacia la construcción de "otros modos de poder, saber, ser y vivir" (interculturalidad crítica).

Ahora bien, la interculturalidad en el marco del PEIBF tiene un alcance distinto del adoptado por la legislación argentina en materia educativa. En Argentina y en América Latina, en general, el discurso y la praxis de la interculturalidad surgieron como una exigencia de los pro- 
gramas de educación intercultural bilingüe de los pueblos indígenas del continente (Tubino, 2004). La modalidad EIB regulada por la Ley n ${ }^{\circ} 26.206$ solo tiene como destinatarios a los pueblos originarios y pierde de vista la transversalidad que estas propuestas deberían tener, excluyendo así a los estudiantes migrantes y no-indígenas. Ésta marcada etnicidad no está presente en el PEIBF y este es un aspecto que consideramos como altamente positivo. Un programa basado en proyectos de aprendizaje interdisciplinar y situado en las necesidades, intereses y motivaciones de los niños y sus familias, es decir que atienda las trayectorias escolares de cada estudiante, sean migrantes, indígenas o no-indígenas podría ser implementado en todo el territorio del Mercosur. Se podría desarrollar bajo el concepto de interculturalidad crítica que permitiría evitar hablar de asimilación o incorporación de los excluidos en las estructuras educativas o de la implementación de programas especiales para lograr una educación normal y universal. Aquí sumamos el pensamiento de Terigi: cada escuela primaria es distinta, no hay 'una escuela primaria' por lo que proponer un único programa homogeneizador sería una propuesta destinada al fracaso.

Afirmamos en esta investigación que el derecho a migrar y el derecho a la educación son derechos humanos fundamentales. Por una parte, el Acuerdo de Residencia del Mercosur (2002) consagra un criterio migratorio fundado en sola la acreditación de la nacionalidad del solicitante de uno de los Estados Parte del Mercosur y Asociados y reconoce a los hijos de los migrantes el "derecho fundamental de acceso a la educación en condiciones de igualdad con los nacionales del país de recepción". En la misma línea, la Ley de Migraciones argentina (2003) prevé "el derecho a la migración es esencial e inalienable de la persona y la República Argentina lo garantiza sobre la base de los principios de igualdad y universalidad" y asegura a los extranjeros que la admisión a los establecimientos educativos de todos los niveles no se verá limitada por la situación de irregularidad migratoria. En consonancia con la legislación migratoria, la Ley Nacional de Educación (2006) garantiza la igualdad, gratuidad y equidad en el ejercicio del derecho a la educación para todos los habitantes y el acceso y las condiciones para la permanencia y el egreso en el sistema educativo, mediante la sola presentación de documentos emanados del país de origen. Concluimos que no existe en el Mercosur una política regional educativa que tenga como destinatarios a los niños y niñas migrantes intramercosur con el objetivo de garantizar su efectivo derecho a la educación en el nivel de la enseñanza primaria. El Acuerdo de Residencia presenta la limitación de ser un marco normativo que aún carece de la fuerza para constituirse en una polí- 
tica pública regional. A pesar de sentar las bases del régimen internacional migratorio y educativo del Mercosur.

La hipótesis planteada que afirmaba que "las aún débiles instituciones burocráticas del Mercosur y el insuficiente desarrollo de políticas públicas nacionales y de alcance regional referidas a las migraciones y a la educación han sido obstáculos para la consolidación del régimen internacional educativo del bloque para dar respuestas a los problemas de inserción de la niñez migrante en el nivel de la educación primaria en el país de recepción" ha sido verificada. No solo por la cuestión burocrática, la desarticulación entre los distintos niveles institucionales, la flexibilidad de cada país para cumplir con las normas y reglas acordadas según sus conveniencias, la efectiva aplicación de lo acordado, las políticas exteriores disímiles y oscilantes, la carencia de evaluación de la implementación del único programa implementado en el nivel primario, sino también por la falta de una perspectiva multidimensional e interdisciplinaria para comprender las trayectorias escolares de los $\mathrm{NN}$ en el nivel primario y, en particular, de los NN migrantes intramercosur. La 'buena voluntad política' de los gobiernos en un momento dado que se plasma en un programa no puede sobrevivir mucho más allá de ese 'momento' sino se convierte a la brevedad en una política pública regional concreta y bien delimitada. Coincidimos con Arpini (2007) en que los procesos de integración son procesos con bases sociales y culturales que requieren todo tipo de mediaciones "espacios para el encuentro, el reconocimiento, el diálogo y la concertación entre sujetos que afirman su diversidad", no son suficientes, no alcanzan los acuerdos de las cúpulas de poder.

En los casi 30 años de existencia del bloque, podemos afirmar que las bases del régimen internacional educativo del Mercosur, del Mercosur educativo o SEM, están establecidas, así como también las bases teóricas internacionales, regionales y nacionales que dan fundamento al reconocimiento del derecho a la educación y del derecho a migrar como derechos humanos. La sustracción del diseño de la política educativa de las prácticas unilaterales de los Estados Partes es parcial. Lo confirmamos en el nivel de la enseñanza primaria donde solo pudimos identificar un programa del SEM que presenta las limitaciones antes señaladas. La aprobación de tablas de equivalencias y el reconocimiento de títulos y diplomas solo da cuenta de la movilidad intrabloque, especialmente la movilidad laboral y de la internacionalización de los sistemas educativo pero muy poco dice del proceso de integración intercultural. Y más aún, consideramos que el 
estancamiento en esta instancia atenta contra dicho proceso de integración intercultural mercosureño.

Nos fue indispensable tomar una mirada interdisciplinaria para comprender la situación y la dinámica de las escuelas de frontera y poder pensar un programa que dé cuenta de la pluralidad de escuelas primarias. Finalmente concluimos que gracias a los aportes de la antropología, la etnografía, la pedagogía y la sociolingüística, logramos obtener un amplio panorama del programa, su concepción, su implementación y sus posibilidades. En el mismo sentido, el estudio y análisis de la situación de los niños y niñas migrantes y su inserción en el nivel de la enseñanza primaria en el país de recepción exigen el mismo enfoque interdisciplinar. A las disciplinas mencionadas sumamos la filosofía, la sociología, la psiquiatría infantil y el derecho internacional, todas ellas complementan el estudio de este fenómeno que abordamos desde las relaciones internacionales.

14.869.775 kilómetros cuadrados, 295.007.000 población total, pluralidad de culturas, lenguas, religiones y etnias, libertad de circulación de personas y acceso a la educación. Estamos frente a un bloque regional con gran extensión de territorio y con una población rica en términos culturales. El Mercosur se reconoce como un proceso de integración económico, comercial, social y cultural. Cuenta con una infraestructura institucional construida a lo largo de los años y con recursos humanos especializados en todas las direcciones más allá de sus fronteras. Como afirmáramos más arriba, las bases del régimen internacional educativo mercosureño están dadas. Es necesario que éste configure el comportamiento de todos los actores involucrados. Y así comprender que los distintos aspectos sociales y culturales de la integración no pueden ser abordados de manera aislada sino que requiere de una mirada abarcadora y multidisciplinar. Creemos que es el camino para dar respuestas a los problemas de inserción de la niñez migrante intramercosur en el país de recepción en el nivel de la educación primaria. 


\section{Bibliografía}

Alfonso, A. (2012). Integración y migraciones. El tratamiento de la variable migratoria en el Mercosur y su incidencia en la política argentina. Cuadernos migratorios $n^{\circ} 3$. OIM.

Alto Comisionado de las Naciones Unidas para los Refugiados - ACNUR (2009). Los derechos de los pueblos indígenas en el Convenio 169 de la OIT. Guía para la aplicación judicial. Organización de las Naciones Unidas.

Alto Comisionado de las Naciones Unidas para los Refugiados - ACNUR (2019). Tendencias Globales: Desplazamiento forzado en 2018. Disponible en https://www.acnur.org/5d09c37c4.pdf.

Arango, J. (2005). Dificultades y dilemas de la política de inmigración. Arbor, 181 (713), 17-25.

Argentina (2012). Indicadores Estadísticos del Sistema Educativo del Mercosur 2012. Sector Educativo del Mercosur (SEM). Sistema de Información y Comunicación del Mercosur Educativo (SIC) Grupo Gestor del Proyecto (GGP). Dirección Nacional de Información y Evaluación de la Calidad Educativa (DiNIECE).

Argentina. Ministerio de Educación de la Nación (2011). La modalidad de educación intercultural bilingüe en el sistema educativo argentino. Ministerio de Educación de la Nación.

Argentina. Ministerio de Educación, Ciencia y Tecnología de la Nación (2006). La inclusión como posibilidad. Ministerio de Educación, Ciencia y Tecnología de la Nación.

Argentina. Ministerio de Educación, Ciencia y Tecnología de la Nación (2019). Aprender 2018. Informe nacional de resultados $6^{\circ}$ año nivel primario. Ministerio de Educación, Ciencia y Tecnología de la Nación. 
Argentina-Brasil (2007). Proyecto "Modelo de enseñanza común en escuelas de zona de frontera, a partir del desarrollo de un programa para la educación intercultural, con énfasis en la enseñanza del portugués y el español". Disponible en: http://www.bnm.me.gov.ar/giga1/documentos/EL001427.pdf [Consultado en noviembre de 2019]

Arpini, A. (2007). Diversidad y conflictividad. Contribuciones a la formulación de categorías heurísticas para la integración y el diálogo intercultural. En José Santos Herceg (Comp.). Integración e interculturalidad. Desafíos pendientes para América Latina (15-30). Colección Idea. Universidad de Santiago de Chile.

Barbé, E. (1989).Cooperación y conflicto en las relaciones internacionales (La teoría del régimen internacional). Afers internacionals, $\mathrm{N}^{\circ}$ 17, 55-67. Disponible en: https://www.raco.cat/index.php/RevistaCIDOB/article/view/27818/51946

Beheran, M. (2012). Migraciones y educación en la Argentina. Transformaciones y continuidades. Susana Novick (Directora). Migración y políticas públicas: nuevos escenarios y desafios (201-226). Catálogos.

Bogado Bordazar, L. (2012a). Migraciones en el ámbito del MERCOSUR, un impulso hacia el “Modelo Social de Integración”. El caso de Argentina. Cadernos Qualis B2, n 7, 15-33.

Bogado Bordazar, L. L. (2020). Migraciones en el Mercosur. Hacia la conformación de un modelo de integración regional. Tesis doctoral. Disponible en:

Bogado, L. (2012). Avances sobre la construcción de una política migratoria del Mercosur. El caso de Argentina. Gerardo Caetano (Coord.). El Mercosur de las políticas públicas regionales (pp. 161 -185). Centro de formación para la integración regional (CEFIR).

Botto, M. (2016). La política de educación superior en el Mercosur: ¿un modelo contra hegemónico? Integración y conocimiento. Revista del Núcleo de Estudios e Investigaciones en Educación Superior del MERCOSUR, ${ }^{\circ}$ 4, 26-45. Disponible en: file://C:/Users/pc/Downloads/14696-Texto\%20del\%20art\%C3\%ADculo-39831-1-1020160619.pdf 
Briones, C. y del Cairo, C. (2015). Prácticas de fronterización, pluralización y diferencia. Universitas Humanística, (80), 13-52.

Brovetto, C. (2010). Educación bilingüe de frontera y políticas lingüísticas en Uruguay. ProPosicoes, v. 21, n. 3(63), 25-43.

Caggiano, S. (2019). Las migraciones como campo de batallas. Desigualdades, pertenencias y conflictos en torno a la movilidad de las personas. $1^{\text {a }}$ edición. Miño y Dávila editores.

Cárdenas Aravena, C. (2011).

CEPAL (2019). Observatorio Demográfico 2018. Centro Latinoamericano y Caribeño de Demografía (CELADE)-División de Población de la CEPAL.

Ceriani Cernadas, P. (2011). Luces y sombras en la legislación migratoria latinoamericana. Nueva Sociedad, $\mathrm{n}^{\circ} 233$, mayo-junio, 68-86.

Ceriani Cernadas, P. y Fava, R. (2010). Estudio sobre los derechos de niños y niñas migrantes a 5 años de la nueva ley de migraciones. Universidad Nacional de Lanús.

Cillero Bruñol, M. (1999). El interés superior del niño en el marco de la Convención Internacional sobre los derechos del niño. Justicia y Derechos del niño $\mathrm{N}^{\circ} 1$. UNICEF.

CIPD (2019). Declaración de Nairobi: Adelantando la promesa.

CLADE (2018). El derecho a la educación y al cuidado en la primera infancia: perspectivas desde América Latina y el Caribe. Campana Latinoamericana por el Derecho a la Educación.

Comisión económica para América Latina y el Caribe (2012). Conferencia internacional sobre la Población y el Desarrollo. Serie población y desarrollo $\mathrm{N}^{\circ}$ 106. Santiago de Chile: CEPAL.

Corbetta, S., Bonetti C., Bustamante, F. y Vergara Parra, A. (2018). Educación intercultural bilingüe y enfoque de interculturalidad en los sistemas educativos latinoamericanos. Avances y desafios. Comisión Económica para América Latina y el Caribe (CEPAL). 
Corte Interamericana de Derechos Humanos (2002). Opinión Consultiva OC-17/02.

Corti, H. G. (2011). Pacto Internacional de Derechos Económicos, Sociales y Culturales. Walter Carnota y Patricio A. Maraniello (Dir.), Tratado de los tratados internacionales (739847). La Ley.

CSM (2020). Conferencia Suramericana sobre Migraciones (CSM) - 20 años- Nora Pérez Vichich. [Video]. YouTube.

https://www.youtube.com/watch?v=xaI0Ir5aKUA\&feature=emb logo

Cumbre de las Américas (2018). Compromiso de Lima ““'Gobernabilidad democrática frente a la corrupción". OEA.

Daviña, L. (2018). Entrevista a Liliam Sofía Prytz Nilsson. Directora a cargo de Políticas Lingüísticas (IPL-Ley VI-141), Ministerio de Cultura, Educación, Ciencia y Tecnología de la Provincia de Misiones. Revista La Rivada, 6 (10), 51-58.

Declaración de Buenos Aires (2017).

Declaración de Lima (2014).

Diez, M. L. (2013). Repensando la interculturalidad en educación: aportes de la investigación socioantropológica a un campo problemático. Política Educativa, $\mathrm{N}^{\circ}$ 51, 5-17.

Díez, M. L. (2020). Experiencias formativas y migración latinoamericana: aportes de la etnografía a una perspectiva intercultural en educación. Perspectiva, Revista do Centro de Ciências da educacao, Vol. 38, $\mathrm{N}^{\circ}$ 4, 1-21. http://dx.doi.org/10.5007/2175795X.2020.e67056

Dirección de Educación Intercultural Bilingüe (2020). Educar en contexto de interculturalidad y plurilingüismo en Corrientes. 1a edición para el profesor. Ministerio de Educación de la Provincia de Corrientes.

Domenech, E. E. (2007). La agenda política sobre migraciones en América del Sur: el caso de Argentina. Revue européenne des migrations internationales. [En línea], vol. 23, $\mathrm{n}^{\circ} 1$, 71-94. [Consultado el 19/4/2019] 
Domenech, E. y Pereira, A. (2017). Estudios migratorios e investigación académica sobre las políticas de migraciones internacionales en Argentina. Íconos. Revista de Ciencias Sociales, (58), 83-108. http://dx.doi.org/10.1714/iconos.58.2017.2487

Espósito, J. (2014). Educación superior en América Latina. Algunas reflexiones sobre la necesidad de políticas educativas institucionalizadas. Revista Anales, 105-112.

Fagaburu, D. (2020). La CSS al desarrollo transfronterizo: el caso del Programa Escuelas Bilingües de Frontera. OASIS, 31, 101-121. Doi: https://doi.org/10.18601/16577558.n31.07

Feldfeber, M., Saforcada, F. y Jaimovich, A. (2005). La educación en las Cumbres de las Américas: su impacto en la democratización de los sistemas educativos. Fundación Laboratorio de Políticas Públicas.

Global forum for international migration and development (2010). Informe de Presidencia de la Cuarta Reunión del Foro Mundial sobre Migración y Desarrollo (FMMD), Puerto Vallarta, México.

Grimson, A. (2000). Introducción ¿Fronteras políticas versus fronteras culturales? En: Alejandro Grimson (Comp.), Fronteras, naciones e identidades. La periferia como centro (pp. 940). La Crujía.

Grimson, A. (2005). Fronteras, estados e identidades en el Cono Sur. En Daniel Mato (Comp.), Cultura, política y sociedad. Perspectivas latinoamericanas (pp. 127-142). Consejo Latinoamericano de Ciencias Sociales.

Grimson, A. (2011). Doce equívocos sobre las migraciones, Nueva Sociedad, ${ }^{\circ} 233$, mayojunio, 34-43.

Grimson, A. (2011). Los límites de la cultura. Crítica de las teorías de la identidad. Siglo Veintiuno editores.

Grimson, A. (2019). Migraciones, interculturalidad y desperdicios humanos. Revista Anales, $\mathrm{n}^{\circ}$ $16,175-194$. 
Guizardi, M. (2016). Migración y cultura: repensar las políticas migratorias en tiempos de realismo capitalista. En: Interculturalidad y migración: ponencias del II Seminario internacional sobre diversidad cultural en Chile y II Coloquio Iber-Rutas de migración, cultura y derechos. Ministerio de las Culturas, de las Artes y el Patrimonio.

Guizardi, M. L. (2017). Migración y cultura. Repensar las políticas migratorias en tiempos de realismo capitalista. En Interculturalidad y Migración (pp. 179-205). Consejo Nacional de las Culturas y las Artes de Chile.

Gurrieri, J. (2005). El proceso consultivo en América del Sur. La Conferencia Sudamericana sobre migraciones. Trabajo presentado a la Reunión del Grupo de Expertos sobre Migraciones Internacionales y Desarrollo en América Latina y el Caribe, Naciones Unidas, México.

Haggins, S. M. (1992). Educación para Todos: finalidad y contexto. Organización de las Naciones Unidas para la Educación, la Ciencia y la Cultura.

Hasenclever, A., Mayer, P. y Rittberger, V. (1999). Las teorías de los regímenes internacionales: situación actual y propuestas para una síntesis. Foro internacional, $\mathrm{N}^{\circ} 158$.

Hecht, A. C. (2015). Educación intercultural bilingüe en Argentina: un panorama actual. Ciencia e Interculturalidad, 16 (8), 20-29.

Hirsch, S. M. (2000). Misión, Región y Nación entre guaraníes de Argentina. Procesos de integración y de re-etnización en zonas de frontera. En: Alejandro Grimson (Comp.), Fronteras, naciones e identidades. La periferia como centro (pp. 278-320). La Crujía.

IIPE UNESCO (2015). Las leyes generales de educación en América Latina. El derecho como proyecto político. IIPE UNESCO Sede Buenos Aires.

Instituto de Estadística de la UNESCO (2015). Con una ayuda que no está a la altura de las circunstancias, un número creciente de niños y adolescentes queda sin escolarizar. Documento de políticas 22, Nota de información 31. UNESCO.

Instituto Nacional de Estadística y Censos (2010). Censo Nacional de Población, Hogares y Viviendas. INDEC. 
Instituto Nacional de Estadística y Censos (2013). Estimaciones y proyecciones de población 2010-2040: total del país. 1a ed. Instituto Nacional de Estadística y Censos (INDEC).

IPPDH (2019a). Iniciativa Regional Foco Niñez Migrante. Memoria. Instituto de Políticas Públicas en Derechos Humanos del MERCOSUR.

IPPDH (2019b). Protección de niños, niñas y adolescentes en contextos de migración. Manual de aplicación de estándares internacionales y regionales de derechos humanos. Instituto de Políticas Públicas en Derechos Humanos del MERCOSUR.

Jelin, E. (2000). Epílogo II. Fronteras, naciones, género. Un comentario. En: Alejandro Grimson (Comp.), Fronteras, naciones e identidades. La periferia como centro (pp. 333-346). La Crujía.

Keohane, R. y Nye, J. (1988). Poder e interdependencia. La política mundial en transición. Grupo Editor Latinoamericano.

Laboratorio Latinoamericano de Evaluación de la Calidad de la Educación -LLECE (2008). Los aprendizajes de los estudiantes de América Latina y el Caribe. Primer reporte de los resultados del Segundo Estudio Regional Comparativo y Explicativo. Oficina Regional de Educación de la UNESCO para América Latina y el Caribe OREALC/UNESCO Santiago.

Laboratorio Latinoamericano de Evaluación de la Calidad de la Educación -LLECE (2016). Informe de resultados TERCE. Tercer Estudio regional comparativo y explicativo. Logros de aprendizaje. Organización de las Naciones Unidas para la Educación, la Ciencia y la Cultura, y la Oficina Regional de Educación para América Latina y el Caribe (OREALC/UNESCO Santiago).

Leones, M., Baruzzi, P., Scorzo, P. y Rivas, N. (2016). Un análisis de los resultados del Segundo y Tercer Estudio Regional Comparativo y Explicativo: el caso argentino -SERCE 2006 y TERCE 2013. Revista Iberoamericana sobre Calidad, Eficacia y Cambio en Educación, 14(4), 135-155. Doi:10.15366/reice2016.14.4.007

Ley Nacional de Educación nº 26.206. 
Lipski, J. M. (2007). Cruzando fronteras/cruzando lenguas. Third Interdisciplinary Colloquium on Hispanic/Latin American Literatures, Linguistics, and Cultures, El arte de (con) vivir/the art of (co)existence, Gainesville, University of Florida, 1-30. http://www.personal.psu.edu/jm134/cruzando.pdf (Consultado el 25/9/2020)

Lipski, J. M. (2018). La interfaz portugués-castellano en Misiones, Argentina: zona de prueba para la alternancia de lenguas. Estudios Filológicos, (60), 169-190. Doi: 10.4067/S007117132017000200008

Luján, C. (2012). Los requerimientos institucionales de las políticas públicas regionales. Gerardo Caetano (Coord.). El Mercosur de las políticas públicas regionales (pp.65-75).Centro de formación para la integración regional (CEFIR).

Marchesi, A. y Garrido, F. (2014). Presentación. Álvaro Marchesi, Rosa Blanco y Laura Hernández (Comp.). Avances y desafios de la educación inclusiva en Iberoamérica (pp. 5-6). Organización de Estados Iberoamericanos para la Educación, la Ciencia y la Cultura.

Marradi, A, Archenti, N. \& Piovani, J.I. (2012). Metodología de las ciencias sociales. 2 da. Edición. CENGAGE Learning.

Marradi, A, Archenti, N. \& Piovani, J.I. (2018). Manual de metodología de las ciencias sociales. $1^{\mathrm{a}}$ edición. Siglo XXI Editores Argentina.

Martín Rojo, L. (2003). Escuela y diversidad lingüística y cultural. En Luisa Martín Rojo (Dir.). ¿Asimilar o integrar? Dilemas ante el multilingüismo en las aulas (19-68). Ministerio de Educaicón, Cultura y Deporte.

Martínez, M. E. y Seoane, V. E. (2020). Disputas por el derecho a la educación y la educación pública en América Latina: políticas, instituciones y sujetos en la gubernamentalidad neoliberal. $R B P A E$, v. 36, n. 1, 17-36.

Massey, D. (2012). Un sentido global del lugar. En Doreen Massey (Comp.) Un sentido global del lugar (pp.112-129). Icaria.

Mendes Thomaz, K. (2011). Escolas Interculturais Bilíngues de Fronteira do MERCOSUL: balanço, desafios e perspectivas. En Ana Carolina Hecht y Elisa Loncon Antileo (Comp.). 
Educación Intercultural Bilingüe en América Latina y el Caribe: balances, desafios y perspectivas (330-340). Fundación Equitas.

Miranda, R. (1999). Cono Sur: regionalismo cultural e integración educativa. Revista de Relaciones Internacionales, $\mathrm{n}^{\circ} 16,59-93$.

Miranda, R. (2003). Argentina en el Cono Sur. Las relaciones interculturales. Universidad Católica de Salta.

Moro, M. R. (2019). La clínica transcultural: epistemología y técnica. La migración como separación. En Marie Rose Moro y Bernard Golse. Crecer en situación transcultural. Una oportunidad para las infancias (pp. 20-21). Miño y Dávila Editores.

Nicoletti, J.A., Gadea, W. y Alvarellos, R. (2016). La movilidad académica internacional en el MERCOSUR según los estudiantes ingresantes a la universidad. Revista Argentina de Educaicón Superior, Año 10, número 16, 144-174. Disponible en: http://www.revistaraes.net/revistas/raes16 art6.pdf

Nikken, P. (2003). La función consultiva de la Corte Interamericana de Derechos Humanos. En El sistema interamericano de protección de los derechos humanos en el umbral del siglo XXI. CIDH.

Novaro, G., Diez, M. L. y Martínez, L. V. (2017). Educación y migración latinoamericana. Interculturalidad, derechos y nuevas formas de inclusión y exclusión escolar. Revista Migraciones Internacionales. Reflexiones desde Argentina, Año 1, № 2, 7-23.

Novick, S. (2005). La reciente política migratoria argentina en el contexto del Mercosur. En Susana Novick, Alejandro Hener y Pablo Dalle. El proceso de integración Mercosur: de las políticas migratorias y de seguridad a las trayectorias de los inmigrantes (6-59). Documento de trabajo $\mathrm{N}^{\circ}$ 46. Instituto de Investigaciones Gino Germani.

Novick, S. (2010). Políticas migratorias en la Argentina: experiencias del pasado, reformas actuales y expectativas futuras. Estado actual y perspectivas de las políticas migratorias en el MERCOSUR. FLACSO - UNESCO. 
Novick, S. (2014). Cómo trabajar con textos jurídicos en ciencias sociales. Documentos de trabajo $N^{\circ}$ 69. Instituto de Investigaciones Gino Germani.

Novick, S., Hener, A. \& Dalle, P. (2005). Documentos de trabajo $n^{\circ} 46:$ El proceso de integración Mercosur: de las políticas migratorias y de seguridad a las trayectorias de los inmigrantes. Instituto de Investigaciones Gino Germani.

OEA (2018).Documentos oficiales del Proceso de Cumbres de las Américas: De Ciudad de Panamá (2015) a Lima (2018): volumen VIII. Secretaría de Cumbres de las Américas, Organización de los Estados Americanos.

OEI (2018). Miradas sobre la Educación en Iberoamérica. Proyecto de revisión de los indicadores de las Metas Educativas 2021. OEI.

Oficina del alto comisionado de las Naciones Unidas para los Derechos Humanos (2006). La Convención internacional sobre los trabajadores migratorios y su comité. Folleto Informativo $\mathrm{N}^{\circ} 24$ (Rev. 1). ONU.

Oficina del Alto Comisionado de las Naciones Unidas para los Derechos Humanos (2012). Folleto Informativo $N^{\circ} 30$. El sistema de tratados de derechos humanos de las Naciones Unidas. Naciones Unidas.

OIM (2013). Informe sobre las migraciones en el mundo 2013. El bienestar de los migrantes y el desarrollo. Organización Internacional para las Migraciones.

OIM (2017). Panorama migratorio de América del Sur 2012. Buenos Aires: OIM Oficina regional para América del Sur.

OIM (2018). Evaluación del Acuerdo de Residencia del MERCOSUR y su incidencia en el acceso a derechos de los migrantes. Cuadernos migratorios $N^{\circ} 9$. Organización Internacional para las Migraciones. Oficina Regional para América del Sur.

OIM (2018b). La migración en la Agenda 2030. Guía para profesionales, disponible en: http://www.migration4development.org/sites/default/files/es_sdg_web.pdf. 
OIM (2019). Glosario de la OIM sobre migración. Organización Internacional para las Migraciones.

OIM (2019). Informe sobre las migraciones en el mundo 2020. Organización Internacional para las Migraciones. Disponible en: https://publications.iom.int/books/informe-sobre-lasmigraciones-en-elmundo-2020.

Organización de Estados Iberoamericanos para la Educación, la Ciencia y la Cultura (2010). Metas Educativas 2021: la educación que queremos para la generación de los bicentenarios. Documento final. OEI.

Organización de los Estados Americanos (2012). Migración internacional en las Américas: Segundo informe del Sistema Continuo de Reportes sobre Migración Internacional en las Américas (SICREMI) 2012. OEA.

Organización de los Estados Americanos (2015). Migración internacional en las Américas: Tercer informe del Sistema Continuo de Reportes sobre Migración Internacional en las Américas (SICREMI) 2015. OEA.

Organización de los Estados Americanos (2017). Migración internacional en las Américas: Cuarto informe del Sistema Continuo de Reportes sobre Migración Internacional en las Américas (SICREMI) 2017. OEA.

Padawer, A. y Díez, M. L. (2015). Desplazamientos y procesos de identificación en las experiencias interculturales de vida de niños indígenas y migrantes en Argentina. Anthropologica, Año XXXIII, N 35, 65-92.

Parker, C. (2007). Interculturalidad e integración en América Latina, una problemática abierta. En José Santos Hercerg (Comp.). Integración e interculturalidad. Desafios pendientes para América Latina (53-91). Colección Idea. Universidad de Santiago de Chile.

Perrotta, D. (2013). El regionalismo de la educación superior en el proceso de integración regional del MERCOSUR: políticas de coordinación, complementación, convergencia y armonización en las iniciativas de acreditación de la calidad de carreras de grado (1998-2012). Tesis doctoral. 
Picotti, D. (2007). Exigencia histórica de integración e interculturalidad. En José Santos Hercerg (Comp.), Integración e interculturalidad. Desafios pendientes para América Latina (pp. 31-38). Colección Idea.

Pinto, G. y Ceriani Cernadas, P. (2013). Niñez, migraciones y derechos humanos en Argentina. Estudio a 10 años de la ley de migraciones. Centro de Derechos Humanos de la Universidad Nacional de Lanús.

Piñón, F. (1998). Educación y procesos de educación: el caso del MERCOSUR. En Gregorio Recondo (Comp.), MERCOSUR, la dimensión cultural de la integración (181-190). Ciccus.

Remiro Brotons, A. (1997). Derecho internacional. McGraw-Hill.

Rhi-Sausi, J. L. y Oddone, N. (2013). Integración regional y cooperación transfronteriza en los nuevos escenarios de América Latina. Integración y desarrollo, vol. 21, n 1, 260-285.

Rodríguez, M. S. (2011). La Declaración Americana de los Derechos y Deberes del Hombre. Walter Carnota y Patricio A. Maraniello (Dir.), Tratado de los tratados internacionales (71-235). La Ley.

Sagaz, M. R. P. (2013). Projeto escolas (interculturas) bilíngues de fronteira: análise de uma ação político linguística. Dissertacã o apresentada ao Programa de Pós-Graduacão em Linguística. Universidade Federal de Santa Catarina. Disponible en: https://repositorio.ufsc.br/xmlui/handle/123456789/122909 [Consultado el 10 de enero de 2020]

Sassone, S. M. (2004). Movilidad de personas y control migratorio en el Mercosur: hacia la reconfiguración de las territorialidades transfronterizas. Actas del VI Simposio internacional y VIII Congreso de Globalización, Integración y Frontera.

Selee, A. (2020). Una nueva era de política migratoria emerge en América Latina y el Caribe ante flujos migratorios masivos. Disponible en: https://www.migrationportal.org/es/insight/nueva-era-politica-migratoria-emergeamerica-latina-caribe-flujos-migratorios-masivos/ [Consultado el 14 de octubre de 2020]. 
Sistema de información de tendencias educativas en América Latina (2015). Cuaderno $n^{\circ}$ 8: $E l$ itinerario de la Convención Internacional de los Derechos del Niño en los sistemas jurídicos y políticos de los países latinoamericanos. Disponible en:

SITEAL (2019). Documento de Sub Eje. Nivel Primario. Educación Básica. Instituto Internacional de Planeamiento de la Educación IIPE-UNESCO Buenos Aires.

Solanas, F. (2012). Intercambio cooperativo versus mercantilización competitiva. Las políticas de movilidad académica de MERCOSUR y Unión Europea. RIES, Vol. 5, №12, 3-22.

Terigi, F. (2006). Las "otras" primarias y el problema de la enseñanza. Flavia Terigi (Comp.), Diez miradas sobre la escuela primaria (191-229). Fundación OSDE/ Siglo XXI.

Terigi, F. (2009). Las trayectorias escolares, del problema individual al desafio de política educativa. Ministerio de Educación de la Nación, Argentina-OEA.

Thisted, S. (2014).Políticas, retóricas y prácticas educativas en torno a la cuestión de las "diferencias". Itinerarios de un siglo largo de en el tratamiento de la cuestión de migrantes e indígenas. Alicia Inés Villa y María Elena Martínez (Comps.), Relaciones escolares y diferencias culturales: la educación en perspectiva intercultural (133-170). Noveduc.

Torres, R. M. (2001). ¿Qué pasó en el Foro Mundial de la Educación?, Revista Educación de Adultos y Desarrollo, (56). https://www.dvv-international.de/es/educacion-de-adultos-ydesarrollo/ediciones/ead-562001/alfabetizacion-y-educacion-basica/que-paso-en-el-foro$\underline{\text { mundial-de-la-educacion }}$

Trucco, M. F. (2011). Los derechos económicos, sociales y culturales a la luz de la Declaración Universal de Derechos Humanos y su influencia en los sistemas universales y regionales de protección. Walter Carnota y Patricio A. Maraniello (Dir.), Tratado de los tratados internacionales (321-464). La Ley.

Tubino, F. (2004). Del interculturalismo funcional al interculturalismo crítico. Mario Samaniego y Carmen Gloria Garbarini (Comp.), Rostros y fronteras de la identidad. Pehuén editores. 
UNESCO (2018). Informe de seguimiento de la Educación en el Mundo 2019: Migración, desplazamiento y educación: construyendo puentes, no muros. UNESCO.

UNFPA (2019). Estado de la población mundial 2019. Un asunto pendiente de la defensa de los derechos y la libertad de decir de todas las personas. Fondo de Población de las Naciones Unidas.

UNICEF (2016). Estado mundial de la infancia 2016. Una oportunidad para cada niño. Fondo de las Naciones Unidas para la infancia.

United Nations, Department of Economic and Social Affairs, Population Division (2019). International Migration 2019: Wall Chart (ST/ESA/SER/A/431).

United Nations, Department of Economic and Social Affairs, Population division (2013). International Migration Report 2013. ONU.

Valles, M. S. (1999). Técnicas cualitativas de investigación social. Reflexión metodológica y práctica profesional. Editorial Síntesis.

Velázquez, R. (2014). Diálogos del SIPI. Conversación con Richard Custodio Velázquez. Niñez, migraciones y derechos humanos en América Latina. SITEAL. UNESCO.

Walsh, C. (2009).Interculturalidad crítica y pedagogía de-colonial: apuestas (des) de el in-surgir, re-existir y re-vivir. En Patricia Melgarejo (Comp.). Educación Intercultural en América Latina: memorias, horizontes históricos y disyuntivas políticas. Universidad Pedagógica Nacional-CONACIT, editorial Plaza y Valdés.

Weis, F., Bussemer, J., Jakob, C., Christoph, W., Kron, S., Reithmuller, D. y Albrecht, F. (2020). Atlas de las migraciones. Parte de nuestra historia. Fundación Rosa Luxemburgo y el Dipló. Disponible en: https://www.eldiplo.org/wp-content/uploads/2020/04/migracionesweb.pdf [Consultado el 10/10/2020]

\section{Normativa}

RME (2006). Anexo IV: Plan de Acción 2006-2010. Acta Nº1/06 de la XXX Reunión de Ministros de Educación de los países del Mercosur. 
Acta $N^{\circ}$ 01/18 de la XXXIV Reunión de la Comisión de Área de Educación Básica

Acta $\mathrm{N}^{\circ}$ 01/18 y su Anexo V de la LII Reunión de Ministros de Educación

Acta Nº 01/19 de la XXXIX Reunión de la Comisión de Área de Educación Básica

Decisión $N^{\circ}$ 35/06 del Consejo Mercado Común. Incorporación del guaraní como idioma del Mercosur.

Plan de Acción 2001-2005

Planes de Acción 2016-2020

\section{Portales y páginas oficiales consultadas:}

Documentos oficiales de órganos y foros del Mercosur: https://documentos.mercosur.int/

Mercosur Educativo: http://edu.mercosur.int/es-ES/

Parlamento Juvenil del Mercosur:

https://www.parlamentomercosur.org/innovaportal/v/17182/1/parlasur/parlamento-juvenil-del$\underline{\text { mercosur.html }}$

Organización Iberoamericana de Seguridad Social: https://oiss.org/

Portal de datos mundiales sobre las migraciones: $\underline{\text { https://migrationdataportal.org/es/sdgs?node }=0}$

Sitio oficial del Mercosur: https://www.mercosur.int/ 


\section{Anexos}

- Tabla n..$^{\circ}$ 7. Normas internacionales ratificados por los Estados Partes del Mercosur.

- Argentina-Brasil (2007).Programa Escuelas Interculturales Bilingües de Frontera (PEBF) según surge del documento conjunto de los ministerios de educación argentino y brasileño (2007)

- Anexo V del Acta $\mathrm{N}^{\circ} 1$ de la RME (2018). 
Tabla n. ${ }^{\circ}$ 7. Normas internacionales ratificadas por los Estados Partes del Mercosur

Fuente: elaboración propia en base datos de la web oficial de la ONU, de la OIT y de la OEA

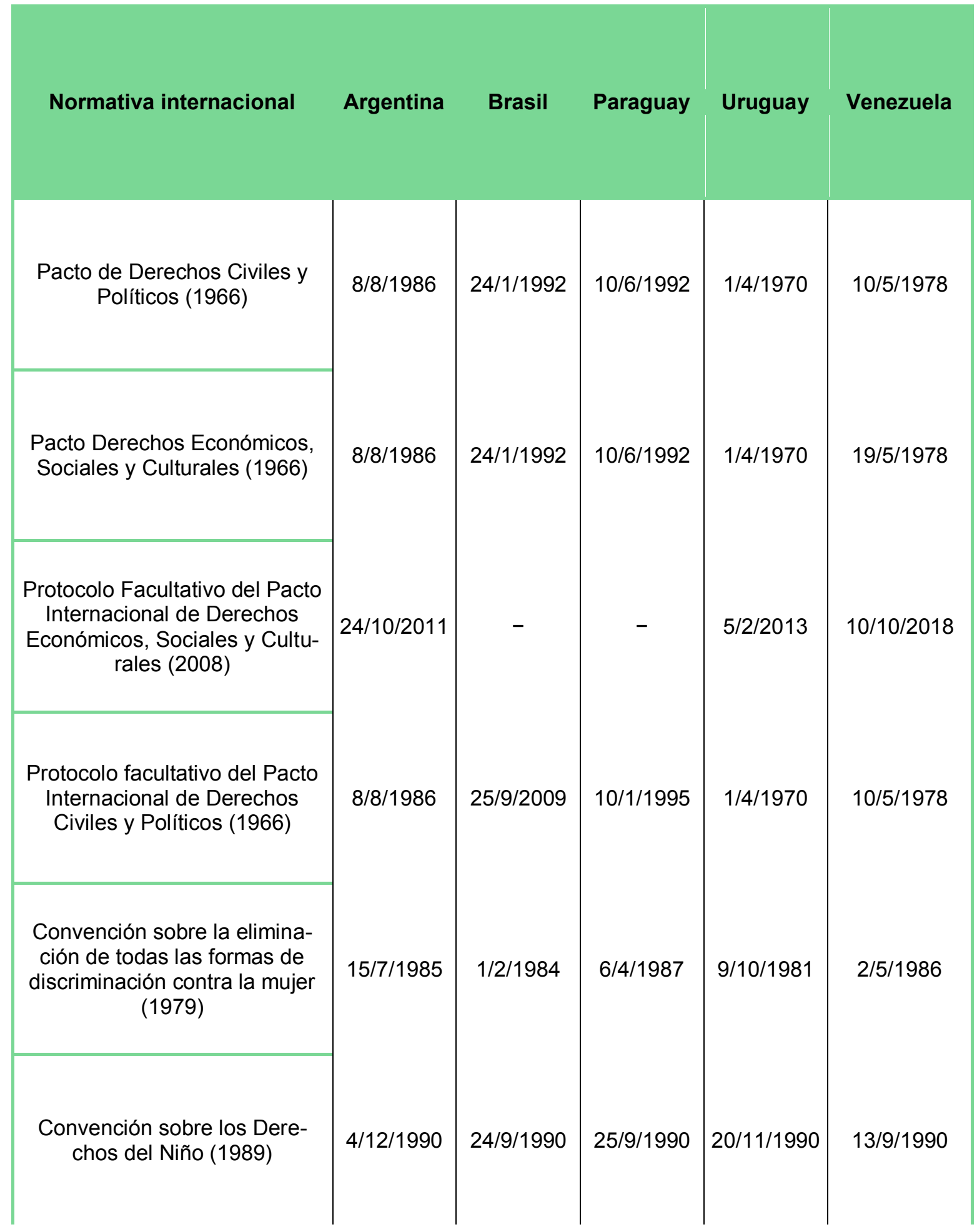




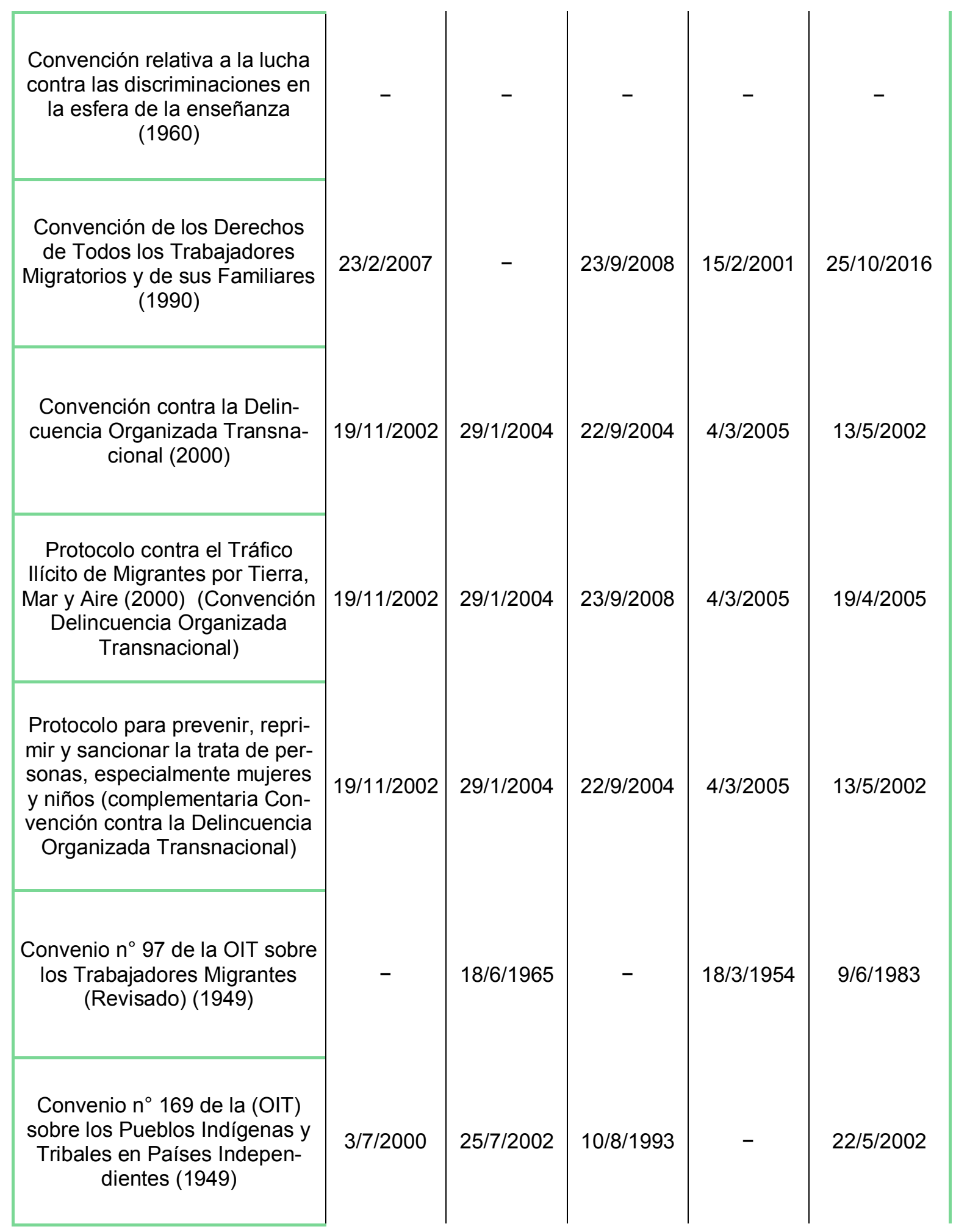


Convenio $n^{\circ} 143$ de la OIT sobre los Trabajadores Migrantes (Disposiciones Complementarias) (1975)

\section{Convención sobre el Estatuto} de los Refugiados (1951)

Convención sobre el Estatuto de los Apátridas (1954)

Convención sobre los Derechos de las Personas con Discapacidad (2006)

Convención Americana de Derechos Humanos (1969)

Protocolo adicional a la Convención Americana en materia de Derechos Económicos, Sociales y Culturales (Protocolo de San Salvador, 1996)

Convención Interamericana para Prevenir, Sancionar y Erradicar la Violencia contra la Mujer (1994) (Convención de Belém do Pará)

Convención Interamericana contra el Racismo, la Discriminación Racial y Formas Conexas de Intolerancia (2013)

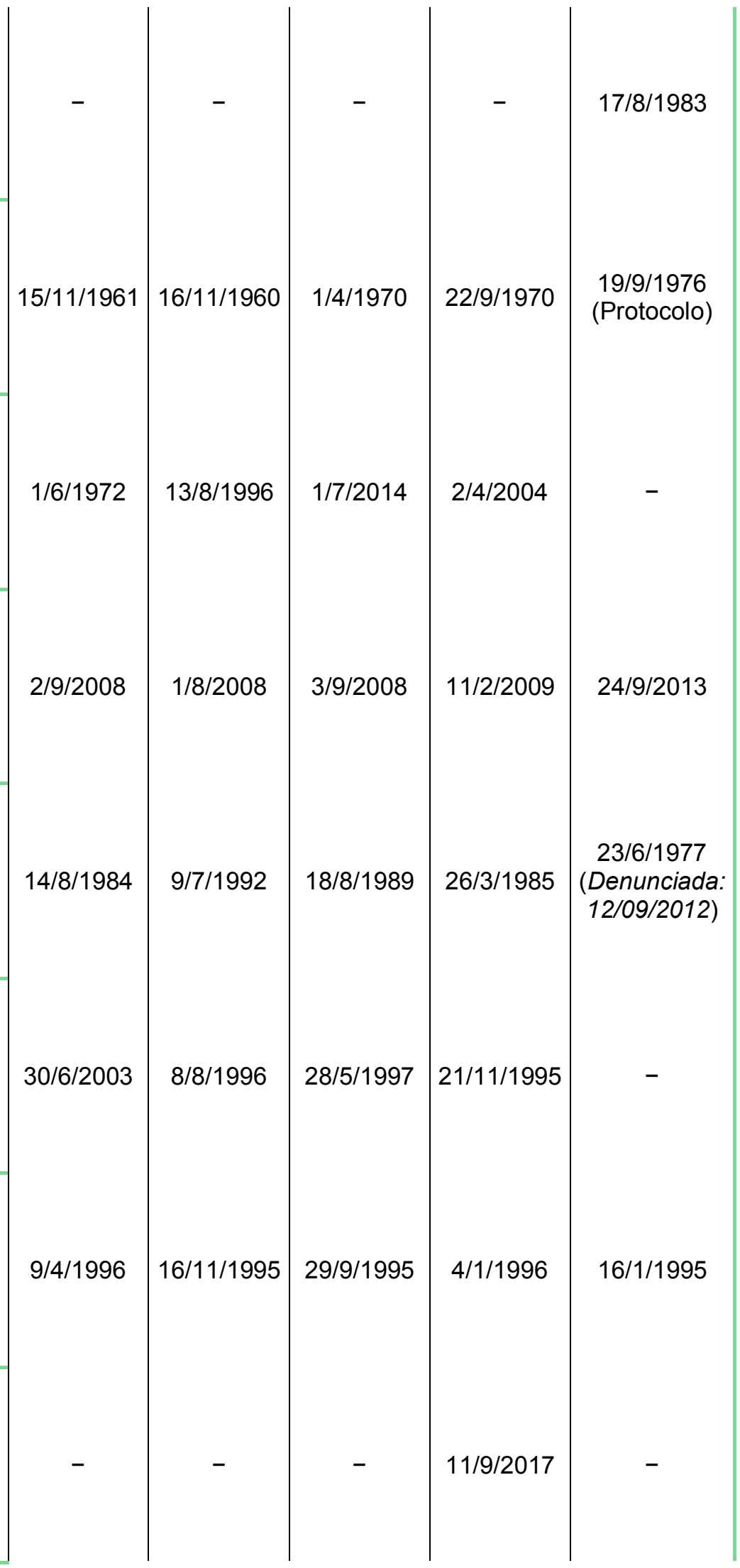




\begin{tabular}{|c|c|c|c|c|c|}
$\begin{array}{c}\text { Convención Interamericana } \\
\text { sobre la Protección de los De- } \\
\text { rechos Humanos de las Perso- } \\
\text { nas Mayores (2015) }\end{array}$ & $30 / 6 / 2017$ & - & - & $7 / 11 / 2016$ & - \\
\hline $\begin{array}{c}\text { Convención Multilateral Ibe- } \\
\text { roamericano de Seguridad } \\
\text { Social para Trabajadores Mi- } \\
\text { gratorios }\end{array}$ & $9 / 6 / 2010$ & $30 / 10 / 2009$ & $15 / 12 / 2010$ & $24 / 5 / 2011$ & $16 / 2 / 2009$ \\
\hline
\end{tabular}




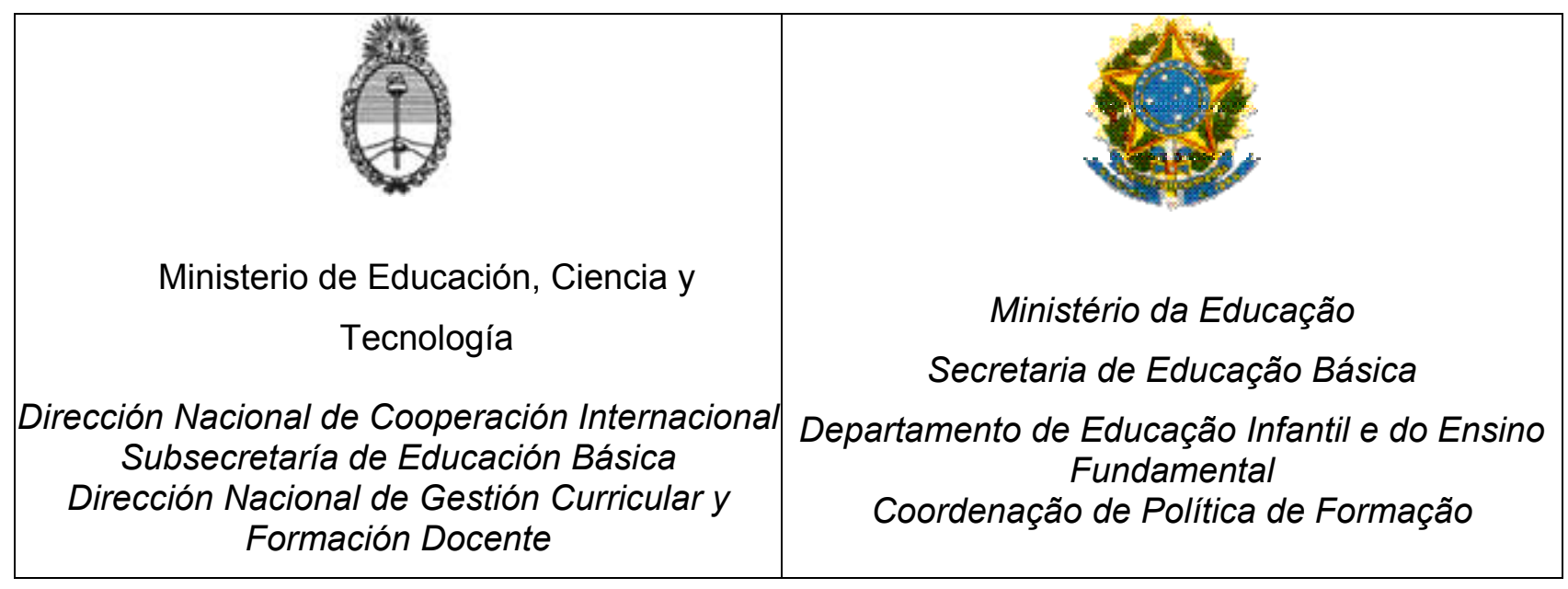

\section{Escuelas de Frontera}

Brasilia y Buenos Aires, octubre de 2007 


\section{PROGRAMA ESCUELAS BILÍNGÜES DE FRONTERA}

(PEBF)

“Modelo de enseñanza común en escuelas de zona de frontera, a partir del desarrollo de un programa para la educación intercultural, con énfasis en la enseñanza del portugués y el español”

Un esfuerzo binacional argentino-brasileño para la construcción de una Identidad Regional Bilingüe e Intercultural en el marco de una cultura de paz e de cooperación interfronteriza 


\section{Introducción}

El Programa Escuelas Bilingües de Frontera nació de la necesidad de estrechar lazos de interculturalidad entre ciudades vecinas de países que tienen frontera con el Brasil. Pasado el primer tiempo de la implementación, es posible establecer una discusión sobre los primeros pasos ya dados y los que están por venir. Es el objetivo de este documento, presentar un pequeño desarrollo histórico del Programa, una rápida exposición de las situaciones de frontera y una descripción del Modelo que se aplica y de su funcionamiento

El desarrollo histórico aquí presentado se refiere al surgimiento del MERCOSUR; a las reuniones que precedieron la elaboración del Programa; a la elección de las ciudades gemelas internacionales, ciudades cercanas en el área de frontera de la Argentina y el Brasil

La frontera entre el Brasil y la Argentina es descripta en una perspectiva sociolingüística, luego de diagnósticos realizados al iniciarse el Programa. La situación de las escuelas involucradas se analiza como referencial para la ejecución de los trabajos.

En "Modelo común para el desarrollo del Bilingüismo y de la Interculturalidad", se encuentra una muestra inicial del programa, un relato de la construcción conjunta que involucra la presencia de docentes de escuelas vecinas en la elaboración de Proyectos de Aprendizaje.

El último ítem trata del funcionamiento del Programa en cuanto a las posibilidades de carga horaria, en cuanto a la vinculación o no de los contenidos escolares, en cuanto a la coordinación de los trabajos.

Este documento es el punto de partida para la construcción de nuestro programa educacional para las escuelas de frontera. 


\section{Índice}

$\begin{array}{lr}\text { Una introducción histórica } & 5\end{array}$

1. La frontera entre la Argentina y el Brasil y sus lenguas 9

1.1 Consideraciones sobre el repertorio lingüístico de los niños 10

2. La interculturalidad en el Programa de Escuelas de Frontera 12

2.1 Formas de exposición a la interculturalidad 14

3. Modelo común para el desarrollo del bilingüismo y la Interculturalidad 16

$\begin{array}{ll}3.1 \text { - Modelo secuencial en construcción } & 17\end{array}$

$\begin{array}{ll}3.2 \text { - Intercambio docente } & 19\end{array}$

4. - Funcionamiento del PEBF 20

5. - Enseñanza a través de Proyectos de Aprendizaje 23

6.- El lugar del diálogo en la enseñanza y el aprendizaje 26

7. Consideraciones finales 32 


\section{Una introducción histórica}

La primera Reunión Técnica Bilateral de los equipos de los dos Ministerios de Educación de la Argentina y del Brasil sucedió, en diciembre de 2004, en Buenos Aires. En esta ocasión, se recordó que la última acción específica para las fronteras de la Argentina fue un proyecto del gobierno militar, en los años setenta, intitulado "Marchemos hacia las Fronteras" que formulaba un trabajo conjunto entre la Gendarmería Nacional (tropa que cuida las fronteras, equivalente a la Policía Federal Brasileña) y las escuelas, para una "educación de defensa" con relación al expansionismo de los países vecinos.

Hubo, por lo tanto, un cambio radical de la perspectiva en las relaciones entre la Argentina y el Brasil en los últimos veinte años, lo que posiciona a los dos ministerios, en este momento histórico, en una estrecha cooperación para la construcción de una ciudadanía regional bilingüe e intercultural, propugnando una cultura de paz y de cooperación interfronteriza

Preceden a esta reunión, sin embargo, una serie de conversaciones y entendimientos bilaterales y multilaterales entre la Argentina y el Brasil, que fueron conformando el actual espíritu de cooperación. A continuación, se exponen algunos de los pasos de este camino de cooperación.

El 26 de marzo de 1991, se firma por los países miembro del MERCOSUR - Mercado Común del Sur- Argentina, Brasil, Paraguay y Uruguay, el Tratado de Asunción que en su artículo 23 declara al portugués y al español como idiomas oficiales del MERCOSUR.

Como parte de este proceso, el SEM -Sector Educativo del MERCOSURdestaca, en sus planes de acción, la necesidad de difundir el aprendizaje del portugués y del español por medio de los sistemas educativos formales e informales, considerando como áreas prioritarias el fortalecimiento de la identidad regional, llevando, de esa forma, al conocimiento mutuo, a una cultura de integración y a la promoción de políticas regionales de formación de recursos humanos con vista a la mejora de la calidad de educación. 
En la reunión de Ministros de la Educación del SEM-MERCOSUR, realizada en Asunción-Paraguay, en el año 2001, se aprobó el Plan de Acción del Sector 2001-2005, el cual destaca, entre otros aspectos, "la educación como espacio cultural para el fortalecimiento de una conciencia favorable a la integración, que valorice la diversidad y reconozca la importancia de los códigos culturales y lingüísticos”. Es en este contexto que el SEM busca avanzar en la sensibilización para el aprendizaje de los dos idiomas oficiales del MERCOSUR.

Con el objetivo de estrechar los lazos en el área educativa, se firmó con la Argentina, el 23 de noviembre de 2003, la Declaración Conjunta de Brasilia, "Para el fortalecimiento de la Integración Regional". En esta Declaración, la educación se reafirmó como espacio cultural para el fortalecimiento de una conciencia favorable a la integración regional, atribuyéndole una gran importancia a la enseñanza del español en Brasil y del portugués en la Argentina. A partir de este momento equipos técnicos de la Argentina comenzaron a elaborar un borrador del Programa en sus líneas generales y a investigar sobre la adquisición y la didáctica de las segundas lenguas y el bilingüismo así como sobre temas de frontera que condujeron a la elaboración de un documento de trabajo que pudiera cristalizar los objetivos de la Declaración Conjunta.

Como resultado de estas investigaciones, surgió la necesidad de elaborar, en abril-mayo de 2004, un relevamiento que pudiera proveer datos con respecto a la realidad sociolingüística de profesores y alumnos involucrados en el programa y que pudiera revelar a) el grado de conocimiento del español estándar de los docentes de las escuelas de frontera de Corrientes y Misiones; b) el grado de conocimiento de portugués de docentes y alumnos y c) las representaciones sobre estas lenguas y otras, como el guaraní. En mayo de 2004 se produjo la primera versión del "Proyecto Piloto de Educación Bilingüe. Escuelas de Frontera Bilingües Portugués-Español".

El 9 de junio de 2004 se firmó en Buenos Aires una nueva Declaración Conjunta que refrendó lo establecido anteriormente, en el marco del "Convenio de Cooperación Educativa entre la República Argentina y la República Federativa del Brasil, suscripto en Brasilia el 10 de noviembre de 1997, y teniendo presente lo 
dispuesto por el "Memorando de Entendimiento" firmado en Buenos Aires el 6 de junio de 2003

Esta nueva Declaración incluía un Plan de Trabajo como anexo. El Programa se denominó "Modelo de enseñanza común en escuelas de zona de frontera, a partir del desarrollo de un programa para la educación intercultural, con énfasis en la enseñanza del portugués y del español". El programa de referencia se presentó en la XXVI Reunión de Ministros de Educación del MERCOSUR, Bolivia y Chile, realizada en Buenos Aires, el 10 de junio de 2004.

La referida Declaración dispone implementar, entre otras, la siguiente acción:

(...) desarrollo de un modelo de enseñanza comun en las escuelas y zona de frontera, a partir del desarrollo de um programa para la educación intercultural, con énfasis en la enseñanza del portugués y del español, uma vez que se cumplan los dispositivos legales para su implementación.

En atención a lo antes dispuesto, a lo largo del segundo semestre de 2004, la Secretaria de Educación Básica del Ministerio de Educación del Brasil, por medio del Departamento de Políticas de Educación Infantil y de la Enseñanza Primaria, inicio tratativas, junto a los sistemas estaduales y municipales de enseñanza de la región Sur del Brasil, buscando la adhesión de las escuelas ubicadas en la región de frontera. Las escuelas interesadas se manifestaron después de la visita de técnicas del MEC a las ciudades involucradas, enviando sus propuestas. Se definieron, a partir de ese momento, dos escuelas brasileñas ubicadas en los municipios de Uruguaiana-RS y Dionísio Cerqueira-SC que tienen fronteras con las provincias argentinas de Corrientes y Misiones, respectivamente.

Se estableció, a finales de 2004, la constitución de un Grupo de Trabajo para encaminar las acciones con el objetivo de implementar el programa en 2005. 
A partir de la confirmación del Programa de la nueva Declaración Conjunta, la Dirección Nacional de Gestión Curricular y Formación Docente, junto con la Dirección Nacional de Cooperación Internacional del Ministerio de Educación, Ciencia y Tecnología de la Argentina convocaron a los Ministerios de Educación de las provincias de Corrientes y Misiones para presentarles el programa y establecer consenso para su ejecución. A partir del compromiso firmado con las autoridades provinciales cada provincia identificó un responsable por el Programa. Durante 2005, el programa involucró dos escuelas, una en Bernardo de Yrigoyen, Misiones, y la otra en Paso de los Libres, Corrientes. En 2006 el programa se amplió hacia las localidades de Puerto Iguazú, Misiones, y Santo Tomé y La Cruz, Corrientes.

Entre 2004 y 2006 se mejoraron los instrumentos de diagnóstico sociolingüístico anteriormente planificados y fueron recolectados datos de todas las escuelas seleccionadas en la forma de cuestionarios con directores y docentes y de diagnóstico de nivel de conocimiento de portugués y español de los alumnos de los primeros grados, en el caso de Brasil y de la Argentina, y en el preescolar, en el caso de la Argentina.

Se definió como lugar privilegiado para el desarrollo del programa el sistema de ciudades gemelas internacionales, es decir, aquellas ciudades que cuentan con una ciudad cercana y colega en el otro país, promoviendo las condiciones ideales para el intercambio interfronterizo. En la frontera argentinobrasileña hay siete pares de ciudades-gemelas, algunas de las cuales involucra a tres núcleos municipales:

- Monte Caseros (Corrientes) - Barra do Quarai (RS)

- Paso de los Libres (Corrientes) - Uruguaiana (RS)

- La Cruz / Alvear (Corrientes) - Itaqui (RS)

- Santo Tomé (Corrientes) - São Borja (RS)

- San Javier (Misiones) - Porto Xavier (RS) 
- Bernardo de Irigoyen (Misiones) - Dionísio Cerqueira (SC) / Barracão (PR)

- Puerto Iguazú (Misiones) - Foz do Iguaçu (PR)

\section{La frontera entre Argentina y Brasil y sus lenguas}

Toda frontera entre países que hablan lenguas diferentes se caracteriza por ser una zona de indefinición e inestabilidad sociolingüística. Esta interacción se produce a partir de los hablantes de la lengua y de la influencia de los medios de comunicación, en particular, la radio y la televisión de un lado y otro de la frontera.

Esto sucede en la frontera entre Argentina y Brasil, por ejemplo, en donde se encuentran presentes, entre otras lenguas, el portugués y el español. Hay alternancias en los usos de ambos códigos con propósitos comunicativos e identitarios. Asimismo se observan aún frecuentemente en la frontera, fenómenos de mezcla lingüística y de préstamos en una y otra dirección. Estos fenómenos, sin embargo, no se generalizan, dado que presentan una configuración diferente en cada una de las fronteras.

Desde mediados de 2004, los diagnósticos sociolinguísticos realizados en el ámbito del Programa indican que, en un primer momento, el corte más característico y de mayor interés para el trabajo de las escuelas participantes es el de la diferencia cuantitativa y cualitativa de la presencia del portugués y del español en las ciudades-gemelas en particular, y en toda la frontera en general.

Mientras que en el lado argentino la presencia del portugués es relativamente constante, como parte del repertorio receptivo, y en menor escala, producto de una parte significativa de los niños de las escuelas de frontera y de sus familias, lo contrario no es verdadero: los datos sobre el lado brasileño no indican la presencia generalizada de niños y familiares hablantes de español o aún familiarizados con la comprensión de esta lengua. Este dato tiene consecuencias directas para la actuación de las escuelas del Programa. 
El español y el portugués son lenguas fónicas, es decir, habladas en el ámbito de una "Fonia": un conjunto de países en los cuales son lenguas oficiales 22 países tienen como lengua oficial al español (La Hispanofonía) y 8 países tiene como lengua oficial al portugués (La Lusofonía, organizada políticamente en la forma de la CPLP - Comunidad de los Países de Lengua Portuguesa) Aproximadamente 330 millones de personas hablan español y 208 millones de personas hablan portugués, de las cuales 182 millones se encuentran en Brasil. Juntas, las dos lenguas románicas son habladas por aproximadamente 540 millones de personas en 5 continentes. El español es una lengua de mayor prestigio internacional que el portugués, y hoy se la considera una de las lenguas de mayor crecimiento demolinguistico en el mundo. En la frontera entre Argentina y Brasil, sin embargo, los datos indican que el portugués tiene una presencia determinante resultado de la asimetría de prestigio a favor de esta lengua, caracterizando de esta forma una micro-situación sociolingüística opuesta a la relación entre las dos lenguas en el ámbito internacional

Esta situación de prestigio del portugués se asocia a la presencia de emisoras de televisión, así como a la oferta de servicios en las ciudades brasileñas de frontera, utilizados también por ciudadanos argentinos. El frecuente flujo turístico en dirección hacia Brasil y de Brasil, causado por las asimetrías cambiarias de la última década, contribuyó para un mayor conocimiento del portugués en la Argentina y para un menor conocimiento del español en Brasil (IPOL - Diagnóstico Sociolingüístico de Uruguaiana y Dionísio Cerqueira, 2006)

Estas asimetrías son menores o mayores de acuerdo con el momento histórico analizado. Sturza (2006) muestra que hasta la década de 1950 el español tenía una presencia mucho mayor en los hábitos lingüísticos de las poblaciones brasileñas de la frontera, principalmente en virtud de la existencia de una integración vial más intensa con Buenos Aires que con las principales ciudades brasileñas.

Teniendo en consideración lo antes expuesto y en función de las decisiones pedagógicas que deberán tomarse para atender a la realidad lingüística de los niños que participan de la experiencia, resulta indispensable precisar el valor de posición de cada una de las lenguas del programa y su relación con las lenguas que circulan en el ámbito familiar y socialmente cercano a los alumnos. 


\section{1 - Consideraciones sobre el repertorio lingüístico de los niños}

Después de algunos meses de actuación de los docentes en el aula, el programa pasó a visualizar con mayor claridad que, desde el punto de vista del repertorio lingüístico de los participantes, se trabaja con dos públicos diferentes: los niños argentinos ya son, en cierto nivel, bilingües, entienden razonablemente bien la lengua portuguesa y muchas de ellos la hablan con facilidad. Esto se debe al hecho de que gran cantidad de ellos son descendientes de brasileños. Asimismo, tienen una mayor exposición a la lengua a través de los medios de comunicación, mayor frecuencia de estadía en Brasil y, eventualmente, a consecuencia de estos factores, se reconoce una mayor disponibilidad de la población argentina de frontera para el aprendizaje del portugués.

Para estos niños y sus comunidades escolares la enseñanza bilingüe significa el reconocimiento de una situación de hecho y puede significar también el reconocimiento de una situación a largo plazo que de comienzo a prácticas de acceso a la cultura letrada (letramento) en ambas lenguas. La función social del portugués se presenta de manera más clara para las comunidades escolares argentinas, pues, entre otros motivos, esta lengua es utilizada en la vida cotidiana, es decir, es la parte más importante del repertorio comunicativo local.

Los niños brasileños de las escuelas participantes, por el contrario, son monolingües en portugués, lo que dificultó sobre manera el trabajo de los docentes argentinos al comienzo del programa porque los alumnos no entendían, en gran cantidad de oportunidades, las consignas mínimas necesarias para el trabajo cotidiano en el aula. Se comprobó así que, para el éxito del programa, era necesario un período de "sensibilización lingüística" para que los niños brasileños percibieran el por qué del aprendizaje del español y desarrollaran una actitud positiva frente a este aprendizaje. Durante este primer momento, fue fundamental el trabajo de los docentes para generar en los alumnos una actitud positiva, y para lograrla, los docentes tuvieron antes, ellos mismos, que comprender la función social de este aprendizaje. 
La actitud de los niños frente a la nueva lengua y sus motivaciones positivas para el aprendizaje advienen de sus experiencias personales de contacto con hablantes de la L2, en nuestro caso el contacto con el o los docentes. Esta vivencia inicial con la lengua en situación escolar, especialmente en el caso de los niños que no son bilingües de antemano y, por lo tanto, tienen en el contacto con el docente su experiencia dominante en la L2, necesita asegurar el gusto y el interés por la lengua a partir de una serie de actividades enfocadas en los diferentes intereses de los alumnos que incluyan situaciones lúdicas, de desafío intelectual entre otras posibilidades, relacionando el aprendizaje de la lengua con otras motivaciones hacia el futuro.

Las actitudes positivas de los niños necesitan, de cierto modo, ser seguidas de actitudes positivas por parte de los padres. Por esta razón, las escuelas han buscado frecuentemente sensibilizar a los padres de los alumnos, ya sea presentándoles a las docentes del otro país que trabajan con sus hijos, ya sea posibilitando que participen en los eventos binacionales de la escuela, o inclusive en actividades cotidianas conducidas por la docente del otro país en la L2, como podrían ser una actividad en la huerta, una observación de campo, una entrevista a una persona de la comunidad relevante para los niños o un ensayo para representar una obra de teatro, entre otras posibilidades.

\section{La interculturalidad en el Programa de Escuelas de Frontera}

Para que los procesos de sensibilización, anteriormente mencionados, tengan éxito es importante partir, asimismo, del conocimiento previo de los alumnos, de las familias y de sus realidades por parte de los docentes del otro país. Se prevé, de esta forma, que las escuelas desarrollen una sistemática de trabajo de sensibilización de los padres para el desarrollo de actitudes positivas frente al bilingüismo y a la interculturalidad.

Una educación para las escuelas de frontera, en este contexto, implica en el conocimiento y en la valorización de las culturas involucradas, teniendo como base las prácticas de interculturalidad. Como efecto de la integración y del diálogo entre los grupos involucrados, se tiene, entonces, relaciones entre las culturas, el reconocimiento de las características propias, el respeto mutuo y la valoración de lo 
diferente como diferente (y no como "mejor" o "peor") Por la interculturalidad podemos entender, por lo menos, dos tipos de quehaceres diferentes:

- Entendemos por "interculturalidad", en primer lugar, un conjunto de prácticas sociales relacionadas con "estar con el otro", entenderlo, trabajar con él, producir sentido conjuntamente. Como en toda práctica social, la interculturalidad se vive en la medida en que se producen contactos calificados con el otro, como por ejemplo, en las planificaciones conjuntas de los docentes de los dos países, en los proyectos de aprendizaje en que interactúan alumnos argentinos y brasileños, cada grupo con su manera culturalmente diferente de mirar para los mismos objetos de investigación, en la participación en eventos propios de cada país, como por ejemplo, cuando los padres y los alumnos de una escuela argentina participan de una "festa junina" brasileña o la celebración de una fecha patria argentina. Esta dimensión de la interculturalidad es la dimensión de las vivencias, fundamental en el campo de los conocimientos actitudinales ${ }^{1}$.

a Entendemos interculturalidad también como conocimientos sobre el otro, sobre el otro país, sus formas históricas de constitución y de organización, conocimientos que necesitan estar presentes curricularmente en los proyectos de aprendizaje planificados y ejecutados en las escuelas. Son estos conocimientos sobre el otro que posibilitarán, a los alumnos, sentirse partícipes de historias comunes, por ejemplo, cuando un estudiante brasileño consigue entender y apreciar el esfuerzo sanmartiniano en la guerra de independencia de Argentina y su dimensión latinoamericana. En esta dimensión de la interculturalidad se incorporarán la historia, la geografía, las dimensiones literarias, artísticas, religiosas del otro país, entre otros aspectos en los proyectos de aprendizaje realizados en conjunto de forma bilingüe. Esta es la dimensión informacional de la interculturalidad.

Asimismo, la educación pensada para las zonas de frontera proporciona a los alumnos de las escuelas del programa el conocimiento y el uso de

\footnotetext{
${ }^{1}$ En este sentido, entendemos por actitudinal el desarrollo de una propensión continua hacia la investigación, el deseo por aprender más.
} 
más de una lengua, lo que contribuye a la calidad de la educación y al mejoramiento de las relaciones comunicativas, teniendo en vista que los alumnos se encuentran, en mayor o menor grado, expuestos a situaciones de utilización de ambos idiomas.

Las relaciones entre el manejo de dos lenguas y la inserción en dos o en varias culturas no son directas, sino dependientes de los contextos y de los modos de circulación de los individuos. De esta forma, la novedad de la propuesta emprendida por ambos países abre un espacio para la investigación de las condiciones que definen el contexto pedagógico del programa tanto para el aprendizaje de lenguas como para el desarrollo de la interculturalidad.

Si bien la tradición en la enseñanza y aprendizaje de lenguas segundas/extranjeras establece una diferencia crucial entre contextos endolingües y exolingües ${ }^{2}$, se tendría que considerar que la heterogeneidad sociolingüística y la fuerte orientación intercultural en la que se desarrolla el programa definen un ámbito complejo en donde lo establecido hasta el momento por los especialistas resulta insuficiente y produce, por este motivo, un estado de tensión permanente. Muchas son las voces que atraviesan la presente propuesta. Voces que provienen de diferentes miradas desde la teoría, desde la práctica, miradas históricas, sociales, políticas, entre otras y que parecen no escucharse o por lo menos no conseguir la armonía necesaria en gran cantidad de oportunidades. Sin embargo, esta heterogeneidad debe considerarse constitutiva del programa y como un punto de partida tanto para la toma de decisiones en la práctica concreta como para la posterior realización de investigaciones que, a partir del diálogo teoría-práctica docente, definan una metodología y una terminología que permitan lograr acuerdos entre todos los participantes.

\subsection{Formas de exposición a la interculturalidad}

El programa posibilita una exposición sistemática a:

\footnotetext{
${ }^{2}$ En el primer caso, el aprendiz puede continuar con el uso social de la lengua que aprende fuera del contexto pedagógico. Lo que establece el docente en la clase no es la única muestra de lengua que posee y por lo tanto, estará expuesto a situaciones diferentes que le producirán inquietud, duda, revisión de estereotipos, entre otras cuestiones y que luego, al llevarlas a la clase, le permitirán reflexionar sobre ellas. Aquí, no hablamos del aprendizaje de una lengua como lengua extranjera sino como lengua segunda o L2.
} 
a) Usos de la L2, en la medida en que la otra lengua pasa a ser parte de manera cada vez mas presente en el cotidiano de la escuela, en donde el niño pasa una parte importante de su tiempo. Estos usos son orales y escritos. La presencia de textos en la lengua objeto de enseñanzaaprendizaje, estimulada desde el primer contacto del niño con la escuela, crece y se diversifica a medida en que avanzan sus posibilidades de lectura, transformándose, con el tiempo, en una presencia constante en todos los actos educativos de las diferentes disciplinas. A este contacto espontáneo con materiales auténticos en la segunda lengua, se le debe agregar también un adecuado seguimiento pedagógico de toda la comunidad educativa para multiplicar o crear situaciones de interacción entre todos los actores de los diferentes países y permitir así enriquecer los universos discursivos en ambas lenguas-culturas.

b) Una relación personal con un hablante nativo de la lengua objeto de enseñanza-aprendizaje. El niño no se expone solamente a usos de la lengua objeto de enseñanza-aprendizaje, sino que se posibilita la formación de un vínculo con una persona que conversará exclusivamente en la lengua objeto de enseñanza-aprendizaje. Este vínculo emocional es fundamental para la formación de actitudes positivas frente al idioma y la cultura que este difunde. Es importante también observar que el vínculo se da con un hablante nativo de la lengua objeto de enseñanza-aprendizaje, lo que posibilita al niño percibir y vivenciar la pragmática que une lengua y cultura.

El reconocimiento de la alteridad implica, asimismo, reflexionar sobre las representaciones que circulan en una sociedad con respecto a las lenguas y las culturas que las contextualizan. Claro ejemplo de ello son los estereotipos con los cuales se identifica tanto a una lengua como a sus hablantes. Las lenguas, en este sentido, son más o menos "fáciles", "alegres", "dulces", "musicales", entre otras apreciaciones estereotipadas. La comprensión de estas representaciones implica reconocer la complejidad del aprendizaje de otra lengua y cultura y, consecuentemente, comprender el alcance del esfuerzo pedagógico a realizar por la escuela. Es a partir de la información y de la reflexión continua entre alumnos y 
docentes que éstas pueden ser resignificadas. La clase se convierte en un espacio para el descubrimiento de características de la L2.

c) un profesional de la comunidad nacional/ cultural de la cual esta lengua es la expresión más generalizada. El contacto es con un profesional del otro país, y que tiene una vivencia institucional en el sistema escolar del país vecino, experiencia también muy importante para el niño, que vivenciará, en su contacto con docentes argentinos y brasileños, las tradiciones pedagógicas institucionales de dos sistemas escolares diferentes.

Aunque estos tres aspectos ocurren efectivamente juntos, esta participación permite entender los beneficios que se producen en los niños no sólo por conocer los usos de la lengua, sino aún más por desarrollar vínculos personales en simultáneo al aprendizaje de estos usos. El miedo, producto del desconocimiento del otro, se convierte en curiosidad, sorpresa y voluntad de aproximación a partir de experiencias conjuntas significativas.

Finalmente, las escuelas partícipes del programa, más allá de la incorporación de la L2 y de las personas de otra nacionalidad en sus rutinas, amplían la base informacional de los contenidos escolares, dejando de enfocar únicamente el nivel nacional y ocupándose también con la Región como unidad de trabajo.

Se trata de un programa que viene proporcionando a las comunidades, a las escuelas participantes y a los Ministerios de Educación de ambos países la oportunidad de vivenciar relaciones de interculturalidad y a desarrollar rutinas de trabajo bilingües, con el uso del portugués y del español, experiencia fundamental para los objetivos políticos expresados en la documentación política de la relación entre los dos países, citada en el inicio de este texto.

\section{Modelo común para el desarrollo del bilingüismo y de la interculturalidad}


El Programa tiene como objetivo el desarrollo de un modelo de enseñanza común en las escuelas de frontera, garantizando, de esta forma, que alumnos y docentes tengan la oportunidad de educarse y comunicarse en las dos lenguas a partir del desarrollo de un programa intercultural. En la fase inicial del programa, las escuelas involucradas en el PEBF siguen los calendarios y las prácticas curriculares de sus respectivos sistemas de enseñanza y hay un sendero de mediano plazo a recorrer hasta que se pueda pensar tanto en un modelo común compartido como en un calendario único para las escuelas que, de esta forma, tendrán más facilidad en planificar conjuntamente.

Este modelo común no es la yuxtaposición de los dos currículos nacionales en las escuelas participantes, sino una serie de acuerdos y negociaciones que los sistemas escolares participantes (escuelas, secretarias municipales y estaduales de educación brasileños, ministerios provinciales de educación argentinos, ministerios nacionales) realizan dentro de un cuadro común establecido en un primer momento en las Reuniones Técnicas Bilaterales (alternadamente en ambos países) y por los trabajos de la Comisión Curricular del Programa que dio comienzo a sus actividades en junio de 2006 y que basa su labor en la experiencia bilateral instalada por el Programa desde finales de 2004 cuando los trabajos en conjunto comenzaron.

Establecido el marco curricular de referencia del Programa Escuelas Bilingües de Frontera, cada sistema escolar y cada escuela participante elaborará su plano político-pedagógico/proyecto educativo institucional de forma más precisa $y$, consecuentemente, sus rutinas y estrategias de trabajo. Este marco de funcionamiento está, en muchos aspectos, establecido de hecho por las prácticas docentes y de gestión en curso y, de jure, en las actas de las reuniones técnicas bilaterales periódicas. En este sentido, las prácticas generan una base curricular común de la cual todos los profesionales e instituciones involucradas son partícipes, y que luego serán sistematizadas por la Comisión Curricular del Programa ${ }^{3}$.

\section{1 - Modelo secuencial en construcción}


El PEBF se inició en 2005 con la presencia en la primeira série do ensino fundamental o en el primer grado de la enseñanza primaria argentina del docente de la "escuela-espejo" del otro país, hablante de la L2, con un determinado número de horas semanales. La proyección es ampliar el número de grupos participantes a cada año y avanzar a los grados siguientes, de acuerdo con las posibilidades concretas de los sistemas escolares, permitiendo a los alumnos también el avance de sus propias experiencias en la L2 y en la familiarización con la cultura y las informaciones referentes al otro país.

De esta forma, se inicia la exposición de los alumnos a la L2 a partir de su llegada a la enseñanza primaria, cuando sus disposiciones y capacidades para el aprendizaje de lenguas son mayores que en la edad más avanzada. Esto no impide que en el futuro también los niños de la educación infantil se involucren en la enseñanza bilingüe e intercultural de manera sistemática, acción que ya viene ocurriendo en algunas escuelas argentinas, con un plantel propio de docentes, como es el caso de la Escuela Bilingüe No. 1 de Bernardo de Irigoyen.

Por otra parte, como apoyo a este trabajo, se planteó una serie de orientaciones - no prescriptivas u obligatorias- que pudiesen servir de apoyo al trabajo docente en establecer una posible progresión de contenidos y actividades previstos en los proyectos y en la posterior evaluación de los avances de los alumnos.

De esta forma, una vez alcanzada una primera etapa de sensibilización a la interculturalidad, es esperable que todos los participantes del programa avancen en un desarrollo creciente orientado hacia la profundización de la interculturalidad y sus prácticas.

Por otra parte, se tiene que resaltar también el valor pedagógico y didáctico que tiene la evaluación para el programa. En este sentido, se complejiza dicha actividad de evaluación, introduciendo diferentes momentos de reflexión metalingüística, metacognitiva e intercultural de los alumnos y docentes, siempre teniendo en cuenta la relación momento de escolaridad-edad de los alumnos.

\footnotetext{
${ }^{3}$ La formación de esta comisión curricular tuvo como objetivo principal elaborar orientaciones curriculares para el programa. En este sentido, la comisión formuló una estrategia comun de PPP(Projeto Político-Pedagógico) y PEI (Proyecto Educativo Institucional) sobre la mirada legislativa de cada uno de los dos países
} 
En este sentido, hay que destacar que el programa tiene como objetivo lograr que los alumnos egresados se transformen en ciudadanos activos para convertir la frontera en un espacio democrático de cooperación. Un ciudadano sensible a la interculturalidad que, a lo largo de su recorrido escolar, haya experimentado diferentes situaciones de contacto con la otra cultura, permitiéndole así generar un criterio amplio y tolerante ante la diversidad. Asimismo, el egresado del programa tendrá un dominio suficiente de la lengua portuguesa y española para interactuar con su par en contextos previsibles de intercambio lingüístico. Al trabajo intercultural y de sensibilización lingüística efectuado en los primeros años de escolaridad, se propone para los últimos años, un trabajo más sistemático que permita a los alumnos manejarse de forma plena en contextos que soliciten la utilización de prácticas sociales de comprensión y producción en las dos lenguas.

La secuencialidad de avanzar grado a grado para el intercambio docente fue y viene siendo necesario en virtud de los muchos ajustes que el nuevo sistema trajo a las escuelas y a los sistemas locales de gestión educativa, siendo necesaria la obtención de recursos para actividades que antes no existían, como el transporte del cuerpo docente, o la ampliación de jornadas de trabajo, o aún la ampliación del espacio físico de las escuelas y la provisión de nuevos equipos.

\section{2 - Intercambio docente}

El Programa tiene como base el intercambio docente a partir de la disponibilización de planteles ya formados en ambos países y que actúan en las escuelas involucradas. La unidad inicial de trabajo, por lo tanto, es el par de "escuelas-espejo", que actúan juntas formando una unidad operativa y sumando sus esfuerzos en la construcción de la educación bilingüe e intercultural. Esta forma permite a los docentes de los países involucrados vivenciar ellos mismos, en su actuación y en rutinas semanales, prácticas de bilingüismo y de interculturalidad semejantes a las que quieren construir con los alumnos, en la medida en que se exponen a la vivencia con sus colegas del otro país y con los niños de diferentes grados con los que actúan.

Igualmente importantes son las demandas por un mayor intercambio entre los alumnos de las dos escuelas-espejo, dado el movimiento positivo que el cruce de los docentes viene provocando en las escuelas, lo que posibilitó el despertar de la curiosidad 
de los niños sobre el otro país. Este movimiento de los alumnos, frecuentemente, ha tenido dificultades por cuestiones de indocumentación (niños sin documentos de identidad, por la legislación de protección al niño, en especial en la Argentina, que impide el cruce de la frontera sin la autorización por escrito de ambos padres. A pesar de esto y de otras dificultades referidas a la autorización del cruce de frontera, hubo varios momentos en que los alumnos de los dos países tuvieron la oportunidad de confraternizar.

\section{4. - Funcionamiento del PEBF}

a) Carga horaria y disposición de las clases en la L2

El hecho de que el PEBF se realice sobre una base escolar preexistente, gestionada por diferentes secretarias de educación o ministerios provinciales hace que no sea posible o recomendable propugnar un modelo único para su ejecución. Concretamente, la discusión con los equipos condujo a la emergencia de tres formas para la organización de las escuelas:

1) Escuela de Jornada Completa (Tempo Integral) con la enseñanza en L1 en un turno y la enseñanza de L2 en otro turno, a partir de proyectos de trabajo binacionales, formulados de manera conjunta, desarrollados por las escuelas-espejo simultáneamente con tareas específicas en cada lengua. En este modelo hay por lo menos dos días semanales de trabajo en la L2 y una carga horaria total de por lo menos 6 horas semanales, con posibilidad de ampliación, de acuerdo con la disponibilidad de espacios escolares adecuados. Al ser una escuela de jornada completa, los alumnos poseen además dos horas reservadas a los proyectos en la L2, otras actividades y talleres en los días no destinados a la educación bilingüe. 
2) Escuela en Contra-Turno con un funcionamiento semejante al de la escuela de jornada completa, pero solamente con las actividades de educación bilingüe intercultural en el turno contrario.

3) Escuela de Turno Único, con proyectos de trabajo binacionales consensuados en la escuela, realizados de forma bilingüe, con tareas específicas en cada una de las lenguas. En dos días por semana la enseñanza se realiza en la L2 dentro del propio turno, con un total de, como mínimo, cinco horas semanales con posibilidad de expandirse a seis horas semanales.

El primero es el modelo utilizado prototipicamente en Dionísio Cerqueira y Bernardo de Yrigoyen, como escuelas de jornada completa. El segundo modelo se lo práctica en Foz de Iguaçu y Puerto Iguazu; el tercero es el modelo desarrollado en Uruguaiana, aunque su escuela-espejo de Paso de los Libres funcione en jornada completa. El modelo de turno único prevé la presencia del trabajo en la L2en la base curricular, mientras que el trabajo en contraturno muchas veces puede hacer que el trabajo sea visto como una actividad extracurricular, lo que no es la intención del PEBF. El turno único ofrece mejores perspectivas para la ampliación del sistema, porque no interfiere tanto en la rutina de la escuela, al no demandar la ampliación del espacio físico y la contratación de personal docente con la misma intensidad que el trabajo en contraturno o en turno completo. El trabajo en contraturno o en turno completo, a la vez, amplia el tiempo de permanencia del alumno en la escuela, estrategia útil para el proceso de aprendizaje del alumno a mediano y largo plazo, pero que encuentra resistencias por parte de los padres, en especial, al considerar a niños menores (6 y 7 años), que realizan su primera experiencia escolar.

En función de las experiencias antes mencionadas y a partir de los debates generados en las reuniones de los equipos de trabajo bilaterales y a lo largo de los diferentes encuentros de capacitación, se observa la necesidad de pensar un nuevo modelo, definido de forma conjunta con todos los a actores participantes del programa, que permita reflejar y dar respuesta a las características específicas e innovadoras de las escuelas interculturales bilingües. 
b) Modelo de educación bilingüe: vinculado versus no-vinculado

En el modelo de educación bilingüe vinculado la presentación de los conocimientos normalmente es imbricada, es decir, el alumno aprende en ambas lenguas UN mismo contenido. Para que UN contenido sea aprendido se necesita, por lo tanto, de ambas lenguas. Esto implica que los grupos deben ser CERRADOS, que no debe haber entrada de alumnos en los grupos bilingües luego del primer grado, es decir, durante la secuencia del proceso de escolarización, porque los recién llegados no seguirán a los otros alumnos que tendrán ya un grado de conocimiento y una práctica en la L2 que los recién llegados, en general, no tienen. La ventaja de este modelo es que el grado de conocimiento de los alumnos avanza de forma coordenada, y se llega al final de los nueve años de enseñanza fundamental con este nivel construida, garantía, por ejemplo, de la posibilidad de construcción de una enseñanza promedio bilingüe de calidad.

En una escuela pública con las características de las escuelas del PEBF, no obstante, el modelo utilizado es el No-Vinculado, lo que implica que los niños nuevos, eventualmente sin el mismo grado de conocimientos de los compañeros, pueden ingresar por traspasos a cualquier grado, aún en los grados más adelantados. Esta posibilidad necesita permanecer abierta en una escuela pública orientada a la inclusión social. Para los casos de traspaso, se discutirán estrategias para mejorar el desempeño escolar de los niños ingresados con posterioridad, de modo que puedan seguir los trabajos realizados en la L2.

c) Estructura, seguimiento pedagógico y registro

El PEBF se constituye por una coordinación en cada uno de los Ministerios de Educación de Argentina y Brasil, por coordinadores locales de las redes gestoras Secretarias Municipales de Uruguaiana, Itaqui, São Borja y Foz do Iguaçu y Secretarias de Estados da Educação de Santa Catarina (Gerência Regional de Educação de Dionísio Cerqueira) y de Paraná por el lado brasileño y de los Ministerios Provinciales de Educación - Corrientes y Misiones -por el lado argentino. Asimismo, cuenta con 
coordinadores en cada escuela. Las escuelas argentinas cuentan con un seguimiento y asesoramiento pedagógico de especialistas designados especialmente para esta finalidad en cada una de las ciudades involucradas en el Programa. Por el lado brasileño, esta función ha sido desarrollada hasta el momento por el IPOL -Instituto de Investigação e Desenvolvimento en Política Lingüística- de Florianópolis, cuyos asesores periódicamente visitan las escuelas bilngüesde frontera.

Estos equipos participan de la planificación conjunta de las escuelasespejo, propician discusiones sobre didáctica de las lenguas y sobre el trabajo con proyectos de aprendizaje para la escuela, asisten periódicamente a algunas clases para colaborar en el mejoramiento de la acción docente de las maestros, organizan las relatorias del PEBF y ayudan a mantener las comunicaciones entre todas las instancias de la organización del trabajo.

\section{5 - Enseñanza a través de los Proyectos de Aprendizaje}

El proyecto es un instrumento para la creación de la cooperación interfronteriza. La concepción de interculturalidad es, en este caso, activa: la escuela será intercultural en la medida en que exista la participación efectiva de profesionales y alumnos de las diversas culturas involucradas en la comunidad educativa (y que no son sólo "dos": la cultura argentina y la cultura brasileña, lo que correspondería a pensarlas como unidades homogéneas) en todas las instancias de convivencia que son propias de la institución escolar.

Por Cooperación Interfronteriza se entiende la posibilidad de superar la idea de frontera nacional como una barrera- "en donde el país termina"- sino al contrario, de entenderla como la visualización del acceso a oportunidades sociales, personales, educativas, culturales, económicas nacidas de la presencia y en la interacción con el otro, superando prejuicios, peleas y disputas originadas en el período histórico anterior, o de la afirmación del Estado Nacional como instancia única de atribución de identidad, y que presentaba al otro como amenaza o como negación.

Además de las reconocidas ventajas pedagógicas del trabajo por proyectos, desde el punto de vista de la cooperación interfronteriza, el PEBF tiene por objetivo permitir, organizar, fomentar la interacción entre los agentes educativos y las 
comunidades educativas involucradas, de manera tal de propiciar el conocimiento del otro y la superación de obstáculos al contacto y al aprendizaje. Este contacto con el otro implica necesariamente el contacto con la lengua hablada por él.

Para este primer punto, por lo tanto, el currículo necesita basarse en formas de organización de las rutinas que permitan a los participantes de las dos ciudadanías y de varias culturas ser parte en la toma de decisiones y en la ejecución de todas las fases de enseñanza, en todos los niveles en que esto se hiciere necesario: la planificación conjunta de los docentes es uno de los pilares de tal procedimiento, pues da las escuelas involucradas un máximo de responsabilidad en la elección de las problemáticas de los proyectos de aprendizaje y en la planificación del tratamiento que éstas tendrán.

Estas fueron algunas de las razones por las que se consensuó el funcionamiento escolar a través de la metodología de la enseñanza via proyectos de aprendizaje (EPA) como un posible camino natural para una escuela de este tipo. La contribución importante de esta forma de organización metodológica es la de posibilitar que se elijan los proyectos a ser desarrollados localmente, por grupo o por escuela, de acuerdo con lo que se considere más oportuno y de acuerdo con las diferentes realidades de las escuelas en cuestión. Esto implica que las escuelas o los grupos diferentes puedan realizar proyectos diferentes entre sí sin perder de vista los objetivos relacionados tanto con el aprendizaje de prácticas característicamente escolares asociadas al avance de la alfabetización plena (letramento), por un lado, como a los objetivos actitudinales asociados a la interculturalidad y al manejo de las dos lenguas, por el otro.

Para el aprendizaje de la lengua del país vecino vale el mismo principio: las prácticas de la escuela serán bilingües en la medida en que los hablantes de español y de portugués convivan en las funciones escolares relacionadas a la producción y a la circulación del conocimiento. El bilingüismo trabajado en este documento presenta una estructura que parte de las prácticas efectivamente construidas en las escuelas, de la convivencia y de los contactos lingüísticos que se hacen presentes en la rutina escolar. La planificación conjunta, como otros encuentros entre el cuerpo docente, son oportunidades de la práctica del bilingüismo: hacen circular discursos hablados y textos escritos en las dos lenguas, permiten escuchar la lengua del otro y, por lo tanto, escuchar al otro y entenderlo en su lengua.

En la perspectiva de la "Enseñanza Via Proyectos de Aprendizaje (EPA) los niños participan de proyectos bilingües que prevén tareas a ser realizadas en portugués o en español, coordinadas respectivamente por la docente brasileña o argentina, de acuerdo 
con el nivel de conocimiento del idioma que posean y de acuerdo con la planificación conjunta realizada periódicamente por las docentes argentinas y brasileñas con sus respectivas asesorías pedagógicas. Los proyectos, por lo tanto, son bilingües: el alumno realiza determinadas actividades en L1 y otras en la L2, pero todas ellas confluyen en un objetivo común, que es el de producir respuestas y mayor comprensión a partir de una problemática central determinada de antemano.

Los proyectos de aprendizaje se originan de los intereses de los alumnos involucrados y son consensuados entre los docentes argentinos y brasileños. Las primeras clases de la docente oriunda de la escuela-espejo tienen, por lo tanto, la doble función de permitir a la docente la familiaridad con sus nuevos alumnos y el relevamiento de intereses que servirán de base al primer proyecto de aprendizaje. A consecuencia de esta práctica, la planificación inicial - aquella que se realiza en el momento que el docente comienza a trabajar con el nuevo grupo- es de corto plazo (planificación clase a clase) y enseguida, una vez establecida la problemática del primer proyecto de aprendizaje a realizarse, se pasa a una planificación de mayor aliento (planificación de mediano y largo plazo) La planificación conjunta es uno de los momentos en los cuales el docente cuenta con el asesoramiento pedagógico local, ofrecido por la escuela o por los ministerios.

La perspectiva de enseñar via proyectos establece la labor con diferentes saberes que trabajan de forma simultánea con conocimientos de información y operativos. Estos últimos se centralizan en el desarrollo de prácticas -capacidad de operar con las informaciones, por ejemplo, e incluyen el acceso a la cultura letrada, el calculo, las capacidades de planificar, ejecutar, trabajar en grupo, exponer las ideas en público, entre tantas otras. En la planificación del programa de aprendizaje los docentes proyectan que saberes deben ser aprendidos por los alumnos, y al final del proyecto de aprendizaje registran cuales fueron efectivamente trabajados y aprendidos. A este procedimiento de registro se le da el nombre de currículo "post-factum" porque se concentra en las acciones y aprendizajes efectivamente realizados por los alumnos, en consonancia con lo establecido curricularmente por cada país y con las disposiciones curriculares comunes desarrolladas por la Comisión Curricular del PEBF.

En lo que se refiere a contenidos, es importante destacar que se piensa en su apropiación espiralada, teniendo en cuenta la construcción continua de saberes a partir de lo trabajado en los proyectos. Esto implica que un contenido puede ser retomado 
varias veces a lo largo del recorrido escolar, complejizándolo y enriqueciéndolo a medida que el aprendizaje del alumno avanza. De esta forma, la utilización de la metodología de elaboración de un curriculo post-factum así como el trabajo por medio de proyectos resultará fundamental a la hora de definir lo que se enfocará en la L2.

Como estrategia de seguimiento y evaluación del proceso de los alumnos se sugirió la metodología de "portfolio" definido como el seguimiento realizado a partir de evidencias de variadas naturalezas de trabajo realizado por los alumnos individual y colectivamente. El port-folio es una estrategia pedagógica proveniente del campo de las artes: son carpetas o conjuntos de memorias de obras realizadas por el alumno individualmente o en grupo. El port-folio es un proceso de selección de muestras que reflejen la trayectoria del aprendizaje de cada estudiante en el transcurso de un proyecto de aprendizaje, permitiendo que los docentes evalúen cualitativamente el crecimiento y las derivaciones de sus aprendizajes.

Del mismo modo, se enfatiza el reconocimiento de la evaluación formativa y continua como instancia indispensable para hacerle saber al alumno cuánto aprendió -y el placer que eso provoca-, así como qué le falta aún construir -ofreciéndole las herramientas para que pueda hacerlo.

Se sugiere que cada proyecto de aprendizaje se extienda por dos meses o un bimestre y que los proyectos no se repitan en la escuela, justamente porque todo el proceso reiterado pierde en fuerza de convocatoria y en la posibilidad de proponer nuevas articulaciones del conocimiento. La metodología de proyectos fue considerada dentro de dispositivos de formación de diferentes escuelas desde que se consensuó su utilización por los ministerios de Educación en la Reunión Técnica de Brasilia en julio de 2005.

\section{6. - El lugar del diálogo en la enseñanza y en el aprendizaje}

Se concibe que el aprendizaje es posible en el marco de ricas interacciones orales. Estas interacciones pueden darse en un aula y una escuela en las que la palabra del docente es la palabra autorizada por su experiencia y su conocimiento, y en las que las voces de los niños son bienvenidas y escuchadas; interacciones en las que se habla de cosas interesantes para los niños y en las que se plantean diálogos genuinos en los que todos -niños y maestros- tienen una voz, algo para decir, para compartir, para acordar, para opinar. 


\subsection{La lectura y la escritura en el PEBF}

Es sabido que los niños tienen distinto grado de conocimiento respecto de la lectura y la escritura al ingresar a la escuela. Esto implica que, más allá de los puntos de partida respecto del conocimiento de la lengua escrita (en sus múltiples dimensiones), la escuela es el principal agente alfabetizador, sobre todo para las clases populares. La escuela tiene una misión intransferible en la constitución de sujetos alfabetizados, entendiéndola hoy como condición de ciudadanía. Por eso, se enfatiza que en todos los contextos la escuela debe ofrecer múltiples oportunidades para que todos los niños participen en situaciones de lectura y de escritura como proceso creativo, placentero, necesario, útil, inteligente y vinculado con la cultura escrita de la sociedad.

\subsection{Alcance de los términos letramento y alfabetização en Brasil y alfabetización en} Argentina

En relación con el aprendizaje inicial de la lectura y escritura resulta necesario aclarar los alcances generales de los términos letramento, alfabetização y alfabetización empleados con distinto significado en los marcos curriculares de Brasil y Argentina y que por ese motivo han requerido explicitación en el marco de las reuniones bilaterales de este proyecto.

En Brasil se emplean los dos primeros términos: el término letramento hace referencia a la apropiación de conocimientos que constituyen la cultura llamada "letrada", es decir, al proceso de enseñanza-aprendizaje de la lengua escrita, pero comprende también a la oralidad y la lectura. En tanto, el término alfabetización aun muy relacionado a una visión de este aprendizaje como un proceso de codificación/ decodificación de sonidos en letras y viceversa.

En el caso de Argentina, en los documentos curriculares ${ }^{4}$ se emplea el término alfabetización en sentido amplio para hacer referencia a los momentos iniciales del

\footnotetext{
${ }^{4}$ Citamos aquí exclusivamente documentos producidos por el Ministerio de Educación, Ciencia y Tecnología de la Nación como los Núcleos de Aprendizajes Priorizados. Lengua ler. Ciclo (2004, con acuerdo del Consejo federal de Educación) y los Cuadernos para el aula. Lengua. $1^{\circ}, 2^{\circ}$ y $3^{\circ}$ (2006). Existen marcos curriculares
} 
proceso de apropiación y recreación de la cultura escrita (letrada) e incluye tanto el aprendizaje de la lengua escrita (sus formas, usos y funciones) como el de los conocimientos del sistema alfabético de escritura (lo que incluye la construcción del principio alfabético de escritura, el reconocimiento y trazado de las letras y el progresivo conocimiento de la ortografía de las palabras) Es decir, que en líneas generales, en Argentina el alcance del término alfabetización incluye los conocimientos que en Brasil se deslindan en los alcances generales de los términos letramento y alfabetização.

"En ambos casos (con el uso del término letramento en Brasil y de alfabetización en Argentina), se hace referencia, entonces, al proceso -profundamente social- de aprendizaje de un producto cultural, la lengua escrita; este proceso es continuo que se inicia, idealmente, en la primera infancia. Esa concepción de letramento / alfabetización como apropiación y recreación de la cultura escrita / letrada implica que, desde el comienzo de la escolaridad, la lengua escrita debe permitir el acceso a los saberes propios de los distintos campos del conocimiento, para conservarlos, compartirlos y transmitirlos.

\subsection{Introducción de situaciones de lectura y escritura en el programa bilingüe.}

Los niños que participan tempranamente de situaciones alfabetizadoras (de letramento), en su entorno primario y en la escuela, adquieren actitudes, expectativas (es decir, la imagen que ellos se van formando de sus posibilidades como lectores y escritores), conocimientos sobre el lenguaje escrito y sus funciones: comprenden que la escritura es lenguaje y que tiene distintas funciones. Es decir que, entre otros aspectos, los niños van tomando conciencia de que la palabra dicha oralmente se puede escribir y lo que está escrito se puede "decir" porque es lenguaje y que leyendo se puede volver una y otra vez a aquello que se escribió. En el caso del PEBF, aprenden, entonces, que tanto el español como el portugués se pueden leer y escribir.

En una escuela y en un aula bilingüe, este último aspecto aconseja la necesidad de que los niños participen, al comienzo, de una etapa oral de contacto con la segunda lengua -claro está, mientras participan de situaciones de lectura y escritura en su lengua 
materna-. En el marco de las actividades con textos orales en la segunda lengua (conversaciones, juegos, canciones, narraciones, rutinas escolares) previstas en los proyectos que se desarrollan, los niños aprenden formas de intercambio, el significado y uso de palabras y expresiones y las reglas de combinación de esa lengua. Dado que la escritura involucra procesos afectivos y cognitivos, no tendría ningún sentido que los niños copien palabras escritas por otro sin conocer su significado.

Ahora bien, cuando en el marco de los proyectos los niños participan en actividades desafiantes e interesantes se observa que les puede surgir espontáneamente, naturalmente, la necesidad de escribir: los nombres de un títere o de un personaje de alguna historia escuchada, su nombre como firma de un mensaje para un amigo de la escuela gemela, un epígrafe para una ilustración a partir de una salida, una palabra "linda" que se repite en una canción aprendida. Estas son instancias inmejorables, muchas veces previstas por los docentes, para incorporar la escritura como actividad de una sociedad letrada, que no se deben desaprovechar. ${ }^{5}$

\section{4 - Presencia de textos completos desde las primeras situaciones de lectura y escritura}

Para que los niños se entusiasmen por aprender a leer y a escribir, es necesario que desde un principio sepan que ese aprendizaje les abrirá las posibilidades de ingresar al mundo de lo escrito. Ese entusiasmo es fruto de la participación en situaciones en las que leer y escribir tienen sentido y esto ocurre si lo que se lee y se escribe son textos, palabras o frases en contexto y con significado para los niños.

Los marcos curriculares de ambos países desalientan métodos o propuestas de actividades exclusivamente centradas en el aprendizaje de las letras o sílabas o, aun, de palabras cuando estas no tienen significado para los niños. En estos casos entonces se les achica la puerta de entrada al mundo de la escritura, por lo que los niños comienzan a sospechar que leer y escribir es realizar actividades mecánicas y sin sentido y pierden rápidamente ese entusiasmo por aprender.

\footnotetext{
${ }^{5}$ Los desarrollos curriculares de Brasil y Argentina (véase Parámetros Curriculares Nacionais. Língua Portuguesa de Brasil; serie Cuadernos para el aula. Lengua $1^{\circ}, 2^{\circ}, 3^{\circ}$ de Argentina) abundan en propuestas de actividades $y$ sugerencias de metodológicas para la iniciación de los niños en situaciones de lectura y escritura en la escuela.
} 
Desde el mismo punto de vista, dentro de la pedagogía de lenguas se desalienta que las actividades se centren exclusivamente en el conocimiento del léxico fuera de los marcos discursivos que lo contextualizan y le dan sentido.

\section{5 - La biblioteca bilingüe y los libros álbum (livro de imagem).}

Según las necesidades que surjan de los proyectos, los niños pueden participar de distintas instancias de lectura y escritura de textos. Pueden necesitar, por ejemplo, escribir con la ayuda de sus docentes epígrafes para las ilustraciones o fotografías que tomaron de un encuentro deportivo, los afiches o las invitaciones a dicho encuentro. Pueden recurrir a los libros de la biblioteca para buscar imágenes de los lugares, animales, personas sobre los que estén trabajando, o para conocer los cuentos y personajes de los libros escritos en la segunda lengua. ${ }^{6}$

Las escuelas del proyecto cuentan con bibliotecas bilingües provistas por los Ministerios de Educación de Brasil y Argentina. Están integradas, en buena medida, por libros creados especialmente para niños. Entre ellos, se encuentran los "libros álbum" (livro de imagem); se trata de libros de edición muy cuidada, bellamente ilustrados, a veces con breves textos, a veces sin texto.

La participación frecuente en situaciones de exploración y lectura de los libros (en este caso supone la lectura de imágenes) desde un comienzo de la escolaridad sitúa a los niños como lectores desde temprana edad, aun cuando no sepan leer con autonomía y no conozcan todas las palabras presentes. Participan de una sociedad letrada hojeando y conversando acerca de los libros, mirando sus ilustraciones, reconstruyendo historias narradas a partir de esas imágenes, escuchando la lectura hecha por sus docentes. Por otra parte, los libros, se sabe, permiten conocer culturas, costumbres, vestimentas, personajes, historias, otras voces diferentes de las del maestro. Frecuentar y conocer los libros de la biblioteca bilingüe, por lo dicho, enriquecen la propuesta intercultural del proyecto.

Explorando libros y leyéndolos por su cuenta y/o escuchándolos leer por el maestro, los niños aprenden también que en las dos lenguas hay diferencias entre el lenguaje escrito y el hablado, que las formas escritas muchas veces no coinciden con las habladas

\footnotetext{
${ }^{6}$ Recomendamos la lectura de los Ejes "Lectura" y "Escritura" de los Cuadernos para el aula. Lengua. $1^{\circ}, 2^{\circ}$ y $3^{\circ}$, (2006), Buenos Aires, Ministerio de Educación, Ciencia y Tecnología.
} 
de una y otra lengua (es decir, que además de distintas lenguas, también hay distintas variedades de una lengua según sean sus modos escrito u oral, además de las variedades regionales de cada país)

De la misma forma, con el análisis prepedagógico adecuado y la planificación conjunta, se trabajaría con materiales auténticos que presenten los elementos lingüísticos-culturales más provechosos para el intercambio entre los hablantes de las diferentes lenguas y, asimismo, que sean relevantes de acuerdo al universo discursivo de los alumnos. Por ejemplo, se podrían utilizar canciones, cuentos y leyendas; poesías, adivinanzas, trabalenguas, versitos, juegos de/con palabras; diferentes manifestaciones artísticas.

\section{6 - La comprensión del principio alfabético}

Tanto el portugués como el español (como el resto de las lenguas que se hablan en América, inclusive las lenguas originarias) son lenguas escritas con un sistema alfabético. Esto quiere decir, que hay un principio "ideal" que supone que cada letra representa un sonido del habla. Esto implica que si los niños conocen el significado de las palabras orales en cualquiera de las lenguas, la comprensión del principio alfabético de escritura que alcancen a partir de la lectura y escritura en su lengua materna puede ser transferido a la otra lengua. Implica también que, escribiendo palabras conocidas de la segunda lengua pueden progresar en la comprensión del principio alfabético.

\section{7 - La cuestión de la ortografía}

En relación con la escritura de palabras, suele existir la idea de que no es conveniente que niños pequeños escriban en más de una lengua (especialmente cuando se trata de lenguas cercanas, como es el caso del español y del portugués), en razón de que los parecidos entre palabras de las dos lenguas pueden inducirlos a confundir su ortografía.

Cabe deslindar aquí varios aspectos. Cuando los niños están iniciándose en el proceso de alfabetización en su lengua materna, se los alienta a escribir según sus propias posibilidades. En un principio, deben comprender la alfabeticidad del sistema, lo que supone reconocer los sonidos de las palabras habladas y adjudicar las letras que corresponde y trazarlas. En función de su desconocimiento de los defectos de 
paralelismos del sistema (que puede haber sonidos que se representan con más de una letra, letras que representan más de un sonido, letras que no representan ningún sonido, etc.) recurren a una ortografía simplificada. Se considera un progreso en la escritura de palabras que los niños se planteen la duda ortográfica (“¿Con qué va?”) Una vez desarrollada, esta duda es transferible a la escritura de palabras en una segunda lengua. Por otra parte, como antes se mencionó, toda lengua presenta distintas variedades orales, algunas más cercanas al estándar escrito. Esta diferencia entre lo oral y lo escrito plantea diversos desafíos a la alfabetización, uno de los cuales es el de la ortografía, sea en lengua materna o segunda.

Mediante la reflexión permanente acerca de las posibilidades del sistema de escritura y de la enseñanza explícita por parte de los maestros, siempre en el marco de situaciones de escritura con sentido para los niños, ellos progresan paulatinamente hacia el conocimiento y uso de la ortografía correcta de las palabras de su lengua y aprenden también que no es lo mismo hablar que escribir (dado cierto grado de opacidad de nuestras lenguas, no todas las palabras se escriben "como suenan") Considerar el problema ortográfico como un obstáculo para que los niños participen (en forma autónoma, en grupos o dictando a su maestro) en situaciones de escritura de los textos que surjan de los proyectos que se implementan en el PEBF impide o posterga su ingreso como "socio pleno" a la sociedad letrada.

\section{7 - Consideraciones finales}

Este documento sintetiza las concepciones iniciales y experiencias vivenciadas por las escuelas participantes en el primer periodo de implementación del Programa. Se elaboró a partir de la descripción de lo que viene ocurriendo efectivamente en las fronteras entre Argentina y Brasil, teniendo a disposición la gran cantidad de relatorias y observaciones in loco que el PEBF posibilita. Se utilizó, asimismo, las actas de reuniones bilaterales que fueron sucediéndose alternadamente en los dos países, y de la documentación previa consensuada entre los gobiernos en el ámbito del MERCOSUR o en los acuerdos bilaterales. Por último, se enriqueció con las observaciones de casi 200 docentes de todas las 
escuelas brasileñas y argentinas, además de dirigentes municipales, estaduales y provinciales que se encontraron en el I Seminario Internacional sobre las Escuelas Bilingües de Frontera, realizado por el Ministerio da Educación de Brasil el 31 de julio y $1^{\circ}$. de agosto de 2006 en Foz do Iguaçu. 
Anexo V 


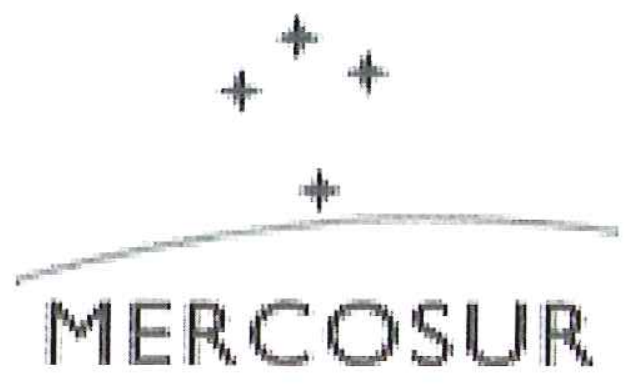

\section{ESCUELAS DE FRONTERA}

DOCUMENTO MARCO REFERENCIAL DE DESARROLLO CURRICULAR
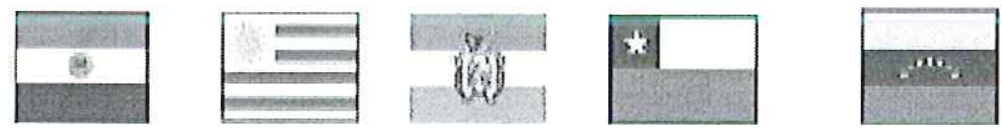


\section{PROGRAMA ESCUELAS INTERCULTURALES BILÍNGÜES DE FRONTERA}

(PEBF)

"Modelo de enseñanza común en escuelas de zona de frontera a partir del desarrollo de un programa para la educación intercultural, con énfasis en la enseñanza de las lenguas predominantes en la región" 


\section{Introducción}

El Programa Escuelas Bilingües de Frontera (PEBF) surge de la voluntad por promover desde el ámbito educativo de los países integrantes del Mercosur un "encuentro intercultural" de escuelas vecinas de la frontera. En este documento se dará cuenta de algunos puntos de la experiencia ya transitada $y$, a la vez, se buscará definir un marco general compartido a fin de contar con directrices orientadoras de la práctica. Es el objetivo de este documento, entonces, presentar un pequeño desarrollo histórico del Programa, una exposición de las situaciones de frontera y una descripción del Modelo didáctico que se aplica y su funcionamiento.

El desarrollo histórico aquí presentado se refiere a la participación del Programa en el Sector Educativo del MERCOSUR, las reuniones que precedieron a su elaboración del Programa, la elección de las escuelas gemelas internacionales en el área fronteriza de los países miembros.

Las fronteras se presentan descripta, entre otras perspectivas, a partir de los datos sociolingüísticos obtenidos al iniciarse el programa. De ese modo, en el documento se da cuenta de las lenguas de circulación en estos espacios y del papel de las mismas en la práctica pedagógica concreta. En el 2010 fueron realizados nuevos diagnósticos conjuntos a fin de contar con datos actualizados y más completos de la situación.

En el apartado "Modelo común para el desarrollo del Bilingüismo y de la Interculturalidad", se presenta el recorrido inicial del programa y el relato de la construcción conjunta que involucra la presencia de docentes de escuelas vecinas en la elaboración de Proyectos de Aprendizaje.

El último ítem trata del funcionamiento del Programa en lo referente a las posibilidades de carga horaria, la vinculación de los contenidos escolares y la coordinación de los trabajos conjuntos. 
Índice

Una introducción histórica

1. Las fronteras y sus lenguas

1.1 Consideraciones sobre el repertorio discursivo de los niños

2. La interculturalidad en el Programa de Escuelas de Frontera

2.1 Las prácticas interculturales

3. Modelo común para el desarrollo del bilingüismo y la interculturalidad

3.1 - Modelo secuencial en construcción

3.2 - Intercambio docente

4. - Funcionamiento del PEBF

5. - Enseñanza a través de Proyectos de Aprendizaje

6.- El lugar del diálogo en la enseñanza y el aprendizaje

7.- Evaluación

8.- Consideraciones finales 


\section{Una introducción histórica}

La primer Reunión Técnica Bilateral de los equipos de los dos Ministerios de Educación de Argentina y de Brasil se llevó a cabo en diciembre de 2004 en Buenos Aires. En esta ocasión, los participantes recordaban que la última acción especifica promovida por la Argentina para sus fronteras se refería a un proyecto del gobierno militar, en los años setenta, titulado "Marchemos hacia las Fronteras". Esta acción formulaba un trabajo conjunto entre la Gendarmería Nacional (tropa que cuida las fronteras, equivalente a la Policía Federal Brasileña) y las escuelas para una "educación de defensa" en relación con el expansionismo de los paises vecinos.

Hubo, por lo tanto, un cambio de perspectiva en las relaciones entre Argentina y Brasil en los últimos veinte años, cambio que posiciona a los dos ministerios, en este momento histórico, en un camino de cooperación para la construcción de una ciudadanía regional bilingüe e intercultural, promoviendo una cultura de paz y de trabajo interfronterizo.

Preceden a esta reunión, sin embargo, una serie de conversaciones y entendimientos bilaterales y multilaterales entre ambos paises que fueron conformando el actual espíritu de cooperación. A continuación, se exponen algunos de los pasos en este sentido.

El 26 de marzo de 1991, los paises miembros del MERCOSUR (Mercado Común del Sur) constituido por Argentina, Brasil, Paraguay y Uruguay, firman el Tratado de Asunción que en su articulo 23 declara al portugués, al español y al guaraní como idiomas oficiales del MERCOSUR.

Como parte de este proceso, el SEM -Sector Educativo del MERCOSUR- destaca, en sus planes de acción, la necesidad de difundir el aprendizaje del portugués y del español través de sus sistemas educativos formales e informales. En ese marco, se considera que el fortalecimiento de la identidad regional es un tema prioritario $y$, de ese modo, se promueve el conocimiento mutuo, la cultura de integración y la promoción de políticas regionales de formación de recursos humanos con vista a la mejora de la calidad de educación.

En la reunión de Ministros de Educación del SEM-MERCOSUR realizada en el año 2001 en Asunción, Paraguay, se aprobó el Plan de Acción del Sector 2001-2005 en el que se 
destaca, entre otros aspectos, "la educación como espacio cultural para el fortalecimiento de una conciencia favorable a la integración, que valorice la diversidad y reconozca la importancia de los códigos culturales y lingüísticos". En este contexto, el SEM busca avanzar en la sensibilización para el aprendizaje de los idiomas oficiales.

Con el objetivo de estrechar los lazos en el ámbito educativo se firmó, el 23 de noviembre de 2003, la Declaración Conjunta de Brasilia: "Para el fortalecimiento de la Integración Regional". En esta Declaración, la educación se reafirma como espacio cultural para el fortalecimiento de una conciencia favorable a la integración regional y se destaca la importancia a la enseñanza del español en Brasil y del portugués en Argentina. A partir de este momento, los equipos técnicos de la Argentina comenzaron a elaborar un borrador del Programa en sus lineas generales y a investigar sobre la adquisición, la didáctica de las segundas lenguas y el bilingüismo como asi también sobre temáticas de frontera que se explicitaron en un documento de trabajo.

Además, como resultado de estas investigaciones, surgió la necesidad de elaborar, en abril-mayo de 2004 , un relevamiento que pudiera ofrecer datos con respecto a la realidad sociolingüística de profesores y alumnos involucrados en el programa y que pudiera revelar: a) el grado de conocimiento del español estándar de los docentes de las escuelas de frontera de Corrientes y Misiones; b) el grado de conocimiento de portugués de docentes y alumnos y c) las representaciones sobre estas lenguas y otras, como el caso del guarani. En mayo de 2004 se produjo la primera versión del "Proyecto Piloto de Educación Bilingüe. Escuelas de Frontera Bilingües Portugués-Español".

El 9 de junio de 2004 se firmó en Buenos Aires una nueva Declaración Conjunta que refrendó lo establecido anteriormente, en el marco del Convenio de Cooperación Educativa entre la República Argentina y la República Federativa del Brasil suscripto en Brasilia el 10 de noviembre de 1997 que, a su vez, tenía presente lo dispuesto por el "Memorando de Entendimiento" firmado en Buenos Aires el 6 de junio de 2003.

La nueva Declaración incluía un Plan de Trabajo como anexo. El Programa se denominó "Modelo de enseñanza común en escuelas de zona de frontera, a partir del desarrollo de un programa para la educación intercultural, con énfasis en la enseñanza del portugués y del español". El programa de referencia se presentó en la XXVI Reunión de Ministros de Educación del MERCOSUR, Bolivia y Chile, realizada en Buenos Aires el 10 de junio de 2004. 
La referida Declaración dispone implementar, entre otras, la siguiente acción:
(...) desarrollo de un modelo de enseñanza común en las escuelas y zona de frontera, a partir del desarrollo de un programa para la educación intercultural, con énfasis en la enseñanza del portugués y del español, una vez que se cumplan los dispositivos legales para su implementación.

De este modo, en el segundo semestre de 2004, la Secretaría de Educación Básica del Ministerio de Educación del Brasil, por medio del Departamento de Políticas de Educación Infantil y de la Enseñanza Primaria, inicio tratativas -junto a los sistemas estaduales y municipales de enseñanza de la región Sur del Brasil- para encaminar los primeros acercamientos a las escuelas ubicadas en la región de frontera. Estas escuelas, a su vez, enviaron las propuestas a las ciudades involucradas y se definieron, a partir de ese momento, dos escuelas brasileñas ubicadas en los municipios de Uruguaiana-RS y Dionísio Cerqueira-SC que tienen fronteras con las provincias argentinas de Corrientes y Misiones, respectivamente.

Se estableció, a finales de 2004, la constitución de un Grupo de Trabajo para encaminar las acciones con el objetivo de implementar el programa en 2005.

A partir de la confirmación del Programa de la nueva Declaración Conjunta, la Dirección Nacional de Gestión Curricular y Formación Docente, junto con la Dirección Nacional de Cooperación Internacional del Ministerio de Educación, Ciencia y Tecnología de la Argentina convocaron a los Ministerios de Educación de las provincias de Corrientes y Misiones para presentarles el programa y establecer acuerdos para su ejecución. A partir del compromiso firmado con las autoridades provinciales cada provincia identificó un responsable por el Programa. Durante 2005, el programa involucró dos escuelas: una en Bernardo de Yrigoyen, Misiones, y la otra en Paso de los Libres, Corrientes. En 2006 el programa se amplió hacia las localidades de Puerto Iguazú, Misiones, y Santo Tomé y La Cruz, Corrientes.

En el 2006 se realizaron algunas modificaciones en los instrumentos de diagnóstico sociolingüístico anteriormente planificados y se recolectaron datos de todas las escuelas seleccionadas. Se trató de cuestionarios hechos a directores y docentes de las escuelas y 
de diagnósticos sobre el nivel de conocimiento del portugués y español de los alumnos de los primeros grados, en el caso de ambos países, y en un Jardín de Infantes, en el caso de Argentina.

Se definió como lugar privilegiado para el desarrollo del programa el sistema de ciudades gemelas internacionales, es decir, aquellas ciudades que cuentan con una escuela cercana en el otro país. En la frontera argentino-brasileña se establecieron cinco pares de ciudades-gemelas, algunas de las cuales involucran a tres núcleos municipales:

- Paso de los Libres (Corrientes) - Uruguaiana (RS)

- La Cruz / Alvear (Corrientes) - Itaqui (RS)

- Santo Tomé (Corrientes) - São Borja (RS)

- Bernardo de Irigoyen (Misiones) - Dionísio Cerqueira (SC)

- Puerto Iguazú (Misiones) - Foz do Iguaçu (PR

Definido el escenario apropiado para el desarrollo del Proyecto como el de "ciudades gemelas internacionales", Uruguay y Paraguay participaron por un tiempo como observadores de la marcha del mismo en un marco de bilateralidad entre Argentina y Brasil.

Ya había existido un antecedente previo relacionado con la modalidad que integra este proyecto. En la década de los 90, el proyecto denominado "Educación sin frontera" fue ejecutado con la participación de los Institutos de Formación Docente y las Inspecciones Departamentales de los departamentos fronterizos de Rivera, Artigas y Cerro Largo. Este proyecto consistió en el intercambio de docentes brasileños de escuelas primarias que impartían clases durante una jornada a niños uruguayos en escuelas de Uruguay. Lo propio ocurría con los profesores de los Institutos de Formación Docente fundamentalmente del departamento de Rivera con frontera terrestre con la ciudad de Santa Ana do Livramento.

En el año 2007, en ocasión del Segundo Seminario del SEM realizado en Asunción, fueran sentadas las bases para la integración de otros países. Uruguay compartió la experiencia de los Programas de enseñanza de Segundas Lenguas en Educación 
Primaria, principalmente en escuelas de la frontera con Brasil. Se explicitaron numerosas experiencias de intercambio pedagógico, artístico, deportivo y cultural ya concretadas en una realidad de natural integración de las fronteras de ambos países.

En ese encuentro quedó planteada la posibilidad de ampliación del proyecto entre Brasil y Uruguay organizándose una propuesta para dar continuidad a la ampliación del mismo en otros países. Quedaron sentadas las bases para que en 2008 se definiera la integración de ciudades gemelas de Brasil y Uruguay al proyecto. Las zonas seleccionadas en principio eran: Río Branco-Yaguarón y Livramento- Rivera para el inicio de la experiencia.

En junio de 2008 en la III Reunión del GT correspondiente en Brasilia, la delegación de Uruguay presentó iniciativas para definir la modalidad de ejecución del proyecto.

Abordadas estas cuestiones, Uruguay junto con Brasil y Paraguay acordaron:

- Establecer contacto con sus autoridades para ratificar alguno de los acuerdos alcanzados en esta reunión.

- Comenzar las acciones en las localidades uruguayas y brasileras de: Rivera/ Santa Ana do Livramento; Chuy/Chui y Río Branco/Yaguarón para finalmente seleccionar dos de éstas.

- Realizar los estudios socio-institucionales para la selección definitiva de las escuelas.

-Planificar la elaboración de instrumentos para el desarrollo del diagnóstico sociolingüístico.

- Realizar reuniones con las escuelas seleccionadas y sus docentes.

En agosto de ese año, el Consejo de Educación Inicial y Primaria en acuerdo con el MEC, resolvió la integración de las escuelas seleccionadas al proyecto quedando entonces ratificada la participación de Uruguay en el mismo. Se seleccionaron finalmente las localidades de Río Branco/Yaguarón y Chuy/Chui. En septiembre de 2008 Uruguay participó en la Reunión del GT realizada en Foz de Iguazú iniciando así el desarrollo de la experiencia ya existente entre Brasil y Argentina desde años atrás.

En el caso de Paraguay, el trabajo realizado en el marco del Proyecto Escuelas Bilingües de Frontera, en el primer año de implementación, forma parte de un proyecto planteado 
desde la Secretaria de Educación del MERCOSUR lo que permitió establecer un acercamiento a las escuelas y así experimentar y descubrir la complejidad del día de día.

El Ministerio de Educación y Cultura en cumplimento al acuerdo firmado por el Ministro de Educación y Cultura delega la tarea a la Dirección General de Educación Inicial y Escolar Básica a través del Departamento de Proyecto que realiza las actividades acordadas en el equipo técnico del Proyecto Escuelas Interculturales de Frontera. En el segundo semestre del 2008 se da inicio a las actividades en la frontera paraguayabrasileña, en comunidades educativas del departamento de Amambay, distrito de Pedro Juan Caballero y el estado de Matto Grosso, ciudad de Ponta Porâ. En ese mismo año se realiza el diagnóstico sociolingüístico en las comunidades de las escuelas seleccionadas. En marzo de 2009 se inicia el intercambio de docentes. En junio del mismo año, se reinicia el proyecto en la misma escuela de la República Federativa de Brasil con una nueva escuela de la República de Paraguay.

\section{Las fronteras sus lenguas}

Toda frontera entre paises que hablan lenguas diferentes se caracteriza por ser una zona de inestabilidad y contacto-conflicto sociolingüístico. Esta interacción se produce, entre otros factores, por la influencia de los medios de comunicación; en particular de la radio y la televisión de un lado y otro de la frontera.

En la frontera de Argentina y Brasil se escuchan, entre otras lenguas, el portugués y el español con las modalidades características: alternancias en los usos de ambos códigos con diversos propósitos comunicativos y también como símbolos de pertenencia identitaria. Asimismo se observan fenómenos de mezcla lingüística, "transferencias" o "Interferencias" -como los denominan algunas líneas de investigación sociolingüística- y de préstamos en una y otra dirección. Estos fenómenos, sin embargo, no deben ser generalizados dado que presentan una configuración diferente en cada una de las fronteras.

Desde mediados de 2004, los diagnósticos sociolingüísticos realizados en el ámbito del Programa indican que, en un primer momento, el corte más característico y de mayor interés para el trabajo de las escuelas participantes es el de la diferencia cuantitativa y cualitativa de la presencia del portugués y del español en las ciudades-gemelas en 
particular y en toda la frontera en general. Mientras que en el lado argentino la presencia del portugués es relativamente constante - como parte del repertorio receptivo- lo contrario no es verdadero: los datos sobre el lado brasileño indican que no hay presencia generalizada de niños y familiares hablantes de español o aún familiarizados con la comprensión de esta lengua. Estos datos, por supuesto, tienen consecuencias directas para la actuación de las escuelas del Programa.

El español y el portugués son lenguas fónicas, es decir, habladas en un conjunto de paises en los cuales son lenguas oficiales - 22 paises tienen como lengua oficial al español y 8 países tienen como lengua oficial al portugués. Aproximadamente 330 millones de personas hablan español y 208 millones de personas hablan portugués. Juntas, las dos lenguas románicas son habladas por aproximadamente 540 millones de personas en cinco continentes. Los datos cuantitativos no siempre tienen su correlato con el "prestigio" de las lenguas: el español es considerada una lengua de mayor prestigio internacional que el portugués y hoy se afirma que es una de las lenguas con mayor crecimiento demo lingüístico en el mundo. En la frontera entre Argentina y Brasil, sin embargo, los datos indican que el portugués tiene una presencia determinante resultado de la asimetría de prestigio a favor de esta lengua, caracterizando de esta forma una micro-situación sociolingüística opuesta a la relación entre las dos lenguas en el ámbito internacional.

Esta situación de "prestigio" del portugués se lo asocia con la presencia de emisoras de televisión y radio como así también con la oferta de servicios en las ciudades brasileñas de frontera, utilizados también por ciudadanos argentinos. El frecuente flujo turístico en dirección hacia Brasil y de Brasil, causado por las asimetrías cambiarias de la última década, se evidencia en el mayor conocimiento del portugués en la Argentina y, por el contrario, en un menor conocimiento del español en Brasil (Diagnóstico Sociolingüístico de Uruguaiana y Dionísio Cerqueira, 2006). Cabe destacar si bien es cierto que ambas lenguas son de prestigio, poseen estatutos sociales diferentes.

Entre otras consideraciones, hay que tener en cuenta que las asimetrias son menores o mayores de acuerdo con el momento histórico analizado. Algunas investigaciones muestran que, por ejemplo, hasta la década de 1950 el español tenía una presencia mucho mayor en los hábitos lingüísticos de las poblaciones brasileñas de la frontera, 
principalmente en virtud de la existencia de una integración vial más intensa con Buenos Aires que con las principales ciudades brasileñas.

Entonces, resulta indispensable precisar el valor y posición de cada una de las lenguas y su relación con las que circulan en el ámbito familiar y socialmente cercano a los alumnos ya que las decisiones pedagógicas están en estrecha relación con la realidad sociolingüística y, por tanto, sociocultural de los niños que participan de la experiencia.

\section{1- Consideraciones sobre el repertorio discursivo de los niños}

Después de algunos meses de actuación de los docentes en el aula, se visualizó con claridad que desde el punto de vista del repertorio discursivo de los participantes se trabaja con dos destinatarios diferentes: los niños argentinos ya son, en cierto nivel, bilingües, es decir, entienden -aunque en distintos grados- la lengua portuguesa e incluso muchos de ellos la hablan con facilidad. Esto se debe, entre otras causas, al hecho de que algunos alumnos son descendientes de brasileños. Asimismo, se observó la ya mencionada exposición frecuente a la lengua a través de los medios de comunicación, traslados continuos y estadía en Brasil y, por tanto, se reconoce una mayor disponibilidad de la población argentina de frontera para el aprendizaje del portugués. Vale la pena hacer una aclaración en este punto ya que, una vez más, las fronteras presentan diferencias entre ellas. Por ejemplo, hay que hacer una distinción entre los movimientos transitorios de los adultos hacia el pais vecino y por otro lado, el contacto efectivo de los niños en estadias del otro lado de la frontera. Si bien es cierto que los intercambios se producen entre los adultos, muchas veces los niños no "han cruzado el puente" como lo manifiestan varias relatorias de los maestros.

Para estos niños y sus comunidades escolares la enseñanza bilingüe significa el reconocimiento de una situación de hecho y puede significar también el reconocimiento de una situación a largo plazo que dé comienzo a prácticas de acceso a la cultura letrada (letramento) en ambas lenguas. La función social del portugués se presenta de manera más clara para las comunidades escolares argentinas, pues, entre otros motivos, esta lengua es utilizada en la vida cotidiana, es decir, es la parte más importante del repertorio comunicativo local. A su vez, el sentido del conocimiento de otra lengua, aún cuando no sea de uso cotidiano, puede relacionarse con aprender aquello que no se tiene en su socialización primaria. Algunas relatorias con entrevistas a los padres de escuelas de 
Corrientes manifiestan la importancia de que sus hijos asistan a escuelas en las que se enseña lo que "no aprenden en casa".

Los niños brasileños de las escuelas participantes, por el contrario, son monolingües en portugués, lo que dificultó la tarea de los docentes argentinos al comienzo del programa. Muchos alumnos no entendian, en varias ocasiones, las consignas mínimas necesarias para el trabajo cotidiano en el aula. Se acordó, entonces, que era necesario un período de "sensibilización lingüistica" para que los niños brasileños percibieran las razones del aprendizaje del español y desarrollaran una actitud positiva frente a este aprendizaje. Durante un primer momento fue fundamental la reflexión docente acerca de la función social de la lengua, sus implicancias en los procesos de enseñanza-aprendizaje de una segunda lengua y de la lengua materna. Estas reflexiones, de diversos modos, fueron trabajadas en el aula con los alumnos en el objetivo de propiciar actitudes positivas no sólo de las "lenguas", sino también de sus "hablantes" sobre quienes se realizan transferencias "según como hablan".

Las representaciones de los niños frente a la "nueva" lengua y sus motivaciones positivas para el aprendizaje se van construyendo, también, con sus experiencias personales de contacto con hablantes de la L2 o "lengua de vecindad", en nuestro caso con la presencia de docentes del otro país. En esta experiencia inicial con otra lengua en el aula - la experiencia dominante en L2 es a través del maestro-, especialmente en el caso de los niños que no son bilingües de antemano, es preciso promover el interés por la lengua a partir de una serie de actividades que incluyan situaciones lúdicas, de desafío intelectual y de intercambio personal.

Las actitudes positivas de los niños necesitan, en cierto modo, ser compartidas por los padres y el entorno familiar. Por esta razón, las escuelas han buscado en distintas oportunidades trabajar en este sentido con los padres y la comunidad educativa: provocando encuentros con los docentes del otro país que trabajan con sus hijos, invitándolos para que participen en los eventos binacionales de la escuela o, inclusive, en actividades cotidianas conducidas por la docente del otro país en la L2 tales como las actividades en la huerta, observaciones de campo, entrevistas a miembros de la comunidad relevante para los niños o un ensayo para representar una obra de teatro, entre otras posibilidades. 
En la frontera de Paraguay y Brasil se conjugan dos modos de vivir diferentes desde el punto de vista económico y lingüístico pero al mismo tiempo similares, al convertirse la lengua mayoritaria (portugués) en vehículo de comunicación y convivencia generando un contexto peculiar. En Paraguay se habla con facilidad en las tres lenguas (guaraní, español y portugués), especialmente en la oralidad con la presencia del "guariportuñol"; no así los brasileños que presentan algunas dificultades en la utilización del guaraní y el español en su comunicación cotidiana.

Los diagnósticos sociolingüísticos realizados en marco del PEIF en un primer momento, revela que el corte más característico y de mayor interés para el trabajo de las escuelas participantes es el de la diferencia cuantitativa y cualitativa de la presencia del portugués, del español y del guaraní en las ciudades-gemelas en particular, y en toda la frontera en general. En menor escala, niños/as de las escuelas de frontera y de sus familias, del lado paraguayo son monolingües guaraní. Los datos sobre el lado brasileño indican que hay un porcentaje considerable de niños y familiares hablantes de español y guaraní, debido a que un alto porcentaje del alumnado es de origen paraguayo lo que no significa que no manejen el portugués.

Según experiencias y registros en la frontera con Argentina se percibe la utilización del idioma guaraní, fundamentalmente en las ciudades de Alberdi, Nanawa y Puerto Flacón, fronterizas con la provincia de Formosa.

La frontera uruguayo-brasileña se caracteriza, en lo que tiene que ver con la situación lingüística, por la presencia de dos lenguas, el español y el portugués, determinando una región marcada por el bilingüismo social. En esta zona (exceptuando las área de Bella Unión en Artigas y Chuy en Rocha) además del español y el portugués estándar, se habla otra variedad lingüística denominada comúnmente "portuñol", "brasilero" o "fronterizo". Diferentes estudios, realizados a partir de la década de 1950, establecen que esta variedad dialectal tiene base portuguesa, lo que equivale a decir que, desde el punto de vista lingüístico, es una variedad del portugués, aunque influida por el contacto con el español. Esta variedad lingüística fronteriza, que ha sido denominada portugués uruguayo 
(Carvalho, 2007) ${ }^{1}$, es una variedad lingüística ágrafa, por lo cual tiene menos estabilidad que las lenguas con larga tradición escrita como el español o el portugués estándar.

La totalidad de la sociedad fronteriza puede ser considerada entonces como bilingüe español - portugués. En las áreas en que se verifica, además, la presencia de portugués uruguayo, el estatus social de ambas lenguas y sus ámbitos de uso son diferenciados. Las comunidades ubicadas en la franja que va desde Artigas (con excepción del extremo oeste del departamento) hasta Río Branco (Cerro Largo) han sido caracterizadas como diglósicas, siendo el español la variedad alta y el portugués uruguayo la variedad baja. Una sociedad diglósica supone una situación de bilingüismo social en la cual una lengua (o variedad de lengua) se usa para fines cotidianos, para la interacción informal en el hogar y entre amigos, y otra lengua es utilizada para fines formales, en las funciones "altas" de la vida en comunidad, como la administración pública, los medios de comunicación y la educación. El portugués uruguayo, como es característico en las sociedades bilingües y diglósicas, es la lengua que se usa en los ámbitos familiares, íntimos y coloquiales, mientras que el español, como lengua oficial del país, es la lengua más apropiada para los ámbitos públicos, especialmente en las instituciones educativas. El portugués uruguayo está más presente en los sectores humildes y menos urbanizados de la sociedad fronteriza, lo que revela que su uso se encuentra socialmente estratificado. Es también una variedad lingüística estigmatizada, por carecer de prestigio social y ser considerada incorrecta, incluso por sus propios hablantes (Carvalho, 2007). El español, por su parte, es la lengua de las clases medias y altas urbanizadas.

\footnotetext{
${ }^{1}$ Carvalho, A. M. (2007) Diagnóstico sociolingüístico de comunidades escolares fronterizas en el norte de Uruguay En: Brovetto, Geymonat y Brian (eds) Portugués del Uruguay y Educación Bilingüe. ANEP, Montevideo.
} 


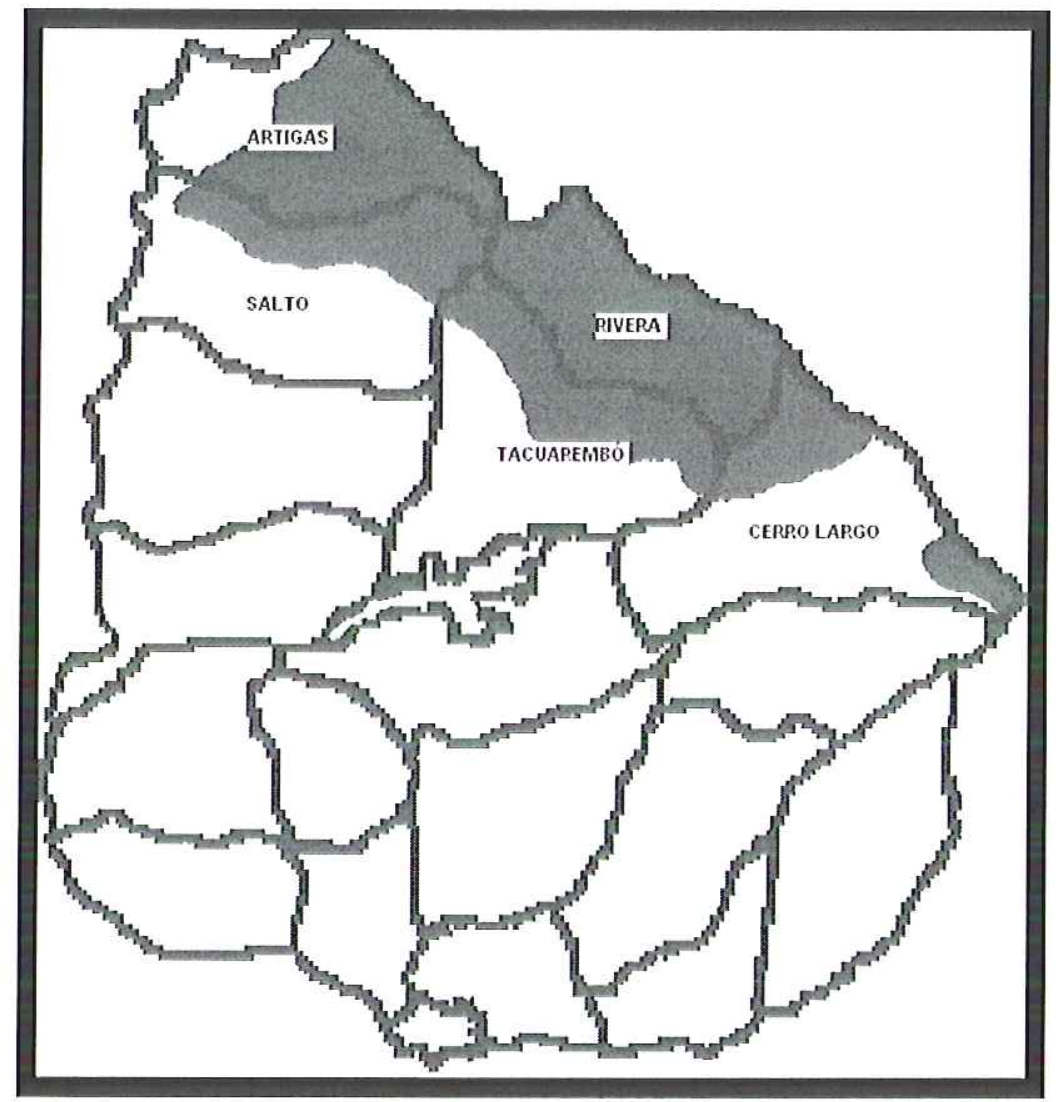

Sin embargo, la matriz diglósica ha sufrido cambios a lo largo de la historia de la región. En las últimas décadas, se constata una mayor identificación de los hablantes fronterizos con el portugués uruguayo, debido, principalmente a su valorización cultural. (Behares, 2007) $)^{2}$ Esta variedad regional, aunque se mantenga circunscripta fundamentalmente a las interacciones más coloquiales, se ha extendido a nuevos ámbitos de uso, aunque sin que se le atribuya el carácter de verdadera variedad lingüística. Solamente se la acepta como rasgo folklórico que caracteriza a la cultura de la frontera y a sus habitantes.

El portugués uruguayo puede ser definido como lengua fronteriza, lengua minoritaria y lengua de herencia. Lengua fronteriza refiere a su ubicación geográfica en una región de contacto de lenguas y culturas. El segundo concepto, lengua minoritaria, supone la consideración del portugués uruguayo como una variedad de lengua que identifica a un grupo social -la sociedad fronteriza- dentro de una sociedad mayor, la uruguaya. La

\footnotetext{
${ }^{2}$ Behares, L. E. (2007) Portugués del Uruguay y educación fronteriza En: Brovetto, Geymonat y Brian (eds) Portugués del Uruguay y Educación Bilingüe. ANEP, Montevideo.
} 
denominación lengua de herencia, implica la conexión personal e histórica que los hablantes tienen con esta variedad lingüistica. (Brovetto et al, 2007) ${ }^{3}$

Históricamente, el sistema educativo uruguayo no consideró esta situación lingüistica tan compleja, hasta que en 2003 se implementa la enseñanza bilíngüe en escuelas fronterizas. La escuela enfocaba esta realidad como un gran problema a resolver, "corrigiendo" las hablas locales. Así, a lo largo de más de un siglo, la institución escolar estigmatizó la variedad dialectal prohibiendo su uso en el âmbito educativo. Se deconocian los beneficios del bilingüismo, ignorándose la importancia social y psicológica del respeto por la lengua materna del niño.

En una sociedad bilingüe con una lengua minoritaria, como en el caso de la frontera uruguayo-brasileña, los beneficios del bilingüismo se desdibujan, dejando de ser una característica positiva de estos individuos, para convertirse en un rasgo de inferioridad o un "problema" educativo. Ello ocurre porque las lenguas minoritarias carecen de prestigio y están asociadas a valores sociales negativos, que se transfieren también a los individuos que las hablan. En este contexto, la escuela ha tenido una gran dificultad en reconocer y valorar la situación de bilingüismo, como un aspecto potencialmente positivo y aún enriquecedor de una sociedad.

\section{La interculturalidad en el Programa de Escuelas de Frontera}

Para que los procesos de sensibilización, anteriormente mencionados, tengan "éxito" es importante partir, asimismo, del conocimiento previo de los alumnos, de las familias y de sus realidades por parte de los docentes del otro pais. Se prevé, de esta forma, que las escuelas desarrollen una sistemática de trabajo conjunto con los padres para el desarrollo de actitudes positivas frente al bilingüismo y a la interculturalidad.

Una educación para las escuelas de frontera, en este contexto, implica el conocimiento y la valorización de las culturas involucradas a través de prácticas interculturales. Como efectos de la integración, negociación y del diálogo entre los grupos, se pone en escena,

\footnotetext{
${ }^{3}$ Brovetto, C., J. Geymonat y N. Brian (2007) Una experiencia de educación bilingüe español - portugués en escuelas de la zona fronteriza En: Brovetto, Geymonat y Brian (eds) Portugués del Uruguay y Educación Bilingile. ANEP, Montevideo.
} 
entonces, relaciones entre las culturas, el reconocimiento de las características propias, el respeto mutuo y la valoración de lo diferente como tal (y no como "mejor" o "peor") Por interculturalidad podemos entender, por lo menos, dos cuestiones:

1- Entendemos por "interculturalidad", en primer lugar, un conjunto de prácticas sociales relacionadas con el "estar con el otro", entenderlo, trabajar con él, producir sentido conjuntamente. Como en toda práctica social, la interculturalidad se vive en la medida en que se producen contactos calificados con el otro, como por ejemplo, en las planificaciones conjuntas de los docentes de los dos países, en los proyectos de aprendizaje en que interactúan alumnos, cada grupo con su manera culturalmente diferente de mirar los mismos objetos de investigación o en la participación en eventos propios de cada país. Por ejemplo, cuando los padres y los alumnos de una escuela argentina participan de una "festa junina" brasileña o la celebración de una fecha patria argentina. Esta dimensión de la interculturalidad es la dimensión de las vivencias, fundamental en el campo de los conocimientos actitudinales.

2- Entendemos interculturalidad también como conocimientos sobre el otro, sobre el otro país, sus formas históricas de constitución y de organización, conocimientos que necesitan estar presentes curricularmente en los proyectos de aprendizaje planificados y ejecutados en las escuelas. Son estos procesos de acceso de los conocimientos, siempre transitorios -subjetivos- y en continua expansión, sobre el otro que posibilitarán a los alumnos sentirse partícipes de historias comunes. En esta dimensión de la interculturalidad se incorporarán la historia, la geografía, las dimensiones literarias, artísticas, religiosas del otro país, entre otros aspectos en los proyectos de aprendizaje realizados en conjunto. Esta es la dimensión informacional de la interculturalidad.

Asimismo, la educación pensada para las zonas de frontera proporciona a los alumnos de las escuelas del programa el conocimiento y el uso de más de una lengua, to que contribuye a la calidad de la educación y al mejoramiento de las relaciones comunicativas, teniendo en cuenta que los alumnos se encuentran, en mayor o menor grado, expuestos a situaciones de uso de las lenguas involucradas. 
Las relaciones entre el manejo de dos lenguas y la inserción en dos o en varias culturas no son directas, sino dependientes de los contextos y de los modos de circulación de los individuos. Además, es preciso advertir sobre la imposibilidad de definir rasgos culturales como entes fijos, monolíticos y a-históricos. Situaciones de cruces, "hibridaciones" que están, además, atravesadas por situaciones de desigualdad social. De esta forma, la novedad de la propuesta emprendida por los países abre un espacio para la investigación de las condiciones que definen el contexto pedagógico del programa tanto para el aprendizaje de lenguas como para el desarrollo de la interculturalidad.

Si bien la tradición en la enseñanza y aprendizaje de lenguas segundas/extranjeras establece una diferencia crucial entre contextos endolingües y exolingües ${ }^{4}$, se tendría que considerar que la heterogeneidad sociolingüística y la fuerte orientación intercultural en la que se desarrolla el programa definen un ámbito complejo en donde lo establecido hasta el momento por los especialistas resulta insuficiente y produce, por este motivo, un estado de tensión permanente. Muchas son las voces que atraviesan la presente propuesta. Voces que provienen de diferentes miradas desde la teoría, desde la práctica, miradas históricas, sociales, políticas, entre otras y que parecen no escucharse o por lo menos no conseguir el consenso necesario en varias ocasiones.

Sin embargo, esta heterogeneidad debe considerarse constitutiva del programa y un punto de partida tanto para la toma de decisiones en la práctica concreta como para la posterior realización de investigaciones que, a partir del diálogo teoría-práctica docente, definan una metodología y una terminología que permitan lograr acuerdos entre todos los participantes.

\section{1- Las prácticas interculturales}

a) Usos de la L2, en la medida en que la otra lengua pasa a ser parte de manera cada vez mas presente en el cotidiano de la escuela, en donde transcurre un parte importante del tiempo de los niños. Estos usos de la lengua son orales y escritos, tiene que ver con las relaciones con el

\footnotetext{
4 En el primer caso, el alumno puede continuar con el uso social de la lengua que aprende fuera del contexto pedagógico. Lo que establece el docente en la clase no es la única muestra de lengua que posee y por lo tanto, estará expuesto a situaciones diferentes que le producirán inquietud, duda, revisión de estereotipos, entre otras cuestiones y que luego, al llevarlas a la clase, le permitirán reflexionar sobre ellas. Aquí, no hablamos del aprendizaje de una lengua como lengua extranjera sino como lengua segunda o L2.
} 
conocimiento y con las relaciones personales. La presencia de textos en la lengua objeto de enseñanza-aprendizaje, estimulada desde el primer contacto del niño con la escuela, crece y se diversifica a medida en que avanzan sus posibilidades de lectura, transformándose, con el tiempo, en una presencia constante en todos los actos educativos de las diferentes disciplinas. A este contacto espontáneo con materiales auténticos en la segunda lengua, se le debe agregar también un adecuado seguimiento pedagógico de toda la comunidad educativa para multiplicar o crear situaciones de interacción entre todos los actores de los diferentes paises y permitir así enriquecer los universos discursivos en ambas lenguasculturas.

b) Una relación personal con un hablante nativo de la lengua. El niño no solo experimenta situaciones de usos de la lengua objeto de enseñanzaaprendizaje, sino que se posibilita la formación de un vínculo con una persona que conversará exclusivamente en su lengua. Este vínculo es fundamental para la formación de actitudes positivas frente al idioma y como vehiculo de cultura. Es importante también observar que el vínculo se da con un hablante nativo de la lengua objeto de enseñanza-aprendizaje, lo que posibilita al niño reconocer la indisoluble relación lengua-cultura.

El reconocimiento de la alteridad implica, asimismo, reflexionar sobre las representaciones que circulan en una sociedad con respecto a las lenguas y las culturas que las contextualizan. Claro ejemplo de ello son los estereotipos con los cuales se identifica tanto a una lengua como a sus hablantes. Las lenguas, en este sentido, son más o menos "fáciles", "alegres", "dulces", "musicales", entre otras apreciaciones estereotipadas. Tomar distancia de estas representaciones, "blanquear" las arbitrariedades de tales ideas se postula como una compleja tarea que le compete a la escuela, en este caso, en el marco de un programa atravesado por prácticas interculturales. Es a partir de la información y de la reflexión continua entre alumnos y docentes que éstas pueden ser resignificadas. La clase se convierte en un espacio para el descubrimiento de caracteristicas de la lengua de vecindad y la cultura que vehiculiza. 
c) un profesional de la comunidad nacional/ cultural de la cual esta lengua es la expresión más generalizada. El contacto es con un maestro del otro país, que tiene una vivencia institucional en el sistema escolar del país vecino, experiencia también muy importante para el niño en tanto podrá vivenciar, en su contacto con docentes, en el caso en que haya intercambios, las tradiciones pedagógicas institucionales de dos sistemas escolares diferentes.

Aunque estos tres aspectos ocurren efectivamente juntos, esta participación permite entender la productividad del trabajo con los niños, no sólo por conocer los usos de la lengua sino aún más por desarrollar vínculos personales en simultáneo al aprendizaje de estos usos. El miedo, producto del desconocimiento del otro, se convierte en curiosidad, sorpresa y voluntad de aproximación a partir de experiencias conjuntas significativas.

Finalmente, las escuelas partícipes del programa, más allá de la incorporación de la L2 y de las personas de otra nacionalidad en sus rutinas, amplían la base informacional de los contenidos escolares, dejando de enfocar únicamente el nivel nacional y ocupándose también de la Región como unidad de trabajo.

Se trata de un programa que viene proporcionando a las comunidades, a las escuelas participantes y a los ministerios de educación de los países la oportunidad de vivenciar relaciones de interculturalidad y a desarrollar rutinas de trabajo bilingües, con el uso de las diferentes lenguas y modos de decir, experiencia fundamental para los objetivos políticos expresados en la documentación de la relación entre los países, citada en el inicio de este texto.

\section{Modelo común para el desarrollo de la interculturalidad y el bilinguismo}

El Programa tiene como objetivo el desarrollo de un modelo de enseñanza común en las escuelas de frontera, garantizando, de esta forma, que alumnos y docentes tengan la oportunidad de educarse y comunicarse en las lenguas involucradas a partir del desarrollo de un programa intercultural. En la fase inicial del programa, las escuelas siguen los calendarios y las prácticas curriculares de sus respectivos sistemas de enseñanza y se discuten algunas propuestas de un modelo común compartido y de un calendario único 
para las escuelas de modo tal que tengan mayor flexibilidad a la hora planificar conjuntamente sus acciones.

Este modelo común no es la yuxtaposición de los dos currículos nacionales en las escuelas participantes, sino una serie de acuerdos y negociaciones que los sistemas escolares realizan dentro de un cuadro común establecido. Las Reuniones Técnicas Bilaterales (que se llevan a cabo alternadamente entre los países) y los trabajos de la Comisión Curricular del Programa (que dio comienzo a sus actividades en junio de 2006 y que basa su labor en la experiencia instalada por el Programa) son las instancias en las que se elaboran dichas negociaciones y acuerdos.

Establecido el marco curricular de referencia del Programa Escuelas Bilingües de Frontera, cada sistema escolar y cada escuela participante elaborará su plano políticopedagógico/proyecto educativo institucional de forma más precisa y, consecuentemente, sus rutinas y estrategias de trabajo. Este marco de funcionamiento está, en muchos aspectos, establecido de hecho por las prácticas docentes y de gestión en curso y, de jure, en las actas de las reuniones técnicas bilaterales periódicas. En este sentido, las prácticas generan una base curricular común de la cual todos los profesionales e instituciones involucradas son partícipes, y que luego serán sistematizadas por la Comisión Curricular del Programa ${ }^{5}$.

A partir del 2012 se reinician las actividades y reuniones de la Comisión con un carácter multilateral.

\subsection{Modelo secuencial en construcción}

EI PEBF se inició en 2005 con la presencia en la primeira série do ensino fundamental o en el primer grado de la enseñanza primaria argentina del docente de la "escuela-espejo" del otro país, hablante de la L2, con un determinado número de horas semanales. La proyección es ampliar el número de grupos participantes y avanzar hacia los grados siguientes, de acuerdo con las posibilidades concretas de los sistemas escolares, permitiendo a los alumnos también el avance de sus propias experiencias en la L2 y en la

${ }^{5}$ La formación de esta Comisión Curricular tuvo como objetivo principal elaborar orientaciones curriculares para el programa. En este sentido, la comisión formuló una estrategia común de PPP(Proyecto Político-Pedagógico) y PEI (Proyecto Educativo Institucional) sobre la mirada legislativa de cada uno de los países. 
familiarización con la cultura y las informaciones referentes al otro país. Los escenarios particulares de cada par de escuelas, de acuerdo a sus realidades nacionales, mostrarán diversas propuestas sobre la extensión y ampliación gradual.

De esta forma, se inicia la exposición de los alumnos a la L2 a partir de su llegada a la enseñanza primaria, cuando sus disposiciones y capacidades para el aprendizaje de lenguas son mayores que en la edad más avanzada. Esto no impide que en el futuro también los niños de la educación infantil se involucren en la enseñanza bilingüe e intercultural de manera sistemática, acción que ya viene ocurriendo en algunas escuelas. Por otra parte, como apoyo a este trabajo, se elaboraron una serie de orientaciones - no prescriptivas $u$ obligatorias- que sirvieron para establecer una posible progresión de contenidos y actividades previstos en los proyectos y en la posterior evaluación de los avances de los alumnos.

Así, una vez alcanzada una primera etapa de sensibilización es esperable que todos los participantes del programa avancen en un desarrollo creciente orientado hacia la profundización de las experiencias de interculturalidad.

Por otra parte, se tiene que resaltar también el valor pedagógico y didáctico que tiene la evaluación para el programa. En este sentido, se complejiza dicha actividad de evaluación, introduciendo diferentes momentos de reflexión metalingüística, metacognitiva e intercultural de los alumnos y docentes.

En este sentido, hay que destacar que el programa tiene como objetivo lograr que los alumnos egresados se transformen en ciudadanos activos para contribuir a convertir la frontera en un espacio democrático de cooperación. Un ciudadano sensible a la interculturalidad que, a lo largo de su recorrido escolar, haya experimentado diferentes situaciones de contacto con la otra cultura, permitiéndole así generar un criterio amplio y de respeto hacia la diversidad. Asimismo, el egresado del programa tendrá un dominio suficiente de la lengua-cultura para interactuar con su par en contextos previsibles de intercambio comunicativo. Al trabajo intercultural y de sensibilización lingüística efectuado en los primeros años de escolaridad, se propone para los últimos años, un trabajo más sistemático que permita a los alumnos manejarse de forma autónoma en contextos que soliciten la utilización de prácticas sociales de comprensión y producción en las lenguas. 
La secuencialidad de avanzar grado a grado para el intercambio docente fue y viene siendo necesario en virtud de los muchos ajustes que el nuevo sistema trajo a las escuelas y a los sistemas locales de gestión educativa: se requiere de recursos y formas de organización institucional para actividades que antes no existían, como el transporte del cuerpo docente, o la ampliación de jornadas de trabajo, o aún la ampliación del espacio físico de las escuelas y la provisión de nuevos equipos.

\subsection{Intercambio docente}

El Programa tiene como base el intercambio docente a partir de la disponibilidad de equipos ya formados en ambos paises y que actúan en las escuelas involucradas. La unidad inicial de trabajo, por lo tanto, es el par de "escuelas-espejo", que actúan juntas formando una unidad operativa y sumando sus esfuerzos en la construcción de la modalidad de educación intercultural y o bilingüe. Esta forma permite a los docentes de los países involucrados vivenciar ellos mismos, en su actuación y en rutinas semanales, prácticas de bilingüismo y de interculturalidad semejantes a las que quieren construir con los alumnos, en la medida en que se exponen a la vivencia con sus colegas del otro país y con los niños de diferentes grados con los que actúan.

Igualmente importantes son las demandas por un mayor intercambio entre los alumnos de las dos escuelas-espejo, dado el movimiento positivo que el cruce de los docentes ha provocado, en algunos casos, en las escuelas, to que posibilitó el despertar de la curiosidad de los niños sobre el otro país. Este movimiento de los alumnos, frecuentemente, resulta dificultoso porque se relevaron situaciones de niños que no poseen documentos de identidad, por la legislación de protección al niño y la cobertura de servicios de seguros que impide el cruce de la frontera. A pesar de esto y de otras dificultades referidas a la autorización del cruce de frontera, hubo varios momentos en que los alumnos de los dos países tuvieron la oportunidad de confraternizar.

\subsection{Otros modelos}

Además del intercambio docente se llevan a cabo otras modalidades de trabajo en las escuelas. 
Entre ellos, por ejemplo, modalidades mixtas con cruces en el primer ciclo y el resto con otras modalidades, estadias de los alumnos en el país vecino (campamentos, programas de intercambio, salidas recreativas y turísticas con contenidos previamente desarrollados y propuestas posteriores), intercambio sistemáticos de correspondencias en diferentes soportes), edición de textos bilingües (diarios, folletos, entre otros), conformación de bibliotecas comunes y estrategias de mediación, elaboración de guias didácticas comunes según los diseños curriculares nacionales con el enfoque basado en tareas, figuras de asistente de idiomas, trabajo en pareja pedagógica con profesores de lengua extranjera de los institutos de formación superior

\section{4. - Funcionamiento en el modelo centrado en el "cruce" de docentes}

a) Carga horaria y disposición de las clases en la $L 2$

El hecho de que el PEBF se realice sobre una base escolar preexistente, gestionada por diferentes secretarias de educación o ministerios provinciales hace que no sea posible o recomendable propugnar un modelo único para su ejecución. Concretamente, la discusión con los equipos condujo a la emergencia de tres formas para la organización de las escuelas, según formatos escolares de cada país:

1- Escuela de Jornada Completa (Tempo Integral)

2- Escuela en Contra-turno con un funcionamiento semejante al de la escuela de jornada completa, pero solamente con las actividades de educación bilingüe intercultural en el turno contrario.

3- Escuela de Turno Único, con proyectos de trabajo binacionales consensuados en la escuela, realizados de forma bilingüe, con tareas específicas en cada una de las lenguas.

El modelo de turno único prevé la presencia del trabajo en la L2en la base curricular, mientras que el trabajo en contra- turno muchas veces puede hacer que el trabajo sea visto como una actividad extracurricular, que no es el objetivo del PEBF. El turno único ofrece mejores perspectivas para la ampliación del sistema ya que no interfiere tanto en la rutina de la escuela, al no demandar la ampliación del espacio físico y la contratación de personal docente con la misma intensidad que el trabajo en contra- turno o en turno 
completo. El trabajo en contra- turno o en turno completo, a la vez, amplía el tiempo de permanencia del alumno en la escuela.

En función de las experiencias antes mencionadas y a partir de los debates generados en las reuniones de los equipos de trabajo bilaterales y a lo largo de los diferentes encuentros de capacitación, se observa la necesidad de pensar un nuevo modelo, definido de forma conjunta con todos los actores participantes del programa, que permita reflejar y dar respuesta a las características especificas e innovadoras de las escuelas interculturales bilingües. $Y$ que, además, permita que le programa pueda ser aplicado en una mayor cantidad de escuelas.

b) Modelo de educación bilingüe: no-vinculado

En las escuelas públicas en las que se desarrolla el programa el modelo utilizado es el No-Vinculado. En este modelo los niños pueden ingresar en cualquier momento del año lectivo y en cualquier grado - aún en los ciclos superiores- inclusive cuando los alumnos no tengan el mismo grado de competencia que los compañeros. Se trata de un modelo inclusivo, propio de escuelas públicas. Para los casos de "traspaso" (niños que vienen de otras escuelas) se discutirán estrategias para mejorar el desempeño escolar de los alumnos que ingresan, de modo tal que puedan seguir los trabajos realizados en la L2.

Por el contrario, en el modelo de educación bilingüe vinculado la presentación de los conocimientos normalmente es imbricada, es decir, el alumno aprende en ambas lenguas un mismo contenido. Para que un contenido sea aprendido se necesita, por lo tanto, de ambas lenguas. Esto implica que los grupos deben ser cerrados, que los alumnos no pueden ingresar a los grupos bilingües luego del primer grado, es decir, durante la secuencia del proceso de escolarización. Las diferencias de conocimientos y de prácticas en la lengua segunda entre alumnos que ingresan en distintas etapas del proceso de escolarización impedirían un desarrollo efectivo.

c) Estructura, seguimiento pedagógico y registro 
Participan diversos actores: los referentes nacionales (técnicos-políticos), referentes provinciales departamentales o estatales, referentes locales (coordinadores institucionales, supervisores, directivos), asesores pedagógicos y docentes.

Las tareas de los asesores pedagógicos participan de la planificación conjunta de las escuelas-espejo, propician discusiones sobre didáctica de las lenguas y sobre el trabajo con proyectos de aprendizaje para la escuela, asisten periódicamente a algunas clases para colaborar en el mejoramiento de la acción docente de las maestros, organizan las relatorias del PEBF y ayudan a mantener las comunicaciones entre todas las instancias de la organización del trabajo.

\section{5 - Enseñanza a través de los Proyectos de Aprendizaje}

El proyecto es un instrumento para la creación de la cooperación interfronteriza. La concepción de interculturalidad es, en este caso, activa: la escuela será intercultural en la medida en que exista la participación efectiva de profesionales y alumnos de las diversas culturas involucradas en la comunidad educativa (y que no son sólo "dos": la culturas de ambos países vecinos lo que corresponderia a pensarlas como unidades homogéneas) y en todas las instancias de convivencia que son propias de la institución escolar.

Por Cooperación Interfronteriza se entiende la oportunidad de superar la idea de frontera nacional como una barrera- "en donde el pais termina"- sino al contrario, de entenderla como la visualización del acceso a oportunidades sociales, personales, educativas, culturales, económicas nacidas de la presencia y en la interacción con el otro. Superar, también, los prejuicios, conflictos y disputas originadas en un pasado o la afirmación del Estado Nacional como instancia única de atribución de identidad en la que el "otro"es presentado como amenaza o como negación.

Además de las reconocidas ventajas pedagógicas del trabajo por proyectos, desde el punto de vista de la cooperación interfronteriza, el PEBF tiene por objetivo permitir, organizar y fomentar la interacción entre los agentes educativos y las comunidades educativas involucradas, de manera tal de propiciar el conocimiento del otro y la superación de obstáculos en las relaciones con el saber y con la interacción con el colega. Este contacto con el otro implica necesariamente el contacto con la lengua hablada por él. 
Para este primer punto, por lo tanto, el currículo necesita basarse en formas de organización de las rutinas que permitan a los participantes de las dos ciudadanías y de varias culturas ser parte activa en la toma de decisiones y en la ejecución de todas las fases de enseñanza como así también en todos los niveles en que esto se hiciere necesario: la planificación conjunta de los docentes es uno de los pilares de tal procedimiento pues da las escuelas involucradas un máximo de responsabilidad en la elección de las problemáticas de los proyectos de aprendizaje y en la planificación del tratamiento que éstas tendrán.

Estas fueron algunas de las razones por las que se consensuó el funcionamiento escolar a través de la metodología de la enseñanza vía proyectos de aprendizaje (EPA) como un posible camino para las escuelas interculturales bilingües. La contribución importante de esta forma de organización metodológica es la de posibilitar que se elijan los proyectos a ser desarrollados localmente, por grupo o por escuela, de acuerdo con lo que se considere más oportuno y de acuerdo con las diferentes realidades de las escuelas en cuestión. Esto implica que las escuelas o los grupos diferentes puedan realizar proyectos distintos entre sí sin perder de vista los objetivos relacionados tanto con el aprendizaje de prácticas característicamente escolares asociadas al avance de la alfabetización plena (letramento), por un lado, como a los objetivos actitudinales asociados a la interculturalidad y al manejo de las dos lenguas, por el otro.

Para el aprendizaje de la lengua del país vecino vale el mismo principio: las prácticas de la escuela serán bilingües en la medida en que los hablantes de español, de portugués y guaraní convivan en las funciones escolares relacionadas a la producción y a la circulación del conocimiento. El bilingüismo trabajado en este documento presenta una estructura que parte de las prácticas efectivamente construidas en las escuelas, de la convivencia y de los contactos lingüísticos que se hacen presentes en la rutina escolar. La planificación conjunta, como otros encuentros entre el cuerpo docente, son oportunidades de la práctica del bilingüismo: hacen circular discursos hablados y textos escritos en las dos lenguas, permiten escuchar la lengua del otro $y$, por lo tanto, escuchar al otro y entenderlo en su lengua.

En la perspectiva de la "Enseñanza Via Proyectos de Aprendizaje (EPA) los niños participan de proyectos bilingües que prevén tareas a ser realizadas en las lenguas, 
coordinadas por los docentes, de acuerdo con el nivel de conocimiento del idioma que posean y de acuerdo con la planificación conjunta realizada periódicamente. Los proyectos, por lo tanto, son bilingües: el alumno realiza determinadas actividades en L1 y otras en la L2, pero todas ellas confluyen en un objetivo común, que es el de producir respuestas y mayor comprensión a partir de una problemática central determinada de antemano.

Los proyectos de aprendizaje se originan de los intereses de los alumnos involucrados y son consensuados entre los docentes de ambos países. Las primeras clases de la docente oriunda de la escuela-espejo tienen, por lo tanto, la doble función de permitir a la docente la familiaridad con sus nuevos alumnos y el relevamiento de intereses que servirán de base al primer proyecto de aprendizaje. Como consecuencia de esta práctica, la planificación inicial - aquella que se realiza en el momento que el docente comienza a trabajar con el nuevo grupo- es de corto plazo (planificación clase a clase) y enseguida, una vez establecida la problemática del primer proyecto de aprendizaje a realizarse, se pasa a una planificación de mayor aliento (planificación de mediano y largo plazo) La planificación conjunta es uno de los momentos en los cuales el docente cuenta con el asesoramiento pedagógico local, ofrecido por la escuela, por los ministerios o las universidades.

La perspectiva de enseñar vía proyectos establece la labor con diferentes saberes que trabajan de forma simultánea con conocimientos de información y operativos. Estos últimos se centralizan en el desarrollo de prácticas -capacidad de operar con las informaciones, por ejemplo, e incluyen el acceso a la cultura letrada, el calculo, las capacidades de planificar, ejecutar, trabajar en grupo, exponer las ideas en público, entre tantas otras. En la planificación del programa de aprendizaje los docentes proyectan qué saberes deben ser aprendidos por los alumnos, y al final del proyecto de aprendizaje registran cuáles fueron efectivamente trabajados y aprendidos. A este procedimiento de registro se le da el nombre de currículo "post-factum" porque se concentra en las acciones y aprendizajes efectivamente realizados por los alumnos, en consonancia con lo establecido curricularmente por cada país y con las disposiciones curriculares comunes desarrolladas por la Comisión Curricular del PEIBF.

En lo que se refiere a contenidos, es importante destacar que se piensa en su apropiación espiralada, teniendo en cuenta la construcción continua de saberes a partir de lo trabajado en los proyectos. Esto implica que un contenido puede ser retomado varias 
veces a lo largo del recorrido escolar, complejizándolo y enriqueciéndolo a medida que el aprendizaje del alumno avanza. De esta forma, la utilización de la metodología de elaboración de un curriculo post-factum así como el trabajo por medio de proyectos resultará fundamental a la hora de definir lo que se enfocará en la L2.

Como estrategia de seguimiento y evaluación del proceso de los alumnos se sugirió la metodología de "portfolio" definido como el seguimiento realizado a partir de evidencias de variadas naturalezas de trabajo realizado por los alumnos individual y colectivamente. El portfolio es una estrategia pedagógica proveniente del campo de las artes: son carpetas o conjuntos de memorias de obras realizadas por el alumno individualmente o en grupo. Como proceso de selección de muestras refleja la trayectoria del aprendizaje de cada estudiante en el transcurso de un proyecto, permitiendo que los docentes evalúen cualitativamente el crecimiento y las derivaciones de sus aprendizajes.

Del mismo modo, se enfatiza el reconocimiento de la evaluación formativa y continua como instancia indispensable para hacerle saber al alumno cuánto aprendió -y el placer que eso provoca-, así como qué le falta aún construir -ofreciéndole las herramientas para que pueda hacerlo.

Se sugiere que cada proyecto de aprendizaje se extienda por dos meses y que los proyectos no se repitan en la escuela. La metodología de proyectos fue considerada dentro de dispositivos de formación de diferentes escuelas desde que se consensuó su utilización por los ministerios nacionales.

\section{6. - El lugar del diálogo en la enseñanza y en el aprendizaje}

Se concibe que el aprendizaje es posible en el marco de ricas interacciones orales. Estas interacciones pueden darse en un aula y una escuela en las que la palabra del docente es la palabra autorizada por su experiencia y su conocimiento, y en las que las voces de los niños son bienvenidas y escuchadas; interacciones en las que se habla de temáticas interesantes para los niños y en las que se plantean diálogos genuinos en los que todos tienen una voz, algo para decir, para compartir, para acordar, para opinar.

Cabe destacar que estas condiciones de producción de la dialogicidad están en estrecha relación con los escenarios $y$, fundamentalmente, con las asimetrías ya enunciados sobre 
las situaciones sociolingüísticas y socioculturales particulares (conocimiento de la otra lengua, universos vivenciales, tradiciones pedagógicas).

\subsection{La lectura y la escritura en el PEBF}

Los niños ingresan a la escolaridad con distintas experiencias y conocimientos respecto de la lectura y la escritura. Más allá de los puntos de partida y de las diversas apropiaciones de la cultura escrita (en sus múltiples dimensiones), la escuela se posiciona como el principal agente alfabetizador, fundamentalmente para aquellos grupos socioculturales en "desventaja" respecto de los saberes considerados legítimos. La escuela tiene una misión intransferible en la constitución de sujetos alfabetizados, entendiéndola hoy como condición de ciudadanía. Por eso, se enfatiza que en todos los contextos la escuela debe ofrecer múltiples oportunidades para que todos los niños participen en situaciones de lectura y de escritura como proceso creativo, placentero, necesario, útil, vinculado con la cultura escrita de la sociedad.

\subsection{Alcance de los términos letramento y alfabetización}

Entendemos por alfabetización-letramento no simplemente los procesos de decodificación en un nivel técnico sino hablamos de la apropiación de la cultura escrita, de los usos sociales de la lengua en sus dimensiones sociales y culturales.

Se emplea el término alfabetización en sentido amplio para hacer referencia al proceso de apropiación y recreación de la cultura escrita (letrada) e incluye tanto los conocimientos del sistema alfabético de escritura (la construcción del principio alfabético de escritura, el reconocimiento y trazado de las letras y el progresivo conocimiento de la ortografía de las palabras) como el aprendizaje de la lengua escrita (sus formas, usos y funciones); en resumen, como el acceso a la cultura escrita.

En ambos casos, se hace referencia, entonces, al proceso -profundamente social- de aprendizaje de un producto cultural: la lengua escrita. Este proceso es continuo y se inicia, idealmente, en la primera infancia. La concepción de letramento / alfabetización como apropiación y recreación de la cultura escrita / letrada implica que, desde el comienzo de la escolaridad, la lengua escrita debe permitir el acceso a los saberes 
propios de los distintos campos del conocimiento, para conservarlos, compartirlos y transmitirlos.

\subsection{Introducción de situaciones de lectura y escritura en el programa.}

Los niños que participan tempranamente de situaciones alfabetizadoras (de letramento), en su entorno primario y en la escuela, adquieren actitudes, expectativas (es decir, la imagen que ellos se van formando de sus posibilidades como lectores y escritores), conocimientos sobre el lenguaje escrito y sus funciones: comprenden que la escritura es lenguaje y que tiene distintas funciones. Es decir que, entre otros aspectos, los niños van tomando conciencia de que la palabra dicha oralmente se puede escribir y lo que está escrito se puede "decir" porque es lenguaje y que leyendo se puede volver una y otra vez a aquello que se escribió. En el caso del PEBF, aprenden, entonces, que tanto el español como el portugués o guaraní se pueden leer y escribir.

En una escuela y en un aula bilingüe, este último aspecto aconseja la necesidad de que los niños participen, al comienzo, de una etapa oral de contacto con la segunda lengua claro está, mientras participan de situaciones de lectura y escritura en su lengua materna-. En el marco de las actividades con textos orales en la segunda lengua (conversaciones, juegos, canciones, narraciones, rutinas escolares) previstas en los proyectos que se desarrollan, los niños aprenden formas de intercambio, el significado y uso de palabras y expresiones y las reglas de combinación de esa lengua y los géneros discursivos de circulación social utilizados. Dado que la escritura involucra procesos afectivos, cognitivos, y fundamentalmente sociales, no tendría ningún sentido que los niños copien palabras escritas por otro sin conocer su significado. Esto debe ser enmarcado en prácticas sociales de lectura y escritura.

En fin, cuando en el marco de los proyectos los niños participan en actividades desafiantes e interesantes se observa que puede surgir espontáneamente, la necesidad de escribir: los nombres de un títere o de un personaje de alguna historia escuchada, su nombre como firma de un mensaje para un amigo de la escuela gemela, un epígrafe para una ilustración a partir de una salida, una palabra "linda" que se repite en una canción aprendida. Estas son instancias inmejorables, muchas veces previstas por los docentes, 
para incorporar la escritura como actividad de una sociedad letrada, que no se deben desaprovechar.

\section{4 - Presencia de textos completos desde las primeras situaciones de lectura y escritura}

Para que los niños se entusiasmen por aprender a leer y a escribir, es necesario que desde un principio sepan que ese aprendizaje les abrirá las posibilidades de ingresar al mundo de lo escrito. Ese entusiasmo es fruto de la participación en situaciones en las que leer $y$ escribir tienen sentido y esto ocurre si lo que se lee y se escribe son textos, palabras o frases en contexto y con significado para los niños.

Los marcos curriculares de los países desalientan métodos o propuestas de actividades exclusivamente centradas en el aprendizaje de las letras o sílabas o, aun, de palabras cuando estas no tienen significado para los niños. Se dice que ese tipo de prácticas obturan la puerta de entrada al mundo de la escritura: los niños asocian la lecto-escritura con actividades mecánicas y sin sentido.

Desde el mismo punto de vista, la pedagogía de lenguas desalienta que las actividades se centren exclusivamente en el conocimiento del léxico en detrimento de los marcos discursivos que lo contextualizan y le dan significación.

\section{5 - La biblioteca bilingüe y los libros álbum (livro de imagem).}

Según las necesidades que surjan de los proyectos, los niños pueden participar de distintas instancias de lectura y escritura de textos. Pueden necesitar, por ejemplo, escribir con la ayuda de sus docentes epígrafes para las ilustraciones o fotografías que tomaron de un encuentro deportivo, los afiches o las invitaciones a dicho encuentro. Pueden recurrir a los libros de la biblioteca para buscar imágenes de los lugares, animales, personas sobre los que estén trabajando, o para conocer los cuentos y personajes de los libros escritos en la segunda lengua. ${ }^{6}$

6 Recomendamos la lectura de los Ejes "Lectura" y "Escritura" de los Cuadernos para el aula. Lengua. $1^{\circ}, 2^{\circ} \mathrm{y}$ $3^{\circ},(2006)$, Buenos Aires, Ministerio de Educación de Argentina. 
Las escuelas del proyecto cuentan con bibliotecas bilingües. Están integradas, en buena medida, por libros infantiles. Entre ellos, hay un amplio corpus de los denominados "libros álbum" (livro de imagem); se trata de libros en los que la imagen y el texto dialogan, las ilustraciones aportan otro sentido al que la palabra ofrece. Son libros de edición muy cuidada, con una fuerte apuesta a la ilustración y la plástica.

La participación frecuente en situaciones de exploración y lectura de los libros - de diversos autores, procedencias, estéticas, temáticas y sellos editoriales- desde el inicio de la escolaridad sitúa a los niños como lectores, aun cuando no sepan leer con autonomía y no conozcan todas las palabras presentes. Es decir, son lectores en tanto participan de una sociedad letrada hojeando y conversando acerca de los libros, mirando sus ilustraciones, reconstruyendo historias narradas a partir de esas imágenes, escuchando la lectura hecha por sus docentes. Por otra parte, los libros permiten "cruzar el puente": conocer culturas, costumbres, vestimentas, personajes, historias, otras voces diferentes de las del maestro o de las de la cotidianeidad. Frecuentar y conocer los libros de la biblioteca bilingüe, por lo dicho, enriquecen la propuesta intercultural del proyecto.

Explorando libros y leyéndolos por su cuenta y/o escuchándolos leer por el maestro, los niños aprenden también que en las dos lenguas hay diferencias entre el lenguaje escrito y el hablado, que las formas escritas muchas veces no coinciden con las habladas de una y otra lengua (es decir, que además de distintas lenguas, también hay distintas variedades de una lengua según sean sus modos escrito $u$ oral, además de las variedades regionales de cada país)

De la misma forma, el análisis y la planificación conjunta permiten un trabajo con materiales auténticos que presenten los elementos lingüísticos-culturales más provechosos para el intercambio entre los hablantes de las diferentes lenguas y, asimismo, que sean relevantes de acuerdo al universo discursivo de los alumnos. Por ejemplo, se podrían utilizar canciones, cuentos y leyendas; poesías, adivinanzas, trabalenguas, versitos, juegos de/con palabras; diferentes manifestaciones artísticas.

\section{6 - La comprensión del principio alfabético}

Tanto el portugués como el español (como el resto de las lenguas que se hablan en América, inclusive algunas lenguas originarias) son lenguas escritas con un sistema 
alfabético. Esto quiere decir, que hay un principio "ideal" que supone que cada letra representa un sonido del habla. Esto implica que si los niños conocen el significado de las palabras orales en cualquiera de las lenguas, la comprensión del principio alfabético de escritura que alcancen a partir de la lectura y escritura en su lengua materna puede ser transferido a la otra lengua. Implica también que, escribiendo palabras conocidas de la segunda lengua pueden progresar en la comprensión del principio alfabético.

\section{7 - La cuestión de la ortografía}

En relación con la escritura de palabras, suele existir la idea de que no es conveniente que niños pequeños escriban en más de una lengua (especialmente cuando se trata de lenguas cercanas, como es el caso del español, del portugués, del guaraní), en razón de que los parecidos entre palabras de las dos lenguas pueden inducirlos a confundir su ortografía.

Cabe deslindar aquí varios aspectos. Cuando los niños están iniciándose en el proceso de alfabetización en su lengua materna, se los alienta a escribir según sus propias posibilidades. En un principio, deben comprender la "alfabeticidad" del sistema, lo que supone reconocer los sonidos de las palabras habladas y adjudicar las letras que corresponde y trazarlas. En función de su desconocimiento de los defectos de paralelismos del sistema (que puede haber sonidos que se representan con más de una letra, letras que representan más de un sonido, letras que no representan ningún sonido, salvo en el caso del guaraní) recurren a una ortografía simplificada. Se considera un progreso en la escritura de palabras que los niños se planteen la duda ortográfica ("¿Con qué va?") Una vez desarrollada, esta duda es transferible a la escritura de palabras en una segunda lengua.

Por otra parte, como antes se mencionó, toda lengua presenta distintas variedades orales, algunas más cercanas al estándar escrito. Esta diferencia entre lo oral y lo escrito plantea diversos desafíos a la alfabetización, uno de los cuales es el de la ortografía, sea en lengua materna o segunda.

Mediante la reflexión permanente acerca de las posibilidades del sistema de escritura y de la enseñanza explícita por parte de los maestros, siempre en el marco de situaciones de 
escritura con sentido para los niños, ellos progresan paulatinamente hacia el conocimiento y uso de la ortografía correcta de las palabras de su lengua y aprenden también que no es lo mismo hablar que escribir (dado cierto grado de opacidad de nuestras lenguas, no todas las palabras se escriben "como suenan") Considerar el problema ortográfico como un obstáculo para que los niños participen (en forma autónoma, en grupos o dictando a su maestro) en situaciones de escritura de los textos que surjan de los proyectos que se implementan en el PEBF impide o posterga su ingreso pleno a la cultura escrita.

\section{7.- Evaluación}

En cuanto a la evaluación es necesario tomar dos aspectos de la misma: a) la evaluación de los aprendizajes de los alumnos y b) la evaluación del proyecto en sí mismo.

a) En cuanto al primer punto, se han acordado criterios generales para el seguimiento del aprendizaje de los alumnos (lengua en uso, ficha individual del alumno, trabajo por géneros textuales de circulación social) entre otros. Estos criterios orientan de alguna manera los ajustes necesarios para el desarrollo del proyecto. Ver en Anexo la ficha individual de monitoreo de los alumnos.

b) Se ha acordado la consulta con organismos competentes en evaluación de cada país, sobre instrumentos de evaluación pertinentes para el proyecto. Como perfil de esta evaluación se entiende pertinente privilegiar un abordaje procesual, de corte cualitativo, indagatorio, de investigación-acción respetando las modalidades de evaluación de cada país.

\section{7 - Consideraciones finales}

Este documento sintetiza las concepciones iniciales y experiencias vivenciadas por las escuelas participantes en el período 2005 hasta la actualidad del Programa. Se elaboró a partir de la descripción de lo que viene ocurriendo efectivamente en las fronteras entre los países, de las variadas y ricas narrativas, relatorías, registros y autoregistros docentes y observaciones in situ con los que cuenta el Programa. Se utilizó, asimismo, las actas de reuniones multilaterales que fueron sucediéndose alternadamente en los países, y de la 
documentación previa consensuada entre los gobiernos en el ámbito del MERCOSUR o en los acuerdos multilaterales. 
